\title{
SENSE OF THE PAST: HISTORIC HOUSE MUSEUMS IN TORONTO, CANADA, AS FORMS OF AN URBAN HETEROTOPIA
}

\author{
by \\ Alevtina Naumova \\ Master of Arts in Communication, Grand Forks, University of North Dakota, USA, 2005 \\ Bachelor of Arts in Journalism, American University - Central Asia, Bishkek, Kyrgyzstan, 2003
}

\author{
A dissertation presented to \\ Ryerson University and York University \\ in partial fulfillment of the \\ requirements for the degree of Doctor of Philosophy \\ in the joint program in \\ Communication and Culture
}

Toronto, Ontario, Canada, 2017

(C) Alevtina Naumova 2017 


\begin{abstract}
AUTHOR'S DECLARATION
I hereby declare that I am the sole author of this dissertation. This is a true copy of the dissertation, including any required final revisions, as accepted by my examiners.
\end{abstract}

I authorize Ryerson University to lend this dissertation to other institutions or individuals for the purpose of scholarly research.

I further authorize Ryerson University to reproduce this dissertation by photocopying means, in total or in part, at the request of other institutions or individuals for the scholarly research.

I understand that my dissertation may be made electronically available to the public. 


\begin{abstract}
Sense of the Past: Historic House Museums in Toronto, Canada, as Forms of an Urban Heterotopia

Alevtina Naumova

Doctor of Philosophy in Communication and Culture

Ryerson University and York University, 2017
\end{abstract}

Historic house museums allow for reconceptualization of the meaning of tangible objects around us. We establish this new relationship with materiality through our sensory bodies. We conceive of ourselves differently and allow ourselves to move and behave in ways that are not acceptable in the world outside of the museum. We perform our new selves with permission granted by the sense of place that cannot be understood other than through embodied experience-of things, of selves, of the environment that brings it all together. In the coming together of all these elements in the immediate, intimate present, the notion of the past is defined as cultural heritage as mediated through the historic house museum curatorial work and space.

I approach historic house museums as socially created and lived kinds of spatiality and sites of social practices and focus on the experiences of people that spend considerable amounts of time there-the museum staff. As a researcher, I have inserted myself within the environment of a historic house museum and attempted to open it to social inquiry through various ways of being within it-observing, writing, interviewing, interacting, sensing, entering it and leaving it. I have carried out a form of phenomenological ethnography, which included a two-year autoethnographic study at the Mackenzie House Museum, in Toronto, Canada, where I volunteered in the position of an interpreter and a historic cook; 24 participant observation visits to other historic house museums in Toronto; and 13 in-depth unstructured interviews with museum staff from various historic house museum sites in the city. The three methods addressed the key conceptual clusters-emplacement, materiality, and performance, which form three analytical chapters of the dissertation.

The dissertation positions historic house museums as forms of heterotopia that function as contestations of the accepted spatial, social, and temporal norms within an urban environment. These museums come forth as attempted reconstructions of anthropological places, in the form of domestic sites that assert significance of material manifestations of familial relations and historical heritage. These sites are immersive environments bridge the gap in the current experience of body, time, and space. 


\section{ACKNOWLEDGEMENTS}

I want to thank my supervisor, Professor Paul S. Moore. In the first year of my PhD programme, Paul got me excited about cultural theory-through his teaching, thinking, and writing. This excitement has not subsided in my five years in the program. I have come to understand that Paul has always had more faith in me than I did. He got me to accomplish more than I thought I was capable of at every turn of this journey. All this makes him more than a supervisor, but a true mentor.

I would also like to thank my committee members, Professors Alison Matthews David and Izabella Pruska-Oldenhof. Alison has been a kind and caring source of support. She was able to point me towards ideas and literature that deepened my understanding of the body in costume. Izabella's class “The Body as Medium” formed my method in this work. Her further guidance helped me develop my thinking. Izabella's relationship with theory and her own analytical processes have been an inspiration to me as an academic thinker and always reminded me that thinking is a joy.

My two external reviewers, Professors Heather Rollwagen and Alan Gordon, provided insights that are essential to me developing my thesis research further. I am deeply grateful for their time and expertise.

Completion of this dissertation would not have been possible without support of Mansur Mamatkulov, who has absolute faith in my abilities and is behind me always. I thank Lorna Joy Vallings, who never doubts my absolute brilliance and has consistently supported my work in ways both big and small. My brother, Konstantin Naumov, has stepped in at two crucial moments in the stages of writing and editing to provide the much-needed momentum to finish both. Thank you, brother. I also want to thank my mother, Natalya Naumova, for her love and for 
having set an example of a relationship with academic work, when I was little. Your influence on my life goes beyond what I consciously understand. I thank my daughter, Maya Mamatkulov, for understanding and levels of empathy that are beyond an ability of an average 7-year-old; and for genuine fascination with all things old. Finally, I want to thank my close friends Han Zhang, Bruce Beaton, Stacey Nordlund, and Ekaterina Pak for their never wavering support. Our friendship is such, that my work on this $\mathrm{PhD}$ has somehow strengthened it, instead of ruining it. Further, I would like to thank administration and staff of historic house museums in Toronto that were included in this study, specifically those working at the Mackenzie House Museum, the Colborne Lodge, and the Spadina House Museum. It was my fascination with your work that inspired my research. Thank you for allowing me to pursue it.

The Student Learning Support services at Ryerson University have made a big difference in my work. I want to specifically thank Natalya Androsova, the Writing Programs Specialist. Natalya's guidance and expertise helped me develop a healthier and a more understanding relationship with my writing. 


\section{DEDICATION}

To my mother and my daughter

Without both of you, this work would not have been possible 


\section{TABLE OF CONTENTS}

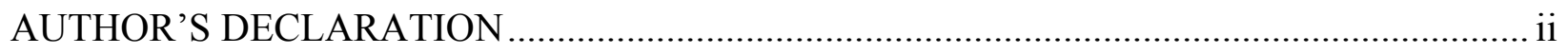

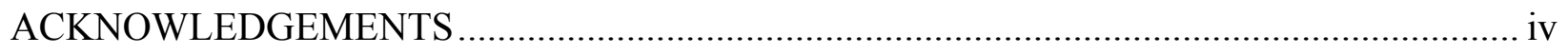

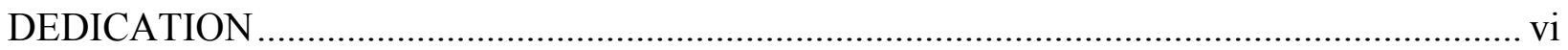

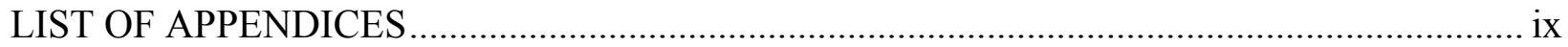

INTRODUCTION: Places, where History Is Always Still Happening Again. Historic house

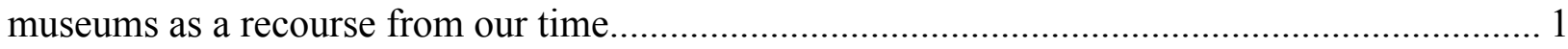

Thesis Statement and the Outline of the Dissertation ............................................................ 5

Location within the Field ................................................................................................... 12

Heritage in Practice: A methodology for the study of the site-specific performance of the past

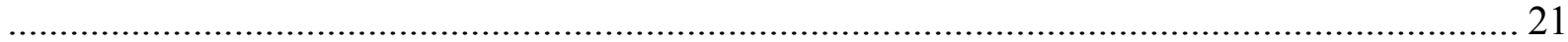

Research Questions and General Notes on the Research Methodology................................ 24

Methodological Concerns Specific to the Study and the Choice of Methods ......................... 28

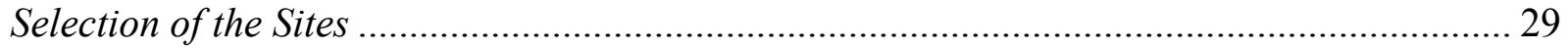

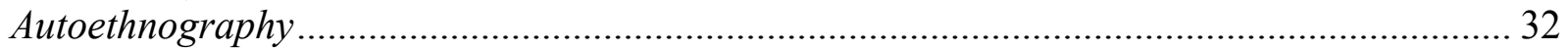

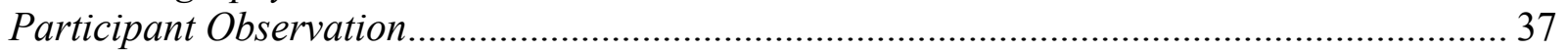

In-depth Interviews ......................................................................................................... 39

Concluding Remarks on Methodology: Understanding the logic of the kaleidoscope............ 41

CHAPTER I: Heterotopia of a Historic House Museum: Alternative spaces within an urban

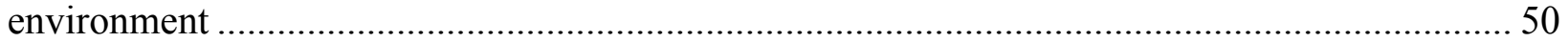

Literature Review: Historic House Museums - "a landscape that is greater than the sum of its

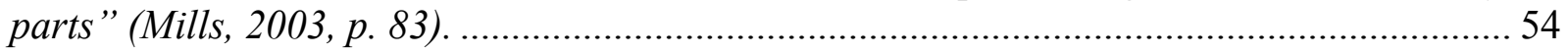

Defining a Historic House Museum ............................................................................ 54

Historic House Museums and Theories "in" Heritage: HHMs from the Operational Point of

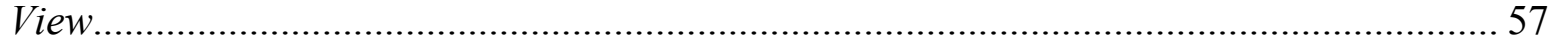

Historic House Museums and Theories "of" Heritage ................................................. 61

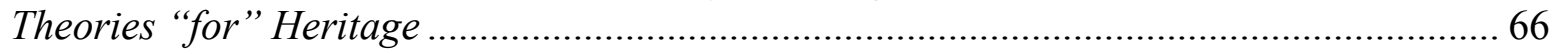

Outlining the Critical Cultural Framework..................................................................... 70

Unpacking the Theory of Historic House Museums as Heterotopic Places ........................... 82

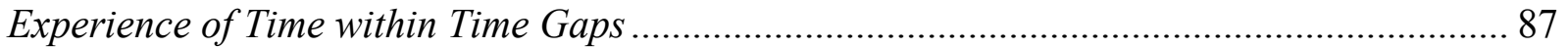

Time Gaps Performing as Memory Sites: The steady and sure that isn't ............................ 91

Historic House Museums: Appeasing nostalgia to enable progress .................................... 95

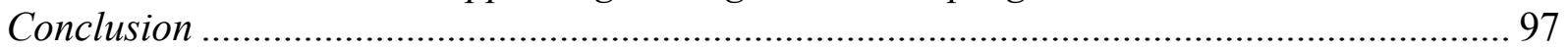

CHAPTER II: Materiality: Touching, biting, craving, and the experience of the "junk of life" 102

Sensing the Past: Historic house museum as a phenomenological text .............................. 106

The Bodies and the Gap of Time: The private communing and the buzzing of in-between

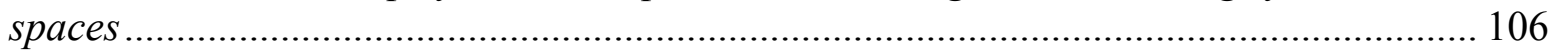

Historic House Museums as Sensory Spheres .......................................................... 110

Touching the Past with One's Body ........................................................................ 114

Time Gaps and Their Things: Problematizing materiality in regards to a historic house

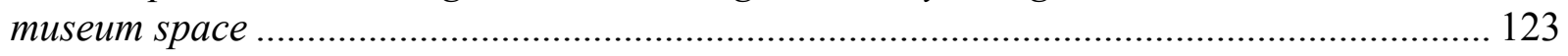

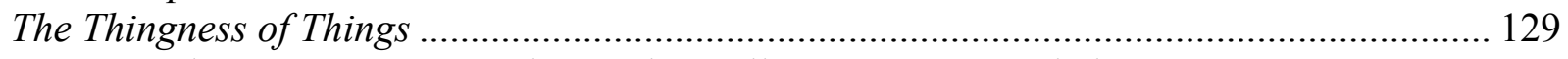

Materiality as a Way Towards Ontologically Intensive Knowledge ............................... 138 
Conclusion 143

CHAPTER III: Emplacement: Playing house in search of home 145

Locating Home in House Museums: Review of literature on the domestic space..... 153

Historic House Museums as Makers of a Home 157

Home and a body/psyche 159

Emplacement: Literature review. 164 Experiences of a Body as a Marker of Emplacement: House museums, fire, and back pain 170 At Home with the Unhomely: The ghost stories and the fear of displacement in historic house museums..... 179

The Reach Beyond the Walls: Historic house museums as sites "outside of all places”....... 186 Conclusion..... 195

CHAPTER IV: Performance of History as a License to Play: Historic house museums and the joy of pretense. 200

Performance and Heritage: Literature review ..................................................................... 203

The Role of the Interpreter: Active agent or a body in costume. 213

Performance as Vivification: Relationship between a performing body and material objects

"This is the House that Jack Built:" People that lived here and the story that never ends ... 223

Performance as a Site of Connection with an Audience ...................................................... 229

Positioning of a Performing Body in Relation to the Space of the Museum.......................... 233

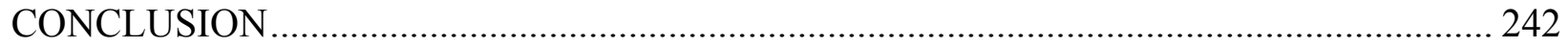

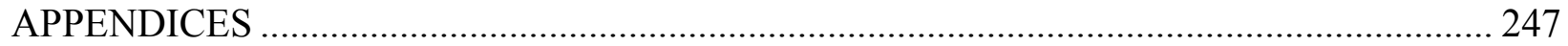

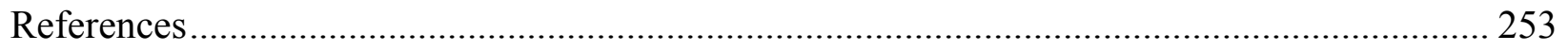




\section{LIST OF APPENDICES}

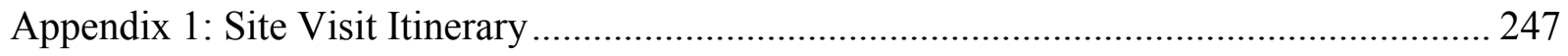

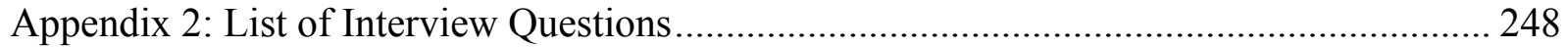

Appendix 3: Interview Consent Form......................................................................... 249 
INTRODUCTION: Places, where History Is Always Still Happening Again. Historic house museums as a recourse from our time

For about three years, I have volunteered as an interpreter at Toronto's Mackenzie

Historic House Museum. William Lyon Mackenzie was the first mayor of Toronto, a newspaper publisher, and the leader of the Upper Canada Rebellion of 1837. The last home of the Mackenzie family has been restored to represent the middle-class lifestyle of 1860 s Toronto. I guide tours of the house and explain how the kitchen works by doing cooking demonstrations, while dressed in period costume: I wear either a thick parlor dress complete with a hoop skirt and a petticoat or a work dress with an apron. Both costumes come with a proper bonnet. In between tours, I catch a break and find a spot to sit quietly, resting both my vocal cords and my back. My muscles ache from carrying the weight of a Victorian-era dress up and down the creaking stairs of the house. I drink warm tea, as a group of school-aged girls walks by. They have just finished their tour. One asks if she could please touch my costume's sleeve. I say yes, and she slowly runs her fingers along its flowery pattern. "You live here, right?" she asks matter-of-factly, and walks on.

I am still smiling about this encounter when I later change into my blue jeans, which, after a day in costume, feel more like pajamas, and walk out into the street. Toronto's central commercial hub of Yonge-Dundas Square is around the corner. I am instantly a part of a crowd, surrounded by noise, lights, towering billboards. It always takes me some time to adjust. I stare at the advertising boards so large they could cover the entire house museum I just left behind. The screens are flashing; somebody is screaming about Jesus. A guy shoves at me a booklet. I hesitate to snap back into my "city self." Another moment passes, and I adjust my movements as I step into the flow of people, all heading underground to board a train. I look right, as I get 
shoved and apologized to, and finally dash towards the steel body of the train. There is no need to rush, an automatic voice reminds us: The next train will be arriving in exactly three minutes. Three minutes seem worth the rush.

The girl's comment suggested that a lady in period costume, quietly sipping her tea, a book on her lap, as she sits steps away from the door to the 1850 s house, somehow inhabits it and thus the past, despite the encounter in the present. Children appear to be quite comfortable employing imaginative leaps to make sense of the temporal dissonance produced by a historic house museum (henceforth HHM) and the game of dress-up enforced by grownups. Some adults, however, may have a sense of displacement during or after a visit to a historic house museum, a discomfort associated with an experience of otherness of space and bodies and time within it. I observe that quite frequently when giving tours. HHMs rupture the linearity of the experience of time by appearing to arrest a moment that is long past and inhabit it year after year, while being located in a contemporary metropolis. Everything - things, bodies in space, interactions - is used to simulate the experience of another temporality. To add to the oddity of it, HHMs accomplish that by contesting an overarching law of physics: They dispute time's prerogative as an organizer of space. Here, the space is used to hold time, to vivify a temporality long past by pretending to be of it and in it.

The work of a historical interpreter normalizes the play of pretense and establishes a gaze from "within the house" - the perspective of a modern person, whose vocation requires intimate familiarity with and simulation of a different temporality for extended periods of time ${ }^{1}$. As a volunteer, my position is within the blurry space between that of an interpreter, who inhabits his

\footnotetext{
${ }^{1}$ This is one of the aspects that affect the relationship between the interpreter and the work of an HHM. I unpack the specifics of the position of the interpreter in chapter 4, "Performance: History as a License to Play."
} 
or her role, at times daily, and that of a visitor. As a researcher, I have found this point of view on the experience of a house museum immensely beneficial, since it has allowed me to recognize the possibility of a broad spectrum of reactions to the experience of an HHM. I am specifically referring to, on one hand, the visitors' sense of misplacement and unease, or, on the opposite side of the spectrum, the thrill and eagerness to engage, to let go into the actuality of a place, in which traditional ways of being within space and time appear to be done away with. An example of that would be the sense of abandon with which participants engage in such events as Steam Punk fairs. Another specific example would be the period simulation at the annual 1920s Great Gatsby garden party at the Spadina House Museum in Toronto, Canada. There is a sense of uninhibited delight in embodying an era popularly envisioned as a time of extravagant parties and the loosening of social norms: Visitors become really invested in their costumes, dance to live jazz, play croquet, and enjoy picnics on the grass with genuine china in front of the restored house.

For me as a tour guide and a researcher, the "otherness" of the experience of a historic house museum comes through quite strongly through what is described as "active interpretation" of the historic 1860s kitchen, which requires that the interpreter stays in the kitchen for the duration of a 5-hour shift dressed in costume and cooking ${ }^{2}$. The interpreter explains the process to the tour groups, as they come through the kitchen, and offers food for tasting. The goal of active interpretation is to unpack the minute details of day-to-day embodied living in a different temporality. It is tied to the use of one room in a reproduced home, which means that the narrative is contextualized within a domestic environment and requires that one "holds" that space, filling it with the presence of a simulated life - smells, warmth, sounds; is a living body

\footnotetext{
${ }^{2}$ Please note that different museums execute this part of their programming differently in terms of time commitments and the types of domestic tasks performed. My autoethnographic experiences are specific to my volunteer position at Mackenzie House for the duration of the research phase of the project.
} 
that knows how to move within that environment and how to interpret it, and fill it with meaning through that movement. This immersion requires that the interpreter conceives of the space and uses it as functional, designed to produce food, rather than as a museum display. Consider these excerpts from my autoethnographic journal entry written in between tasks during an active interpretation shift:

It feels very strange, this ability to just be, the imperative to just be. I find I take my time mixing the ingredients, notice whiffs of cinnamon raining from my hands as I work butter and molasses into the mix of dry ingredients. I am writing this sitting by the fire, the palms of my hands are warm from working the dough and keeping the fire going. They smell of butter and cinnamon. (...) I found it hard to get the oven to the 350 degrees as required by the 1830s recipe, which I am using today. I just have to wait and see how long it is going to take for the cookies to rise. This offers a very different perspective on time. Instead of waiting for the timer to let me know when things are done, I sit by the stove, feeding the fire, waiting for the cookies to look just right. (...)

It feels unsettling, this 5-hour long retreat into the quiet. It seems timeless, the rhythm of my work governed by the temperature of the oven and by how cold my dough is. At random times, it is interrupted by the groups of visitors (they go through about once an hour), but I have no control over that. I feel disturbed, I am not used to being alone with myself for such long periods of time without specific work objectives in mind. I bitterly think about how common it is now to yearn for time and space that is devoid of technology, it is understood as the time when one could encounter an authentic self.

The beginnings of my volunteer work at an HHM were marked with a sense of confusion in relation to the narrative of the place (Why is it that I have an agency to compose my own? How do I approach this responsibility?), to my costume (Am I being silly? How far do I go in inhabiting the pretense? Why am I really wearing this?), to the people who lived here and whose story I get to tell (How much do other people really know the truth about my own life? Why do I construct a narrative of a time period through the personal lives of people we really don't know all that much about?) The paragraphs from my autoethnographic journal I quote above go even 
further in addressing the sense of loss at discovering the state of embodied being that is very much outside of my day-to-day experiences in the world outside of the museum walls. ${ }^{3}$

\section{Thesis Statement and the Outline of the Dissertation}

In this dissertation, I unpack the cultural role of historic house museums and draw on Michel Foucault's (1986) articulation of heterotopias as sites that can only be fully understood as places that "suspect, neutralize, or invert the set of relations that they happen to designate, mirror, or reflect" (Foucault, 1986, p. 24), rather than through the set of social relations that define them. Following Foucault (1986), I examine house museums as sites that present as if they existed outside of the temporal and spatial logic of postmodernity, while in reality being entirely dependent on it for their purpose and function. These organically occurring ${ }^{4}$ social and cultural institutions emerge to contest the organization of the postmodern life space; they sustain a version of reversed relations with time, space, and materiality, and locate the postmodern metropolis in opposition to itself. This relationship between house museums and the city is the reason, I suggest, we consider the kind of curatorial and heritage work that house museums perform in the context of the cultural environment they are in.

House museums interpret physical space and objects within it to construct a sense of communal emplacement, familial continuity, and temporal permanency, thus appeasing the sense of anxiety over the loss of time and the fractured social and city space which is characteristic of postmodernity. HHMs offer an alternative interpretation of the meaning of built environment and community, a form of artificially created anthropological emplacement in the midst of a postmodern environment that is organized along the logic of capitalist production and

\footnotetext{
${ }^{3}$ My research project did answer the questions I mention here briefly. I cover them in detail throughout the chapters of this dissertation.

${ }^{4}$ The description of a government institution as "organically occurring" requires an explanation, which I provide in Chapter 1 of this dissertation.
} 
consumption $^{5}$. The heterotopia of a house museum asserts the authority of communal practices of emplacement over the functional capitalist space of consumption; it suggests the existence of a transhistoric familial home that seemingly can never be lost, and offers a sense of a permanent hierarchy of relations through unchanging practices of a domestic space and the materiality of objects within it.

The simulation of a temporality is central to the work of a historic house museum. Such a museum appears to arrest a moment in time, detaining a particular year (which, in reality, ended generations ago) in a never-stopping rotation. This is unlike the version of time hoarding practiced by the heterotopia of a library archive or a natural history museum building their collections. A historic house museum offers the simulated permanency of a slice of time as a form of recourse from the present; it also functions as a site where nothing is ever forgotten or lost, because it is always already happening again.

My study of this specific heterotopia spirals like a seashell around my focus on the cultural phenomenon. The centre of the spiral - the work of the heterotopia - functions as a mediator between a willing participant and his or her imagination by engaging the senses. It mediates between a participant and his or her memory, too, by allocating an alternative sense of self within a domestic space and within the flow of time, an alternative sense of one's past and one's present. For instance, while the Mackenzie House Museum does not represent a shared communal past of white European descent for most visitors, I frequently observe that the domestic space of the house and the objects within it address common experiences of people's

\footnotetext{
${ }^{5}$ In my interpretation of anthropological places, I draw on Augé's (1995) and Entrikin's (1991) discussion of the uses and meanings of place in postmodernity. I unpack the idea of a historic house museum as an anthropological place in chapter 3, "Emplacement: Playing house in search of home." This chapter also offers a review of the discussion of the relationship between capital and urban space.
} 
pasts from various countries. The wood oven is a frequent point of connecting one's family's past with the experiences of the Mackenzies. I also had a visitor say: "My grandmother had this kind of a washboard, and she taught me to wash my socks on it." Another remarked: "I remember the story of why my great-grandma was nicknamed 'cat.' They had a dry sink in the bedroom, just like this one, and she washed her face in it the same way cats do." The themes within the narrative of immigration, the common thread among Toronto's HHMs, are another resource for drawing out shared themes of individual family histories and personal pasts. All of these stories and experiences, while being highly personal and at times intimate, are entries into the spiral — things that visitors use to turn themselves into engaged participants by making the past of this house, in part, their own. Further, the spiral of the heterotopia disrupts the linearity of the temporal flow outside the walls of the museum and allows for a possibility of a different future. This disruption of the linearity of time by HHMs gives space to events such as steampunk fairs, contemporary art exhibits, and dramatic and dance performances that consider alternative readings and versions of the past, the present, and the future. ${ }^{6}$

The study of how these processes present themselves - through the way they attribute meaning to materiality and emplacement in reconfiguring a domestic space and create specific conditions for engaged participants to occupy them—circles around their central focus on appeasing anxiety over the loss of time. Such appeasement, I suggest, is the role these heterotopias are there to fulfill. These places do not function in linear ways. If anything, they disrupt the linearity that informs the structure of the city and of how we form relationships with our bodies, our spaces, and our day-to-day time. The heterotopia of a house museum offers an experience of the other, an alternative dimension that has its rules of engagement. It is quite

\footnotetext{
${ }^{6}$ I address this point further in Chapter 3, "Emplacement: Playing house in search of home."
} 
possible that a way to unpack it, to truly understand its mechanics and meanings, is to follow the same non-linear way of thinking that informs the movement of the spiral.

In this work, I seek to develop and substantiate a theoretical framework for understanding these instances of renegotiated temporality and spatiality - the heterotopia of historic house museums. These museums allow for reconceptualization of the meaning of tangible objects around us. My dissertation asks what constitutes experiential reality of the past as simulated by an HHM, what these cultural practices say about the human condition in postmodernity, and how this form of heritage simulation informs our understanding of the modern metropolis. An embodied engagement with the built environment of a historic home is one of the central concepts I use in developing my theoretical framework. I suggest that the heterotopia of a house museum posits the lived experiences of a sentient body as essential to interpreting a historic space as a museum professional and in forming an experience of it as a visitor ${ }^{7}$. This perspective adds to my discussion throughout the analytical part of this dissertation. I organize my analysis around three key conceptual clusters — emplacement, materiality, and performance — which form three respective analytical chapters of the dissertation, following a chapter that unpacks the larger theoretical concepts I use to substantiate my analysis.

In the first chapter of my dissertation, I articulate the critical cultural studies approach I employ in this dissertation and locate it within the review of the current academic discourse on historic house museums. I then unpack my articulation of HHMs as heterotopic spaces that present as experiential environments that offer both an illusion of belonging (cultural, familial)

\footnotetext{
${ }^{7}$ Here, I refer to Merleau-Ponty's (1962) articulation of a "lived body" as a unity of a system that integrates the mind, the body, and the world as it is encountered. I unpack this perspective further through my analysis of the roles of materiality in Chapter 2, "Materiality: Touching, Biting, Craving, and the Experience of the "Junk of Life."
} 
and an experience of time at a standstill. I explain the term I develop to describe these sites“time gaps”- and draw on Carey's (1989) take on ritual communication, Warner's (2002) work on publics, Foucault's (1986) articulation of heterotopias, and Nora's (1982) discussion on memory sites to unpack the reason for the creation of time gaps and the specific ways in which they perform their cultural role.

I begin my analysis in Chapter 2, "Materiality: Touching, Biting, Craving, and the Experience of the "Junk of Life,"” at the most intimate site: the relationship between the body and the meanings of materiality as they emerge within a historic house museum environment (Dudley, 2010, 2012; Levent, N., Pascual-Leone, A., \& Lacey, S., 2014; Wood and Latham, 2011; 2014). This initial layer of my inquiry focuses on the kinds of meanings that emerge when the body is introduced as a starting point in the process of making sense of a built and lived urban environment and a historical narrative. I begin the chapter by suggesting that historic house museums function as sensory spheres, as opposed to visual spaces designed within the curatorial paradigm of traditional historic museums. I suggest that historic house museums foster bodily awareness of space, time, and materiality of objects from the past by employing touch, vision, smell, and hearing. This corporeal engagement precedes the analytical work of the mind and transforms one's experience of the site into a connective encounter with the materiality of space and one's lived experiences within it. I also discuss the auratic quality ${ }^{8}$ that material

\footnotetext{
${ }^{8}$ When using the term "aura" or an "auratic quality" throughout this work, I refer to Benjamin's (1986) cultural criticism of capitalist production. Benjamin (1986) argues that an object loses its unique value through mechanical reproduction. He writes that "even the most perfect reproduction of a work of art is lacking in one element: Its presence in time and space, its unique existence at the place where it happens to be" (Benjamin, 1986, p. 50), and, that "the unique value of the 'authentic' work of art has its basis in ritual, the location of its original use value." (p. 52) An aura of a thing within an HHM, then, is something that captures the singularity of an experience or an object, and the meanings exclusively attached to it within the context of the time gap. When using the term "aura" in the context of the discussion on HHM, I refer to the objects' ability to function as a key to the experience of the time gap, to tell the story of the time from the inside out.
} 
objects within these sites hold, which allows them to recreate the mood that once informed the design, function, feel, colors, and purpose of the objects within the rooms. The premise is that the way human nature once expressed itself was through the space of the house and the interplay of the objects it holds. I end this chapter by considering the implications of the experiential nature of knowledge attained within these environments on articulating the meanings of materiality in time gaps. I point out that the historic house museum model places the visitor within the environment with things that he or she came to study ${ }^{9}$. This practice affirms the experiential nature of knowledge attained within this environment and points to the fact that meanings here are not limited to interpretation, but also emerge from doing, assuming the form of an impact (Lash \& Lury, 2007).

In the third chapter, “Emplacement: Playing House in Search of Home,” I begin by anchoring my explanation of HHMs as artificially created instances of "anthropological places" in my literature review on urban spaces in modernity ${ }^{10}$. I specifically draw on the work by Augé (1995), Entrikin (1991), Soja (1989), and Lefebvre (1992). Here, my argument is that one of the layers of the heterotopic work done by time gaps addresses the need to allocate spaces informed by meanings and values that communicate shared mythologies (Barthes, 1972) of the common past and purpose, thus contesting the logic of the contemporary urban geography informed by consumption and production. I extend my examination of emplacement into a consideration of HHMs as instances of a transhistoric reconstruction of a lost home, where the urban uncanny

\footnotetext{
${ }^{9}$ Lash (2010) suggests that this produces an "ontologically intensive knowledge" (Lash, 2010; 8).

${ }^{10}$ In this work, I argue that the appearance of historic house museums was specific to satisfying the needs of modernity (see, also, Gordon, 2016). When unpacking the meanings of places in modernity for the purposes of my analysis, I draw on the work by Augé (1995), Foucault (1986), Entrikin (1991), Soja (1989), and Lefebvre (1992), and Nora (1982). When unpacking the day-to-day embodied experiences in today's Toronto, frequently I draw on the work on postmodernity, specifically, Baudrillard (2001; 2005; 2012) and Jameson (1994). My use of the terms "postmodernity" and "modernity" is specific to these discussions.
} 
assumes its tangibility (Freud, 1953; Vidler, 1992). I first examine houses as environments in which people can make use of their natural instincts and be driven towards light and warmth. I suggest that visitors and staff at the museums frequently rely on intimate familiarity with domestic spaces as an entry point into making sense of the experience and the story of a historic house museum. I also consider the cathartic function of the experience of domesticity in providing a sense of familial continuity. I discuss how this affects the workings of the complex institutional structure that is both a house and a museum ${ }^{11}$. Further, I examine the relationship between the psyche and the organization and understanding of a domestic space. I connect the experience of the uncanny to both the ghost stories traditionally associated with these sites and the experiences of temporal and spatial breakage afforded by them. I end this chapter by discussing the interrelationship between time gaps and the rest of the city in the experiences of my interviewees and in my experiences as a historic interpreter.

In my last chapter, "Performance: History as a License to Play," I consider house museology as an expressive cultural form, which fosters reenactment through the play of pretense (Anderson, 1982; Daudbjerg, Eisner \& Knudsen, 2014). I address this theme last in my analysis, because, I argue, it is the affective and intellectual engagement with the site, objects within it, and its narrative, that turns the space of an HHM into a time gap, "rotating" the spiral of the heterotopic work. Thus, I need to draw on my analysis of HHMs' uses of materiality and meanings of emplacement in order to fully address the theme of performance. I identify performance as the kind of engagement that presents as "buying" into the spatial and behavioral logic that the heterotopic space commands. Thus, performance can be unpacked as a kind of

\footnotetext{
${ }^{11}$ Although I will not focus attention on gender explicitly, I recognize that the notion of domesticity invites a feminist analysis of an HHM as a gendered space. To be sure, my entire study is saturated with gendered experience, performance and practice. For studies of HHMs and gender, please see Beranek, 2011; Christensen, 2011; Peacock, 2011; and Terry, 2013.
} 
behavior that adheres to the interpretation of the space as indeterminately lived in. Another marker of performative behavior can be attempts at prying open historically contextualized uses of HHM space and the objects within through their active use in the present or through embodied lived experiences of these spaces and objects in the present. The prism for the discussion in this chapter is the position of a historic interpreter. I largely draw on my interviews with historic interpreters and my own autoethnographic experiences. I examine how interpreters relate to their performing selves, and the narratives they present, and the question of agency in the context of these discussions. One of the specific sites for positioning this discussion is the question of a period costume. Another angle I choose for unpacking these experiences is the question of what constitutes the leaving and the entering of the heterotopic space; and how one's performative experiences within the time gap inform his or her life in the outside world.

The analysis of how these three conceptual themes-materiality, emplacement, and performance-interact with the experiences of the body contributes to a deeper understanding of historic house museums as intersections of experiential, material, mental, and cultural phenomena that constitute the workings of the time gap and reveal the human condition in postmodernity.

\section{Location within the Field}

In her keynote address to the Association of Critical Heritage Studies Third Biennial Conference “What Does Heritage Change?” Professor Lucie Morisset (2016), Canada Research Chair on Urban Heritage, advanced the point that heritage has no meaning beyond the one invested in it and determined by the current cultural, social, and political momentum. This perspective reflects the dominant view on heritage advanced in critical heritage studies (see, for instance, Smith, 2006; Harrison, 2013). In 2006, in Uses of Heritage, a book pivotal to the 
development of this new field, Laurajane Smith described heritage as "an act of communication and meaning-making" (p. 2) and suggested that:

the real sense of heritage, the real moment of heritage when our emotions and sense of self are truly engaged, is (...) in the act of passing on and receiving memories and knowledge. It also occurs in the way that we then use, reshape and recreate those memories and knowledge to help us make sense of and understand not only who we 'are,' but also who we want to be. (p. 2)

In her speech, Morisset (2016) focused on the role of heritage as a political tool, a way of claiming power through the means of self-definition or an external attempt at defining a community by drawing on its past. This view corresponds to the analytical agenda of critical heritage studies, which engages with issues of power and is driven by social change ${ }^{12}$ (Smith, 2006). One of the key notions developed in Uses of Heritage was the identification of the Authorized Heritage Discourse (AHD) as "a discursive and rhetorical justification for understanding heritage as old, aesthetic, material, Western and expert interpreted, which was not just found in heritage texts but also as a dominant sentiment and professional mindset of heritage professionals" (Smith, L., Campbell, G., 2015, 443; see also, Waterton et al., 2006). In her speech, Morisset (2016) suggested we rethink the use of heritage by approaching it not as a victim in the struggle for power, a narrative that is often fractured and distorted, but as a means to empowerment.

Given that my research does not directly address questions of power, how does my work contribute to the field or fit within the range of issues it engages with? Is it even the right field to identify my work with, the right vocabulary to have used? How can my research change

\footnotetext{
${ }^{12}$ In their Research Development Seminar at the Association of Critical Heritage Studies Third Biennial Conference in June, 2016, Laurajane Smith and Gary Campbell suggested that researchers in the field of critical heritage studies should always ask themselves: "How does this paper address issues of power and representation, networks of power, and consequence?"
} 
anything? Does it have any applicable value? Can it influence the way we ask questions and articulate ideas in regards to heritage?

Critical heritage studies foster a form of discussion that explores larger underlying mechanisms of production and maintenance of heritage, theories that look beyond specific case studies and even individual cultural contexts. Since critical heritage studies have reframed heritage as a socially and culturally constituted process that is rooted in the experiences of the present and thus shifted the focus of inquiry to issues of consequence, the field has also made it necessary to make sense of how people engage with the ideas of the past and construct the sense of self in relation to where they come from. The process of heritagization, when approached this way, occurs on multiple levels of human experience and is by no means limited to the social and political ones that the field considers as its focus. I suggest that we acknowledge the range of questions on the human condition and the cultural moment as they pertain to our encounters with the present. I believe there is a great potential for research here that, while not appearing to explicitly address issues of power and representation, may build theoretical and methodological ground that enhances this line of questioning; the kind of research that conceptualizes heritage as an open-ended and an ongoing process that is rooted in lived and embodied experiences of the present. I see my contribution to the field of critical heritage studies as the unpacking of these underlying processes, but also, on the wider scope, the further unpacking of what kinds of issues constitute the problematic of the field.

Having that said, let me carefully locate my work in relation to academic discourses on heritage and history. To start, I am not studying historic house museums as places of specific, factual history or as forms of Authorized Heritage Discourse (AHD) (Smith, 2006). I do not consider the histories of the sites nor the policies shaping their management. In The Heritage 
Crusade, Lowenthal (1998) carefully distinguished heritage and history in terms of politics, as public practice, but my study sits outside that distinction. Instead, my work privileges present day, immediate subjective experiences of interpreters working in historic site. I argue that unpacking this layer in the production of heritage leads to further understanding how general senses and ideas about the past are formed by visitors. In that sense, my study allows heritage to be a general public engagement with a generic sense of the past. I suggest that the work of historic house museums is not about grounding Toronto in its specific, detailed historic past. Rather, it is about facilitating a public experience of a past time and space. For that reason, my research risks conflating a vague sense of pastness with specific historical knowledge, because I am interested in how people who work in museums orient exactly to that slippage in visitors' understanding of history. My study of museum work is about experiences of these spaces that are firmly rooted in the present and responsive to the needs of the present. The historic house as a genre of museum dictates an attempt at capturing and isolating a perceived essence of a past time period within the experience of the present space ${ }^{13}$. This, in turn, creates a vernacular sense of pastness that visitors tap into and people who work in time gaps orient towards ${ }^{14}$. In that sense, I suggest, an interpreters' primary job is to facilitate the public's curiosity and interest in the space and things within it. And it is no surprise or a carefully hidden trade secret, that the best interpreters orient their handling of the content towards experiences of public in the present.

My study widens the range of methodological approaches taken in the theorization of heritage as Authorized Critical Heritage Discourse, which suggests heritage is an institutionalized version of a narrative about a community's past and that this narrative and the

\footnotetext{
${ }^{13}$ Mills (2003) suggests that HHMs present a time period as an artifact.

${ }^{14}$ For specific criticism on HHMs' work as having a negative effect on the public's understanding of history, see, for instance, Harvey, 2001; Handler and Saxton, 1988; Hewison, 1987; MacLeod, 2006; Walsh, 1992 ; Terry, 2013.
} 
ways in which it is performed and used towards a political goal is constitutive of the community's sense of self. Yes, the field of critical heritage studies generally dismisses the idea of a manageable and objectified heritage, and considers heritage as the meanings attached in the present to the past. Yet, its view on the centrality of discourse accepts heritage as a closed-ended and defined narrative, a story that is already told, which, in a way, merely transforms the space back into a manageable object. I argue that there is a way to separate the discussion on heritage from questions of power by considering it as an ongoing and organic process, and recognizing that it can be a process that involves the community asking questions about its past as much as coming up with answers. In doing so, I agree with Harvey (2001), who, in his seminal paper Heritage Pasts and Heritage Presents: Temporality, Meaning, and the Scope of Heritage Studies, makes a clear and simple argument:

Every society has had a relationship with its past, even those which have chosen to ignore it, and it is through understanding the meaning and nature of what people tell each other about their past; about what they forget, remember, memorialize and/or fake, that heritage studies can engage with academic debates beyond the confines of present-centered cultural, leisure or tourism studies. (p. 320)

While Harvey's (2001) critique of the approaches to heritage focuses on leisure and tourism studies, I suggest that the political stance critical heritage studies take in developing its definitions and its course presents a range of confines as well. I would compare it to the way women's studies, at some points of its development, have essentialized the very notion of a "woman," therefore imposing methodological constraints through definition. Critical heritage studies is a very new field and it considers a range of burning issues. It is at the point in its development when development of perspectives and theories is critical to the kind of interdisciplinary work it may invoke and the range of issues it will engage with. I suggest that authors consider the course of development of other critical fields that came before and the 
outcomes of the theoretical work that they do and the kinds of inquiries it makes possible for the development of this emerging field.

I would like to illustrate this idea with the central argument on theorizing gender Butler (2011) makes in her introduction of Joan Scott's work. Butler (2011) writes:

Joan Scott is credited with having developed a theory of gender, but if we mean by "theory" a timeless set of precepts or principles, then we have missed the point of Scott's theoretical explorations. For Scott, theory always proceeds by way of questions, and questions are the means through which taken-for-granted presuppositions are contested and new ways of thinking and analyzing become possible (...). This became very clear at the moment within women's history when Scott, along with some other scholars, proposed that it was not enough to look at images of women in certain historical scenes or even how women are treated differentially within certain contexts. Whereas both of these kinds of inquiry have their place and even their urgency, they only make sense once we start to ask how gendered meanings are produced. In other words, we cannot take gender, or gendered meanings, for granted, since gender is precisely that which is being produced and organized over time, differently and differentially, and this ongoing production and mode of differentiation has to be understood as part of the very operation of power or, in Scott's words, a "primary way of signifying power." (p. 3, emphasis in the original)

Following this line of reasoning, I suggest that we consider political and capitalist agendas as just some of the categories of power that contribute to processes of heritagization and that we ask larger questions about what determines the relationship between the present and the past: How the meanings of the past are produced and made sense of in the immediately experienced present; who initiates these experiences and how are they mediated; what are the consequences of these processes; what is true about the current processes of heritagization that was not true before; how does the relationship between the human condition and the cultural momentum determine the function of heritage experiences. How do we make sense of our encounters with heritage? Why do we seek them out? Which internal resources do we use to make sense of them?

Drawing on Butler's (2011) vocabulary, I suggest that we consider heritage as a category of meanings and practices that organize our relationship with the past and our selves in the 
present, and acknowledge that these meanings have been produced and made sense of differently at various points of human history. This category of meanings is a significant factor in the way we function both as a larger social group and as individuals. As any category of meanings that deals with identity, it can be treated as a commodity and a power tool. Further, what we need to consider is that, much as it is the tool of differentiation and community building, heritagization is also a process invested in the production of a fixed sense of self.

If I were to pursue the current critical heritage studies' focus on reconstruction of the relationship between cultural authority and the production of heritage discourses in my dissertation, I would have to approach the study of historic house museums through the relationships of power that define them and as an established publically shared narrative. That would lead me to a study of a range of issues such as, for instance, how the socio-economic status impacts the way visitors engage with historical accounts of the past, or how do historic house museums contribute to the representation of Canada as a country of Anglo-Saxon origin, therefore neglecting its history before colonization. These lines of inquiry would engage with the range of socio-economic and political questions of production of heritage discourses. My own pursuit of an open-ended conceptualization of heritage, which I put forward in this dissertation, has led me to consider intimate experiences of heritage as an embodied lived experience of a performance of the past in the present.

Alan Gordon's (2016) Time Travel: Tourism and the Rise of the Living History Museum in Mid-Twentieth-Century Canada is a recent major work on what I describe as historic house museums in Canada. Gordon refers to them as "living history museums," which places an emphasis on their role animating history, whereas my focus is on the domestic cadences of a place that used to be a house. My approach shares much with Gordon, such as an emphasis on 
how these museums are historic artifacts that represent, he suggests, first and foremost the cultural intentions of the $20^{\text {th }}$ century in preserving earlier history, rather than taking these museums as primarily standing in for the time they are attempting to recreate. I see my research as complementing Gordon's. His positioning of HHMs as cultural products of the time they were established as museums is important context for my exploration of them in terms of the lived spatialities of those who work and manage them, aiming to help people form relationships with an idea of the past in the immediate and intimate present. On the other hand, Gordon (2016) explores them as products of the $20^{\text {th }}$-century need to form a coherent sense of Canadian national identity (see, specifically, chapters 9 and 10), and he identifies specific factors that helped mold their development, such as the Second World War, government policies aimed at diversifying regional economic growth, the growth of tourism, the impact of multiculturalism, and decreased government funding in more recent years, among other factors. While his work establishes social, political, and economic roots of the phenomenon of historic house museums, my research instead helps unpack the experiential layer in the immediate present.

Gordon talks about constraints on the presentation of history that the format of living history imposes. He opens the book with the story of the community's outrage at the staging of a mock medieval fair at Upper Canada Village in 2009, anachronistic with its preserved time period and role in Canadian history. Given that Upper Canada Village is a collection of moved buildings intended to represent a typical pioneer community, Gordon (2016) asks: "Why, one might wonder, would people expect a fictional past to be accurate and authentic? And, from another perspective, what was the problem with replacing one fantasy of the past with another, even if for just one day?” (p. 5). This question reminded me of one of the conversations I had with a curator at an HHM in Toronto during the research phase of this project. The curator 
buckled at the suggestion of hosting a "steampunk" tea party event at the museum and argued that "we need to figure out who we are, before we do something like that." In both these cases, the museum's rigid definition of itself was at odds with a general public attraction to them as interesting places. The uncertainty of what these sites are appears to evolve especially in reaction to a clearer sense of what they might not be. While the medieval fair is now a yearly event at the Upper Canada Village, and a steampunk fair takes place regularly at various historic sites in Toronto, there is still an obvious resistance to stretching the boundaries of the narrative attached to the historic house and its past residents, which, from my point of view, presumes a specific kind of imagined authenticity that has the intuitive dimensions of the historical past, albeit tentatively and vulnerable to reimagination. Conveying the motivations for a historic house's designation as a museum would not click into place and provide the intended experience, if tempered with. This is one of the instances, where the difference between Gordon's (2016) and my studies lay. While both of us acknowledge that HHMs are not bound to the imperative of authenticity and benefit from moving towards other values and meanings, his research is specifically into the historical context behind the resulting cultural product that is living history. My focus, on another hand, is on the present-day meanings and values of those occupying the museum on a daily basis. Thus, my methodologies exclusively inhabit, observe, and interview, myself and others, about our experiential dimensions working within living history.

This suggested perspective of developing the theory of heritage disrupts some of the operational assumptions within the field of critical heritage studies, such as that the production of heritage narratives is the privileged domain of cultural authority or that all heritage is public (see, for instance, Harrison, 2013; Smith, 2006; Smith, Campbell, 2015). Instead, I suggest we assume that all have the ability to produce heritage and that individual processes of heritage production 
are worthy of consideration in academia, since they may be symptomatic of larger cultural processes. It also counters the idea of heritage as a fossilized version of history, broken away from context and historical progression of time, a point in time that is fixed and performed for the entertainment of the masses (see, for instance, Hewison, 1987). In essence, on the level of a theoretical contribution, I follow Waterton and Watson (2013) and seek to make an argument for “decentering notions of heritage itself" (p. 548) by considering it as an affective and creative process that serves the purposes of the present.

My final point here will deal with the question of mediation of heritage. Morisset (2016) conceptualized heritage as information, a point that is reflective of mainstream theoretical discourses and methodological work in critical heritage studies. I would like to emphasize the fact that experiences of heritage are dependent on and mediated through people, places, and objects. Encounters with heritage that produce a reaction do not necessarily originate in a way that is already coded symbolically. I suggest we recognize that, firstly, we adapt our ideas of our selves in accordance with the environment that we are exposed to; and further, that there are intimate experiences of heritage that are formed before the discourse on it is completed. In that sense, I want to suggest that there is space for academic discourse on heritage that would treat it as a kind of an environment, that both constitutes our experiences and is being constituted by them. I address this idea further in Chapter 2 of this dissertation, when talking about materiality.

Heritage in Practice: A methodology for the study of the site-specific performance of the past In The Gap of Time, Jeanette Winterson writes: "He doesn't take a photo or a video because he wants to remember-by which he means he wants to misremember because the moment is made up of what the camera can't capture." Here, Winterson emphasizes the "uncapturable" qualities of what makes up a moment and suggests that the substance of it cannot 
be retained through the precise technology of photography and videography. What is the substance of the moment, then, and how can one go about retaining it if one is so inclined? Winterson's protagonist wishes to "misremember," by which he means to let go of the factual detail and to retain the make-up of all that is subjectively significant for him in that moment. This perspective posits the central role of subjective and narrative values in making sense of an experience, poetizes the misremembering.

The tradition of historic house museums invites this same perspective by transforming historical accounts into intimately relatable, coherent stories, personalizing them, connecting them to the lives of visitors, as well as larger social agendas of today. The value of a highly personal encounter as crucial to grounding the experience of the visitor is evident in the way the interpretive work is carried out. One of my interviewees, Ashleigh, a museum professional with over ten years of interpretive and administrative experience in several of Toronto's historic house museums, suggested that her job has been about "inspiring excitement and interest in people through sharing the stories of people." "I have always been a firm believer that history is not historical dates," she continued: "I've always been the one to tell the stories of individuals, and I've always liked to include stories of as many people as possible (...)." Emma, who has worked as a historic interpreter at Spadina House for several years, is more specific in her explanation of this approach:

I think [historic house museums are the best way to connect to history], because you are seeing many... not all, but a majority of artifacts you see in museums, you see them in context. So, they are not just paintings on a wall in a gallery, it's paintings on the wall above the fireplace. They put it there for a reason, you know. The light hits it in just the right way. So, it shows you a certain part of a painting that you would not necessarily see, if it were on a gallery wall. The carpets... they are not just hung or rolled up, so you can see bits of the stuff that were actually on the floor... And artifacts that have been picked up from travels. That were created in different countries to be knick knacks for tourists... or become knick knacks. So, you actually see them in situ, sitting on the fireplace or by the chair, that's how they would have had them. So, we see the beds, and the clothing, so, we 
really... I think it connects people with their own lives as well. Because going to a museum is fun, and you get to see some really cool stuff. But when you look at that stuff, you don't see it in context, so you don't really connect it with your own life. You don't make that connection, so... when people come to Spadina, I try really hard to make them see it. As this is the place that if circumstances were a little bit different, they could be living in this house. Or this could be a friend's house... someone that they might have known could have been living here. And I always like to say that Spadina is a historic home, not a historic house, a little different. Because it makes you feel as if you were actually in a home (...).

An argument could be made that construction of a relatable narrative is an established educational tool that is used in traditional museum settings as well. Perhaps historic house museums merely take it further than, for instance, a natural history museum would. My research suggests that the relationships formed within the space of an HHM and the stories it holds go beyond a possible pedagogical model; that a possibility of relating intimately to the experiences associated with the houses is an important part of the vocation. Consider this example that speaks to the value of an immediate subjective experience to a museum professional working at an HHM. Here, Emma shares a private experience in response to my question in regards to what got her interested in working for a historic house museum:

So, in 2006, the King Tut exhibit came to [a local museum of art]. It was a beautiful, beautiful exhibit, so I really enjoyed walking through... and I remember being really frustrated, because there were too many people around. And I wanted to be alone with all of the artifacts. And then we got to the middle of the exhibit, and right in the middle was the King Tut's throne. And then there was a smaller chair, which was a throne for his sister. And the throne for his sister... you could still see the imprint... the butt imprint of hers... from sitting there... and I just... I sat there, and stared at it, and stared at it, and it was like "oh my God, that is amazing." And just the idea, that you could see an impression, a physical reminder of someone who had been dead for thousands of years. And that was the moment. "That's it, I'm working in museums." Basically, so I could be alone with the artifacts. There would not be people in my way. So it was kinda selfish. But that was the moment I decided [...].

The very staging of the environment in a historic house museum, the curatorial work that goes into making specific experiences possible, suggest an attempt at constructing moments designed 
to be "misremembered," encounters with space and one's body that are to be made sense of and told about in a wider experiential and narrative context; experiences that are collective, but mostly valuable in the framework of an individual life. These are designed to make a day in one's life in a contemporary city fuller, to fill in the gaps in one's experience of life outside of the museum walls. In the search for one's self, this teaches us that remembering precisely is not essential. When intimacy of embodied experiences is built into the peculiar nature of the designed experience, photography and videography will do little to help one retain the memory of it. The best they can do is function as memory triggers. This is the reason I decided against illustrating my dissertation with photos of HHMs. This understanding of the value of HHM experiences as resting within their subjective nature was also what informed my methodological choices.

\section{Research Questions and General Notes on the Research Methodology}

Considering the discussion above, I have approached my task as a methodologist with the following questions: What is the make-up of one's experience within a historic house museum space? What do we desire for it to consist of? What delineates the criteria of significance for remembering and explaining it to other people? How do we go about explaining its meaning? And, since the road to misremembering is, among other things, lined with suppression, what is the impasse, the core issue that seeks to be resolved, but is almost never openly addressed. These questions applied as evenly to me, I realized, as they did to other people who partake in these experiences. In an attempt to translate the discussion above into applied terms, I suggest that the general research question I ask in my dissertation is what constitutes an experiential reality of the past as simulated by a historic house museum. I will begin explaining my methods by transforming the larger conceptual areas used in my discussion, materiality, performance, and 
emplacement, into research questions. This will lead to a detailed description of the methodology I designed and introduce empirical entry points into the study.

Since I considered historic house museums as heterotopic spaces, the study of materiality needed to go beyond the assumption that these sites handle objects solely as artifacts - things that have expert-assigned value due to their described provenance: Heterotopias contest the underlying logic of the world they mirror. If one moves beyond that analytical entry point, she has to ask how do these sites construct the meanings of materiality to begin with, and what purpose do these ideas serve in advancing the work of the heterotopia. Since I considered the lived body as an analytical prism in my study, I also asked how do these meanings contribute to the construction of the experiential reality of a historic house museum, and what is the role of an embodied experience in maintaining these meanings. Further, I ask how is the spatial breakage from the outside world performed, and what, from the point of view of the experience of the manifestations of the material world, constitutes the leaving and entering of the heterotopia of a house museum.

When considering the work of historic house museums from the point of view of emplacement (what I describe as artificial creation of an anthropological place (Augé, 1995; Entrikin, 1991; Foucault, 1986), I sought to uncover what specifically makes the place of a historic house museum different from the location of that same museum, and what are the elements that have to come together for it to work? In other words, how does one create a place out of a site? How does one maintain that? And, further, what is the relationship between the experiences of the body and place within historic house museums? What is the role of a lived body in creating and sustaining the sense of emplacement? 
The consideration of the issue of performance raised questions dealing with the relationship of the interpreter with him or herself as mediated through the work of this heterotopic space. What is it that makes the heterotopic space capable of enabling a willing engaged participant to experience a departure from a historically situated self, and what is the role of an active contemporary self in the construction of these experiences? Further, once the departure takes place, what is the relationship between the heterotopia and the performance? How does a performing body sustain the meanings of place and vice versa? Why do historic house museums invoke play? How does an individual performance of a historically removed self feed into a sense of a collective space? Further, I considered how the transcendence of the mindbody dualism, characteristic of an embodied performance, inform the nature of historic house experiences? In the case of the visitors, do these performances assume deliberation or do they emerge as a result of the context? Can they be consequences of the material setting? What other contributing factors, besides the setting, are there?

In pursuing my answers to these questions, I also attempted to unpack how the heterotopia of a house museum can inform our understanding of the uses and meanings of heritage and cultural memory in the present; and what is the cultural narrative about history, memory, and temporality that the practices of historic house museums help produce.

My perspective in this dissertation draws on the established tradition of ethnographic research in heritage tourism, which understands knowledge as constructed through the experience of the world (see, for instance, Cohen, 2004; Cole, 2004; Edensor, 1998; Ireland, 1990; Moore, 1980; Palmer, 2005; Tucker, 2003). Both heritage tourism and heritage work are then described as activities that people use to make sense of their world and give meaning to their lives. Palmer (2009), when exploring ethnography as a methodology for researching 
heritage tourism, suggests: "Given that my overarching aim is to explore how individuals make sense of the world, through their experiences of it, then encounters with the heritage can shed light on how sense-making in the present is structured in relation to the past" (p. 123). This approach to theorizing heritage tourism through the prism of social anthropology was first introduced by Dean MacCannell in his work The Tourist: A new theory of the leisure class, which was published in 1976 and proved formative to the development of the field. MacCannell (1976) identifies his theoretical goal as an "ethnography of modernity" (p. 4). He approaches tourism as an inherent feature of modernity, and argues that the "first apprehension of modern civilization (...) emerges in the mind of the tourist" (p. 1). His theoretical conclusion is that "tourist attractions are an unplanned typology of structure that provides direct access to the modern consciousness of "world view," that tourist attractions are precisely analogous to the religious symbolism of primitive peoples" (p. 2). MacCannell (1976) conducted a form of an ethnographic study, which included following groups of tourists around Paris, at times joining in their activities, and at times observing them from afar. His methodology also included the study of secondary data. The overall goal of the work was to unpack the social structure behind the practice of tourism.

MacCannell's (1976) approach shifted the focus in tourism research from studying the effects of tourists on what and who they were observing to examining them as a social group, whose worldview was constructed through the practice of tourism and whose behavior was a representative part of a larger social and cultural context. This theoretical approach is the one I assume in my study. 


\section{Methodological Concerns Specific to the Study and the Choice of Methods}

The broader methodological goal of this research project is to explore how places, objects, ideas, and subjects are entwined within the museum space, what is unique to these experiences, and what happens similarly or dissimilarly in the everyday life outside of that environment. A truly comprehensive answer to this question is possible by pursuing it on two distinct levels: interpretive and experiential. This poses a methodological challenge, since the methodological framework and toolkit for the study have to allow for the study of interpretive practices, while maintaining the focus on the experiential reality of a museum space and the sensory and emotional aspects of the encounter.

My goal as a researcher was to insert myself within the environment of a historic house museum and attempt to open it to social inquiry through various ways of being within it observing, writing, interviewing, interacting, sensing, entering it and leaving it. Thus, I have articulated my methodological goal as the study of the phenomenological makeup of lived experiences as objects of ethnographic inquiry (Kusenbach, 2003). My objective was to carry out a form of phenomenological ethnography, which benefited from combining the strengths of indepth interviewing and participant observation with self-reflexive tools such as autoethnography. I employed ethnomethodology as my methodological framework and designed a toolkit with an emphasis on phenomenological sensitivity (Gubrium, Holstein, 2003; Kusenbach, 2003; Maso, 2001). The research design had three major elements: analytic autoethnography, participant observation, and in-depth interviewing. The implementation of each one of these tools is described in more detail below.

Since my project is essentially the study of a production of an alternative temporality within the structure of a modern city, my methodological goal was to examine situations in 
which the phenomenon comes through the strongest, and collect reports from people who are most engaged in the performance of these sites-interpreters, most of whom do their work in period costume and spend their work days within the recreated space of a historic home. Thus, this study focused on the experiences of a social group of invested participants. I realize the limit of the scope of my research for drawing general conclusions in regards to experiences of people living in a large metropolis. After all, quite a few never visit these places, and some who do, do not encounter them in ways approximating the kinds of engagements the staff working there develop. However, the fact that these sites exist is undeniable, and so are the very specific ways in which they suggest we use material objects, spaces, and our bodies. The ubiquity of these sites in postmodernity and the uniformity of the experiences they offer point to a cultural phenomenon, which, I believe, is intriguing and the understanding of which could provide new insights into all that constitutes the bricolage of a postmodern metropolis (Jameson, 2006). After all, people who do not go to historic house museums still live in the kinds of cities where these sites exit, altering the structure of spaces and meanings attributed to them.

\section{Selection of the Sites}

In designing the study, I have adopted the multi-site ethnographic model articulated by Marcus $(1995 ; 2007)$. He suggests that the turn to this mode in ethnography is caused by transformation in and of locations of cultural production in postmodernity and describes the approach the following way:

[Multi-site ethnographic research examines] the circulation of cultural meanings, objects, and identities in diffuse time-space. (...) It develops (...) a strategy or design of research that acknowledges macrotheoretical concepts and narratives of the world system but does not rely on them for the contextual architecture framing a set of subjects. This mobile ethnography takes unexpected trajectories in tracing a cultural formation across and within multiple sites of activity that destabilize the distinction, for example, between 
lifeworld and system ${ }^{15}$, by which much ethnography has been conceived. Just as this mode investigates and ethnographically constructs the lifeworlds of variously situated subjects, it also ethnographically constructs aspects of the system itself through the associations and connections it suggests among sites. (p. 96)

Marcus' $(1995 ; 2007)$ perspective affords the possibility of studying multiple contextual layers of cultural and social experience through a single analytical lens. In the case of my study, the multi-site approach has allowed me to widen my exposure to the various ways in which space, objects within it, narratives, and bodies are used to perform different interpretations of a domestic space and offer it in the form of heritage experience. Further, my study was also to test whether or not my conceptual cornerstones of emplacement, materiality, and performance stood as an operational analytical framework that could explain the workings of historic house museums as kinds of a heterotopia. If tested on just one house museum, the framework could not be used to substantiate a theory which considered the relationship between these cultural institutions and larger societal structures.

The project focused on the network of ten historic site museums owned and operated by the City of Toronto, Ontario, Canada, plus an eleventh museum, Campbell House, which is owned by the City but managed by a private foundation. All these sites, when taken together, form a coherent community, much like a 19-century city and nearby small towns, now preserved within the boundaries of a modern metropolis. The network includes a downtown townhouse (Mackenzie House Museum), a stately estate (Spadina House), a country inn (Montgomery Inn), a home of an official (Judge Campbell's House), a schoolhouse (Zion Schoolhouse), a military fort (Fort York), an industrial site (Todmorden Mills), a country lodge (Colborne Lodge) and etc.

\footnotetext{
${ }^{15}$ Here, the original text contains a reference to Holub, R. C. (1991). Jurgen Habermas: Critic in the Public Sphere. New York: Routledge.
} 
Many of these sites are connected not just by a historical context, but through the personal stories they tell. For instance, Judge Campbell ruled in William Mackenzie's favor following the infamous Types Riot. The owner of Spadina House once served as Mackenzie's indentured apprentice and, along with George Gibson of Gibson House, was one of the rebels who followed Mackenzie during the Upper Canada Rebellion of 1837. George Howard of Colborne Lodge was the city planner William Mackenzie hired, when he became the first mayor of newly-renamed Toronto. This list could go on.

For the purposes of my dissertation, out of eleven historic site museums owned by the City of Toronto, I omitted Zion Schoolhouse and Market Gallery, since these did not fit with my emphasis on domestic spaces where people dwelled ${ }^{16}$. All nine were studied through the participant observation of tours and special events. Out of these nine, I selected three as paradigmatic cases for a closer study: Mackenzie House, Spadina House, and Colborne Lodge. At the planning stage of my research, I anticipated that three exemplars would carry through my three conceptual themes. Spadina House spoke to my focus on the meanings and uses of materiality. Mackenzie House, where I deliver tours in costume, would allow me to consider the role of performance in the museum practice. Colborne Lodge offered a unique investigation site as an exemplary case of material performance of emplacement. I considered heritage as a metatheme, which informs the work of all of these sites. In practice, the conceptual focus in my

\footnotetext{
${ }^{16}$ The nine museums are: Campbell House, Colborne Lodge, Fort York, Gibson House, Mackenzie House, Montgomery’s Inn, Scarborough Museum, Spadina Museum, and Todmorden Mills. Including the Fort York National Historic Site may seem at odds with my focus on domestic spaces. However, in the historic period that the site is interpreting, the Fort served as a domestic space for soldiers, many of whom had families. In addition to that, Fort York was where many historic recipes were adapted to modern ingredients and translated into current cooking terms. These recipes are now widely used in historic kitchens in most of the HHMs in Toronto. Those familiar with the full range of museums in Toronto may further note that Case Loma and Black Creek Pioneer Village were omitted first because they are not city-owned museums, but also because I felt they were not historic, domestic dwellings.
} 
investigation into the performance of these sites was not as clearly bracketed. While this initial planning drove me to dig deeper into exploring how my anticipated conceptual themes expressed themselves in practice, I did not ever draw data from my study of a single site in discussion of any of the three conceptual themes.

All three museums that were selected as paradigmatic exemplars were studied through indepth interviews with the staff and participant observation of the tours. The Mackenzie House Museum was the site of my autoethnographic investigation. Although by the time I had to make this methodological choice I had already been giving tours there for two years, I strongly felt that the choice was far from being a mere victim of opportunity for two reasons - its location and its popular cultural narrative. Mackenzie House recreates a middle class $19^{\text {th }}$-century lifestyle at the very heart of Toronto's downtown, minutes away from its financial district and one of its biggest retail centres. With this site, the sharp contrast between the experience of the outer world, which intrudes on one's senses, and the gentle inner world of the museum, which asks that one makes a conscious effort to engage to make sense of this place, is particularly striking. The Mackenzie House Museum also has a reputation of being the most haunted home in North America ${ }^{17}$. These two factors contributed to a very strong narrative that could illustrate (or completely disprove) my discussion on historic house museums as heterotopic sites and on the functions of these places for maintenance of cultural memory and heritage.

\section{Autoethnography}

I realized that the key to carrying out an effective autoethnographic inquiry was acknowledging the ambiguity imbedded in the method early on. To begin, it is rooted in the

\footnotetext{
${ }^{17}$ There is a number of popular web-sites that describe the house in these terms. See, for instance, Toronto and Ontario Ghost and Hauntings Research Society's report on Mackenzie House at http://www.torontoghosts.org/index.php/the-city-of-toronto/public-buildings/73-mackenzie-house. I further address the issue of hauntings when talking about the uncanny in chapter 3.
} 
history of the positivist ethnographic tradition of observing the other. Even at its most ethical and humanistic best, ethnography is a critical gaze that is directed outward. Autoethnography, I realized, is the bringing together of the inward and the outward gazes in producing the narrative that makes sense of the conversation between the two critical selves, the ones looking out and in. In the process of the study, I have also discovered that it is the bridging of the realm between my private and my public selves, since as an autoethnographer I was operating in both spheres simultaneously. Thus, I defined my goal as an emotional and intellectual engagement that would be carried out in a self-reflexive manner and would produce an engaged narrative grounded within a specific community. Hammersley and Atkinson (1983) describe this process the following way: "[t]here is, then a constant interplay between the personal and the emotional on the one hand, and the intellectual on the other. Private response is thus transformed, by reflexive analysis, into potential public knowledge” (pp. 166-167).

In conceiving of this portion of my research project, I was guided by Tedlock's (2005) articulation of the method:

Autoethnography at its best is a cultural performance that transcends self-referentiality by engaging with cultural forms that are directly involved in the creation of culture. The issue becomes not so much distance, objectivity, and neutrality as closeness, subjectivity, and engagement. This change in approach emphasizes relational over autonomous patterns, interconnectedness over independence, translucence over transparency (...). (p. 467)

When designing the study, I was aware that my focus on heritage as an embodied and sensory process suggested the use of evocative autoethnography as a research tool. However, for the purposes of my project, I set out to apply a form of analytic autoethnography, which fits with the epistemological propositions of the analytic/realist ethnographic tradition (Anderson, 2006). The specific reasons for this choice of methodology were twofold: (1) Analytic autoethnography allowed me to understand and interpret my own experiences as a member of the group within a 
larger social context, therefore contributing to a better theoretical understanding of the social phenomena of a historic house museum; (2) not focusing entirely on the personal and expressive account of my experiences did not preclude me from being aware of them.

This choice of analytic autoethnography fitted with the overall methodological goal of my study to understand the everyday work of historic house museums by placing it within a broader social analytic context. Anderson (2006), when describing the procedural application of analytic autoethnography, includes the following five features: “(1) complete member researcher (CMR) status, (2) analytic reflexivity, (3) narrative visibility of the researcher's self, (4) dialogue with informants beyond the self, and (5) commitment to theoretical analysis" (p. 358). I followed these guidelines in the way I carried out this portion of the study.

My autoethnography relied on my position as who Patricia and Peter Adler (1987) describe as an "opportunistic" CMR: I acquired intimate familiarity with the group and the place I wanted to study prior to my formal engagement with this project. I secured permission from the Ryerson REB to draw on my initial experiences of encountering the Toronto historic house museum circuit as a visitor and a volunteer. In the summer of 2013, I underwent a typical training, costume fitting, and general introduction to the behind-the-stage work of a historic house museum in Toronto. As I was beginning to write my dissertation, I was in the third year of providing regular tours and assisting in the organization of special events. To the two years' worth of my volunteer work at the museum, I added six months of a formal autoethnographic study-spring through fall of 2015. A year is the cycle of the curatorial programme at a typical historic house museum, since visual displays, the content of the tours, and educational programming change to correspond to seasons and holidays and to showcase what a household would have looked like during different times of the year. This planning ensured that I would 
have two to three full yearly "cycles" to draw on in my analysis and writing. This initial immersion in the world of historic house museums proved to be crucial to the success of the study. It worked as an exploratory phase that helped design the research project and gave me a status as a member of the community before the beginning of the research phase. My responsibilities at the Mackenzie House Museum (or at any other location where the museum was organizing an event: cemeteries, historical sites around the city) included giving tours of the house museum, doing active interpretation of the kitchen, assisting in special events, and baking treats that were offered to visitors at special events. In total, over the two and a half years, I made close to 80 site visits, on which I could draw for the purposes of my research.

The methodological goal behind my use of autoethnography was to examine a firsthand experience of entering the world of HHMs as someone with the agency to interpret it and to invite others to make sense of it on their terms. ${ }^{18}$ The generous stretch of time I spent at Mackenzie House allowed me to observe and record a type of evolution in my relationship with the space, and the idea of the historic house, and the kind of engagement it appeared to command for visitors. I progressed from being surprised by some of the practices, charmed with the atmosphere of the past, and committed to objectivity as an impartial museum interpreter, to being greatly agitated at the seeming inauthenticity of a batch of cookies made using a period recipe, because the museum kitchen happened to be missing one of the required spices. As an autoethnographer, I recorded my scepticism of my newly acquired, emotionally charged

\footnotetext{
${ }^{18}$ It is often assumed that museum tour guides repeatedly use a narrative that is given to them. I have found the opposite to be true in the case of Toronto's HHMs. All the historic interpreters I have come into contact with during my research confirm that they get to build their own interpretive narrative of the period home based on the extensive literature provided and, quite often, their own research of the house and the time period. Most also suggested that they changed the focus of their tour prompted by expressions of interest from the visitors. Finally, the visitors form their experience of the house based on individual responses to the house space and the objects within it: While some might engage with the idea of managing a social life within the space of the house, others respond to symbols of everyday domesticity, such as a washing board or cooking utensils, and question the height of the stove.
} 
devotion to authentic detail that bore no consequence for the experiences of the public who were to consume the food, but appeared to be a cause in and of itself - an obsession with historical accuracy for the sole sake of being a part of the process of making the thing in the exact way it was supposed to be made. Thus, the autoethnographic analysis allowed me to document and then analyze a journey of first encountering the space and a social group that maintained it, my experiences of it and in it, and the evolution that occurred in ways that I grew to relate to it.

In the case with this particular tool, the phenomenological sensitivity referred to above was expressed not entirely through the choice of the method, but in the way I carried this portion of the research out and interpreted the results (Pink, 2009). Autoethnography allowed me to collect first order accounts of embodied experiences within the museum spaces and critically engage with and provide a personal and expressive account of an embodied phenomenological experience of my own. Further, this version of autoethnography allowed me to evaluate my own experiences as a museum guide in the context of the experiences of other members of the staff and visitors.

I quickly discovered that autoethnography in a historic house museum setting is tiring labor. An altered temporal environment is filled with smells, sounds, textures that seem to take on new and unexpected meanings. Consider the smell and the feeling of parched skin as bleach evaporates from my hands. That's me, washing dishes in the "modern" kitchen. Here, there is a sound of the radio and I can chat with whoever is on the reception duty. I dash downstairs, to the smell of cinnamon, cloves, and burning wood, as I enter the historic kitchen. Here, I go virtually unnoticed by the visitors, because I perform a quiet role of an assistant, but, more so, because I am wearing jeans and a sweat shirt in preparation for multiple spills, and my functional modern presence does not quite fit with the narrative of this warm, lit up space, filled with stories, smells, 
and tastes of times past. Feeling, analyzing, recording, listening, while simultaneously occupying the space as a tour guide, a cooking assistant, a historic baker, turned out to be an arduous project to take on. At some point, closer to the end of my research, an empathetic curator inquired about my progress. She was somewhat taken aback when I exhaled: "It is wonderful, but I am so tired of feeling things. I am so ready to write!”

\section{Participant Observation}

Participant observation has traditionally been a central part of anthropological fieldwork, with other tools, such as interviewing and the study of secondary sources, used to further explore the themes it unearths (Marcus, 1995; Palmer, 2009; Willis \& Trodman, 2000). In the case of my study, this method carried the same weight as the other two parts of my methodological triangle - interviewing and autoethnography. That, I believe, has allowed me to maintain a more critical perspective on my own ethnographic gaze and create larger spaces within my research and analysis for participants to interpret their own experiences and attribute meanings to them. Establishing balance among the three methods of data collection has also allowed me to delineate the amounts of time I dedicated to collecting field data more effectively.

The theoretical perspective on heritage tourism as a social institution, the study of which could allow one to deepen one's understanding of the workings of the larger cultural and social structure, suggests that tourists and heritage workers alike could be approached as a form of a society. Palmer (2009) describes this society of tourists as "highly mobile and in which membership is fluid, temporally contingent, and determined both by location and purpose" (p. 124). She explains that this understanding of tourists "enables the act of tourism to be visualized as a totality capable of investigation and analysis from a variety of different perspectives, including that concerned with the culture of tourist society, namely social anthropology" (p. 
125). In developing my methodology, I have articulated my understanding of the social group comprised of heritage tourists and practitioners along these theoretical lines. From this point of view, within the context of a tour or a special event at a historic house museum, both historic interpreters and the visitors emerge as co-creating the experience of the place, of mediating the reality of it for each other ${ }^{19}$.

The goal of participant observation in my study was to take membership within a group of visitors. I focused on observing and recording behaviors of historic interpreters and tourists within the space of a historic home and/or its grounds. I considered how tour guides and visitors interact with stories, objects within the house, each other, as well as the built environment. The ethnographic data on the experiences and reactions of the visitors and the staff was collected and recorded with the purpose of developing a thick description of these instances as contextualized events (Geertz, 1973). My goal as an ethnographer was to understand and to unpack behaviors in a way that would disclose their meaning within the culture of the institution.

The participant observation portion of the research project was carried out in eight of the Toronto's historic house museums ${ }^{20}$ in the period between March $24^{\text {th }}, 2015$, and March $24^{\text {th }}$, 2016, and consisted of at least two visits per site. Initially, my goal was to observe one regular tour and one special event, such as a ghost tour, a cooking workshop, a fair, a book club meeting, at each site, to form a more comprehensive idea about how homes interpret themselves to visitors. However, the line between what is "regular" and what is "special" was not always easily

\footnotetext{
${ }^{19}$ Here, I articulate my understanding of heritage tourists and professionals as a social group to unpack my perspective as a methodologist. In my further conceptual analysis, I draw on the same themes of fluidity and temporal and spatial contingency in considering this group from the point of view of Warner's (2002) definition of a public.

${ }^{20}$ The Mackenzie House Museum was excluded from this list, since I studied it as an autoethnographer. I made a point of assuming a position of a visitor at several of the events, but, again, that was done to acquire a sharper lens in my work as an autoethnographer.
} 
distinguishable. For instance, active interpretation of a kitchen may not qualify as a "special event," but it adds a very different value to the experience of a historic home. Thus, I have stopped at two visits per house in the course of a year, with an attempt to participate in events, beyond the regular tour, that are designed to further the visitors' experience of the house. The itinerary of my participant observation work is available in the appendices.

In total, I made 20 visits to the sites in the role of a participant observer. I made discretionary choices to visit some of the sites more than others, if an additional special event promised unique opportunities for new observations and, I strongly felt, added to my data. For instance, I attended an Etsy fair at Gibson House in the fall of 2015 in addition to the two other visits, since that appeared to be an unconventional and intriguing way of presenting a historic space to the public. In that case, I was invested in unpacking the intersection between the two contemporary cultural trends of a staged experience of the past and an institution of a peer-topeer handmade and vintage movement.

\section{In-depth Interviews}

Most of Toronto's historic house museums are serviced by about twenty members of staff and volunteers. In each one of the cases, about ten to fifteen people form the basis of a regularly recurring team. Also, people working at these museums tend to stay in the system for decades. They generally know each other quite well. During the preparatory stage of my research, I connected with some of the key actors, whom I planned to interview in the spring of 2015 . I then used the chain-referral sampling in connecting with others.

Between April and November of 2015, I conducted in-depth interviews with 13 members

of the staff at the Mackenzie House Museum, Spadina House Museum, and Colborne Lodge. I made this initial decision to select interviewees associated with the three sites with the goal of 
developing a deeper understanding of the museums chosen as paradigmatic exemplars. While this plan did work quite well, it turned out that most of the staff at the time of the interviews worked in at least one other museum in the city. In most cases, my interviewees have had experience giving tours and teaching workshops in at least two to four historic sites in Toronto in their careers as museum professionals. Thus, while I could tailor some questions to unpack the performativity of specific sites, my interviewees were able to put their answers in a wider institutional context, thus making the data more universal and drawing a broader, more comprehensive picture.

It was essential that the interviews I conducted were unstructured, since my questions dealt with people's account of their emotive and sentient encounters of special significance, something that I wanted my subjects to engage with on their own terms. The interviews varied depending on the interviewees' narratives and their relationship with the museum. The general question I worked to unpack was: "How do these people experience their personal as well as their social lives in their relationship with the sense of the past, as well as temporalities and spaces that they occupy?" While being aware that I needed to be flexible with the direction my interviews took, I translated this one general questions into a series of more specific questions and used them as a guide in my conversations. I started each interview by asking general questions about what led the subject to his or her work at the museum. A separate set of questions dealt with things and experiences that the interviewees could describe and unpack as especially meaningful or providing the most satisfaction: Tasks or experiences he or she looks forward to in the day, a part of the curatorial year he or she found especially enjoyable, their favorite objects within the house, and others. The final cluster of questions dealt with ways in which my interviewees' work at the museum affected their lives outside of it-their leisure time, 
their perspective on Toronto, what they thought about their own everyday life in their proper historic temporality. Here, I also attempted to understand what constitutes the leaving of an HHM space. While I asked a specific question on the subjects' interpretation of their role within the museum, the narrative they created through the interviews was read as a commentary on their position in relation to their work and the HHM space.

Concluding Remarks on Methodology: Understanding the logic of the kaleidoscope

One of the unexpected benefits of my triangulation method-participant observations in all of the museums, autoethnography in one of them, and in-depth unstructured interviews at three sites selected as paradigmatic exemplars-came from having to shift between my roles as a tour guide, assistant at workshops, and a guest in workshops and on tours. This continuous switching of the positions-in relation to what was happening in the museum, to the space and the people in it-provided insights into things that I grew to take for granted in my two years as a volunteer tour guide and a historic cook. It helped me break through the habitual behavioral and thinking patterns, even the way I moved through the space of the museum, and forced me to continuously experience the site and people within it on new terms. Van Meijl (2005), quite appropriately, compares the position of an ethnographer to that of a mythological trickster. "As tricksters have multiple identities to mediate the unmediated (...)," he writes: "so anthropologists adopt different identities in the field to reconcile the irreconcilable demands that are essential to ethnography" (p. 235).

The in-depth unstructured interviewing was the tool that brought out the most surprising results. While my work as an autoethnographer certainly never felt stale, I had spent two years prior to the beginning of my research volunteering at Mackenzie House and had a general idea about what the experiences I was observing would entail. I had encountered myself, my own 
reactions, and the environment before; I also had the luxury of making sense of my experiences on my terms: I would plan my time so that I could sit down immediately after visiting a site to unpack my notes and to write a deep description of my experience. The same level of prior familiarity applied to my experiences as a participant observer. I had met most of my interviewees in casual social situations before the research started and knew the settings they worked in quite well as an observer. Never before my interviews, however, was I privy to the intimate relationships between the people and spaces they worked in, some of them for decades. As the interviews showed, in some of the cases, neither were my subjects.

As a researcher, I invited my interviewees to examine their drives, interests, and experiences, to consider and articulate back to me reasons behind their occupation. One of the things that helped was that I could conduct all but two interviews within the museum settings in kitchens, parlors, and day rooms. In some cases, my interviewees were in costume. This placement within the physical context of what we were discussing added immediacy and, in some cases, secured my interviewees in the sense of legitimacy of what they were telling me. On several occasions, I had my interviewees stand up and demonstrate why they did not think a certain object performed the function we think it did, because, "look, I cannot use it in this dress!"

As I progressed with interviews and patterns began to emerge, I realized that the very process of fine-tuning my questions, of knowing how to phrase them and when to ask them-in other words, what I was doing in response to the answers I received-can be as telling as the answers themselves. That process of discovery, the figuring out which questions worked better than others, I consider a result of the research as well. For instance, by my fourth interview, I had added a question: "Do you find that you have developed feelings about the people who lived in 
this house before?" This might appear like a presumptuous question, the kind that suggests an answer, but it was based on a theme that had emerged in the first three interviews in very pronounced ways, with my subjects using strong emotional language when discussing how they felt about the people who used to live in the house. I turned it into a question to test if it was, indeed, a pronounced pattern in the way the house museums were conceived of.

Some questions, however, that I thought would definitely "work," did not work at all. This question: "Do you think your work at the museum affects the way you see Toronto every day?" seemed to throw the interviewees off. Because of the focus of my work, I approached their experiences in the museum in the context of their everyday life in a major metropolitan area; but the interviewees appeared to separate their two lives, lives inside the museums and lives outside. Most of my subjects also appeared to be reluctant to talk about this. It seemed obvious to my interviewees that the answer to this question should be "yes," and so it was, more often than not, but the responses felt forced. For instance, one of my interviewees started to answer this question by referring to how her work at the museum informs her understanding of social rights in the city, then mentioned walking through the streets thinking about what they looked like back then, but very briefly, and went back to talking about research, reading about how Toronto became what it is. She appeared to be connecting her ideas about Toronto not to her experiences in the space of the museum, but rather to her reading on its history. This same general perspective appeared in most answers I received.

I also discovered that historic house museum work appears to be a form of tribal activity. The peculiar nature of the skill set and the knowledge the job requires can be one of the reasons behind the seeming exclusivity of the club. Another reason is that, at least in Toronto, professionals work multiple part-time contracts in several museums at the same time for 
extended periods of time; people in this line of work generally know each other or of each other. The HHM circle is a close-knit and rather small community. When interviewing people in museums other than Mackenzie House, I found it extremely helpful to mention my experiences with costumes, tours, and especially cooking workshops. I appeared as someone privy to the unusual world of running a $19^{\text {th }}$-century house, someone that they could trust with their own experiences.

At first, I wrote this off as evidence of the fact that my experiences were helpful in the way I was able to communicate my interest and formulate questions. To test this theory, I attempted to disclose my "membership" mid-way through interviews or not disclose it at all. The difference in interviews with people who knew I had worked at a museum and people who were not aware of that was so stark that I had to stop this unplanned experiment. The interviewees who did not know I was “one of them" were visibly on guard and avoided engaging with some subjects that they felt I would not understand. For instance, people were normally very hesitant when it came to talking about the costumes. I gradually started to refer to this sense of discomfort at approaching subjects perceived as sensitive, or something that cannot be quite understood by an outsider, as "the guarding of the impasse."

I first observed what I later started describing as an "impasse ${ }^{21}$ " the first year of my volunteer work at Mackenzie House. In February of 2014, the Single Thread Theatre Company staged a performance of "Firebrand," a play by Alex Dault. The play dealt with the story of the Mackenzies' return to Toronto and used the house museum as the setting. I saw the people, the story of whom I felt intimately familiar with at this point, go through their lives within the walls,

\footnotetext{
${ }^{21}$ Alan Blum unpacked his take on impasse analysis as a method of social inquiry on November 6, 2015, in his talk Culture of Cities Centre, Toronto, Canada, as part of the Centre's Interpretive Workshop series. In my work, I draw, in part, on his perspective. The idea of impasse is addressed in more detail later in this dissertation.
} 
in which my telling of the story was placing them week-end after week-end. It was an intense experience. A colleague of mine offered that it was nice to see someone else come in and get it, referring to the playwright and the actors. That it was nice to have someone else understand "the way we do things." He felt he did not need to explain more, as I nodded in whole-hearted agreement, and my research has grown to become about the $i t$ that the staging of the play found a way to feed off of and feed into; the point that, I felt, my interviewees could connect over, but no one was willing to articulate. It is the point that is felt and shared in the coming together of the people who "get it."

I acknowledge that there are a number of questions that arise in regards to attempting to research something that interviewees avoid identifying openly. My argument here follows Denzin (1970), who writes that: "[my] stance justifies "unannounced," disguised research methods. If we are not permitted to study things that people wish hidden then sociology will remain a science of public conduct based on evidence and data given us by volunteers" (p. xiii). I do not go so far as obscuring my research objectives to my interviewees in an attempt to uncover that which is hidden. When articulating impasse, I draw on Geertz' (1973) metaphor of a kaleidoscope, which he uses to explain how socially constructed knowledge can be rearranged to form multiple patterns:

for, as in a kaleidoscope, one always sees the chips distributed in some pattern, however ill-formed or irregular. But, as in a kaleidoscope, they are detachable from these structures and arrangeable into different ones of a similar sort. (p. 353; emphasis in the original)

It is this deep-seated reason, one that informs the internal logic of the structure, the specific assembly and angling of metaphorical mirrors and the source of light, that, while allowing objects to move within the kaleidoscope, always secures their position in place. 
One of the ways I chose to address the guarded impasse without directly pointing it out was to suggest my interviewee consider why he or she chose to answer a question in a specific way. For instance, in response to a question about the most intriguing object in the house to her, Ashleigh focused on how its use can be interpreted. Consider her answer:

I was thinking about the toilet itself. Only because it is a bodily function that everyone does and everyone is actually very interested in learning about. Even if you watch a TV program, it's like: "where do they go to the toilet?" How does it work... How did they use it... Or even the chamber pots and outhouses. Because I am not convinced women used outhouses. I am absolutely not convinced... having spent 20 years in period costume. ...from 1810 to 1860 I'm not convinced women went to outhouse. So, I guess it would have to be a chamber pot, a commode, and a toilet.

...do you mind if I just go take a look at it? I just want to... (goes to look at the toilet again) Ok... I just wanted to make sure that my thoughts were accurate for myself. Unless someone shows me a quote that it's his actual thinking, (referring to the house owner wanting to conceal the toilet door) I don't buy into it. Just because it's wall-papered does not necessarily mean to me that it's secret and it's hiding it. Because there's no mechanism on the door to actually latch close it. And it's in the private side of the house. And there is a door in the dining room that would be closed, presumably no one visiting the house would see it. Or... if they need it, they would still be going to it... and... so, until I see a quote saying that's what he actually had in his mind, I think it's open for interpretation. We all like our toilets discretely placed. I know people who won't buy a house or rent an apartment, if the toilet is off the kitchen. We all want them discretely placed, so... I don't know about that.

I followed up on this answer by pointing out that Ashleigh was attempting to figure out the thinking process of the owner, his perspectives on how a specific bodily function was to be performed, by analyzing the organization of the house and the door. I suggested that this type of interpretive work is dependent on spending some time within the house and using the objects, and asked her to comment on that. In response, Ashleigh agreed and extended her answer by describing how she invites the public to "put themselves in this life" and attempt to form answers to their own questions by making an imaginative leap into inhabiting these spaces. The idea of an imaginative leap, the term that I borrow from my interviewee Liam, whom I quote just below, echoes the response by Emma, in which she states that she wants the visitors to consider the 
house as a place where they or their friends could have lived. The invitation for the visitors to insert themselves within the life in and of the house, as well as the slice of time that is the content of a house museum, extends beyond the experience of the domestic and into the other layers of the historic narratives that HHMs address. Another one of my interviewees, Liam, explained it the following way:

There is a thing about the house that is immersive. Right? It allows you to step into it in the way that you can't when you walk along, say, Bay Street. Bay Street, to me, is an atrocity of architecture. It's all glass and marble. And it has no sense of what it was a hundred years ago or its history, at all. Whereas if we are coming to this place here... A lot of what I do here is about: "What was it like then... Well, this is part of what it was like then." There was no running water in the house. They had to use the toilet in the back yard. For me, this allows for an imaginative leap, an immersive imaginative leap into this world, that is not just about the water or the lack of electricity. It is also about the changing ideals that were going on here as well. It can't just be about the domestic side of the experience. It needs to be about what this place means, and why it is preserved, and why it is important to who we are. Mackenzie, for me, is a major, major identity building block in terms of my home town.

I am from Toronto, born and raised here. And I think if you are going to understand Toronto, you need to understand a few things about it. You need to understand that it was set up initially to be a bastion of loyalty to the English system of governance. And then you need to understand that there were a bunch of people who arrived here afterwards, who said "no" to that. I think those are two key things about this place. My mother arrived here from England in 1959, I think it was. When she arrived here, it was still a conservative, loyal place in a lot of ways. The First World War here... The First World War was very loyal here... there was no doubt, once war was declared, this place went to war. So, I think an investigation into the imbedded nature of who or what this place is, is facilitated in a building like this in an imaginative way: "... can you imagine what it was like..."

It's interesting, we get a huge multi-ethnic diversity that comes through here. Within that I see people who are capable and interested and keen to make this significant imaginative leap. I took a private Muslim school through here. I take grade 7s through here. I've taken senior citizens through here. I've taken First Nation teens through here. I've taken a wide variety of people through here. And it seems to me that people are keen to hear the story, they are keen to hear the story about how somebody stood up and said "no" to what was offered here. They are keen to hear that story. I think that's the universal quality of the Mackenzie story. And so if you are in this house, it allows for, sort of, a leap of imagination. I mean I don't do "the good old days" stuff in terms of time travel, which is part of the traditional museum house thing. I do "you know what, it was crappy back in those days. Drinking water was taking your life into your hands." It was different. I'll do things like... when I am talking about the Legislative Assembly and the Executive, I say: 
"Imagine your parents fought in the American Revolution. And you fought in the War of 1812. I would then ask you, as a Lieutenant Governor, to come on to my Executive Counsel. Oh, sorry, I would not ask you, because you are a woman." Let's dismantle some of the good old days stuff here. But it allows us to talk about how it might have been. It allows for an imaginative leap, if you will.

If I am capable of putting the visitor in the drama and let it play out a little bit, I have done my job.

These examples above are intended to point to what I see as an attempt at discerning the workings of the Geertz' (1973) kaleidoscope that is an HHM. These examples unpack how, from the point of view of an interpreter, one may enter into a relationship with the space of an HHM and the things it holds. This point of entry, it so appears, works on multiple levels. It engages with one's take on his or her gender, relationship with one's body and the things that it does, and sense of identity or cultural belonging, among others. An interpreter can enable this point of entry through smells, by telling ghost stories, through how she wears her hair, ${ }^{22}$ and so forth. This, however, is just one of the angles of the mirrors that form the whole. Both methodologically and analytically, my goal in this dissertation was to understand what is the it that makes the pieces in the kaleidoscope fall into place. How this deep-seated logic expresses itself from the point of view of things, stories, bodies, spaces, and what people do with all that in historic house museums. What is it that makes the pictures form and what fails, when they do not.

As a trained interpreter, I was taught to explain a historical period through stories of little things: I can connect the history of modern day muffins to the War of 1812, and it would not even be that much of a stretch. The way one of my interviewees put it, a large portion of our investment lies in what happened "on an average day, to an average person, during their average

\footnotetext{
22 "Costume hair," although never required, is something that some interpreters choose to maintain.
} 
life.” In my dissertation, I take a similar approach. This work will contain a lot of stories about lives and work of people who, more often than not, have to wear period clothing in their jobs and have a working knowledge of how to stuff a sheep's intestine with a mix of oatmeal and ground lamb and not let it all explode when cooking over fire. When it came to understanding and connecting to the experiences of these people, I sought to appreciate and recognize the mechanics of their everydayness. I listened for what it was that happened to them on an average day, why they chose to be there, and what were the average things in these days and in these environments that formed their experiences of space, time, materiality, and their bodies. While I drew on the bulk of my observations, conversations, and interviews to form a basis for my analysis, some representative instances emerged in my writing, once again, in the form of stories or seemingly small details, such as an apparent obsession with getting the spices right.

Throughout my dissertation, I also refer to one specific text, which, while not being strictly academic in nature, carried legitimacy and turned out to be quite helpful in broadening the scope of both my observations and my analysis - 18 Folgate Street. The Tale of a House in Spitalfields by Dennis Severs (2002). Severs, who died in 1999, was an artist and curator who developed a run-down property in the Spitalfields, a neighborhood in London, into a house museum. While the family that, he suggests, once lived there, was fictional, the appearance of the house is historically accurate down to the tiniest painstaking detail. The objective of Severs' creation was not to merely reconstruct a domestic interior that could have been possible, but to tap into the experience of a historically situated human condition. 
CHAPTER I: Heterotopia of a Historic House Museum: Alternative spaces within an urban environment

"It's a poor sort of memory that only works backwards, says the White Queen to Alice." Lewis Carroll, Alice's Adventures in Wonderland \& Through the Looking-Glass.

One of my interviewees, Lana, who has worked in two of Toronto's historic house museums (henceforth HHM) at different points through the last decade, laughingly told me a story about the events that once took place at Colborne Lodge, one of Toronto's historic house museums located in the midst of the 400 -acre park called High Park. The house got snowed in during a snow storm, she said, and the staff decided to order pizza, hoping that maybe a delivery car would make it down the park's roads. Indeed, it did. The pizza delivery driver was rather confused from the start, since the place looked more like a house than a museum. He was even more confused when the person who opened the door and happily accepted the box was wearing a Victorian era dress. "You forget that what you are wearing around here is weird in the outside world," Lana explained: "And then she probably forgot she was in that dress in the first place."

The experience of the driver in this story represents a powerful instance of urban uncanny: A snow storm in an old park, the winding roads, the address, that appears to be for a lived-in house, rather than for what he originally thought would be a government institution. He knocks on the door, it opens, and there stands a woman wearing a white bonnet and a long oldfashioned dress complete with a hoop skirt and maybe a white apron. She looks welcoming, as people working with the public often do. To the driver it felt, perhaps, as if a door into the past, or a kind of a time gap, had opened in the midst of a snow fury in the park, which, in a storm, looks more like a forest. The house looked, no doubt, inviting. It would have smelled as if a fire were lit, and, likely, of wreaths, since they make them from scratch at that museum around 
Christmas time. There was also probably a smell of gingerbread and, perhaps, apple cider, the two staple treats for visitors that time of year. It would also have been warm and lit up.

The pizza delivery driver felt quite perturbed having essentially "fallen" into another era in the midst of a storm, the story goes, while the interpreter, on another hand, had no idea why the driver looked so terrified. To her, the temporality vivified by her work at the museum, the being within it, felt so right and familiar, that she forgot someone else might see it as out of place. To the driver, it was a breakage in the linearity of the city space, the kind of a disruption that, in a way, betrays the arbitrary nature of it, turns it in into a kind of a matrix. If it were possible to gaze into the 1860s in the midst of a snow storm in High Park, what other failures in the logic of his space were possible? The story may appear funny, because it illustrates what happens when the space of a historic house museum engages with the world external to it outside of the established protocol for the encounter; when it is simply stumbled into.

This encounter happened on the threshold of a home where the year 1865 was ceaselessly repeating itself; between the worlds, where time and space appear to follow different relational logic. Yet, the two connected over the hot pizza box and the imperative to pay for it, thus forming one coherent whole. In this chapter, I articulate my theory of historic house museums as heterotopic spaces from the position on the threshold: I describe the two worlds in relation to each other and explore them together as parts that constitute the whole of a postmodern metropolis. This perspective is made possible by my positioning this discourse on HHMs from the point of view of critical cultural studies, rather than museum theory, the perspective I substantiate in the literature review section in this chapter. There, I cover the main entry points into the discussion on HHMs, and the various ways of identifying this genre, and offer my own definition of a house museum. I explore the major themes in the academic discourse on HHMs 
and suggest that the discussion can be enriched by the introduction of critical cultural theory. I specifically focus on Carey's (1989) idea of the ritual model of communication, Innis' (1951) description of time-biased media, Warner's (2002) articulation of publics and counter publics, and Anderson's (2006) take on imagined communities.

Following the literature review, I unpack my theoretical entry points into the discussion on HHMs as forms of heterotopia. I suggest that historic house museums provide resolution to a set of interconnected problems that are rooted in the cultural experience and the human condition in postmodernity. I articulate my take on the work of HHMs by drawing on Foucault's (1986) work on heterotopias and Nora's (1989) theory of memory sites. While Foucault's (1986) perspective explains the reasoning behind the formation of alternative urban spaces and outlines their operational protocols, Nora's (1989) discourse fleshes out details that are specific to cultural and social experiences of history, memory, and heritage as they pertain to the current cultural condition. I suggest that the resolution that an HHM affords is the possibility of an experience of another version of a lived reality, the kind of place that makes it possible to have, do, and feel things that the place that it mirrors-the context of the everyday life of a city dwellercannot. The questions, then, are: What kinds of possibilities do HHMs turn into a site-specific reality? And, more specifically, what are the things that a person gets to experience?

I suggest that in the midst of a fractured functional urban space that is organized to service the logic of capitalist production and consumption (Augé, 1995; Entrikin, 1991; Nora, 1989; Soja, 1989), HHMs offer an anchoring in a co-imagined idea of a shared past by creating artificial anthropological places (Augé, 1995; Entrikin, 1991). These sites ritualize a tribute to shared origins and identity, feed into a cultural myth that interprets the diverse fractured Toronto as a coherent whole (Anderson, 2006), and offer tangible, seemingly non-transient evidence of 
the past. Foucault (1986) talks about "desanctification" of space in the modern world (p. 23), and Nora (1989) points to "the permanent secularization" of "the completely historicized world." "Memory installs remembrance within the sacred; history, always prosaic, releases it again," he argues (p. 9). I suggest that HHMs address these two issues - desanctification of a place in postmodernity and the loss of cultural continuity through shared memory - by infusing historic sites with the sense of a living memory that supports the cultural myth of national belonging. Further, in interpreting practices of memory and space as one of the aspects of the philosophy of the current cultural experience, my discussion aligns with discourse on the workings of nostalgia in the age of postmodernity that I refer to in this chapter. It extends that line of thought in its consideration of the specific ways in which the anxiety and longing of the current era seek to appease themselves through a transhistorical reconstruction of a lost home, namely the infusion of a domestic space of a family long dead with everyday life, that is forever repeating itself, ritualized.

I unpack the theoretical articulation of a time gap, a term I coin to describe the working of HHM heterotopias. I describe time gaps as socially and culturally constructed forms of spatiality that contest traditional confines of time and space; they are a result of a search for a state of being that is beyond both the spatial and temporal logic of postmodernity. As such, they sustain an alternative temporal dimension by creating immersive embodied experiences of uncanny understandings of space and time. Time gaps both point to the vacancy in the postmodern experiences of time and space, and create opportunities for bridging them. The heterotopic work of time gaps, for instance, expresses itself through maintaining seeming permanency of material objects through time, while in the context of a postmodern world, in which objects are transient. 
I use my three conceptual themes - materiality, performance, and emplacement - throughout the chapter to expand on my discussion on HHMs as heterotopic spaces.

Literature Review: Historic House Museums - "a landscape that is greater than the sum of its parts" (Mills, 2003, p. 83).

\section{Defining a Historic House Museum}

Historic house museums are not as straightforward a museological genre as it might first appear. The difficulties in defining what an HHM is are understandable, considering the wide variety of professional work done in museumization of restored dwellings, which includes period rooms, folk museums, and open air villages. They can be run by communities, professional organizations, or heritage boards. A person attempting a definition could understandably wonder if the house would have to be restored to be a house museum? Would it have to be a home that someone lived in? Can it be an in-door market? A school? Can it be a ruin? Must it be furnished to look like a home? Do things have to be original to the family or merely to the time period? Does it have to tell a story of the original inhabitants? Can it tell a different story?

Young (2007), in her exploration of the genre of historic house museums, notes that they comprise "real estate, physical fabric, arranged or decorated settings, items of furnishing, household equipment and fittings; not to mention the load of human associations past and present, often including the extended family of occupants and sometimes including residents" ( $\mathrm{p}$. 60). Despite this layered complexity of what comprises a house museum experience, Young's (2007) definition of these sites is surprisingly simple: She writes that they are museums, in which "meaning, content, and container" are one (p. 60), and that "it is a dwelling, museumized and presented as a dwelling" (p. 60). The "unity of shell and domestic contents" (Radu, 2014, p. 5) is the common core in various definitions of this museum genre, along with the expressed goal of interpretation and preservation (see, for example, Pavoni, 2001; Radu, 2014; Young, 2007). 
In my work, I adhere to this general outline, while suggesting three of my own identifiers that emerged out of my research on Toronto's historic houses and help specify the museological and heritage work characteristic of these sites. I describe historic house museums as an exhibitionary museological format, which (1) relies on represented simulation of everyday practices pertaining to domesticity; (2) is characterized by live interpretation ${ }^{23}$; and (3) in which the dwelling itself becomes museumized and is presented as a dwelling. I also agree with Radu (2014), who suggests that house museums are characterized "by a unity of grounds and outbuildings," in addition to "an architectural shell and its domestic contents" (p. 5).

The definitions of house museum outlined above are specific to the discipline of museum studies, and yet they point to an element that is central to my cultural studies interpretation of these sites - the unity of the "container" with the meaning of the content, the museumization of the dwelling, and the integration of the domestic into the institutional. Pavoni (2001), for instance, when unpacking her definition of a historic house museum, describes it as a hybrid institution that "captures the conservational and educational qualities of museums and also the communicative, cognitive and emotional connotations of the house" (p. 53). While my work positions historic house museums as theoretical constructs, this alignment of the container with its contents stands for the storehouse of the museum emerging as the meaning, rather than a mere vessel, and blurs the binary between the interiority of the domestic space within a house museum and its institutional agenda.

There is no agreement in regards to the origins of the historic house museum tradition. Jay Anderson (1982) described them as "simulation of life" in the past and cited Skansen, an open-air village near Stockholm, opened in 1891, as the first museum of this genre (p. 291).

\footnotetext{
${ }^{23}$ Anderson (1982) emphasizes the importance of live interpretation in historic house museums as well.
} 
Linda Young (2007) traces the origins to stately British homes, which initially blurred the boundary between a house and a museum by becoming storehouses for elaborate collections accessible to visitors through invitation. It is evident, however, that the historic house museum genre experienced a surge in popularity in the 1960 s and 70 s, which is when many museums and historical and heritage boards in North America were established. That coincided with a rise in interest in social history. The Toronto Historical Board was established in 1960, and, as part of its duties, it has gradually taken over the management of all but one of Toronto's historic house museums from community groups run by private citizens, with the Mackenzie House Museum becoming the first HHM to be run by the City of Toronto.

I have identified three major themes in the academic discussion on historic house museums and unpack them in detail below. I identify these broad themes as: (1) museological concerns that deal with issues of materiality, interpretation, and research; operational questions are also included in this category, since they are posed to address issues of preservation and interpretation (see, for instance, Cabral, 2001; Pavoni, 2001; Radu, 2014; Young, 2006, 2007); (2) questions in regards to the kinds of ideas on history and historical progression house museums create and perpetuate (see, for instance, Bann, 2000; Bruner, 1994; Casey, 2003; Dicks, 2000; Handler, Saxton, 1988; Mills, 2003; Schwartz, 1996); (3) issues of social consequence, such as the portrayal of gender, class, and race in museum narratives or issues of depolitization in museum narratives (Beranek, 2011; Christensen, 2011; Dicks, 2000; MacLeod, 2006; Pendlebury et al., 2004; Terry, 2008; 2013). Some of these themes overlap. For instance, the issue of historical progression is discussed from the point of view of museum studies, history, and critical cultural studies, and so is the issue of authenticity. 
These themes are reflective of general developments in tourism studies, museum studies, history, cultural studies, and anthropology over the past forty years. One of the goals in this literature review is to also explore how the varying perspectives on theorizing historic house museums fit with different ways of conceiving of the meanings and functions of heritage. It is from this angle that I will work to explain how my own perspective and findings can enrich and add nuance to the current ideas on HHMs.

In order to unpack the angle of heritage in my analysis of the literature, I consistently draw on Waterton and Watson's (2013) study of the origins of theory in heritage studies and theoretical approaches that have been formulated as a result. In their article "Framing theory: Towards a critical imagination in heritage studies," Waterton and Watson (2013) pose questions in regards to what theory can do to the field and for it. They make a point that, given the field's long-standing investment in issues of conservation and interpretation, its roots in ideas about the past as expressed through materiality, and the interdisciplinary nature of the current inquiries, researchers need to be more explicit in our formulation and use of the term "heritage" and more aware of the approaches to research that frequently get taken for granted. Instead of proposing a grand theoretical narrative of heritage or one unifying theory, Waterton and Watson (2013) explore the fabric of heritage theory through "critical imagination," whose imperative, they propose, is to unpack "ideas, constructs, concepts and levels of abstraction that are theoretically informed without necessarily constituting fully-fledged theories in themselves" (p. 547). They identify theories in, of, and for heritage.

Historic House Museums and Theories "in" Heritage: HHMs from the Operational Point of $\underline{\text { View }}$

Theories in heritage, the oldest in the field, deal with issues of preservation and management and are the ones that originate in the fields of archaeology, art history, architecture, 
anthropology, and, later, tourism studies (see, for instance, McKercher \& du Cros, 2002; Hall and McArthur, 1998; Moore, 1994; Tilden, 1957). Here, theory is used to facilitate the understanding of effective delivery of heritage to a consumer; encounter with heritage is conceived in terms of identifying the profile of a consumer. Waterton and Watson (2013) refer to Uzzell's (1998) development of the themes-markets-resources model as an example of this kind of theorizing. Some of the important concepts that were first addressed within the framework of theories in heritage deal with issues of authenticity, community, and identity.

Theories in heritage are the ones that I see as corresponding to the operational point of view on HHMs. I identify this viewpoint with the body of literature that is concerned with issues of preservation, visitor management, and interpretation (see, for instance, Cabral, 2001; Pavoni, 2001; Young, 2007). It, too, originates in the fields of archaeology, museum studies, art history, architecture, anthropology, and, later, tourism studies. Understandably, these were also the first discussions to engage with the topic of historic house museums. They are the closest to the material nature of their subject matter, and they are also the ones that suggest that there is innate value in objects of heritage; that these objects need and should be managed, preserved, and interpreted. These are also perspectives that do not conceptualize heritage beyond its relationship with material objects and understand visitors partaking in the experiences of heritage as “consumers" (Smith, 2006, Waterton, 2010; Waterton, \& Watson, 2013). Understanding visitor engagement is boiled down to conceiving of them as 'recipients' (see, for instance, Uzzel, 1998). Finally, when one considers house museums as an example of "the museum idea to make specimens out of the material world" (Young, 2007, p. 59), one of the primary issues that arises is that of definition and classification (see, for instance, Radu, 2014; Young, 2006, 2007), since 
these are the questions that define how a particular site is to be managed and whose responsibility it becomes.

For an example of this discourse on historic house museums, consider the following passage from an article by Linda Young (2007), "Is there a Museum in the House? Historic Houses as a Species of Museum:”

The management of intact collections informs the collector's house, or the house with highly significant material intrinsic to its being. They constitute the most obvious crossover with the conventional museum - but there is a critical difference. Like a personal archive or an archaeological deposit, an intact house collection contains meaning in its original assemblage, which should be preserved as is to maintain its significance. In practice, an intricate house collection cannot be left untouched, especially if the objective is to open it to the tax-paying or admission-paying public. The integrity of the collection must therefore be underpinned by meticulous documentation. The sum of such knowledge can never be total or final, but it enables informed management, including the possibility of temporary rearrangements for interpretive purposes. (p. 73, emphasis in the original)

What sets this kind of literature on historic house museums apart from literature on heritage management in general is that, in the case with house museums, or, as they are sometimes called, "living history museums," some of the museological and research work dealt with consistent use of objects within recreated historical contexts. The scholarly community was slow to pay any real attention to this specific museological genre, but when they did, this feature was the one they initially focused on. The first scholar to describe historic house museums was Jay Anderson, who in 1982 coined the term "living history" and described it in his article "Living History:

Simulating Everyday Life in Living Museums." 24 Anderson (1982) notes that:

Living history has been used by archaeologists to measure the energy needed to pull a wooden moldboard plow on a 1770s Pennsylvania farm. It has helped folklorists rediscover how Pilgrims built their houses and brewed their beer in 1627 Plymouth, and it has

\footnotetext{
${ }^{24}$ I avoid the term "living history" in my work: I have noticed that museum professionals working in Toronto house museums treat it with caution and that the term carries an association with practices of amateur history buffs. Some elements of living history are, no doubt, present in the practices of contemporary house museums in the form of cooking workshops, production of seasonal decorations, costumed garden parties, and etc.
} 
provided historians with a method of communicating to contemporary Americans the network of social classes operating in an Indian frontier village during the 1830s. (p. 290)

Another theme that sets the operational discourse on historic house museums apart from the rest of the literature is the discussion on the division between the domestic and institutional and the kind of museological work that is required to convert a living space into a museum (see, for instance, Cabral, 2001; Pavoni, 2001; Pinna, 2001). While this literature brings up issues of domesticity and interiority, it deals with them, quite literally, from the point of view of representation, and is concerned with how to address it in a way that is conducive to three commonly identified museum goals - preservation, research, and education. Here is how Cabral (2001), director of the Memory and Documentation Centre of the House of Rui Barebosa Foundation/Ministry of Culture, Rio de Janeiro, Brazil and one of the the DemHist regional coordinators, explains it:

(...) thinking that a mere reconstruction of ambience-the documentary record-will make communication possible, because the reconstruction contains information, generation of knowledge or cognitive synthesis, is a great mistake. Life is not reproduced in a house museum, it is represented-like in any other museum, which is, par excellence, the space for representing the world and its things. (p. 42)

Cabral (2001) continues her argument by focusing on what is essentially a drawback of this museological genre from the museological point of view: “(...) objects have histories and trajectories, and the reconstruction of ambience 'freezes' the objects into just one specific context" (p. 42) ${ }^{25}$ She explains this by arguing that:

(...) the museum is essentially an institutionalized way of transforming objects into documents, but that it is not enough to intend to transform an object into a document, because physical insertion sets up a dialogue-picture of motivations, expectations and associations that could escape by chance, and that only the museum can offer in depth. (...)

\footnotetext{
${ }^{25}$ Hewison's (1987) comment about how a time period can be turned into an artifact comes to mind here. I address it further in this literature review.
} 
The process of transforming an object into a document, which is the essence of museums, introduces references to other spaces, times and significations in a contemporaneity which is the museum, the exhibition and its user (...). (p. 42)

Waterton and Watson (2013) note that these first approaches to conceptualizing heritage as manageable and objective "have become part of the 'fabric' of heritage theory, where they remain extremely relevant" (p. 549). They note that such issues as authenticity, commodification, community, and identity came out of the productive tension between the view on heritage as objectified and manageable and the observations of the kinds of social and cultural consequences the practice of heritage brought with it (see, for instance, MacCannell, 1973, 1976; Cohen 1988; Littler and Naidoo, 2005; Waterton and Watson, 2011).

\section{Historic House Museums and Theories "of" Heritage}

Waterton and Watson (2013) describe theories of heritage as a movement towards interpreting it as situated within the present social and cultural context. This body of theorizing developed starting in the 1980s in the fields of history and cultural studies and focused on the critical study of heritage as a form of industry (for major works in the field see, among others, Lowenthal, 1985; Wright, 1985; Hewison, 1987; Samuel, 1994). The analytical approaches and the critical lenses they proposed were representative of the theoretical discourses dominant at the time: Post-structuralism, postmodernism, constructivism, post-colonial theory, and Marxism. Waterton and Watson (2013) suggest that, within this body of theory, "representational practices employed in heritage came to be understood as things that could be deconstructed to reveal deeper meanings, as well as saying something about the processes of encoding such meanings" (p. 550). Scholars, working from this perspective, are generally "concerned with questioning the representation of meaning, especially hegemonic meanings, about a past that effectively validates a national present or re-inscribes it with essentialisms when it might be considered to 
be under threat from economic restructuring, changing social attitudes or the nation-negating effects of globalisation" (p. 550) ${ }^{26}$.

\section{Discourse on Historic House Museums and Deconstruction of the Historical Timeline}

One of the intriguing themes in the discussion on heritage in general, and historic house museums in particular, was a discourse on authenticity in representation and experiences of history, which is one of the sites in which the distinction between meanings of history and heritage, perhaps, could be made. The earlier critique of the emerging trend of house museums is indicative of the general academic attitude towards heritage industry. For instance, Hewison (1987) in his landmark work The Heritage Industry: Britain in a Climate of Decline refers to heritage as "bogus history" (p. 144). He also suggests that heritage "draws a screen between ourselves and our true pasts" (p. 10) by isolating a point in time from a larger historical context. Hewison introduces the idea of heritage as something that is fossilized; a moment in time becomes hardened, cut off from the natural progression of history. Mills (2003) suggests that heritage sites present the time period itself as an artifact. Walsh (1992) develops the critique of heritage as a form of popularized history in line with thinking on postmodernity and suggests that "heritage sites are constructed as "time capsules" severed from history (...), they represent a form of a historical bricolage, a melting pot for historical memories" (p. 103). In supporting his argument, he refers to Baudrillard's (1988) articulation of a "dead point," a point where history ceases to be real (p. 190). This general critique translates into a discourse on the objects of heritage themselves. Di Giovine (2009), when writing about the UNESCO heritage sites, suggests that they "are often comprehended not as objects with life stories but as vestiges,

\footnotetext{
${ }^{26}$ Smith's (2006) theory of Authorized Heritage Discourse fits within this body of theory. For more recent work within this framework, see Graham et al. (2000), Harvey (2001), Watson \& Waterton (2001).
} 
authentic remnants calcified in a particular time and space despite the ceaseless evolution of the world surrounding it” (p. 301).

This same view on heritage provides grounding for the perspectives that critique material objects within a heritage setting as props that validate a narrative that is made coherent. Casey (2003) points to the fact that material objects and their placement within the casing of a historic site appear to validate the story, therefore suspending disbelief. Schwartz (1996) suggests that "Living Museums tend to choose that which authenticates over that which is authentic, a cultural congenial deceit" (p. 279, emphasis in the original). Handler and Saxton (1988) suggest that house museum practitioners, aware that they could never recover all the details of the past, pick out facts and objects available to them in pursuit of narrative coherence. Bruner (1994) supports this perspective in suggesting that a historically accurate representation of the time period is accomplished through the staging of the rooms with objects that adhere to an idea of a historically accurate representation of a domestic environment in a way that appears credible.

I myself have observed that at multiple sites in Toronto's historic house museums. The entire Mackenzie House Museum, for instance, contains no more than five objects that belonged to the original family, to the extent of my knowledge. The rooms are set up to contextualize and explain the lifestyle of a middle-class Toronto's family in the 1860s, and the issue of authenticity of the interior is usually either mentioned in passing or as an answer to a direct question from the visitors. This adding of the parts in pursuit of a coherent story results in a "landscape that is greater than the sum of its parts" (Mills, 2003, p. 83). Discretely placed museological elements in a house museum, then, "dissolve into an overall, harmonious image" of the represented house (Bann, 2000). This pursuit of the narrative is also apparent in the presence of objects that decidedly should not be there. Above the piano in the Mackenzies' parlor hangs a portrait of 
John Montgomery, William Mackenzie's friend and supporter of the Upper Canada Rebellion, which Mackenzie organized. The portrait really would not hang in the parlor, the museum interpreters admit, but it does, and it provides a great segue into the story.

The general agreement in academic discourse that focuses on the role historic house museums play in forming the public's idea of national history, historical progression, and historically contextualized social and political life is that meanings of heritage sites rest with their social value (Harvey, 2001; Hewison, 1987; Di Giovine, 2009; Walsh, 1992). This is a considerable step away from conceiving of heritage work that house museums do from the point of view of materiality of heritage. However, this critical discussion of heritage as something that is steeped within the current cultural momentum and serves its cultural and social needs, while voiced, did not yield much in the way of academic research into the work of historic house museums until the early 2000s. Dicks (2000) in her article "Encoding and Decoding the People: Circuits of Communication at a Local Heritage Museum" phrases it the following way: " [the critics] have neglected the ways in which these museums, in different ways, mobilize discourses (...) of local identity, belonging, place, environment and, above all, constructs of people and community" (p. 62) ${ }^{27}$.

\footnotetext{
${ }^{27}$ Radu's (2014) recent dissertation Making Ourselves at Home: Representation, Preservation \& Interpretation at Canada's House Museums identifies house museology as a distinct genre within the typology of museological institutions and addresses the character and function of these museums in Canada. Her project, Radu (2014) writes, came as a result of the general lack of academic scholarship that would address the nature and purpose of these sites in Canada. My review of Canadian scholarship on the subject matter agrees with Radu's (2014). I too have found that most of the work either focuses on international examples or examines two or three house museums that are located in close proximity to one another. However, my perspective negates the importance of scholarship specific to a national context. Instead, I hope to contribute to the understanding of the phenomenon by drawing on the study of Toronto house museums as a basis for an understanding of the phenomenon that can be applied across national borders.
} 
Historic House Museums and Issues of Political and Social Consequence

This particular body of academic literature on HHMs theorizes heritage as a product of power relationships reinforced through the means of an Authorized Heritage Discourse (AHD) ${ }^{28}$. MacLeod (2006), for instance, when writing about the Fortress of Louisbourg National Historic Site in Louisbourg, Nova Scotia, argues: "Museums are not neutral; their interpretations function in a hegemonic way to define the boundaries of national unity" (p. 367). Terry (2013), who studied historic house museums in Ontario, following MacLeod (2006), observes that:

(...) specific aspects of the past are often selected for interpretation and subsequently depoliticized and refashioned to present images that are marketable, non-confrontational and appealing to a wide range of consumers. Often, the views of the dominant culture are enshrined and reinforced. As such, these institutions often determine what is significant to Canadian history. (p. 107)

The authors who consider HHM work as a political act examine the kinds of consequences this use of heritage produces for the public's understanding and normalization of meanings and ideas pertaining to communal history and community (Dicks, 2000; Waterton, E., Watson, S., 2011; West, 1999), power relations, social class, and labor (Dicks, 1997, 1999; Shackel, 2001), culture, race, and identity (MacLeod, 2006; Pendlebury et al., 2004; Terry, 2008), and gender (Beranek, 2011; Christensen, 2011; Peacock, 2011; Terry, 2013). Although some research from this point of view had been done prior to 2006, the book Uses of Heritage by Laurajane Smith, published that year, is considered to be foundational to the development of this body of work, along with Rodney Harrison's (2013) Heritage: Critical Approaches. This literature conceives of house museums in particular and heritage sites in general as sites where meanings are culturally, socially, and symbolically produced, maintained, and communicated.

\footnotetext{
${ }^{28}$ For more on articulation of AHD see Smith, L., Campbell, G., 2015; Waterton et al., 2006.
} 


\section{Theories "for" Heritage}

I identify my work with what Waterton and Watson (2013) describe as theories for heritage, perspectives that move away from representational theories and towards "questions that ask us about our very being, and what happens to our bodies, ourselves? (...) How have we changed, what is different?" (p. 551) The body of work that addresses these questions considers heritage not from the point of view of its role in current social and political practices but as an embodied and affective process that constitutes our ideas of the selves in relation to our ideas of the past, the present, and the spaces that we occupy. "At their core," Waterton and Watson (2013) write, "they are questions about the role played by the personal, the ordinary and the everyday, within spaces of heritage, whether they are physical, discursive or affective" (italics in the original, p. 551). What this literature suggests is that "while representations of heritage do undeniably complex work, there is further 'work' ongoing in our engagements - bodily work that exceeds those textual and visual registers" (Waterton and Watson, 2013, p. 551).

Waterton and Watson (2013) note several avenues in which theoretical inquiries for heritage should add to the conceptual work done within the field. First, they would need to identify the specific terms on which the study of heritage itself would need to be approached, which is what I do in this dissertation by proposing the notions of emplacement, body, materiality, and performance as a framework for the study of heritage as a culturally situated, subjective, and embodied practice. Next, they suggest that this kind of inquiry brings forth an imperative to define (or redefine, perhaps, since these notions are already widely used) the notions of "practice" and "process." I am skeptical about this call for several reasons. First, the implied division between the two suggests a division between something that we "do" and something we "experience," and, perhaps more so, the divide between the "heritage practitioner" and a visitor. The use of the term "practice" bears the burden of its methodological provenance 
in heritage studies research and is steeped in the field's roots in preservation and interpretation (heritage practice, then, emerging as something that is akin to "museological" practice). I recognize there can be a legitimate argument made about the use of the term "practice" to describe the "doing of heritage" or being part of an experience that brings forth the encounters with the past on various terms and for various reasons. Still, the two suggested terms do not appear as wholly appropriate for articulating and unpacking this newly suggested perspective on heritage. For the purposes of my dissertation, I have focused on the use of performative behaviors in theorizing the "doing" of heritage as a form of practice aimed at enabling the workings of these heterotopic spaces. While this term worked well for what I needed it to do, more work definitely needs to be done in developing the vocabulary for these kinds of inquiries into heritage work.

Waterton and Watson (2013) observe several directions that the studies for heritage have taken so far. First, they identify developments in the study of anthropology of emotions, more specifically, the work in bringing together science and cultural theory in the study of affective responses and emotions as something that is "socially and symbolically produced, expressed and felt" (Leavitt, J., 1996, quoted in Waterton \& Watson, 2013) ${ }^{29}$. Further, they note the usefulness of the mobilities theory and actor-network theory (ANT) and observe the value in Deleuzian perspectives. This range, no doubt, lacks the kind of clearly defined focus that theories in heritage and of heritage have.

I see two prominent points that bring together theories for heritage. First, it is the idea of heritage as something that is not limited to a specific area of our life or sites within our physical

\footnotetext{
${ }^{29}$ For more examples of work from this perspective or discussion on the uses of it, see, for instance, Leavitt (1996); Papoulias \& Callard (2010); Saldanha (2010).
} 
environment, but as something that we encounter as any other expression of the condition of being human-an encounter with a culturally and temporally situated self. Certainly, to study heritage at a place created for the performance of heritage makes sense, and it is exactly what I did in my project. However, the self-evidentiary nature of this methodological choice should not negate the idea of heritage that

(...) disrupts its conventional positioning as a thing separate from other experiences and stirs it back in with being human and living, so that it emerges from the feelings of being, becoming and belonging in the flows and complexities that characterize life. (Waterson \& Watson, 2013, p. 553)

The second point is that this identified need to stir the heritage in with "being human and living" emphasizes that subjective experiences of heritage take place within one's body that is located within a socially and culturally constructed, and publically shared environment. This perspective on heritage as an embodied process that is both subjective yet symptomatic of our membership in society, specific to our location in history and space, gives a healthy surge of theoretical uncertainty in the field that up until recently had its feet firmly grounded in issues of preservation, museological interpretation, and materiality. While I have already mentioned the value of Butler's idea (2011) about moving theory by way of questions asked, I would like to unpack this idea further here by referring to the idea of "weak theory" by Stewart $(2007 ; 2008)$. Stewart (2008) writes:

To inhabit a space of attending to things is to incite attention to co-existing forms of composition, habituation, performance, and event and to the "weak" ontologies of lived collective fictions comprised of diacritical relations, differences, affinities, affects and trajectories (Stewart, 2007). For me, then, the point of theory now is not to judge the value of analytic objects or to somehow get their representation "right" but to wonder where they might go and what potential modes of knowing, relating, and attending to things are already somehow present in them as a potential or resonance. (p. 73) 
What I am proposing, then, is the kind of theoretical and methodological work in heritage that does not seek to identify specific models of communicative engagement-big systems-but is comfortable with observing how "things jump into forms" to form categories of meaning and bring forth consequence (Stewart, 2008, p. 73). Cromby (2007) suggests that:

We know heritage through our experiences but it is no longer quite so easy to write 'it' down or formulate clear impressions of what it does - what it circulates, what it produces. Consequently, we need to enlarge our thinking by bringing into the mix a means of capturing the embodied state beyond, but along with, discourse, thereby including the 'sensual, haptic, corporeal and kinaesthetic.' (p. 96)

I suggest that this point in the development of theories for heritage is not a space lacking in clearly defined theoretical articulations, but a space of opportunity, where we as scholars can observe how the density of meanings builds up, which ideas it brings forth, how it manifests itself, how it intersects with pre-existing meanings and modes of being. This new body of work can draw on developments in heritage and of heritage and the understanding of heritage as an experience that is creative, affective, embodied, subjective, and yet steeped in the physical, social, and cultural reality, the perspective that I work to advance in this dissertation. This perspective suggests the importance of going beyond representational theory and requires articulating new terms on which heritage can be understood. My study, in particular, focuses on the role of the body, performance, materiality/space, and emplacement in the practice of heritage.

In this dissertation I suggest that, first, the embodied relationship between a human and materiality of an object and space be explored as one of the underlying mechanisms that form personal constructions of the past. Second, my dissertation unpacks these experiences of recreated instances of anthropological emplacements in the context of a life in a fractured urban space by suggesting that we attempt to produce "sacred" places, mark where we are, build a connection between the "where" and the "we" by producing places that feel authentic 
(MacCannell, 1976; Schackel, 2011). Actual authenticity of an object in this process emerges as secondary to the authenticity of an immediate embodied experience. The purpose of these experiences is not to be accurate, but to produce a sense of continuity and belonging via experiences that perform that function the best in the current cultural condition. Thus, my approach questions the conventional scope of heritage thinking and suggests that we consider heritage along the lines of performance, affect, creativity, and impermanence.

\section{Outlining the Critical Cultural Framework}

There are a number of theories in critical cultural studies that, I believe, can enrich the current academic discourse on the kind of work the HHMs perform in the life of a postmodern city, how they do it, and the functions they serve. In this section, I outline the analytical framework that informs my conception of the phenomenon and explore which definitions and entries into analysis it points towards.

The central theoretical point that I would like to begin with is the articulation of heritage work as a process of communal meaning-making. This idea counters the established perspective in the field, which conceptualizes heritage as information (Morisset, 2016) that is produced through the means of and forms the Authorized Heritage Discourse (AHD) (Smith, L., Campbell, G., 2015, 443; see also, Waterton et al., 2006) and then imparted to the public. The perspectives on HHMs that I associate above with theories in heritage and for heritage fall along these general theoretical lines. In both of these cases, the experience of heritage is understood as a result of an exposure to a pre-established narrative communicated through things, places, and stories. The juxtaposition of these two approaches - heritage work as communal meaning-making and as a form of transmission of information - has a lot in common with the two conceptions of the 
communication process as outlined by Carey (1992) in his book Communication as Culture: Essays on Media and Society.

Carey (1992) identifies the origins of the transmission view of communication with a "metaphor of geography or transportation" and suggests that "the center of this idea of communication is the transmission of signals and messages over distance for the purpose of control" (p. 15). This emphasis on control, too, corresponds to the many authors' well-justified focus on the consequences of political and social ideas that are built into heritage discourses (see, for instance, Dicks, 1997, 1999, 2000; MacLeod, 2006; Peacock, 2011; Pendlebury et al., 2004; Shackel, 2001; Terry, 2008, 2013; Waterton, E., Watson, S., 2011). In either case, the focus of the inquiry is on the message. The receiver by and large is understood as a passive party that is affected by the pre-established message.

Carey (1992) describes the ritual model of communication as "a symbolic process whereby reality is produced, maintained, repaired, and transformed" (p. 23), directed towards "the maintenance of society in time; not the act of imparting information, but the representation of shared beliefs" (p. 18). As applied to my project, the ritual model of communication explains the experience of an HHM as a site where the public can define itself in relation to its position in time and in space. The focus here is not on commemoration, a narrative equivalent of placing a plaque on the wall, but on the kind of ongoing self-definition that is anchored in the perceived relationship between what presumably connects the present to the past and is intended to inform the future - and the sense of the city.

According to Carey (1992), the ritual view of communication derives from a view of religion that downplays the role of the sermon, the instruction and admonition, in order to highlight the role of the prayer, the chant, and the ceremony. It sees the original or highest manifestation of communication not in the transmission of 
intelligent information but in the construction and maintenance of an ordered, meaningful cultural world that can serve as a control and contained for human action. (p. 19)

The re-telling of the narrative-through space, simulation of the domestic life, and the de facto retelling of the story-works to sustain the underlying logic of the community's structure, establishing and reaffirming the relation of forces in a story of life. Carey (1992) describes this process as "a presentation of reality that gives life an overall form, order, and tone" (p. 21). This re-telling of the story is the continuous process of structuring us into a community that connects through its relationship to a physical location and an agreement on what we consider to be our past and our present. As such, in Carey's (1992) terms, both the narrative and the space function as "an artificial though nonetheless real symbolic order that operates (...) to represent an underlying order of things" and "to manifest a fragile social process" (p. 19). Thus, Carey's (1992) ritual model also addresses the common complaint concerning the lack of authenticity in the displays of HHMs, which I referred to earlier. According to Carey (1992), "space is made manageable only by reduction of information" (p. 28). In the case of a house museum, we alter the physical and historic reality for it to make sense within the parameters of the story. Authenticity, in this case, is welcome, but not essential to the overall goal of the creation and sustaining of the narrative.

From Carey's (1992) point of view, the tie of this urban narrative to physical space becomes essential for two reasons. First, it represents a community's attempt to chart its territory and control its physical environment through the use of symbols. Secondly, it is the ritual of maintaining a historic house that establishes the significance of the story, defines its location within the urban space, and stipulates the re-telling of the story through cyclical changes the house goes through (for example, Christmas, Halloween, and Easter celebrations). In the first 
instance, the house acts as a symbol of the past, in the second as a symbol for a version of heritage as defined by the community. This transition from a symbol "of" to a symbol "for" illustrates the dual capacity of all symbolic forms, according to Carey (1992): "as symbols of" they represent reality; as "symbols for" they create the very reality they represent" (p. 29).

Kreps' $(2003 ; 2005 ; 2008)$ is one of the voices in museum studies that, I believe, aligns with the view of museums as sites of communal meaning-making. She advocates for a grassroots approach to museological work (including preservation and curation) that is reliant on local knowledge and participatory processes. In her work, Kreps (2003) focuses on what she describes as "indigenous curation," an umbrella term, which to her encompasses cross-cultural (or "nonWestern”) models of heritage preservation. In explaining the concept, Kreps (2005) offers, among others, examples of Maori meeting houses of New Zealand, the haus tambaran of New Guinea, and Micronesian bai. While this grouping of diverse museological behaviors under the definition of "non-Western" is symptomatic of a colonial gaze, I agree with Kreps' (2005) general description of museological practices as "exemplif (ing) holistic approaches to heritage preservation that are integrated into larger social structures and ongoing social practices" (p. 3), a definition that places heritage-thinking outside of traditionally identified museological objectives of education, preservation, and research. To Kreps $(2005 ; 2008)$, this feeds into the idea of museums as forums for social change. In the case of historic house museums, this inclusive take on what may constitute museological work leads to an understanding of them as contextualized cultural institutions with an ability to establish their own ways of caring for and making accessible cultural heritage.

I see the discussion by Innis (1951) on time and space-biased media as appropriate to unpacking the cultural phenomenon of a house museum and understanding it as heterotopic. In 
many ways, it feeds into some of the articulations by Carey (1992). Innis (1951) worked to explain media in relation to the cultural context in which they dominated. For him, forms of communication technology hold biases that inform the kinds of changes they can inflict upon society. Innis (1951) sees the introduction of new media as capable of bringing on drastic social shifts and destabilizing systems that existed prior to it. He describes time-biased media as durable and hard to move (for instance, speech or clay and stone tablets), and argues that they do not encourage territorial expansion, but are capable of extending the life or order of life in an empire over time. These are the media that establish and maintain dynasties, develop and reaffirm social hierarchies, and uphold ideas on the moral and the sacred. Innis (1951) associates highly portable space-biased media with secular societies that are capable of easily extending into space, taking over and controlling larger territories. Oral communication, from Innis' (1951) point of view, is a time-biased medium, since it requires immediate face-to-face contact. Knowledge that is passed down orally depends on lineage of transmission, such as ancestry. Innis (1951) associates time-biased media in general with preservation of traditional culture and knowledge. He describes them as being ritual-focused and concerned with preservation of the past. It is quite poignant that the kind of content that the mass medium that is an HHM was developed to maintain-an illusion of the first-hand experience of the past-could only be sustained within the form that Innis (1951) would associate with time-biased media: HHMs communicate through site-specific and embodied heritage practices and rely on storytelling. Within the framework of an HHM, knowledge about the past is communicated by means of an oral narrative, the physical space of the house, objects within it, as well as behavioral practices. These are not the modes of communication that could expand the message beyond the immediacy of the site and the moment in which communication occurred. These sites are 
experience-based for the visitors, and mostly experience-based for the interpreters, as well. I believe that the communicative form of an HHM-the physical and communicative "container" in which and through which the past is maintained and experienced-is heterotopic, because this time-biased cultural institution has been created and is maintained in the age in which communication media are predominantly space-biased. The heterotopic nature of its content required a very different form of transmission, the kind that reaffirmed and maintained the message that it carried. Foucault (1986), in his unpacking the functioning of heterotopias, noted the shift in the meanings of cemeteries and the dead bodies, when the transition to a more secular society occurred in the West:

This cemetery housed inside the sacred space of the church has taken on a quite different cast in modern civilizations, and curiously, it is in a time when civilization has become 'atheistic,' as one says very crudely, that western culture has established what is termed the cult of the dead. Basically, it was quite natural that, in a time of real belief in the resurrection of bodies and the immortality of the soul, overriding importance was not accorded to the body's remains. On the contrary, from the moment when people are no longer sure that they have a soul or that the body will regain life, it is perhaps necessary to give much more attention to the dead body, which is ultimately the only trace of our existence in the world and in language. (p. 5)

Following this argument, I suggest that HHMs are an example of ritualizing memory, embodied experiences of the domestic, cultural and historical continuity, that emerged in the age of the predominantly functional approach to time, space, bodies; the time when material goods are transient, and one's identities and communities feel fragmented ${ }^{30}$. While they feed into the cult of memory, they also ritualize forms of communication that, Innis (1951) would suggest, have the ability to reaffirm tradition, create the very sense of continuity.

\footnotetext{
${ }^{30}$ It was Nora (1989) who suggested that modernity ritualized sites of communal memory, because there was not enough of it left. I address his arguments in more detail later in this chapter.
} 
Anecdotes, gossip, story-telling are narrative forms associated with oral traditions (Stokes, 2013). HHMs provide their interpreters with a written guide on the history of the family and the house; however, all interpreters I interviewed testified to actively learning from each other, andmost of them-in quite substantial ways. While under training to give tours, I was told that "it takes time to build your narrative." I later realized that the process of "narrative building" constituted slow development of a knowledge base substantial enough to take people of different interests and backgrounds through the house. This process did take time and, I found, relied, for the most part, on conversations with other tour guides. Interpreters turn to each other to refresh their memory of dates, names, and facts. They also contribute newly discovered bits to each other's narratives. Finally, there are a few who have spent decades working in the HHM circuit, and these "hubs" are said to know everything there possibly could be known about houses, the people who lived in them, the history of these sites as HHMs, as well as records of ghostly encounters over the years. One can wonder why is it that all this information is not just gathered in one conveniently accessible source. In part, it is so because the kind of knowledge that one needs to possess in order to be a good interpreter cannot possibly come from books. One needs to be trained in person to know how to run a printing press, how to cook over fire, how to put on the costume properly, how to move in it. A good house tour also depends on the intimate knowledge of the specific domestic space, which is built over time that is physically spent within it, testing the space for "livability" and asking questions about it (these are also almost always directed at other interpreters). This intuitive knowledge that comes from years of interpretive work and shared narrative-building quite often gives birth to HHMs myths: An object gets interpreted the wrong way or certain themes become omitted or unexpectedly added for reasons that have little to do with the historic, cultural, or social context. These myths then become 
entrenched through shared story-telling. It is very hard to trace them back to where they came from, as it is equally hard to do away with them. For instance, the portrait of William Lyon Mackenzie that is hanging in the modern gallery of the Mackenzie House Museum for years has been described as having been commissioned by Prime Minister Mackenzie King. We would also tell the visitors that it was his mother, Isabel Mackenzie King, who sat for it, because her facial structure was similar to her father's. To my knowledge, no one really knows where that story came from: The interpreters learned it from each other. It was discovered in 2016 that it was completely wrong. It is intriguing how detailed this false account had become over the years, however: I have heard interpreters make references to the Prime Minister's relationship with his mother, while telling it, and identifying the powerful jaw line and the eye brows as distinct features that the painter relied on.

Following Carey (1992) and Innis (1951), HHMs emerge as socially and culturally created, "artificial though nonetheless real" (Carey, 1992, p. 19) forms of media, whose goal is to establish and reinforce culturally specific ideas about the community's placement in time and space-in relation to its past, future, as well as its geographical location. This kind of reinforcement is done through ritualized and site-specific performances designed to re-affirm the validity and importance of the story. When viewed this way, HHMs fit with what Anderson (2006) would describe as a shared culturally constructed narrative that feeds into the construction and maintenance of an "imagined community" (p. 6). Anderson (2006) considers theoretical ramification of understanding nations as socially constructed. He argues that a nation is "imagined because the members of even the smallest nation will never know most of their fellow-members, meet them, or even hear of them, yet in the minds of each lives the image of their communion" (p. 6). Anderson (2006) suggests that imagined communities are constructed 
through what he describes as "print capitalism" (p. 28), the wide spread of accessible forms of mass media that establish a common language and a common discourse ${ }^{31}$. HHMs, from this point of view, emerge as a cultural product that binds national imaginings into a form of a narrative that explains the imagined community to itself from the point of view of its cultural and historical origins, thus further establishing its idea about itself.

It is important to note that, following Anderson's (2006) line of argumentation, the past is used to define aspects of the shared present and to validate it through the use of artifacts and a selection of documents. This formed narrative, however, is much more invested in maintaining the integrity of the body of imaginings, rather than in issues of authenticity, for instance. This point speaks to the common criticism of HHMs that I have covered in the literature review to this chapter - the fact that HHMs often add up elements in creating a narrative "landscape that is greater than the sum of its parts" (Mills, 2003, p. 83; for more on this, please see Bann, 2000; Casey, 2003; Handler and Saxton, 1988; Schwartz, 1996). It also speaks to the concerns in regards to the political ramifications of how the themes of the origins of the nation and national identity are handled through the HHMs' interpretive practices (see, for instance, Dicks, 2000; MacLeod, 2006; Pendlebury et al., 2004; Terry, 2008; Waterton, E., Watson, S., 2011). I would also like to point out important parallels here between Anderson's (2006) arguments and another important body of ideas in critical cultural studies, Barthes' (1972) unpacking of cultural myths. Barthes (1972) articulates mythologies as a way in which culture signifies and assigns meaning to its world by "dressing up" its reality (p. 10). Myths, according to Barthes (1972), are cultural manifestations that are grounded in ideology, making cultural narratives imposed by the political

\footnotetext{
${ }^{31}$ I would like to note that Anderson's (2006) idea that proliferation of a type of mass media, specifically print capitalism, can actively mold a certain kind of a society shares a lot with Innis' (1951) articulation of space-biased media.
} 
agenda of the bourgeoisie. Fundamental to Barthes' (1972) arguments is the understanding that mythologizing is an innate function of human experience.

Anderson (2006) believes in media's ability to create communities by addressing citizens as a form of a public, the point that resonates strongly with Warner's (2002) discourse. Warner (2002) problematizes the term "public" and argues that it is a form of practical fiction that is essential to the existence and evolution of the social world. He characterizes public as a social space and a social entity created through circulation of discourse. Warner (2002) shares Anderson's (2006) idea of publics as a social entity consisting of strangers that are both brought together and form this space by virtue of being addressed. Further, Warner (2002) establishes that: "All discourse or performance addressed to a public must characterize the world in which it attempts to circulate, projecting for that world a concrete and livable shape, and attempting to realize that world through address" (p. 81). This line of thinking assigns staff and volunteers of an HHM to what Warner (2002) could possibly describe as a counterpublic that is organized in opposition to the mainstream discourse, the role of which, in this case, constitutes the compilation of social and cultural practices in regards to the use of time, space, material objects, and the meanings attributed to them. The discourse formed through HHMs in the way of oral narratives, established behaviors, and professional practices constructs a social entity, a community of strangers that know each other without knowing each other by virtue of being addressees of the HHM discourse and active participants in its circulation.

By articulating my research position as that of an observer who stands on the threshold of a historic house museum, door wide open, considering the relationship between the space inside and the space outside of an HHM, I locate my project within the domain of critical cultural studies. To clarify this further, my perspective places the sites of the HHMs within the city and 
considers them as public, culturally constructed spaces that need to be entered by a willing engaged participant and then left behind in order to fulfill their purpose. The angle of my study is, thus, the counter relationship between the space of the metropolis and the domestic space of a historic home. This theoretical placement allows for a movement away from the conception of museums as either politicized producers and distributors of information or sites that can be objectified and managed through their relationship with the objects of assigned value that they hold (i.e., senders in the transmission model of information (Shannon, Weaver, 1949); and towards an understanding of them as means to communal meaning-making (Carey, 1982). In other words, I consider HHMs not as a museum but as a third entity, a cultural hybrid, if one were to talk in terms of categories, that draws on the aspects of the museum genre to form its independent entity as a cultural institution. As with any form of communication media, historic house museums emerge to address a specific problem (the loss of time, a sense of disengagement from one's ancestral history and community), while servicing a myth that time is not, in fact, lost, but can be revisited in its physical form as a kind of a place. The ways of accomplishing that, first-hand embodied experience of a version of a recreated domestic past, are a result of immediate culturally contingent circumstances.

Following this perspective, I suggest that HHMs are sites that allow Toronto to acquire a different perspective on itself, they are bearers of a different idea of this place, an alternative view from within the city onto itself. Consider this passage that Liam, one of my interviewees, offered in response to my question in regards to the role of HHMs in Toronto:

I think that the people who come here are hungry for a knowledge that goes beyond this glass marble newness that's here. So, I will drop little details into my interpretation that will open it up in the way that they did not know. Things that I have learned since I have started working here. An instance of this is... for example, I will talk about $1793 \ldots$ Simcoe arrives here... building this tiny town of York... and I will talk about how it is surveyed along for concession lines: Queen, Bloor, St. Clair, and Eglinton. If I say those four names 
of those four streets, most Torontonians, most visitors to Toronto would have at least heard of the first two, Queen and Bloor. Then I talk about how they are all the same distance apart. They are all 6600 feet apart. So, there is a hunger for the things that are underneath here. For an unveiling of the bones of the place. And I think that the Mackenzie story allows for a very interesting investigation into the bones of this place. And it allows for a step into that world in a way that you might not notice if you walk through the streets of Toronto.

What's interesting about Toronto is that the signs are there. I mean there is a Victorian suburb preserved where I live, I live in Kensington market. And when you walk through Kensington market, you look above where all the crazy fancy shops are, you'll see the Victorian suburb. There are clues about these things here, in the city of Toronto, but this sort of stuff isn't offered anywhere, in any educational processes here in terms of how we look at the memory of the place. We often refer to ourselves in museums as memory workers. We have the memory of the city here within us. Is it important? I think it is. And for me, it is important in terms of the memory and the creation of identity, I think that closely relates. There's this whole thing... well, it is a cliché now about the lack of Canadian identity. But I think there's something to that cliché. And I think a part of that is the lack is the full communication of the memory of the place.

My study shows that HHMs, while working with what Liam refers to as the "bones" of the city, do far more than preserve, research, and educate. This cultural studies perspective on the function of these sites within the city offers an alternative range of entries into the study and makes it possible to ask different questions. The three themes along which I organize the inquiry in this dissertation-materiality, performance, and emplacement-came from my initial encounter with the data in this research and allowed me to both question theoretical assumptions that result from the view of HHMs solely as sites that museologize a version of a past and to uncover their work as public spaces with a hybridized and contextually contingent cultural function. Finally, my critical cultural studies perspective on HHMs allows me to articulate this point of interrelationship between the space of an HHM and the city as the relationship between a heterotopic space and the space that it mirrors. After all, the work and function of the heterotopia can only be understood in relation to the reality that it contests and from which it provides a reprieve. 
Unpacking the Theory of Historic House Museums as Heterotopic Places

Foucault (1986) opens his articulation of heterotopia by arguing:

The space in which we live, which draws us out of ourselves, in which the erosion of our lives, our time and history occurs, the space that claws and gnaws at us, is also, in itself, a heterogeneous space. In other words, we do not live within a void, inside of which we could place individuals and things. We live inside a set of relations that delineates sites which are irreducible to one another and absolutely not superimposable on one another. (p. 23)

Further, Foucault (1986) suggests that heterotopic sites perform a function that is significant to the survival of a social group that invents and maintains them. He offers an example of the Victorian institution of a honeymoon trip, which he describes as a "crisis heterotopia" (Foucault, 1986, p. 4), a heterotopic space for those who are in the position of crisis in relation to the social group they are in. In this case, the very point of the heterotopic space was that it was to be devoid of geographical markers: "the young woman's deflowering had to take place nowhere" (Foucault, 1986, p. 5). This heterotopic space afforded the couple an opportunity to consummate their relationship, therefore resolving an issue that could not otherwise be properly resolved within the existing structure of social relations and places.

The issue that the heterotopic space resolves should be the starting point for developing a theory of one. In this dissertation, I argue that the overarching issue that the heterotopic work of HHMs addresses is the kind of a progression of time that appears to be sweeping away with it a sense of communal belonging, grounding in the permanence of social values, security associated with the familial hierarchy, and the ties between one's cultural identity and his or her geographical emplacement. I address the discourse on nostalgia in modernity further in this section and suggest that the heterotopias of HHMs cater to the very peculiar kind of nostalgia that is specific to modernity, the malaise of a person whose yearning is no longer limited to wanting to revisit the time of his or her childhood as a kind of a place. It is directed to all that 
appears to represent a version of authenticity that points to things, places, and values as nontransient and absolute, even if we are to artificially create a spatial and a narrative context to make it true. Carey's (1992) words about the social order being "artificial, though nonetheless real" (p. 19) come to mind.

I suggest that historic house museums resolve that need by creating a third kind of a temporality, a kind of a "timespace" that is outside of both the present and the historic past. Imagination is the stronghold here. The fact that it is an imaginary construct ensures that it can never be lost to the natural progression of one's life or history. The fact that this imaginary construct is shared makes this place and the participation in it a heterotopic: In it, we converge as a social group to form experiences that make our life outside of it manageable.

I coin the term "time gap" to describe the specific heterotopic role that historic house museums play. My reasons behind the use of the word "gap" are threefold. To begin with, the gap stands for space that performs the third kind of temporality - the time outside of the historic past, but also outside of the contemporary present. Another meaning of the term gap is a hole or a void in a contemporary person's experiences of his or her present cultural condition that he is or she is craving to fill-the void that is experiential, but also a longing for cultural continuity, for a sense of time and place that is not transient, but filled with anthropological meaning. Finally, the gap is also a break in the temporal space of a contemporary urban metropolis, something that disrupts the linearity of its experience. Thus, the definition of the term points to the cause for a postmodern malaise that requires the treatment, and the treatment itself. It is the gap in time, but also the bridging of the gap.

From the point of view of materiality, I suggest that time gaps aim to make possible a connective experience with a humanized space and bring into existence communal co- 
imaginings the house museum sustains (Anderson, 2006). I argue that they accomplish that by positioning the body as an important entry point into the study of historically contextualized human experience of the every day. This perspective, on one hand, points to the consideration of phenomenological touch (Dudley, 2010, 2012; Levent, N., Pascual-Leone, A., \& Lacey, S., 2014; Wood and Latham, 2011; 2014) as an important entry point into the study of the meanings of materiality as understood by the time gaps. On another hand, it shifts my focus as a researcher to the study of an HHM as an immersive multi-sensory environment, the discussion that I begin by drawing on the work of McLuhan (1997). Further, the power of objects-their meaning and purpose-is not so much tied to their expert-defined values. Rather, it is made sense of from the point of view of the narrative they feed into by being within the context of each other, the immersive sensory environment of the domestic space that they co-create, and by their being "signposts to the thinking of other times" and "centerpieces to a perception of a time" (Severs, 2002, p. 6). To understand the heterotopic function this handling of materiality of museum objects and the space of the museumized house performs, I refer to Baudrillard's (2005) discussion on the shifting meanings of material culture in the age of modernity and on O'Neill's (1985) work on the embodied human experience at that age.

From the point of view of the relationship between a person and a physicality of his or her geographical locale (which I specifically address in chapter 3, "Emplacement: Playing House in Search of Home"), I suggest that the heterotopia of a historic house museum resolves what both Foucault (1986) and Nora (1989) describe broadly as a kind of a desanctification of place. O’Neill (1985), Entrikin (1991), and Augé (1995) are more specific in suggesting that places in modernity lose their qualities of anthropological emplacement as places that hold relational, sacral, or communal value that extends beyond that of material profit or serves the organization 
of the communal space along the lines of logic of consumer capitalism and production. HHMs perform their function by providing conditions that help participants piece together an experience of a lost home out of representational elements-experience of warmth, food, hierarchy of familial relationships-and, in part, by mapping the psyche onto a domestic space through the experience of the uncanny (Freud, 1919/1953). A discussion I got to be a part of in the course of my research could illustrate this point quite well. I was at a meeting of volunteer historic cooks at Mackenzie House. There were about seven other participants. The two questions that we opened the meeting with had to do with the role of cooking in HHM work and what got this group of volunteers interested in contributing their time to active interpretation of the historic kitchen. Consider these responses:

Participant A: "I remember coming here as a child and peeking through the front door... Back then they let the visitors through the front door of the house. And then a woman in costume would answer it. It really felt like I was back in time and I was visiting someone's home."

Participant B: "Cooking brings the house alive."

Participant C: "I think cooking really turns the museum into a house..."

Participant D: "Yes. It is something that really pops the 'home' part up."

In my analysis of the heterotopic work done by time gaps, the question of performance comes last, because, I argue, it is the embodied, affective, and intellectual engagement with the HHM on the behavioral terms normalized within the time gap, what I identify as "performance" in this dissertation, that activates the heterotopia, turns an HHM into a time gap. I interpret this engagement as a site of active mediation between a willing participant and his or her imagination. Following that line of thought, I identify the performative behavior that is brought forth by a time gap as a site of self-reflexivity and catharsis, where the bridging of the time gap occurs. For instance, from that point of view, the life stories of other people, objects of the 
historicized narratives, emerge as vacant outlines, which can be filled through the lived experiences of the interpreters. There are several layers of analysis that I engage with in my final chapter, "Performance of History as a License to Play: Historic house museums and the joy of pretense." First, I consider what kind of performative behavior has the ability to turn an HHM into a time gap, while opening up alternative ways of being within a public space. I extend this argument further by identifying performance with the process of the ritualized making of the world (Carey, 1992; Casey, 2003; Terry, 2008) that is the time gap. I also explore the relationship between the time gap and the public as a site, where a fluid social entity (Warner, 2002) is formed and reformed by virtue of being addressed by the HHM discourse and by actively participating in the ongoing maintenance of it. Further, I consider the interrelationship between the world inside an HHM and the world it mirrors and contests (Foucault, 1986). In particular, I discuss what constitutes the entering and the leaving of a heterotopic space; how the interpreters negotiate the relationship between their time gap selves and their outside selves.

One of the underlying arguments in Foucault's (1986) discourse on heterotopias is that material changes alone do not determine and cannot be used to explain changes in subjectivity. Social changes can only occur as a result of equivalent shifts in life-practices, values, discourses, and the material reorganization of space. Thus, Foucault suggests a possibility of a process that emerges as a back and forth movement between social practices and needs - and the material environment, where, on one hand, discursive and social practices precede changes in the material space and inform the meanings and uses of physical environments, and, on another hand, the established environments may then make possible and reinforce specific behaviors. It is this perspective that leads me to describe time gaps as "organically occurring," while all the while talking about a government institution, an argument I feel compelled to unpack further. To begin 
with, I would like to note that, according to Foucault (1986), heterotopic spaces exist and have existed in most societies throughout human history; they are a necessary part of the structure that contributes to it being functional. Further, I would like to note that, while all but one HHMs in Toronto are now run by the city, most of them were once abandoned sites that were then managed by groups of private citizens. This is poignant, considering, as Hodge and Beranek (2011) note, that sites that become house museums normally go through a transition point, at which any number of scenarios can develop: Houses can get demolished, turned into office space, or museumized. In this case, I suggest, that it is what happened at that turning point and how it was handled that should be of utmost consideration and that the eventual institutionalization of these sites and their status as city-run museums do not affect the cultural function of the HHM phenomenon in the $21^{\text {st }}$ century. Having been saved from demolition by invested citizens, the HHMs absorb the story of their salvation into the narrative of redemption (Hodge, 2009). This is especially prominent in the case of Toronto's Campbell House, for instance, which was physically transported across town while surrounded by a crowd, within hours of its supposed demolition. The Mackenzie House's narrative, too, pays tribute to its near death, the only one of the line of row houses left standing, its fortune also having been decided last-minute. I suggest that the rhetoric of salvation is one of the tools used by the HHMs to create a sense of a sacral ground, to construct a narrative fence around what presents as a set of communal values.

\section{Experience of Time within Time Gaps}

The way time and a linearity of a temporal progress are handled by time gaps is what sets them apart as a distinct kind of a heterotopia. The theme of time in the definition of heterotopias emerges in Foucault's (1986) discourse quite strongly - he describes the experience of a heterotopia as an experience of a "discovery of time" (p. 26). "Heterotopias are most often linked 
to slices in time - which is to say that they open onto what might be termed, for the sake of symmetry, heterochronies. The heterotopia begins to function at full capacity when men arrive at a sort of absolute break with their traditional time," he writes (p. 26). Foucault's interpretation of Polynesian vacation villages comes quite close to the more general statement I make in regards to house museums:

the huts of Djerba are in a sense relatives of libraries and museums, for the rediscovery of Polynesian life abolishes time; yet the experience is just as much the rediscovery of time, it is as if the entire history of humanity reaching back to its origin were accessible in a sort of immediate knowledge. (p. 26)

The questions are, then, what specifically can heterotopias do with their "slices of time," and how are time gaps different from other heterotopias preoccupied with time. Consider, for instance, what Foucault (1986) has to say about libraries and traditional museums dedicated to building their collections:

Museums and libraries have become heterotopias in which time never stops building up and topping its own summit, whereas in the seventeenth century, even at the end of the century, museums and libraries were the expression of an individual choice. By contrast, the idea of accumulating everything, of establishing a sort of general archive, the will to enclose in one place all times, all epochs, all forms, all tastes, the idea of constituting a place of all times that is itself outside of time and inaccessible to its ravages, the project of organizing in this way a sort of perpetual and indefinite accumulation of time in an immobile place, this whole idea belongs to our modernity. The museum and the library are heterotopias that are proper to western culture of the nineteenth century. (p. 26)

A historic house museum, which is interested in representation of life or vivification of a historical experience that are specific to a point in history, rather than an establishment of a "general archive" of all things history, then, could be studied as a kind of a heterotopia that is designed to "arrest" time or, rather, the continuity of it. This arresting occurs within the ritual of repetitive performance, but also through a curatorial narrative that follows the cycle of the year, taking a domestic space through the seasonal changes, celebrating the same holidays much the 
same way and, in the case of such places as Fort York, reproducing the same historical events, year after year. Many HHMs conduct continuous research into the social context, historical events, and personal lives that they bring to life. This contributes to the nuancing and framing of the story, but never alters the fact that the performed life is forever rotating through the same year.

The important question that arises here is what does that say about how time gaps problematize memory and temporality? And, further, what does this handling of time do for the functioning of the time gaps? One of the important characteristics of time gaps is the non-linear way in which they approach performance of temporality. Much like our memory does not function in linear ways in relation to the temporal dimension of our life experiences, the space of a time gap disrupts the linearity of the idea of a historical progression. Memory does not simply work backwards in terms of our understanding of the present or past experiences, just like our anticipation of the future is not in a linear relation with our past. Similarly, much like in Cummings' (1922) novel The Girl in the Golden Atom, time within time gaps loses its ability to organize space to keep "everything from happening at once." That is true for the space within a time gap, where the physicality of the space holds time, and where temporality condenses and proceeds in a circle. It is also true for the interrelationship between the time gap and the outside world, which affirms that different temporalities can, in fact, be concurrent.

The space of the time gap is the space that affords a temporal disruption that can be interpreted in an open-ended way. On one hand, it can temporarily make up for the loss of time in allowing us to submerge into the experience of an unchanging domestic environment. On another hand, this temporal disruption affords a historic house museum an opportunity to "mediate the space between memory of the past and the imagination of the self" and an 
alternative progression of time (Petrov, 2011, p. 211), to question what could have been, why what was - was. An example of that is the opportunity to re-imagine gendered power relations in history through an event such as the Maplelea Heritage events for girls at the Black Creek Pioneer Village, where girls get to partake in performance of a version of a $19^{\text {th }}$-century village, which celebrates tween girlhood for a day - with games, crafts, dancing, etc. Another example of that could be such events as a Steampunk fair, where people dress up and perform an imagined temporality, a version of the present, that would have been possible had the Victorian aesthetic and steam technology persevered. Another important trend that fits with the loosening of the border between reality and the imaginary, history and art, are contemporary art exhibits and performances within historic sites, such as the art project "He named her Amber" in the Grange Museum, Toronto, by Iris Haussler (2008-2010), in which the house was interpreted to unsuspecting visitors as a home to a made-up maid to have them question what we take for granted in our consumption of public narratives. Thus, within a time gap, the space becomes key to experiencing a temporality, or versions of time, an operational re-distribution that Foucault (1986) observes on a much larger scale when he describes the relationship between time and space in modernity: “(...) the anxiety of our era has to do fundamentally with space, no doubt a great deal more than with time. Time probably appears to us only as one of the various distributive operations that are possible for the elements that are spread out in space" (p. 23).

In a time gap, which refutes the imperative of a historical progression, space and materiality are experienced as a temporality; time is held among things, within things. The experience of a temporality within a time gap is always in the immediacy of the moment. These sites are fixated on the accumulation of physical objects in their relationship with time, and, as 
such, they function as a vessel of time in its spatial and material manifestation. Time gaps hold the thingness of time.

\section{Time Gaps Performing as Memory Sites: The steady and sure that isn't}

Another issue that is closely connected to time and temporality that time gaps address, as they work to bridge the gaps in the day-to-day experiences of the human condition in postmodernity, is the question of memory. In this sub-section, I explore Nora's articulation of memory sites in describing how time gaps act to counter the sense of the breakage in cultural continuity and restore the sanctity of communal memory and space. I also make the argument that time gaps, ultimately, fail to deliver on their promise: Being products of postmodernity, they function essentially as referents of themselves.

Nora, as many other authors do (see, for instance, Baudrillard, 2001; Lefebvre, 1992; Huyssen, 2003; Urry, 1996), points to the cultural amnesia of postmodernity as the root of an increased interest in all things past. "We speak so much of memory because there is so little of it left," he writes $(1989$, p. 7). Nora unpacks this process by suggesting that it is this tear of the collective sense of temporality and community that necessitates the creation of "lieux de mémoires," designated sites, which both contain and embody a form of communal continuity. He explains that:

(...) if we were able to live within memory, we would not have needed to consecrate lieux de mémoire in its name. Each gesture, down to the most everyday, would be experienced as the ritual repetition of a timeless practice in a primordial identification of act and meaning. (Nora, 1989, p. 8)

Nora takes his discussion further, however, by suggesting that "hopelessly forgetful modern societies," who have severed ties with the pre-modern knowledge of their community and space, use history to organize their past, further eradicating organic memory. Nora understands history 
as "a reconstruction, always problematic and incomplete, of what is no longer" (Nora, 1989, p. 8) and describes it as a mere representation of the past, which is in continuous opposition with memory. Memory, according to Nora, is a "perpetually actual phenomenon, a bond tying us to the eternal present" (p. 8), and: It is "in permanent evolution, open to the dialectic of remembering and forgetting, unconscious of its successive deformations, vulnerable to manipulation and appropriation, susceptible to being long dormant and periodically revived" ( $\mathrm{p}$. $8)^{32}$

I believe Nora would have been rather mournful if he were to analyze the performance of historic house museums as instances of attempted revival of this kind of sense of continuity of communal memory. He would, perhaps, see them as attempts at creation of an embodied form of a communal memory out of historical discourses to produce an experience of ownership and belonging that is inaccessible in the framework of traditional historic museums. I believe this quote from Nora's text would accurately describe his take on this phenomenon: It is "a memory without a past that ceaselessly reinvents tradition, linking the history of its ancestors to the undifferentiated time of heroes, origins, and myth, (...) nothing more in fact than sifted and sorted historical traces" (p. 8). However, this movement from history as a mega discourse to the focus on an embodied engaged personable experience of a historic narrative and a site "frozen" and cut away from the progression of history, signifies the emergence of the important role heritage plays in postmodernity and is worth a thorough analysis.

\footnotetext{
${ }^{32}$ Memory, according to Nora, is the continuous making sense of the present through investing it with the absolute. This idea resonates through the large body of literature that offers theorizations of heritage. For instance, Hardy (1988) interprets heritage as a "value-loaded concept," implying that, despite its form, its very nature relates entirely to its current circumstance (p. 333). Further, Tunbridge and Ashworth (1996) note that "the present selects an inheritance from an imagined past for current use and decides what should be passed on to an imagined future" (1996, p. 6).
} 
Following the discussion by Nora (1989), Huyssen (2003), and Arnold de Simine (2013)

on the relationship between history and memory, I would like to note that what characterizes the phenomenon and performativity of the historic house museum is the postmodern shift from history as the master discourse on the past to the paradigm of heritage and memory. This could be explained by the shift in the era's interest from creating a historically accurate account of the past to establishing a sense of the continuity of culture. A quote from Cubitt (2007) might serve as a way of locating historic house museums in their relationship with cultural memory and history within this general trend. He suggests that "the long-established habit of imagining memory as a storehouse has been transmuted into the reverse suggestion that storage systems might be understood as forms of memory" (Cubitt, 2007, p. 8). It is this idea of a space that can appear to hold the past within it through materiality and therefore command a different form of being that constitutes the performance of historic house museums as time gaps. Nora's (1989) description of memory sites unpacks this idea further:

Our interest in lieux de mémoire where memory crystallizes and secretes itself has occurred at a particular historical moment, a turning point where consciousness of a break with the past is bound up with the sense that memory has been torn - but torn in such a way as to pose the problem of the embodiment of memory in certain sites where a sense of historical continuity persists. There are lieux de mémoire, sites of memory, because there are no longer milieux de mémoire, real environments of memory. (p. 7, emphasis in the original)

I have suggested before that time gaps are both a symptom of the longing for things that are lost, and a way of appeasing the anxieties of misplacement and spatial, temporal, and cultural fracture. The way this compensation is performed is specific to both the needs of a modern person and the way he or she experiences time and space. On the level of embodied experiences, the gaps of time offer a way to be present within a space that performs the kind of spatiality in which time is sure and steady, and objects of material culture are non-transient and point to the 
permanence of the domestic and the familial. On the level of the discursive, these sites offer a historical account in the form of the performance of a communal memory that is specific to their placement within the community and is told through the story of a family, several families, or specific individuals.

I describe HHMs as instances of artificial anthropological emplacements, not due to their origins or a consistently performed role within their community, but because they are recreated versions of what we know we long for, but that no longer isn't. These sites are deliberate, planned, and curated, not just as museums but as spaces, where a historic everydayness can be experienced in its mundane detail. As per Nora's (1989) definition of memory sites, historic house museums originate "with the sense that there is no spontaneous memory, that we must deliberately create archives, maintain anniversaries, organize celebrations, pronounce eulogies, and notarize bills because such activities no longer occur naturally" (Nora, 1989, p. 12). Each historic house museum has its own history of having been "saved" (this is the theme I noted earlier. For more on this, see Hodge, 2009), but most share a very similar history of restoration, which involved being emptied out, restored to an image of what they probably looked like at a particular point in time, and made sense of as a juncture in a historic timeline, captured, preserved against the natural flow of time. They are not left to disintegrate as monuments in a cemetery are, which is what would have happened if we had the kind of abundance of spontaneous memory that Nora (1989) describes as a privilege of a pre-modern society. Instead, they are recreated to become a material manifestation of a created communal memory.

Another important feature of memory sites, according to Nora (1989), is that they no longer have "referent in reality, or, rather they are their own referent: pure, exclusively selfreferential signs" (p. 23). As recreated junctions in a historic timeline, memory sites function as 
places where people come to pay homage to the fragmented "pastiched" memory of their fragmented selves (Jameson, 2006). These memory sites function as foster homes for dreams in the age when dreams are divorcing themselves from the modern cityscape. It is possible to draw a parallel here with the current fetishization of "authenticity" in the hipster culture, which opts for the "unprocessed" romance of vinyl, container gardening, and urban cycling. I observe the same mechanisms in place when it comes to an attempt to re-create experiences of a self, emplaced within the continuity of time and tradition, and experiences of an unmediated "authentic" self, both endeavors defined through a culturally constructed and mediated referent.

The heterotopia of a historic house museum appears to function as a confused snake that has captured and is now eating its own tail, since the authenticity of the experience is often imagined, which, of course, does not make it any less valuable. Historic house museums, thus, can be described as sites without an authentic referent, turning into the very thing that they promise to deliver us from. This point can be best illustrated with a quote from Baudrillard's (2012) Simulacra and Simulation, where he addresses the emergence of nostalgia in the world of the hyperreal:

When the real is no longer what it was, nostalgia assumes its full meaning. There is a plethora of myths of origin and of signs of reality - a plethora of truth, of secondary objectivity, and authenticity. Escalation of the true, of lived experience, resurrection of the figurative where the object and substance have disappeared. (p. 390)

\section{Historic House Museums: Appeasing nostalgia to enable progress}

Finally, connected to the questions of time and memory, is the question of nostalgia and how, and whether, historic house museums address it in their work as heterotopic sites. Boym (2001) describes nostalgia as a "symptom of our age," a "historical emotion, coeval with modernity itself" (p. xvi), brought on by the new understanding of time and space. Attempts to 
explain Western society's sudden infatuation with the past identify several specific causes. To begin with, nostalgia is perceived as a tool society uses to counter the temporal and spatial collapse. Huyssen (2003), for instance, suggests that new memory discourses are used "to regain a strong temporal and spatial grounding of life and the imagination in a media and consumer society that increasingly voids temporality and collapses space" (p. 6). Further, nostalgia is seen as a way to appease the anxiety associated with the collapsing belief in the future, which came in the aftermath of modernity's infatuation with it. "The twentieth century began with a futuristic utopia and ended with nostalgia (p. xiv)," Boym writes, and "nostalgia inevitably reappears as a defense mechanism in a time of accelerated rhythms of life and historical upheavals" (p. xiv).

This anxiety, in part, is expressed through the craving for the auratic qualities of the past (Benjamin, 1940/1986), which are perceived as grounding and embodiments of non-transient values (Boym, 2001; Harvey, 2001; Nora, 1989). Huyssen (2003), for instance, describes modernity as the age in which objects of material culture are understood as transitory, since the ways of continuous progress devalue the means of the past. He writes that "the price paid for progress was the destruction of the past ways of living and being in the world. There was no liberation without active destruction. And the destruction of the past brought forgetting" (Huyssen, 2003, p. 2). Nora (1989) also describes modernity's love affair with the past as the result of a "general perception that anything and everything may disappear" (Nora, 1989, 7).

From the point of view of nostalgia, a historic house museum holds a promise that an ideal home can be rebuilt. Nostalgia is a tribal activity, it goes beyond the boundaries of individual psychology (Boym, 2001). It is also the desire that converges time with space. Hodge (2011) suggests that: “As a material and emotional discourse, nostalgia binds memory, place and experience (p. 116) (also see Hodge, 2009). While nostalgia, although tribal, can also be divisive, 
the heterotopia of a historic house museum does not pull us apart but brings us together, since it is a mythologized space, an invented locale. Possessed by nostalgia, we accept the mythologized past. It is an attempt "to repair the longing with belonging" (Boym, 2001) in the time, when an urban dweller feels disconnected from his or her community.

Further, within nostalgia is embedded the possibility of an ideal home, even if it is imaginary. It is the kind of longing that can be romanced, whose bitterness can be savored in pursuit of its satisfaction (Boym, 2001). Historic house museums are places where we come to romance the fantasy of an integrated domestic space, of a familial ritual, of a familial history that informs the familial present. Much like historic house museum sites emerge as sites of memories in the world, where there is little memory left, they also perform as sites, in which the meanings of home converge with ideas of familial hierarchy, which, some imagine, was part of their childhood. In both cases, it is the desire to re-experience belonging, and the inability to do so, that is what mobilizes this long-distance relationship with our imagined selves. It is the inaccessibility of the object of one's longing, which affords the luxurious bitterness of nostalgia.

\section{Conclusion}

I would like to conclude this chapter by describing the work of a house museum site that, while attempting to do a number of things that house museums do, fails to deliver as a heterotopic space because of its cultural and historic context. This particular house museum is located in San Sebastian del Oeste, a small village about 47 miles away from the closest major city, Puerto Vallarta, Mexico. The museum is called The House Museum of Dona Conchita Encarnacion (Casa Museum de Dona Conchita Encarnacion); it overlooks the town's main square. 
The museumized space is the actual site of day-to-day life of the family the museum is dedicated to. The time period it focuses on is the turn of the $20^{\text {th }}$ century and, indeterminately, onwards, spanning the period between before the Mexican Revolution, which led to the town being abandoned by the mining industry, and on through the century, as San Sebastian lost more than 75 percent of its population and turned into a small agricultural community. Most of the artifacts at this museum speak to the life in the industrial glory years of San Sebastian, the time the town enjoyed prosperity and growth. All of that appears to be the ground for the potential success for this HHM. On paper, it could gift the community with an ability to situate and explain its present in relation to its past, immerse itself into the life that was once filled with the promise of opportunities, re-live the time of proud success, and re-connect with its industrial heritage. Finally, it could connect this now tiny agricultural town with a different version of itself, allow for shared re-imagining, thus opening the present and the future to a variety of interpretations.

In reality, this particular house museum looks like a very old attic that a family member has been making gradual attempts to sort through. It appears as though some things were deemed worthy of special consideration, and so they have been pulled out of the piles that time and multiple generations of hands have placed them. The connections between items on display look as though they could make sense to a family member who is sorting through her family history, but to no one else, and, at times, seem whimsical, such as the examples of late Victorian-era pornographic images next to the family's wedding photos. The artifacts are placed so that they would be easy to re-visit with, and the collection (which looks more like an assortment of things) does not tell a coherent story. It is also obvious that this family member is not completely done 
with her attic excavation project, as a variety of random personal belongings, books, and boxes still pile up in the corners at precarious angles.

Being an aspiring museum anarchist (Vagnone, Ryan, 2016), and thus aspiring to encounter HHMs in ways that draw out experiences of the site as a lived-in humanized space, while on a visit to the museum in December of 2016, I turned right when I was supposed to turn left, and walked into what until a few decades ago was obviously a functioning kitchen, but is definitely not a part of the tour. This place looked no less odd than the sitting room (used as a museum space) and raised a number of questions as well. Somebody quite literally walked out of this kitchen at some point and never came in to light the fire again: All the pots, pans, knick knacks, and tiny insignificant things, that turn the space of an uninhabited Ikea display into a lived-in environment, were still there; all of them covered with a thick layer of dust. A window into the back garden was at some point broken, but never fixed.

The most basic questions this place brings up are: "How is this a museum? Who comes here? Why?" Further, one wonders: "How does this place substantiate itself as a point of interest? How does it add to the experience of San Sebastian?"

The answers to these questions, I believe, rest in its location. The story of San Sebastian is not the story of the fall of a mining town and its redemption as a site of successful eco-tourism, nor is it a story of a town that fell into social and economic degradation following the depletion of its mines. Instead, since about the 1920s, the town entered a sort of a time warp. The population quickly diminished from over 20,000 at its peak to a little under 1,000, according to the latest census, with the remaining inhabitants turning to agriculture as the main source of income. The prosperous haciendas surrounding the town were abandoned and then absorbed by the forest, most of them now in ruin. Nestled high up in the Sierra Madre Mountains, San 
Sebastian was cut off from all major roads up until the government built a bridge to connect it to the main road in the 80 s (the era of the mining ended before the transportation network in the area was fully developed, so it was quite easy to cut the small community off for a century). For the length of the $20^{\text {th }}$ century, it served as a destination for religious pilgrims. The tourists did not come until very recently, and they, too, have a hard time getting there. There is still no direct bus route from Puerto Vallarta to San Sebastian.

In a sense, the trip to San Sebastian feels like a form of a pilgrimage, except to most Westerners the mystical experience is that associated with time travel. The effect of San Sebastian's isolation is quite stunning: The town strongly resembles the photographs of itself from the 1800s. All streets are laid out in cobble stone, crawling around houses up and down the mountain slope. Its layout does not allow for the movement of large vehicles. There was no Internet connection up until a few years ago, and the regular phone connection has been unreliable. The rhythm and pace of life here depend on the season of the year. In a sense, San Sebastian feels very much like a site of utopia.

I suggest that Dona Conchita's museum does not function like a heterotopic space, because a place such as San Sebastian has no need for one. It has not lost its sense of continuity that is grounded in its culture or a natural course of historic progression. For now, San Sebastian is a city that got preserved, or, from a Western viewpoint, museumized (as in fossilized, cut away from the external world as if it were in a bubble). Within this site, an encounter with history that makes sense is the sorting through an equivalent of one's family's old attic, and this kind of an engagement does not look strange or unfit to function as a public space. The outside of what constitutes a museum in San Sebastian-the roads, houses, the very arrangement of buildings, the vista-are the kinds of things that one would want to see to encounter the past. All of that is still 
of the past as much as it is of the present. Thus, the inside of the museum is the tribute to the only other kind of engagement with the community's history that makes sense - the personal things, letters, clothes, books, and documents of one family in one semi-abandoned house, a family, that, unavoidably, has a connection to most other families in town.

It makes sense, then, that the family members are the ancestors of Dona Conchita, who is also the curator and a tour guide in the museum. In HHMs in North America, the fact that living relatives are still around complicates the work of the interpreters. Several of my interviewees at Spadina house in Toronto cited that as one of the reasons why they do not wear costumes during tours ("It would be like I'm performing the life of someone's family," one of my interviewees suggested) and mentioned that it affects the interpretive work. They cannot use the story freely as an entry into the historic and social context and the time, if it is still, in a way, a part of somebody's personal life. That also affects how such things as suicide and mental illness of some of the former inhabitants of HHMs are addressed. Finally, the visitors cannot feel quite as freely “inhabiting" the space that is established as still "somebody else's." In San Sebastian, the past still freely reaches into the present, just like the present reaches into the past; all of San Sebastian has a feeling of being "somebody's."

At the moment, San Sebastian is a town suspended between its century-long retreat into communal agricultural past, with a town square and a church functioning as a centre of the community, - and a most certain future as a site of a tourist attraction, once the province and private citizens build up the logistics for it to become one. With time, it will be the gaze of a tourist that will reform the site into the logical extension of its own self and make other forms of heterotopia necessary and, therefore, possible. 
CHAPTER II: Materiality: Touching, biting, craving, and the experience of the "junk of life"

Behind you is the face of Mrs. Edward Jervis. Before you her tea table, her own blend of tea, her earrings, tea apron and fan. In your mind this is her "withdrawing room." It is a matter of science that without her invisible presence it might become only a room furnished with antiques - like a museum display. Terrifying isn't it? Like celebrating the millennium as a number without Christ.

Dennis Severs, Signage from 18 Folgate Street, Dennis Severs' House

As a volunteer interpreter and a researcher, I got to spend considerable time in Toronto's house museums doing things visitors do not usually get to do. All of the more exciting experiences had to do with touching things that, as a visitor, I would not normally get to touch, and going into the rooms where visitors do not normally get to go. Lana, an interpreter from Colborne Lodge, in an interview once referred to the kind of historical perspective that HHMs offer as "the backdoor of history," explaining that all of history is really about "how people lived and what they did."

My research has given me a scullery maid kind of an entrance. At some point, the Mackenzie House Museum needed to take interior photos with someone dressed in costume, and so I got to play the piano in the parlor. It is dreadfully out of tune-perhaps the reason the ghosts stopped playing it in the 60s. I got to play the grand piano original to Spadina House that same year, one of the few of its calibre and kind in the country, and there, it was not the touching that brought on the shivers, but the making of the sound and the realization that all of Toronto's most prominent people heard those same sounds throughout the $20^{\text {th }}$ century. Picking up personal items - glove stretcher, a hook for doing shoe laces - off of Mrs. Mackenzie's dresser, while

\footnotetext{
${ }^{33}$ Parts of this chapter have been previously published as "Touching the Past: Investigating Lived Experiences of Heritage in Living Museums" in The International Journal of the Inclusive Museum, 7(3), pp. 1-8. Common Ground Publishing. February, 2015.
} 
peering into her mirror, is another good example. Catching moments of absolute quiet and solitude while alone in the house gives a very similar feeling of being privy to someone else's intimate life. Not having been invited, then, makes me feel uncomfortable. At times, it was very much a voyeuristic experience of pulling out drawers in a house where I was a guest, while the hosts were in the parlor entertaining my parents.

According to most of my interviewees, these immediate, intimate experiences of everyday personal things are exactly what visitors need. Further in this chapter, I suggest that these are the experiences that function as a key to the "backdoor of history" that Lana referred to. In answer to the question: "What would you want to do differently in your work in the museum?" most responses dealt with allowing visitors to touch more things and to do more with them. Having more things that were involved in the mundane everydayness was another popular answer. Consider the following comment by Ella, who has worked in three of Toronto's HHMs for close to ten years:

I have read the paper by someone who was saying... this won't apply to this family, but they were saying: "Where are the diapers?" You look into a nursery at a Victorian... in a restored home and there's prams, and there's cots... there's pretty things with a lot of frill, but where are the diapers? Where are they? There should be piles and piles of diapers. And that's kind of like when I look into all of the rooms, I just think: "Where's the equivalent of the diapers?" And some of that ends up being the stuff that got used all of the time. She was saying that the thing about the stuff that gets used all the time is that the stuff that gets used all the time is used until it is used up, and then it gets thrown out. So, not only it is the matter than no one chose to preserve it as an artifact, but it was never available to be preserved as an artifact, because it was used until it was disposed of. And then you get into... how much we can take... reproductions? In a historic home... Sort of the authenticity of it being an artifact. But when it comes to everyday textiles and stuff like that... Maybe all that needs to be repro. Maybe we just need to say for the certain kinds of very consumable products, we have to do that. But it is not something we have done very much of. It's not something I have seen very much of in the houses.

"The junk of life," as Ella referred to it later in the interview, feeds into a creation of a lived-in intimate domestic space, the kind of home that feels like an extension of a human body. When 
talking about the Mackenzies' home, Ella underlined the importance of transferring Mr.

Mackenzie's personal characteristics onto the historic space he occupied: "This is a chaotic man! And we don't even have enough chaos there. There should be so much more chaos. It should look like some kind of fire hazard, right? It should be that kind of thing that if fire services came in they would say: "It has to go." Further, the coming into contact with that space on one's terms gives people an ability to interact with that historically contextualized extension of a human body, grants entry through the backdoor and into the slice of time of the time gap. Jordan, one of the newer interpreters working at two of Toronto's HHMs at the time of our interview, said he wished the museum had a sofa kids could actually jump on: "Then they would know how slippery horse hair is!"

In chapter 1, I unpacked my understanding of the cultural purpose behind historic house museums as time gaps: I interpreted them as spaces that allow the bridging of gaps in the experiences of the everyday in a metropolis by hosting a different slice of temporality, in which the terms of the relationships between bodies, physical of objects, and spaces are rearranged. In this chapter, I begin to explore what happens within time gaps to accomplish this work. Specific to chapter 2 is the discussion on conceptual questions of how historic house museums use physical objects; why they do it the way that they do; and what meanings do these uses attach to materiality. The chapter has two parts. The first section of the chapter, "Sensing the Past: Historic house museum as a phenomenological text," focuses on the relationship between a sentient body and an HHM space. I begin by unpacking my idea of the body as a point of analytical entry into the study of the time gap. I then move on to the discussion on the analytic potential of HHMs as sensory spheres, as opposed to visual spaces (spaces created to be experienced through the ocular and not interacted with in any other way) designed within the 
curatorial paradigm of traditional historic museums. This approach suggests the view of historic house museums as multi-sensory environments, which foster bodily awareness of space, time, and materiality of objects from the past, by employing touch, vision, smell, and hearing. I suggest that within a sensory sphere of a time gap, corporeal engagement makes possible one's experience of a historic house museum as a connective encounter with the materiality of space and one's lived experiences within it. I extend this discussion further by considering the role of a phenomenological touch in a historic house museum. I pick the specific sensory experience of haptic touch, since the focus of the discussion is on the implications of sentient embodied experience in an HHM on the construction of the meanings of materiality.

The second section of this chapter, "Time gaps and their things," concerns the implications of my discussion on the relationship between a sentient body and the HHM space and objects within it on how time gaps attach meanings to materiality of their objects and physical spaces. Time gaps attempt to offer these kinds of encounters with material spaces and objects within them, I suggest, because of the shift in meanings of material culture in the age of postmodernity, an analysis I offer in the second part of this chapter. In building the interpretive framework for this discussion, I draw on Baudrillard's (2005) analysis of the cultural system of modernity, which "underpins [things'] directly experienced everydayness" (Baudrillard, 2005, p. 2). I suggest that the "thinging" of things within a time gap aspires to create a self-referential and closed system of meanings and uses: Things explain themselves in connection to other things within the logic of the slice of time the time gap is regurgitating. Further, I suggest that time gaps use spaces and things as means of experiential connection between bodies through and in time. They create the possibility of tapping into experiences of every day routines, functioning as 
invitations to another time's way of thinking, a quality of HHM experience that is frequently used as a means towards ontologically-intensive research.

Sensing the Past: Historic house museum as a phenomenological text

Historic house museums offer a tactile experience of culture and history while creating both narrative and physical spaces for visitors to insert themselves within the cultural performance of heritage. The notion of phenomenological touch and psychoanalytic articulations of primary processes work to advance our understanding of the corporeal experience of the communal past. This analysis provides the ground for articulations on how experiences of tangible heritage (which assumes the form of things that can be seen and touched) translate into the experiences of intangible heritage (which assumes the form of ideas), namely the lived experience of the communal and personal past and reconsideration of the personal and communal present. The goal of this discussion is to unpack some of the processes through which symbolic properties of space are formed. In my analysis, I draw on the notion of a sentient body as an entry point into this kind of analytical work.

The Bodies and the Gap of Time: The private communing and the buzzing of in-between spaces

I suggest that time gaps posit a sentient human body as the basis for and the means to the experience of the site. This, in part, emerges as a part of the heterotopia's function of mirroring and contesting experiences of a body in a postmodern fragmented world. This leads me to ask: In what ways do we use the body to make sense of the experience of an immersive domestic environment that is a historic house museum? What significance does the embodied nature of the museum's experience have in how museum spaces are organized and made sense of by the staff?

I use O'Neill's (1985) articulation of a communicative body in unpacking the ways this approach maps onto the conceptual levels in my analysis and explains the use of a sentient body 
in a heterotopia's mirroring of disembodying cultural practices in postmodernity. In his book Five Bodies: The Human Shape of Modern Society, John O'Neill (1985) explores humanity's shift from its anthropomorphic past, which made the creation of cohesive communities possible, to present-day fragmentation of families, communities, and individuals. In his analysis of this process, O’Neill (1985) points out contemporary society's loss of ability to see the world from the position of a "sensory mind" (p. 44) as a holistic lived-in cosmos shaped around the needs and properties of humanity, rather than as an object that needs to be managed and quantified.

O’Neill (1985) unpacks this proposition by, first, identifying the body as a starting point for shaping humanity's vision of the world and a "critical resource in the anthropomorphic production of (...) our social, political, and economic institutions" (p. 16). O'Neill (1985) points to the division between the physical body and the communicative body, and establishes the communicative body as "the general medium of our world, of its history, culture, and political economy" (p. 17), the very medium through which the very "having" (p. 17) of the world is made possible. According to O'Neill (1985), it is the communicative body that enables people to relate to each other, to commune with the world, and, ultimately, build functional cohesive communities. The communicative body is also a source of creative agency. To unpack this point, O'Neill (1985) explores ways in which anthropomorphism once served as a resource for shaping both cosmology and structures of human societies through the agency of communicative bodies.

O’Neill (1985) spends a large portion of the book exploring how the present day split between the communicative body and the physical body leads to the turning of a human being into a "docile instrument of commercial, educational, and medical practice" (p. 20) and to fragmentation of social structures, the process that benefits political systems of control. This split, according to O'Neill (1985), is, in part, enabled by policies and discursive practices of 
therapeutic states, which are interested in fostering passivity and extending their control further in the domains of now-fragmented bodies and lives. While communicative bodies, with their lived experiences, familial past, and communal membership, are "messy," hard to manage and categorize, physical bodies can be objectified, studied, and explained in pre-defined terms. Bearing no history and no ties, physical bodies are easy to describe and classify and, therefore, can be both managed and "serviced" by bureaucratic institutions.

Time gaps offer us an opportunity to form relationships with space and time from the position of a communicative body. These sites foster performances of one's ties to the past, one's community and family, and they suggest that the willing bring together their embodied, emotional, social, and intellectual selves in forming the experiences of place. In my analysis in this chapter, I engage with several theoretical articulations of the body. The first is a phenomenological body, the body as given in the immediacy of the experience. The second is the psychoanalytical conception of body, that body that can be propelled by internal energies, led by instincts. Finally, I discuss the body as a site where the catharsis is achieved through the willing engagement with the workings of a time gap.

The very idea of unpacking a historic era through interpretation of day-to-day living points to the centrality of a body in understanding this kind of history. This suggests specific avenues for research and interpretive angles, and outlines the relationship between the material space of the house and the body within it. Within a house museum space, a body emerges as a measure of the functionality of the space and the objects within it: The house was originally built to keep a body warm, safe, clean, as a place to feed it, give birth to it, raise it, a place it would long to come back to. The physical constraints framing the telling of a story are the constraints of a home. As a result, I believe, visitors conceive of people who used to live here as having had 
bodies, as opposed to a cool functional non-place of a contemporary history museum weaving narratives of people as historical figures. Very frequently, when guiding the tours at Mackenzie House, I had to answer questions about the height of William Lyon Mackenzie, or how tall people were in general, a question that usually arises from observing the size of chairs, beds, the height of a kitchen table. The trying on of a temporality using one's own body becomes a natural entry point through "the backdoor of history:" People on tours frequently attempt to imagine what their day would have been like considering the kinds of chores that needed to be done to keep the house running; the kinds of clothes they needed to wear; how early it would get dark in the house. The further line of questioning normally has to do with how the bodies would feel. Would their lower backs hurt from cooking, doing the laundry by hand, and carrying the water from the well? Would their skin crack in the wintertime?

As an interpreter, I have found that bodies in history attract an ambiguous kind of attention. Questions about chamber pots, body smells, dying bodies, and sick bodies surface with either surprising detail, which demonstrates that they have been pondered, or do not come out at all. Children do not usually hide their curiosity about bodily functions. Whenever I see children on tour, I know that there are two questions coming up: "Where did they poo?" and "Is there a ghost?"

Consider how Ashleigh addressed the angle of the body in history in her discussion of her work:

My favorite piece of clothing to interpret would be women's underwear (...) Women's (underwear) today... even men's. Even though people are not meant to see it, you still want it to be really flashy. And it's no different historically. And that also applies to stockings and the hems of petticoats. You still want them pretty, because they may be shown. There was also flirtation involved... They were not wearing striped and decorated stockings, because just in case they may not be seen. Skirts were made to be pulled up for outdoor air, so you were showing off your petticoats. The little pullies... that they would 
put on the outsides of their skirts... but yes, underwear is my favorite piece of women's clothing to interpret. Women's underwear...

There's stories, and it's fun interpretation. Because it is the first piece of clothing women stole from men. And it happened in the Empire Era fashion... Can Can was so popular, because they were wearing crotchless underwear. I think the movie Piano actually has historically accurate underwear, which I was very impressed with. And that picture... there's an $18^{\text {th }}$-century print of a woman on a swing, going back and forth, and her lover laying in front of her, with a big smile on his face. She's got no underwear on! It's petticoats and then naked flesh. Yes, he is smiling! And it just makes interpreting bodily functions simpler... hygiene simpler... A lot of things make more sense to the visitors, when they find out about the underwear.

The intimate is made immediate by the HHM environment, and the encounter with it-whether it is reading a line from a personal letter admitting feeling joy or feeling utterly lost and hopeless, or noticing that a petticoat, when folded onto itself and hung on the side of a mirror, produces the shadow of a spider on the wall-is the experiential manifestation of a "backdoor of history" being opened. An acknowledgement that those people, too, wore underwear, might well be the first step through it.

\section{Historic House Museums as Sensory Spheres}

My first step in exploring the kinds of interactions that a sentient body engages in within the space of a HHM is the articulation of the entirety of the container of the HHM domestic space as an object of the experience - the way it smells, the sounds that it makes, the amount of light it lets in, and so on. I have found two distinct movements in museum research that address one of the elements of what I refer to as museum as an HHM sensory sphere: The first is the idea of a multi-sensory museum and the second is the conception of a museum space as an integrated entity.

The discussion on how museums could benefit from a variety of senses (see, for instance, Chatterjee, H., 2008; Dudley, S., 2010; 2012; Levent, N., Pascual-Leone, A., \& Lacey, S. 2014; Wood, E., Latham, K., 2014; Schorch, 2013) for educational purposes, understandably focuses 
on sentient experiences associated with the objects (shaking, smelling, touching, making, and so on). While these new perspectives on multi-sensory museum practices advance a number of important points, such as that museums need to take advantage of the fact that cognition is embodied (Levent, N., Pascual-Leone, A., \& Lacey, S. 2014; Wood, E., Latham, K., 2014), despite the references in its name, the multi-sensory approach to museums does not necessarily suggest the consideration of the museum experience as resting in the sensory potential that is an innate quality of its container. For instance, some museums attempt to recreate a multi-sensory historical experience, but that requires first blocking out the awareness of the immediate museum space. For example, the civil rights museum in Atlanta, GA, recreates the lunch-counter protests, when black students staged sit-ins, demanding to be served food alongside whites. Visitors are invited to put on headphones and place their hands on the counter. They then can hear the sounds of shouting, taunting, the protests of the person next to him or her as he is being dragged away. The counter begins to shake, and so does the chair the visitor is sitting on. "How long can you last?" says the writing on the wall in front of them. The isolation of sensory-specific experiences within a museum space has a long history in the West. Kirshenblatt-Gimblett (1998) explains it the following way:

(...) the European tendency has been to split up the senses and parcel them out one at a time to the appropriate art form. One sense, one art form. We listen to music. We look at paintings. Dancers don't talk. Musicians don't dance. Sensory atrophy is coupled with strong focus and sustained attention. (...) Aural and ocular epiphanies in this mode require pristine environments in which the object of contemplation is set off for riveting attention. In contrast with conventional exhibitions in museums, which tend to reduce the sensory complexity of events they represent and to offer them up for visual delectation alone, indigenous modes of display, particularly the festival, present an important alternative. (p. 57)

HHMs are truly an exception as a Western museum genre, since the entire container of the museum presents as an artifact, a coherent part, but also a vessel of and for the story. 
Considering the passage above, it is poignant that I have found similar articulations of the museum site in the literature on indigenous forms of curation, specifically the work by Malnar and Vodvarka $(2013 ; 2014)$. These authors describe sites that they refer to as "cultural centres" or "research centres" as places that have an immediate and a meaningful connection with the objects that they hold and suggest a "purposeful, even causal relationship between artifacts and individuals" (p. 214). Kreps (2003, 2005, 2008), whom I referred to earlier, describes indigenous forms of curation along similar theoretical lines.

Further, another movement in the study of museums considers them as integrated spaces/entities or as forms of configuration. Whitehead (2009), for instance, argues that museums, just like maps, "are made of spatialized knowledge" (p.137). An exhibit, then, emerges as a form of a text (see, for instance, Bal, 2006, 2007; Peponis et al., 2004; Ravelli, 2006; Wineman and Peponis, 2010). Ravelli (2006), in her book Museum Texts, suggests that "an exhibition, created through an organization of exhibits and spaces, a selection and construction of content, and a construal of role relations, is a meaningful text: it is a space that visitors move through, and a space which they "read" (p. 123). Bal (2006) studies the narratives of exhibits as emerging from the visitors' walk through them; thus, a route through an exhibit emerges as a form of discourse. While this body of literature tackles an important point that is the relationship between the museum space and its curriculum, it does not engage with layers outside of the experiences of the discursive and the ocular.

I hope to add another nuance to these ways of thinking of a museum space by suggesting a discussion on HHMs as sensory spaces. This articulation is based on the ideas of Marshall McLuhan (1997) concerning the differences between visual and acoustic spaces. McLuhan first discussed his notion of acoustic space in his 1967 book The Medium is the Massage. In 
developing the idea, McLuhan builds on his understanding of the environment as being both constructed through our senses and being constitutive of them. McLuhan (1997) posits that, in contemporary Western culture, where visual perception is the dominant way of navigating through the world, the understanding of space is tied to consideration of physical objects that occupy it. Visual space, then, is understood as a three-dimensional space defined through the spatial relationships between visually perceived objects. McLuhan (1997) describes "acoustic space" as a "sphere," rather than a "space," without "fixed boundaries," "a favoured point of focus," or a vanishing point (p. 41). Inside an acoustic sphere, instead of focusing the senses on a particular point in space, people are submerged in a flexible and an ever-changing environment with transient dimensions.

I would like to build on McLuhan's (1997) juxtaposition of visual and auditory spaces by likening it to fundamental differences between traditional historic museums and historic house museums. Historic museums, dedicated to conservation of material heritage and education of the public, build their displays to create points of ocular focus. The space that holds the objects is traditionally designed to subdue all other senses. Visitors are surrounded by pastel-colored walls with very few, if any, windows. They are discouraged from talking; one is trained to be quiet in a museum, and, for the most part, strictly prohibited from touching objects of expert-defined value.

Historic house museums move past this model of transmission of knowledge and strive to recreate that indefinable sense or aura of the time period (Severs, 2002), of what it could have been like to be in that space back in the day. They stage a version of lived reality that can be accessed only through embodied presence and lived experience of the space and materiality of objects that it holds. An HHM necessitates activation of all senses, a state of alertness to the uncontrollable world around us. In a traditional historic museum one may close his or her eyes to 
block him or herself from the world; in a house museum, the smells, the movements of air, the creaking of the centuries-old floorboards under one's feet, conversations of the visitors, and the working of a frequently present printing press will prevail despite the shut eyelids. In that context, not just material objects, but also words, smells, voices, movements of air, and flavors emerge as artifacts that add up to a story. One of my interviewees, Ashleigh, stated that she found her knack for remembering precise quotes helpful in her work as an interpreter. She explained it the following way:

(...) 'cause people like hearing the original words. The original words are almost like an artifact in itself within the story. Would you like an example? (I said "yes") There was a slaughterhouse by Fort York, so we'd often have the stench of the slaughter waft across our grounds, and the kids would always get disgusted by it. And so, Sir Walter Gleam, in his Peninsular War diary, or journal, states that the "smell of the battlefield," the closest that he can put it, is to "that of the slaughterhouse right after the kill." So... it's a perfect quote. Even though it is the smell of the slaughterhouse wafting across, and it is 1990, it is still an interpretive opportunity to link it back to a soldier's experience on a battlefield, even if at first glance they seem unrelated.

House museums draw on engagement of multiple senses and, thus, constitute organic and integral spheres, rather than spaces defined through the relationship between objects that we identify visually. While McLuhan (1997) focuses on properties of the sound in constructing his notion of acoustic space, my discussion of a historic house museum space implies the intersection between multiple senses - tactile, auditory, visual, and that of taste - in understanding the sensory sphere constructed by an HHM space.

\section{Touching the Past with One's Body}

In this section, I will talk about the meaning of touch, or what I would rather refer to as “person-object transaction” in HHMs. In North America, touching in museums became off limits by the beginning of the 19 th century. Since the second part of the 20 th century, there has been an attempt on behalf of museums to engage the public more, in part by suggesting visitors interact 
with material objects. Wood and Latham (2011) note, however, that in most cases, when an object is integrated in an educational activity in a traditional museum setting, it plays a supporting rather than a primary role. Thus, the objective is to teach something using the object, not an interaction with the object itself: "The focus is not necessarily on the object itself, but rather the object is part of the process of doing something in a hands-on way, not the center of attention itself" (Wood and Latham, 2011, p. 56). Malnar and Vodvarka (2014) note that this way of handling historical artifacts (positioning them behind a glass or producing replicas to aid in a process of teaching something, what they call a "sensory-specific application") betrays a static view of what may constitute an interaction between a visitor and an artifact (p. 213).

The last decade has brought on a rise of interest in the meanings of haptic experiences in museums. The most prominent books on the subject include the two volumes edited by Sandra Dudley, Museum Materialities: Objects, Engagements, Interpretations (2010) and Museum Objects: Experiencing the Properties of Things (2012); Chatterjee's (2008) Touch in Museums: Policy and Practice in Object Handling; and Pye's (2007) The Power of Touch: Handling Objects in Museum and Heritage Context. In her introduction to Dudley's (2010) Museum Materialities, Pearce (2010) writes that this shift in interest marks the museum's coming of age as a site, where the material constitution of the human existence is examined. The research work conducted along these conceptual lines (including this dissertation) suggests that museums can be considered as spaces to study relationships between people and objects, sites that bring together individual embodied experiences, artifacts, art, and public culture, thus having potential to contribute to the study of cultural anthropology, rather than merely disseminating knowledge. For instance, Dudley (2010) argues that the work with materiality in museums needs to move away from the study of expert-defined valuables and to the site of the simultaneous engagements 
of the producer, the object, and the visitor. My contribution to the discourse on the purpose and meanings of haptic experiences in museum settings is concerned with applying the notions of person-object interaction (Dudley (2010) uses the term "human-object engagement") and phenomenological touch to my study of visitors' and interpreters' interactions with material objects in historic house museums, and the suggestion of how these experiences inform the meanings of materiality within time gaps (p. 1).

Before I start the discussion on my observations at the Mackenzie House Museum, I must unpack two theoretical articulations: the notions of a "person-object transaction" and of a "phenomenological touch." In formulating these, I draw on the work of Merleau-Ponty (1962/2004), who argues that it is the lived experiences of time, space, body, and "other" that inform our understanding and interpretation of the world. This position adopts the view that physical engagement, particularly haptic experiences of the world, is the definitive mechanism of being in the world, the coming to a "communion" with it and within it. The "phenomenological touch," then, is the coming together of everything that constitutes an external object and everything that is contained within a person; it denotes the coming together of a persona and an object. I would also like to note that Merleau-Ponty (2004) points to the integral unity of the various qualities constituting an object and to the complex intersection of sensory experiences that constitute a reaction to an object: "Indeed our experience contains numerous qualities that would be almost devoid of meaning if considered separately from the reactions they provoke in our bodies" (p. 46).

Dudley (2010) articulates her definition of human-object engagement along similar lines in suggesting that "it is only through the object-subject engagement that the material artifact or specimen becomes real at all” (p. 5). Wood and Latham (2011, p. 55) follow suite in defining 
"person-object transaction" as a "juncture where the lived experience occurs" (p. 55). The authors argue that "in the person-object transaction, the object truly enters the viewer's consciousness" (p. 55). This conception of the person-object transaction as the site where a kind of a lived reality is produced leads Dudley (2010) to formulate her take on materiality as the coming together of objects, sense, and feeling.

I would like to begin my analysis by noting that within the sensory sphere of a historic house museum space, touching does not just describe the reaching out with a hand and coming into physical contact with a historic object. Unlike in traditional historic museums I refer to above, in house museums physical objects are frequently used as the primary focus of a museum experience. Since the entire space of the house constitutes an artifact, visitors touch it with their feet, by leaning onto a wall, by operating a printing press, or by soaping their hands with soap produced from an original recipe. Visitors can also bite into it by tasting cookies made from a Victorian cookbook during Christmas celebrations.

There are several key observations in regards to what object-subject engagements produce for the experiences of visitors in HHMs. First, touching moves the past into the domain of immediacy, translating stories of the seemingly remote and inaccessible past into a lived and, at times, highly intimate experience of the present. Touching, then, becomes a form of interaction with people who used these objects before, a form of time travel. The story acquires weight and validity through the palpable reality of a physical contact with an object. As an example, for a lot of female visitors this “aha!” moment happened, when, during a tour, I asked them if they would like to try on a corset and a crinoline. Visitors rarely refused, even if in the beginning the suggestion was met with reluctance. There was normally a laborious process of getting the items on and adjusting them, and we talked about what it must have been like to go 
through the mundane work of getting ready in the morning in mid-nineteenth century.

Oftentimes, I produced additional hooks and talked about the process of lacing one's shoes while wearing a corset and a crinoline. When in costume, women almost always attempted to move through the room, some swaying side to side. Some tried sitting down or bending forward, others even attempted a dancing move to really feel what it must have been like - to move through the house wearing these clothes. This led us to a conversation on why the number two cause of death for women in Toronto at the time was fire. A little later, down in the kitchen, wearing the full historic costume, I demonstrated kneeling before the stove to show how the folds of my dress came close to the roaring fire (and the fire is, indeed, roaring at times during the winter months) and then instinctively reached for the fire blanket that is hanging nearby.

This discussion on the sense of immediacy of history achieved through a person-object transaction leads me to my second point, which is that experience of the materiality of the space and objects within it authenticate the story (Dudley, 2010; Latham, Wood, 2011). Merely looking at an object does not produce the same sense of the real, especially in the contemporary age, when visual manifestations are produced with such ease. It is the sensation of the object in one's hand or, in the case of a crinoline, around one's hips, that establishes the validity of a story. For me personally, an educated woman living her everyday life in Toronto in the beginning of the $21^{\text {st }}$ century, reading that so many women used to die from cooking in long dresses was not enough to fully acknowledge the possibility that this, in fact, was true. It seemed highly improbable and absurd in its unfairness. It was the physical motion of kneeling down in a dress in front of the Victorian-era stove, the sensation of the heat of the fire during the cookie-baking workshop at the museum, and the instinctive reaching out for the heavy wool fire blanket that drove the message home. 
The majority of questions I received on a tour were somehow tied to the material objects within the house and material properties of the space: "What kind of wood is that? Was it cheap at the time?" -always accompanied by running one's fingers along the surface of a door). "Was that the original color of the floorboards?" -while tapping their shoe on the floorboards. "Where did they get their water from? Was there a well on the property?" -while considering the size of the tub used for doing laundry. Finally, visitors also frequently referred to how it felt to be inside the house. These remarks were normally tied to questions concerning the Mackenzie House Museum's reputation as one of the most haunted houses in North America. On average, I gave about three to five tours during a single shift, and at least twice during a typical day heard people remark that "it feels cozy in here," "like they were happy here," frequently in context with "it does not feel like there are any ghosts at all." This leads to my final point concerning the implications of person-object transactions in a historic house museum setting: Any immediate experience of the materiality of an object always reflects our own life experiences, something that cannot possibly be strategized by a museum educational program. Within the setting of a house museum, a human-object connection allows visitors to dip into their individual life world experiences that inform their sense of an object, the way it feels to hold it, how they interpret it and understand the story that comes with it. While traditional historic museums, according to Wood and Latham $(2011 ; 2014)$, still have ways to go to fully incorporate phenomenological curriculum into their educational programs, house museums traditionally draw on visitors' lived experiences of the museum space, as well as prior experiences of a domestic space, as a way to enable and frame experiences of heritage. The learning process in these environments is imbedded within the spatial movements within the house and person-object transactions. 
Thus, I suggest that HHMs move the experiences of the past into the domain of the immediate lived embodied encounters of all that constitutes a human subject and all that constitutes an object (Dudley, 2010; Merleau-Ponty, 1962/2004). It is in this coming together, within this communion of the two, that the sense of the real is produced; both history and the lives of the people who used to live in these houses gain buoyancy by, quite literally, gaining tangibility within the site of the lived encounter between an object and a sentient body. In that sense, within the space of the time gap, the material gets to embody the temporal, because this is specifically what it is there to authenticate, to make real. Further, the materiality's ability to make the temporal real is the imperative of the time gap, the quality that enables its heterotopic work. I suggest that this process, through which a temporal alternative truth becomes real within the lived experience of a phenomenological touch (Merleau-Ponty, 1962/2004) as a function of a time gap, be described as the "trump effect."

In his discussion of auditory space, McLuhan (1997) links auditory perception to our emotional life through the relationship between the auditory sense and the instinct of selfpreservation. Hearing is relied on for the sense of continuous awareness (one cannot "close" his/her ears the way they can shut their eyes) about possible dangers coming from the surroundings, and the first reaction is always the emotional one, which is fear. In the case of the sensory sphere, which constitutes a historic house museum environment, the first level of engagement is always the sensory one. When walking into a new room, one examines what it their senses tell him or her about being there first, and attempts to rationalize these sensations second. Historic house museums, then, facilitate a range of learning experiences that originate at the roots of perception. We learn the way children do: By sensing the place first and by analytically rationalizing it second, thus moving the ideas from the domain of the sensory, pre- 
logic experiences of space and objects, into the domain of symbol production. My central argument here is that visitors to a historic house museum get a chance to draw on the pre-logical cognition of the world, the place of wide awareness, in forming a specific symbolically manifested understanding of their heritage. I see two specific properties of a historic house museum space as essential to this process: The sensory nature of the experience first and its playful nature second.

The notion of wide awareness refers to a state in which the mind engages with a multiplicity of sensory signals without consciously filtering them or engaging with the world through a preconceived frame of perception (Milner, 1981). The world is thus witnessed in its as is state. Infants perpetually exist in a state of wide awareness, and young children can access it as well, as can adults after considerable practice. I find that John O'Neill's (1985) definition of a “sensory mind" addresses this notion (p. 44). O’Neill (1985) argues that the sensory mind views the world as a holistic, lived-in cosmos shaped around the needs and properties of humanity, rather than as an object that needs to be managed and quantified. Milner (1981) views the state of wide awareness as an opportunity for in-depth work with the unconscious space within us, since this state of mind allows us to penetrate deeper within ourselves through its uncensored engagement with the external world. One of the important properties of the state of wide awareness, as it applies to time gaps, is that it removes the conception of temporal linearity, since the conception of time as linear is one of the filters the mind uses to make sense of the world ${ }^{34}$. In the state of wide awareness, the world is not conceived of, but is simply perceived. The state of wide awareness, then, can be considered as one of the things that facilitates the work of the

\footnotetext{
${ }^{34}$ Munn (1992) conceives of temporality as a symbolic process that is continually produced and maintained through the practices of the everyday. For more, also see Hodge (2009).
} 
"trump effect" I describe earlier, in which an alternative reality emerges as real through the lived experience of a phenomenological touch.

A visit to a historic house museum, on some levels, represents the inversion of the learning process from being focused on the study of visual properties of individual objects and subsequent analytic work, to emerging from a wide range of sensory experiences. Visitors to a historic house museum are submerged into a sensory "bath:" Instead of encountering objects neatly encased within glass boxes, they become aware of a new range of sounds, spaces that look uneven and weird, smells, light angles, and etc. This sensory submersion is made possible through the properties of a historic house museum as a sensory sphere, as outlined above, and facilitates the emergence of a wide(r) awareness. The invitation to sensory engagement with a new space also normalizes situations in which adults "get" to learn like kids: through sensing first and through thinking about it second.

This state of imposed child-like world awareness is advanced with an invitation to engage with the space and objects within it in ways that are prohibited in a traditional museum setting. Not all adults know how to handle these new conditions and some have troubles gauging just by how much they can alter the conventions. At Mackenzie House, I have heard an interpreter call these people "Curious Georges" in reference to a character of a well-intentioned yet troublesome monkey from a beloved children's book series. "Curious Georges" are adults that go too far in "engaging" with the materiality of the space. They attempt to peek into the rooms of the house where they are not allowed, take a nap on a day bed in the day room, or, in a most dangerous situation, turn the knob of a working gas lamp in passing, presumably thinking that the lamp is there just for decoration. 
Time Gaps and Their Things: Problematizing materiality in regards to a historic house museum space

In this section of the chapter, I focus on how time gaps construct the meanings of materiality. I begin by exploring what are the conditions of the experience of the transient consumable reproducible material objects in postmodernity that are contested within and through the experience of a time gap. Further, I examine how the ways in which spaces of the time gaps and objects within these spaces are experienced (which I unpack earlier in this chapter) implicate the purposes and meanings behind materiality.

Baudrillard (2001a; 2001b; 2012) suggests that the new media have brought on an emergence of cultural forms in which objects and discourses lack referents. This new culture cannot be understood using previously established theoretical conceptions and requires a new approach to make it intelligible. Lyotard (1984) describes this same phenomenon when he suggests that the previously established metanarratives no longer capture this new reality. Baudrillard (2012) approaches this new cultural environment as a linguistic reality, and argues for the need for a semiological model that would explain the newly emergent processes of the construction of meaning. Baudrillard (2001a; 2001b) suggests that new communication forms impact every element of a contemporary person's everyday life. While his central argument evolves through the decades of his work, it is his analysis of how our relationship with objects shifted in the age of postmodernity that I would like to focus on for the purposes of this section. In The System of Objects and For a Critique of the Political Economy of the Sign, Baudrillard (2001b; 2005) offers a critique of capitalism beyond the scope of the Marxist theory of the mode of production, since, according to Baudrillard, Marxism can no longer fully explain the relationship between a person and a commodity. In the age of monopoly capitalism, Baudrillard suggests, it is consumption that functions as a primary determinant of social order. Thus, 
according to Baudrillard (2001a; 2001b), the concepts of use value and exchange value no longer grasp the complete nature of consumer objects, since large companies are concerned with managing demand in addition to lowering the costs of production. He suggests that advertising "codes" consumer objects by assigning them signs and that it is these signs and the relationships between them that now constitute a system that classifies social behaviours and relationships. Baudrillard (2001b) coins the term "sign value" to describe the meaning of an object and of its consumption. Thus, from Baudrillard's point of view, the new social life world is organized around consumption and display of commodity objects, whose sign value is used to assign social status, prestige, and identity to the consumer. For Baudrillard, the realm of sign values is very similar to the linguistic system. Thus, just like words acquire meaning depending on the context, sign values take on meaning based on their positioning.

In The System of Objects, Baudrillard (2005) suggests that consumer objects modify behaviors through the linguistic sign function and, therefore, have to be analyzed through the use of linguistic categories. He applies social semiology to analyse the signified meanings and the systems that they comprise. The site of his analysis is the sociology of the everyday. Baudrillard does not directly address the notion of materiality in his discourse, but he builds a fertile argument for developing one. One of the central arguments in the book is that in the age of capitalist monopoly, "consumption means an activity consisting of the systematic manipulation of signs" (Baudrillard, 2005, p. 218; emphasis in the original). Objects become arbitrary, since their sign values always are, and objects operate as signs. Signs are consumed by virtue of their positioning in the sign system and because of their abstract and systematic differences. Baudrillard argues that sign values take precedence over use values and eventually reconstruct the human life. He notes that material objects are "in perpetual flight (...) towards their 
secondary meanings, from the technological system towards a cultural system" (Baudrillard, 2005, p. 6). Thus, he continues, "the everyday environment remains to a very great extent an 'abstract' system”' (Baudrillard, 2005, p. 6).

Levin (1984) points out that this fetishism of the system comprises a self-referential "closed" system of signification resulting in the loss of personal significance of the experiences of the lived environments and material culture. The domestic environment, for instance, is no longer used to mediate an intimately meaningful personal space. Instead, the material culture is mediating the system of signs. Baudrillard (2005) suggests that these domestic spaces are conceived of in terms of their functionality, rather than as sites that uphold a familiar order of interpersonal relationships and hierarchy. In a traditional bourgeois environment, Baudrillard (2005) writes:

The pieces of furniture confront one another, jostle one another, and implicate one another in a unity that is not so much spatial as moral in character. They are ranged about an axis which ensures a regular chronology of actions; thanks to this permanent symbolization, the family is always present to itself. (p. 13)

I believe the language used here-"confront," "implicate," "jostle"-is intentionally animistic. To Baudrillard (2005), the objects-and the relationships between objects in such traditional environments-personify human relationship and acquire a certain "density," an emotional value. Baudrillard notes that, while functional environments are more open, they are also fragmented into a variety of functions. He interprets this gap between the closed spaces built around the structures of familial relationships and freer, fragmented lived spaces of modernity as "the gap between integrated psychological space and fragmented functional space" (Baudrillard, 2005, p. 17). I suggest that time gaps aim to replicate an experience of a personified lived-in space, organized around hierarchy of relationships and infused with intimate meaning, rather than 
through function, an entry into which is possible only through an intimate embodied experience of it. The organization of the lived-in environment within the time gap is dependent on objects having meaning beyond their sign value or their immediate function. Time gaps appear spaces, where inhabitants were, once, presumably able to be present to their intimate experiences of life and relationships they formed with each other, a space where once felt they could belong.

The questions pertaining to the functions of historic house museums as heterotopias in view of their relations with materiality and spatiality of a domestic space invite a further discussion on the philosophical meaning of materiality in general. This discussion on the thingness of things can take one of the two major theoretical directions. I could follow the more popular route and pursue the theory of things, approach things as artifacts. In its pure form, this line of thought suggests that the physical world is a form of a tabula rasa, which is then infused with meaning when it comes in contact with a social being ${ }^{35}$. Material culture, then, is examined as a "network of homologous orders emerged as the powerful foundation for more or less everything that constitutes a given society" (Miller, 2005, p. 7).

My other option is to attempt to transcend the dualism between the subject and the object (the Cartesian split that Dudley (2010) is referring to, when talking about materiality in museums). This line of thought considers the domains of the imaginary and the ephemeral and leads to the exploration of the plurality of forms of materiality. My argument will follow the latter line of thought, since my discussion focuses not on contemplating a museum as housing valuable artifacts, but as a heterotopia, a perspective that would allow for a study of materiality in its full sense. This broader perspective on how the space of the museum comes to manifest

\footnotetext{
${ }^{35}$ The works by Alfred Gell (1998), Maurice Godelier (1988), Erving Goffman (1975), Pierre Bourdieu (1977), and Ernst Gombrich (1979), among others, could serve as examples of applications of this perspective on materiality in social science thinking.
} 
itself is essential, since its experience is not limited to the ocular-centred examination of objects on display, as I have demonstrated above, but is a lived corporeal experience of a new environment, which involves, among other things, the sense of taste, the smell of an old house, the warmth of a fireplace, and, at times, experiences of unintentional remembering.

There have been a number of significant attempts in the field of material culture to reconsider the boundaries of the material object. For instance, in his popular material engagement theory, Renfrew (2001) marks a shift from Godelier's (1988) perspective on objectsubject relationship by arguing that "mental realities, representations, judgments, principles of thought" (Godelier, 1988, 11) emerge not from within the world of society, which is distinct from the external material world, as suggested by Godelier (1988), but from the interactive engagements of human beings with said materiality. However, even this drastic reconsideration of the nature of object-subject relationship maintains the polarity of mind and matter in exploring these interactions, as the encounters become engagements of matter with incorporeal mind. Gell (1998) focuses on the notion of agency in the discussion on the nature of subject-object interaction and posits people and their intentionality as a primary reference point behind the world of material objects. Thus, an interaction with an object of material culture is interpreted as an interaction with the people who created it. Central to Gell's (1998) discussion is the theory of abduction. In short, he argues that whenever we encounter a social effect, we have a need to attribute the agency that caused it. Finally, Pels (1998) suggests that an object can affect the course of affairs by virtue of its material presence. That is, the things' ability to act back is grounded in their sheer materiality. Pels (1998) describes this logic as "fetishist," where an object is conceived of as capable of affecting the course of affairs through its mere presence. 
My own analysis follows the conceptualization of materiality by Ingold (2007), who suggests that it is the circulation of things through space and time that determines changes in their materiality and endows them with agency. Ingold (2007) writes that "far from being the inanimate stuff typically envisioned by modern thought, materials in this original sense are the active constituents of a world-in-formation" (p. 7). A human being, according to Ingold (2007), is another manifestation of such materiality:

Like all other creatures, human beings do not exist on the 'other side' of materiality but swim in an ocean of materials. Once we acknowledge our immersion, what this ocean reveals to us is not the bland homogeneity of different shades of matter but a flux in which materials of the most diverse kinds - through processes of admixture and distillation, of coagulation and dispersal, and of evaporation and precipitation - undergo continual generation and transformation. The forms of things, far from having been imposed from without upon an inert substrate, arise and are borne along - as indeed we are too - within this current of materials. (p. 7)

Ingold's (2007) take on materiality shares a lot with Merleau-Ponty's (2004) understanding of a human being's lived corporeal experience of being thrown into the world of materiality, of being a body among other bodies. The historic house museum space, then, becomes the "space, in which we reside and to which we relate with our bodies" (Merleau-Ponty, 2004, p. 53).

Both Brown (2001) and Miller (2005) posit that a move away from the object/thing dialectic would allow us to explore the "social life of things," something that Appadurai (1986) described as "methodological fetishism" (p. 5). In his introduction to The Social Life of Things, he suggests that "even though from a theoretical point of view human actors encode things with significance, from a methodological point of view it is the things-in-motion that illuminate their human and social context" (Appadurai, 1986, p. 5, emphasis in the original). Ingold (2007) takes this perspective further still by arguing that “(...) things are active not because they are imbued with agency but because of ways in which they are caught up in (the) currents of the lifeworld" 
(Ingold, 2007, p. 1). Following this line of thought, I approach the question of materiality of the environments of historic house museums by trying to unpack how the objects' thingness is performed: What this thingness denotes and how it manifests itself.

\section{The Thingness of Things ${ }^{36}$}

I will begin the discussion on the meanings and uses of materiality in time gaps by noting that the thingness of the objects on display in historic house museums is not upheld through their value as potential exchange commodities. In fact, museums under question are almost never equipped to house expert-defined valuables. The value and meaning of things within time gaps rests in them having been a part of an era, having belonged to specific people, or visitors being able to pretend that they have. The latter is important with replicas that are used for simulation of life. Thus, the thingness of these objects is determined through their ability to lock in temporality and lend materiality to the people that inhabited the time gap back when it was a home.

The almost magical ability of historic house museums to function as a form of a time machine, or, rather, as time gaps, is, in part, made possible by the things' location within the context of each other and out of context with the outside world. For example, on its own, a Victorian "fire blanket" ${ }^{37}$ is just a piece of heavy wool, but when hung by an 1850s stove it acquires its thingness. In the context of a historic house museum, everything is in its place only as much as everything is out of its place. The things acquire their thingness only by preserving

\footnotetext{
${ }^{36}$ My use of the term "things" (as opposed to "objects") designates them as having an ability-acquired through being placed within the system of meanings that is an HHM-to facilitate the experience of a time gap. HHMs, my work suggests, use things-and contextual relationships between things-as "vessels" for time. Things acquire new narrative meanings after being placed within the house and in the context with each other. As one of my interviewees argued, "we tell stories with things here [...]," a suggestion that agrees with Severs' (2002) description of things at his museum as "a cast of characters" (p. 7). Finally, I suggest that things create the environment for performative behaviors by giving them weight and validity (Nichols, 2008). It is this property of things that I refer to, when I say "thingness" of things.

${ }^{37}$ A blanket used to put out a dress caught on fire, while the woman was kneeling by the stove.
} 
their own temporality while inserted in a contemporary temporal zone. Thus, much like the fetishist system of signs in Baudrillard's discussion mentioned above, the objects within a historic house museum space represent a self-referential system, which, in part, enables the site's performativity as a time gap. It would appear as though this thought follows the argument by Gombrich (1979), who conceptualized a painting's frame as conveying to us the appropriate mode by which we should encounter that which is framed. For instance, we perceive something as art, because it is framed as such, both by a literal frame and an institutional frame. On the surface, this appears to be a rather straightforward perspective on social contexts identifying specific subject-object relation. However, in the case with historic house museums, it is the "thinging" of the things that is allowed to come forward and create a frame for the experience. This "thingness of things" here, in other words, is about constituting the referential point for experiences of time, space, and one's self.

This environment lends the power to shift temporalities to people as well, except that in the world in which people are personified through things, a human dressed in period-specific clothing becomes objectified, a part of a temporal constitution. The reason behind this, I believe, is two-fold. First, it is because nothing can be granted agency to create in the world in which everything that was to be created, was created, everything that was to be spoken, was already uttered, and everything that was to happen, has already taken place. The second reason is that it is the materiality of the environment, rather than the historic narrative, that plays a central role in performativity of these spaces. The people that lived at that time, in this place, are long dead, and it is the material objects that now embody lives, they are the ones that have to lend their own materiality to the lives ended long ago. These people are immaterial, but made material through spaces, the material imprints that they have left behind. A human body, then, becomes what 
Merleau-Ponty (1974) described as "a thing among things" (p. 284). The performing body within the space gap is the body that submits to this environment.

One way of examining the work of making sense of material objects within a house museum would be to describe a house as a self-referential system, within which the location and purpose of one thing explains and validates the other through the narrative of an operative house. Thus, the value, the meaning, and the purpose of the object is determined by its relationship to the house and to the narrative. The objects that allow the other to make sense can be wide apart and their logical links are not always obvious at the first glance. For instance, recreated homes from the 1860s would have metal bed pans in the upstairs bedrooms and hanging salt boxes in the basement kitchens. Both of these items are there because room temperature in Victorian homes was maintained by burning fire. Wood and coal were expenses that needed to be regulated. The upstairs bedrooms were often unused and cold during the day in winter, with lower and middle-class families spending most of their time in the dayroom adjacent to the basement kitchen. A bedpan filled with burning coal would have to be placed between the sheets before bed time. Salt lumps were pounded in a mortar with a pestle to create free-flowing salt. Placing it inside a box attached to a wall close to the fire-burning stove insured that the salt would not absorb moisture from the air and create new lumps.

This perspective on interpreting the coherency of the house space is very much objectoriented and explains the meanings and uses of the artifacts in the telling of the story, but not so much in the creation of the environment capable of functioning as a time gap. What accomplishes that, in part, is the space between these objects. Ackroyd (2002), in his introduction to Dennis Severs' (2002) book 18 Folgate Street: The Tale of a House in Spitalfields, writes: "the air between objects (...) becomes charged with their presence, that 
intangible and ineffable "aura" which holds being together in its capacious embrace" (p. ix). So, what exactly does that mean?

The multiple references to aura in Severs' discourse (2002) on historical objects adds a Benjaminian sensitivity to the discussion and points to an alternative way of addressing the issue of authenticity when it comes to performativity of historic house museums. It is not merely provenance, materials, and craftsmanship. Rather, things are to have the ability to charge these immersive environments with meaning, to enable a different kind of experience of being, of inhabiting one's body, temporality, and the space of the house. Thus, the narrative relationship between objects is but a layer in unpacking what they do to produce the experience of a time gap. Severs (2002), who explored the relationship between objects and time in an embodied way, talks about material objects as a way of unlocking a mood of a time period. For instance, a contemplation of a shape of the milk jug brings on a greater understanding of the same age's fashion and design: “( $\ldots)$ by its similarities to other objects - including architecture and musicI could eventually work out what the mood was that once related them all: the spell which once constituted an 'age" (p. 6). To him, objects became "signposts to the thinking of other times" and "centerpieces to a perception of a time" (p. 6).

I suggest that the charge of historic house museums is the recreation of the mood that once informed the design, function, feel, colors, and purpose of the objects within it; the way human nature once expressed itself through the space of the house and the interplay of the objects it holds. Aura is imbedded in the objects' ability to function as keys to the human nature, telling the story of the time from the inside out (Benjamin, 1940/1986; Severs, 2002). When talking about how the interrelationality of objects expresses itself in the experience of a historic house space, Severs (2002) writes: 
(...) remind yourself of the FOUR DIMENSIONS. The FIRST dimension is back and forth - the SECOND is up and down; both (...) are flat. The THIRD dimension is not flat, but comes forward and goes back to constitute a space between. Within it life happens. (...) The third dimension before you contains something more than space: as thick as treacle - it hosts a foreign fourth. And the FOURTH dimension (...) is Time. So, into Another Time... you go. (p. 11)

The Mackenzie House Museum for years hosted an exhibit of the Rebellion boxes, little mementoes produced by the imprisoned rebels following the Upper Canada Rebellion for their loved ones. The boxes hold within them the unevenness of lines worked by hand, the roughness of the conditions in which they were made, communicating care, memories, dedication, and longing. The narrative of that exhibit focused on the intimate, rather than simply examining it as a representation of voices of resentment to a repressive regime. Much like the unevenness of lines in the Rebellion boxes is needed to take people back into the shared image of a rebellion, a collection of items on a dining room table in a historic house is needed to convey the "messiness of life," the sheer presence of junk charging the in-betweenness of things with life specific to a family long dead. In the context of a historic house museum, a toilet emerges as more significant than a piece of art, because it communicates life in a different temporal dimension, the placement of that toilet within the house makes this life accessible, turns the space of the museum into a time gap that can be accessed. The objects within that space are engaged with from the position of a sentient body of a person with an experience of living in a world populated by things and other people.

This observation is confirmed by a well-articulated longing for signs of life in the home of the long-dead, as expressed by most of my interviewees, to which I referred in the very beginning of this chapter. The question itself - "if you were to do something differently in the house, what would it be?" - was not on the list of the ones that I started out with, but the need 
became obvious quite early on. The question dealt with both personal and professional engagements with stories, objects, and spaces, and yielded the most revealing answers. Since historic house museums negate the divisionary binary between a home and a museum (the point I discuss further in the next chapter), they also negate the division between the personal and professional investment in the experience of the space. After all, how does one maintain professional detachment, when part of one's job is humanization of a domestic space? The answers opened up a yearning for "buzzing" of the in-between spaces, where there did not feel like enough. Consider the following discussion by Ella:

In some ways, I feel like that family is not as present in the house as I would like for them to be. As you are asking the question, I'm thinking: "I don't feel... currently that the stories that I tell... that are specific to the family, not sort of life in general... but specific to the family... are really connected to the space and the objects as much as I would like for them to be." I think the one exception would be the way we reconfigured the dining room, and we've now got Mackenzie and his stuff all over the table. That I find very satisfying. I feel like his presence is really in that space. And I can imagine him there. The rest of the house is not quite full enough. The rest of the house feels very staged. And I know we are having conversations about bringing some mess into the house. I'm just desperate for some mess (...)

Note the use of the word "satisfying" and the comment about how the house "does not feel full enough" to Ella. This points to the fact that she has a clear idea of what a house museum space is supposed to feel like - and that idea is not of a contextualized space that adds up or validates a historical account of what $a$ lived space looked like at a time (it is already that, but that is not enough), but of a space that creates a sense of a life that was capable of leaving traces of an embodied everydayness.

My study has shown that the question of a museological practice that makes possible an experience of life versus a representation of life emerges as a contested point between the museological perspective on house museums and the house museum practice (also see Vagnone, 
Ryan, 2016). As I mentioned earlier in my literature review, the goal of a museum is generally described as conservation, research, and education (or communication). I have also quoted Cabral's (2001) suggestion that "life is not reproduced in a house museum, it is represented like in any other museum, which is, par excellence, the space for representing the world and its things" (p. 42). From that point of view, a house museum is to represent artifacts as documents (Cabral, 2001), and the reproduction of domesticity itself, the arrangement of things, emerges as a document that can be contextualized in the discussion on the evolution of gendered roles in history, for instance. Following this line of thought, the fact that the genre of a house museum 'forces' the space and artifacts to 'freeze' in time emerges as an educational drawback, a failure at contextualizing social history within the continuity of it or in ways that one could engage with critically ${ }^{38}$. Cabral (2001) does pose the question: “( $\left.\ldots\right)$ what movements and associations would be capable of enlightening what had been the space of an everyday experience?" (p. 42) She answers it the following way:

Using the most diverse tools-temporary exhibitions, publications, multimedia programmes, CD-ROMs, audio-guides, staged performances, visits for various age groups, etc.-museums can increase their possibilities for communication, provided that the actions developed from these tools seek a dialogical picture of motivations, expectations and associations. This is because no matter how varied the means, communication resolves itself at the human level, and a museum is a space for human relationships. (p. 43)

While Cabral (2001) describes the museums as a "space for human relationships" (p. 43), her suggestion moves from humanization of a house museum space as the site of the domestic and towards museumization of it. Whereas Cabral (2001) proposes we dialogue with the past from our vantage point in the present, my interviewees suggested we enhance the thingness of time

\footnotetext{
${ }^{38}$ This point is shared with the cultural studies critique of heritage in general. See, for instance Hewison, 1987; Walsh, 1992; Mills, 2003.
} 
gaps to allow ourselves to submerge in the messiness of all that is a humanized lived space. The pursuit of that goal appears to make it worth doing away with some of the traditional issues of museological concern: Authenticity and provenance of objects, historical and social contextualization of the experience of motherhood (in the case of the diapers in the nursery earlier in this chapter) appear as secondary to the imperative to create the "buzz" of life. The range of museological concerns that my interviewees addressed dealt with the accessibility of "junk" (things that would be either reproductions accessible for touching and general use or period pieces that would have been part of everyday life without holding much value outside of their having been part of the age) and the issue of properly maintaining spaces filled with such signs of life. Here is how Ella explained this concern:

It's a challenge (...) Because it is not just how you get the stuff, it's also how do you secure all the stuff. How do you make the space accessible to the public, especially if they are self-guided. Which they sometimes are, right? The other museum I work at, Gibson House... when it was decided that we would allow self-guided tours sometimes, we went through and stripped everything out. It's really empty, because anything that's smaller than a large mug is now gone. Anything that can be easily put into a pocket or a purse is gone. And now it just looks like anybody lives there. At all. (...) It's hard to find that balance. To find the junk of life. And then to make sure that the junk of life does not get stolen.

To further my discussion on the buzzing of life in in-between spaces, I would like to refer back to the quote by Severs (2002) in regards to "the foreign fourth" dimension in-between things, "thick as treacle," what he describes as the essence of time held within his reproduced house museum (p. 11). Han Zhang (2017), who, in her dissertation The Root of Excellence: An interpretive approach to understanding elder care among Chinese Canadians in part deals with the issue of death as a form of impasse in constructing the notion of elder care in transnational contexts, uses Sartre's (1956/1992) metaphor of the experience of honey to explain how aging is grappled with. She suggests we "conceive aging as a phenomenological notion of sticky 
ambiguity that sits in-between articulate forms of interpretation." I would like to use that same metaphor in unpacking phenomenological dimensions of the experience of the very temporality that is outside of the past and the present, what Severs (2002) describes as the "fourth dimension," the space in-between objects (p. 11). This "charge" that is, in part, the interplay of objects and bodies within the space of historic homes, is "sticky:" It clings to objects in the form of imprints worn into wooden handles, or chipped-away paint, or a worn patch on the leather covering of a door leading into the formal dining room, like the one at Toronto's Spadina House. Those are marks of bodies coming into repeated contact with the surface of a door - the elbows of servants who carried trays and dishes. It was the only way to open the door while carrying a tray, but did it give them a sense of satisfaction? The assumed permission to leave a physical mark? To make a sound? Within the time gap, the stickiness of the fourth dimension gets absorbed into one's hair as a smell of fire, penetrates one's skin after an afternoon of working the dough by the open fire. Encountering this fourth dimension is not unlike feeling snow for the first time after a lifetime in a country with no winter. Following Sartre (1956/1992), we can compare it to the experience of a child sticking his or her fingers into this new sticky substance, that is both firm yet liquid, that can both flow and stay still, that has a visible substance of its own and yet passes light.

The encounter with the stickiness of the fourth dimension is a messy business. Embodied experiences appear to precede the intellectual engagement with the museum space. As I entered into the state of mind of a 5-hour cooking shift in the historic kitchen, I felt my body and thoughts slow down, responding to the need to pace my work with the amount of heat emanating from the fire; the change in the quality of the sound space; the need to negotiate my habitual moves with the layer of fabric wrapped around my body. It felt as though my body had been 
thrown into a fourth dimension, and my internal self, my thought processes had to catch up and once there, they located my sentient self-clothed in a different kind of temporality, submitted to stickiness. Severs (2002) appears to have a similar view on these processes when he writes: "we have only to travel in Time to find that one part of us or the other, has already got there and made itself the better part of the Age" (p. 12).

Giving oneself permission to enter into the fourth dimension and then submitting to it can have a dramatic misplacing and unsettling effect. The experience of the sticky "charge" that brings forth a distorted form of temporality can blot out the sense of the present, something that is evident in my own experiences in the kitchen, which sometimes resulted in me smuggling in my phone in an attempt to form an umbilical cord tying me to my own temporality. The fourth dimension is a new land with unclear rules. An engaged participant becomes absorbed by the story, consumed by the time gap, his or her present taken over by this new temporality. The sense of unsettlement, then, can be compared to the fear experienced by characters in novels on time travel, who feel consumed by a different temporality, afraid of never being able to return to the world that is familiar. In my experience, the sense of misplacement experienced by some visitors is a form of a presentiment of that fear.

\section{Materiality as a Way Towards Ontologically Intensive Knowledge}

Because of the nature of the relationship between an embodied self, the space of a historic house museum, and objects within it, meanings frequently emerge within interactions with objects and spaces. Anderson (1982) describes simulation and play as research tools used within the tradition of what he describes as "living history." My experience as an interpreter makes me uncomfortable with his choice of language - "simulation" and "play." Although these probably appear as self-evident to an outsider, they suggest a very superficial level of 
engagement with an object or an activity. To a museum professional, active engagement with spaces and objects within them, the doing of the work, the being within the environments dressed in period clothes are a way to develop an interpretive layer that is inaccessible through passive interpretation. It is serious museum work that requires simultaneously a high level of expertise and an ability to problem-solve on the go.

My first encounter with the phenomenon of what Lash (2010) describes as "ontologically intensive knowledge" (p. 8) in my experience as a historic interpreter occurred during a baking workshop. I was assisting a historic cook who was supervising a large group of visitors in producing a range of baked goods. One of the tedious tasks involved beating half a dozen egg whites into stiff peaks by hand. I watched the cook as she took a bowl with one handle off the wall and pressed it into her waist on her left side, holding it just with her left hand. She used the right hand for whisking and proceeded to walk around the room making sure all cooking assignments were going well. It seemed like an oddly specific use for a bowl and, equally, an instance of expert knowledge of a historic artifact peculiar in its detail. I asked her about it during our interview, and it turned out that the effective use of the oddly shaped bowl came as a result of trials and errors. Whisking egg whites in a bowl atop a low table was very uncomfortable. Pressing a bowl with two handles into her side was painful. This is how one museum professional explained her finding:

I did not realize that's what it was until I was looking around trying to figure out. I thought: "I know we should have a metal bowl. Do we have a metal bowl?" And I saw this metal bowl hanging on the wall and I thought: "Oh... I looked right past it..." So here I am, an interpreter, and that thing has been hanging on the wall for two years before I wondered: "What is it for?" And I think this is a challenge with most of us. Unless we are actually doing it, we walk in, we just say: "This is the kitchen, they did the cooking, it's got old stuff..." But what is it actually for? I did not even bother to ask, until I needed it. So that's why using the kitchen, I think, is very important. 
The continuous discoveries at times come as a result of dealing with a suggested solution that does not make sense, even though it might have been interpreted in a particular way for years. Consider, for instance, the multiple myths ubiquitous in historic house museum narratives. The making sense of a material object, then, comes as a result of attempting to use it towards a successful completion of a goal that is seen as desirable to further the performance of the temporality of the time gap.

I would like to emphasise that it is the encountering of the physical constraints of the materiality of the time gap, the dealing with the limitations they impose on a modern body, and the problem solving that the conditions require that constitute the site of deepening one's understanding of the workings of this temporality and grant an ability to proceed further into it. This kind of relationship with spaces and objects is based on an attempt to answer questions about how other bodies in other times made these spaces and things work and thus functions as another way of entering a time gap, of transcending the temporal divides. A museum practitioner is no longer straddling the imaginative divide between passive and active knowledge, the ideas about a time period learned from books and a first-hand experience of living in one's own home. He or she passes through the picture frame and inhabits the space - even if just for a short period of time. Consider how this interviewee is articulating one of the most mundane of the physical challenges she encounters in her work at the museum:

(...) I remember a couple of months ago ... it was during one of the cooking programs (...). I hiked my skirt with my left hand, and I had one thing in my right hand, and that was all I could do. I can't get up the stairs without hiking up my skirt, so now I have only gotten one hand free, and I just thought to myself: "Well, at night time, if you've got your skirts in one hand... and you've got a candle in the other, that's it." And that has occurred to me many times. I thought: "How can you be productive after dark..." I wonder what they do. Do they just wander around in the dark? Is it that you've memorized the house? Is it that somehow they are better at hiking up their skirts than I am? I don't know what that is. But you know what? Every time I walk up the stairs, I think: "Oh thank God, I am not 
wearing that stupid skirt." Because it just seems incredibly inefficient. Like it's disabling. It's physically disabling.

I find it essential to acknowledge the importance of physical processes, these coming together of modern bodies and material objects and spaces, that happen within a house museum, in understanding the kind of interpretive work these spaces excel at. It is the only profession, perhaps, in which the reflective thinking on the positioning of a dry sink within a kitchen space or the practice of knitting may be understood as ways of deepening one's understanding of historical processes. I have discovered that within the curatorial and research work of historic house museums this is readily acknowledged. For instance, during a meeting for volunteer historic cooks at Mackenzie House, we were invited to contribute insights into the interpretation of the kitchen space as we continued using it. It was not an academic expertise in history that was understood as substantiating the value to our contributions, but the physical work of dealing with heat, water, light, our bodies, and material objects within that space.

Ashleigh offered the following example of how her work in the print shop has helped answer some of the questions in regards to the day-to-day work in a print shop:

(...) myth abounds in the print shop. (...) Proof copies! How they would do proof copies to look for typos. And that never made sense to me, because why waste the paper. These are trained professionals, men and women, who could read type set. Upside down reading was not a problem for these individuals. And I have read enough books published before 1870 and facsimile copies from the $18^{\text {th }}$ and $19^{\text {th }}$ century to know that there are typos. And the only way you would find them is if you did a proof copy. But these typos exist in these books, which would be a material proof that there was no proof copy done. And even some book... was it Christmas Carol? A facsimile copy? You could tell that they were under pressure to get it finished. As the book went along, the number of typos increased. And these are all-because I have had a letter press experience-easy typos, if you have done a proof copy you would have caught. But they would not do a proof copy, because they were in a rush. They were in such a rush, they could not even do a proper copy of proofing the hand set type. And I actually did get a printer in and said: "This is fantastic! You can tell me about letter press printing." And his eyes threw daggers at me, when I suggested proof copies were done. And I said: "No! It makes sense to $m e$ that the proof copy would not be done. But others... (...)” 
The best example, perhaps, of the use of an embodied encounter with a material object towards a deeper understanding of just how things were done has to do with the study of the Rebellion boxes by Chris Raible, John Carter, and Daryl Withrow, who published their findings in 2009 in the book From hands now striving to be free: Boxes crafted by 1837 Rebellion prisoners. An analysis and inventory of 94 boxes. No other rebellion has ever produced anything quite like it: Boxes carved by inmates carrying inscriptions and passed on to their loved ones, almost all produced within a few months following the hanging of Samuel Lount and Peter Matthews. About 125 of them have survived to this day. The visual analysis of the boxes and the study of the inscriptions allowed for a rather superficial understanding of them, since their value does not necessarily lie in the level of craftsmanship. These boxes-carved by hand from firewood-were meant to communicate the commitment to the cause, sadness, love, memory. They were made for the special people in the rebels' lives. The care with which they were designed and made was likely as much a part of the message as the text on the top.

Withrow, a woodworker at Pickering Museum Village and a former prosthetic technician, started replicating the boxes, so that the reproductions could be handled by visitors. Through this work, he concluded that the boxes were not individual projects, which had previously been the general idea, but, in most cases, were the results of collaboration, with each man contributing his expertise. The measurements confirmed to exact imperial rules (for example, 2.5 inches and 3.75 inches), with corners perfectly square and circular details done with the precision of a cutting tool, rather than by free hand. Using the same design for the lid was common as well, with dovetailed edges fitting tightly within dovetailed grooves in the box, so that the lid could slide sideways. Withrow was also able to specify the types of tools that were used by working the same varieties of wood. The study of the boxes - these technical details, inscriptions, 
dedications, engraved initials - shed light on the living conditions of the imprisoned men following the Rebellion of 1837, and extended the message of the boxes beyond the visual study and the reading of the words on them.

\section{Conclusion}

Within the space of the time gap, an authentic reality of the objects and physical spaces is achieved within the site of object-subject engagement, the coming together of all that constitutes a person and all that constitutes an object (Dudley, 2010; Merleau-Ponty,1962/2004).

The constitution of an artifact rests in its relationship with the rest of the places, objects, and spatial circumstances within the house, and is informed by the transhistoricallycontextualized logic of the time slice sustained through and within the time gap. Further, this constitution is informed by the imperative of embodying a life long gone, its work as a "signpost" of its time, a sponge that absorbed the cognitive and affective processes that led to its design and manifested as the spirit of its age. The purpose of this constitution is, in part, the condensing of "the treacle" of in-between spaces (Severs, 2002). Through that, material objects, like vessels, hold what Severs (2002) refers to as the auratic spirit of the time, a process that I would describe as the enabling of the workings of the time gap.

This communion between bodies and things takes place within the sensory space (McLuhan, 1997) of a time gap, the space that can be explored in the state of wide(r) awareness (Milner, 1981). The productive contact with an object (that I refer to in this chapter), the kind of contact that could enable the entry through the "backdoor of history" and into the time gap, is possible through the means of a communicative body (O'Neill, 1985), a body that is used as a measure of the functionality of the domestic space, but also as a means of making sense of its meanings and purpose. I suggest that the kinds of meaning-making processes that the encounters 
between objects and bodies within historic house museums enable, make possible the leap between an embodied experience of an object and the conception of a human condition, an imaginative leap between bodies rooted in different temporalities. These kinds of engagements with materiality, while being authentic, aim to uncover universal truths about how bodies moved in spaces, wore things, made things, ate things. This perspective aligns with Merleau-Ponty's (2004) understanding of a corporeal experience as that of being thrown within the world of things, of being a body among other bodies and things. In the case of time gaps, this corporeal experience emerges as transhistorical. 
CHAPTER III: Emplacement: Playing house in search of home

The nights at the end of October in 2015 were clear and cold, perfect for ghost walks, which are hosted by many of Toronto's HHMs. 2015 was the year I did my research, and that October I went on the ghost tour of Colborne Lodge, a house museum located in Toronto's High Park. The tour also included a walk to the gravesite of John and Jemima Howard, the family who lived in the house. Both of them are buried close by. As Jemima was slowly dying of cancer, through her bedroom window she could observe her gravesite being built. Jemima's pain was managed with hallucinogenic drugs. In order to keep her from wandering through the park (which was more like a forest in the 1870s), her bedroom was fitted with a door that locked from the outside. Indeed, Jemima did not wander far: These days, visitors to High Park frequently see an outline of a female body in the window of her bedroom on the second floor of the house museum. On the night of the tour, a mannequin was installed by that same window to ensure that there would, in fact, be a silhouette visible from the outside, the ghost evidently deemed unreliable to provide one for the tour. The mannequin was dressed in period mourning clothing, which made it even more unsettling, since "Jemima" appeared to be mourning either an unidentified kind of death (who is to die, then?) or mourning her own passing.

Seeing the tour guides dressed in period clothes-long capes, bonnets, dresses-walk through the dark park carrying candle-lit lanterns, felt mystifying even to someone who was taking this experience in with a fair degree of skepticism. Their capes were moving as they walked, the wind making the long ends of the bonnets swing back; the light in the lanterns flickered but never went out. The setting of the park at night made them look almost eerie. The house was lit by candlelight, the corners darkened, deep shadows flickering on the walls. All the sounds of an old home amplified in this darkened space: The creaking of the staircase, the sound 
of the wind outside. All portraits and mirrors in the house were covered, something that the tour guide explained as a Victorian tradition associated with the passing of a family member (in fact, the whole house was set up as if a family member just died). This added yet another uncanny quality to the experience of the house: It seemed that the pictures and mirrors were covered to protect us from the horrors that they kept, as if covering them acknowledged some mystical powers that mirrors and portraits of the departed may hold on the night of Halloween.

The critical engagement with the experience, required of me as a researcher, made me wonder about why most HHM ghost stories hold references to physical experiences: They are always about things that happened to bodies. For instance, people often report feeling sick to their stomach, about to throw up, as they run out of the house ${ }^{39}$. Visual manifestations are not nearly as common as embodied experiences such as "cold spots," smells that sometimes accompany the apparitions, being slapped, accounts of hearing the creaking of floor boards, sounds of steps, knocking, children's laughter, and accounts of lived environments suddenly changing their material properties, as in getting hotter or colder. Finally, the very frequent accounts of simply being "watched" come to mind.

So, it is not so much about what people get to see in the space as how their bodies feel within the space ${ }^{40}$. This reminds me of a story from the Mackenzie House ghost folklore, in which the wife of a manager/curator woke up in the middle of the night to the ghost of a woman in a white lace nightgown hovering above her (back then, the managers lived on the third floor of the historic house). The ghost reached back and punched the woman in the face. In the morning,

\footnotetext{
${ }^{39}$ One of the members of our tour group, a boy of about 12, got nauseous and had to be taken outside by his mother. He said that the feeling "came on" him, as he entered the house.

${ }^{40}$ My own experience of what would have been described as supernatural within this narrative framework also involved a strong bodily reaction with no visual experience to accompany it. I refer to it later in this chapter.
} 
she had a black eye. This assault seems unusually straightforward, but, interestingly, it was not this act of supernatural violence that made the couple eventually move out. After the assault, the woman started feeling as though she was continuously being watched. She could not eat, lost large amounts of weight, and was perpetually anxious. Eventually, the couple had to move. That same idea that a body somehow knows on some base level that it is in the presence of a haunting is especially prominent in stories involving animals. The tour guide shared a story about a dog not wanting to go up the stairs, howling and growling, while staying at the bottom. If one is to consider the ghost narratives from the point of view of a sentient body, the idea of something primal in a human being as being able to recognize the presence of the supernatural at some base animalistic level, before the cognitive function registers the threat, brings up questions about the relationship between a living contemporary body and the space of the domestic as manifested through the HHM.

Further, I observed that ghosts at Colborne Lodge were described as having both agency and a special relationship with the domestic space they presumably occupied as people. For instance, the painting above Jemima's bed was mysteriously left intact during a sprinkler malfunction in her bedroom, which left the rest of the room drenched. The ghosts' investment in things is not something I observed at Mackenzie House, where, apart from a specific chair reportedly rocking on its own, the ghosts go about their business without demonstrating any specific ties to the place or preference for material objects within it. Within the narrative framework of the HHM ghost folklore, however, that apparently was an issue in need of explaining: I have heard several interpreters suggest that it was, perhaps, so, because the Mackenzie House Museum holds only a few objects that belonged to the family, while most of the items at Colborne Lodge were used by the Howards. 
These observations bring up a number of questions about the work of HHMs. The most important one is, perhaps, why historic house museums host ghost walks? There is something about house museums that suggests the presence of ghosts and the freedom to make them part of the HHM experience as borderline obvious. So, what is it, specifically? And further, what these ghost stories (the way people experience the paranormal; the relationship between the ghosts and the objects within the houses, among others) explain about the meanings and purposes of the domestic spaces staged by and within the HHMs?

There are companies in Toronto that do haunted walks of the city, and there are more tours around Halloween. However, none of these companies claims special investment in the depth of their historic research or holds themselves accountable for preserving the sites. Also, none of the tour guides walking the city stays in a single place long enough to form an extended experience of cohabitating with a presumed spirit. While some HHM interpreters deny the presence of the supernatural and avoid the subject altogether ${ }^{41}$ as inappropriate in a museum setting, there are many who openly admit to having had one or several experiences over the years of working at the same place; they also share stories of others', as well as observations of the visitors. The collection of these stories gradually forms a site-specific body of stories that span decades. There are also visitors who partake in forming similar long-term connections with the supernatural of Toronto’s HHMs. My first year at Mackenzie House as a volunteer historic interpreter, I was warned that there are some for whom coming to the museum is a yearly Halloween ritual, and that these are people who are far less invested in the larger historical context. I also had an experience of a mother bringing her children to the museum because she

\footnotetext{
${ }^{41}$ In general, HHMs specifically avoid conversations about ghosts if the descendants of the family whose life they interpret are still alive. Toronto's Spadina House Museum is one such HHM.
} 
herself once had a ghostly encounter there as a child. That experience affected her deeply, and she wanted to share that with her children.

Thus, there appears to be a relationship between house museums (or the way people conceive of them) and the spirits that are no more. These houses, while straddling the boundary between the lived-in and the abandoned, make home for the uncanny third: They emerge as spaces that hold neither life nor death; where objects can hold time by serving as embodiments (vessels) of and for memories. Lindbergh (1991) in The Gift from the Sea compares one's home to a whelk shell, a structure that corresponds to a body's unique shape and needs, built to hold it in, while comprising a boundary from the outside world. Mallett (2004) echoes this metaphor by referring to a home as an "intimate shell of our lives" (p. 83). A shell abandoned by a snail does not seem eerie: Its natural purpose is to be ground into dust with the passage of time, contribute to something else. In its abandoned form, it is aligned with the natural stage in its decay. There is nothing natural, however, about the way HHMs preserve the "intimate shells" of lives that ended over a hundred years ago (Mallett, 2004), which is why in this work I refer to them as artificial transhistoric recreations of domestic spaces. The clothes that warmed those bodies were supposed to rot - so why are they laid out neatly on the bed? The mice were supposed to die out, so there is no need to keep the candles in the special boxes nailed to the wall in the kitchen. The wallpaper was to hang in pale strips, the glue loosened by decades of humidity, the colors burnt out by the sun. The bodies are gone, but bodies' extensions into space (clothes and walls that kept them warm, spoons that fed them, books that excited them) are still there. If HHMs did not normalize this kind of preservation, it would seem macabre. The eeriness of HHMs is similar to the uncanny of a whelk shell that continues its journey across the ocean floor, even though the snail has decayed. 
Considering that I have identified intimate everyday objects as extensions of bodies into space, perhaps it would be helpful to use one of Vidler's (1992) examples of the uncanny, and compare the maintenance of life in an HHM to the movement of limbs unattached to a body. Thus, I suggest that HHMs still maintain the metaphorical transhistoric movement of an "intimate shell" across an ocean floor (Mallett, 2004); they work to maintain the movement that is the life of a home. Here, the memories of lives continue on in the dimension that is beyond the agency of the living, granting this agency, instead, to the house and the objects within it. ${ }^{42}$

The questions that stand before me, as I begin my discussion in this chapter, are: How do HHMs problematize the notion of a home? And, further, how does their interpretation of a home enter into the broader theoretical analysis of HHMs as sites of emplacement? How does one negotiate the relationship between the public and the private; a curated museum and a performed, experienced home, that, I suggest, come together in the experience of an HHM? In other words, how does one separate a home from the house, and does one do that to begin with? Finally, what constitutes the heterotopic work performed by time gaps as sites of emplacement?

I use the examination of a transhistoric reconstruction of a familial home as my analytical entry point into the study of the meanings and workings of emplacement. I review literature on the meanings of home in an attempt to explore which experiential triggers and symbolic markers in the Anglo-European imaginary HHMs draw on to invoke the idea of a home. I ask: How do we engage with the sense of a home? And what constitutes the movement of the shell across the ocean floor; in other words, what are the markers of the maintenance of a domestic life? I

\footnotetext{
${ }^{42}$ The failure to comply with the universal law of living and passing is unsettling and confusing enough, perhaps, to become one of the themes the museological genre that are the HHMs are described in relation to. For instance, the BBC documentary on Dennis Severs' house is titled "The House that Refused to Die."
} 
suggest that, since HHMs are artificially constructed sites of emplacement, their interpretation and performance of a domestic space invites an understanding of a home as a poetic metaphor, a shell for a set of ideas and meanings, rather than lived experiences of personal lives and familial kinship. This idea of an HHM as a poetic metaphor for a home further explains my articulation of time gaps as instances of construction of sites imbedded with anthropological meaning, which mark where the community is and where it belongs by imbuing a site within the geography of a fractured metropolis with communal meaning.

Whenever contemporary scholarly literature addresses the issue of emplacement, it is always discussed as something that is lost or is disappearing, and in context with the discussion on the properties of its opposite, a location, a space stripped of its anthropological qualities (see, for example, Augé, 1995; Entrikin, 1991). I believe my research to be quite a unique opportunity to weave a narrative of what I believe is a recreation of an anthropological place in postmodernity that not only is not disappearing, but, quite the opposite, is gaining momentum as a form of contestation of the prevailing model of uses and functions of space in a metropolis. For the purposes of this project, I define emplacement as a creation of a site that reflects the hierarchy of communal meanings in their relationship with the past. The questions I ask to further unpack this in relation to my thesis are: How is a historic house museum different from the location of that same museum? If it is, in fact, different, and if the element of emplacement is crucial to the performance of a site, what does this place embody and what are the elements that have to come together for it to work? In other words, how does one create a place out of a location of a historic site? How does one maintain that? My analysis attempts to uncover markers that identify historic house museums as forms of emplacement on the levels of the day-to-day experience of it, of the interpretive narrative, and of administrative management of the site. 
In chapter two, I considered how time gaps problematize materiality and attach meanings to the physical space of the house and objects within it. In this chapter, I draw on this analysis and further consider how the things' ability to function as vessels for an alternative temporality, and their coming in contact with bodies and with each other, help produce and condense the meanings of emplacement. In other words, I consider what contributes to the symbolic and experiential potency of time gaps as sites of emplacement. I suggest that from the point of view of their heterotopic function, time gaps create a sense of hierarchy of places in the urban space that is repetitive, fractured, and hostile. On the level of the communal, these sites function as anchors that ground the city in an idea of a shared past. Experientially, they serve the function of affording these same experiences on the plateau of a sentient body living its day-to-day life: These sites are places that affirm that space is not infinite, but is made sense of within the constraints of one's ideas of a domestic world. Their primary function is to arrest the flow of time, to condense it as a substance thick with meaning. The tragedy of this specific heterotopia, however, rests in the fact that it is attempting to subvert the meanings of space by appropriating it, delimiting it and formalizing it, which is the only way to utilize and inhabit the space in the era of postmodernity. It is precisely the kind of a relationship with the idea of space that the experience of emplacement precludes.

Following this line of thought, my analysis in this chapter will address the issue of emplacement on four levels. First, it will consider the experiential ways of being that these spaces produce and maintain. Here, I build on the idea of a communicative body (O'Neill, 1985) as a way of studying the experiential within an anthropological place. Second, I consider types of social relations that these built environments evoke in the case of historic house museums. Further, I present my observations on how the staff appear to negotiate the relationship between 
the kind of temporality performed by a time gap and the temporality external to the space of a house museum. Finally, I discuss historic house museum sites as instances of the uncanny. Thus, my discussion will progress from considering the body within the space of a built environment, to the types of spatial relationships these environments foster, to discussing the performativity of sites of the domestic as instances of social and cultural imaginary. The central conceptual point in this chapter of my dissertation is the study of emplacement as instances of anthropological projection of the body onto its lived space.

\section{Locating Home in House Museums: Review of literature on the domestic space}

There have been several attempts at developing a comprehensive overview of academic discourse on home in the past several decades, either in the form of literature reviews or anthologies of interdisciplinary writings on the domestic space (see, for instance, Briganti, Mezei, 2012; Despres (1991), Mallett, 2004; Sommerville, 1997). I have observed a general agreement on a number of a key ideas. The first point of agreement is that the interest in exploring the domestic in academic discourses, and also in literature and in art, that emerged in the past two decades, is due to cultural experiences associated with nations becoming a part of global and transnational economies (see, for instance, Briganti, Mezei, 2012; Mallett, 2004). In other words, these discourses emerge in contestation to the larger economic processes and the impact they have on our day-to-day life. Second, the academic discussion on the meanings of home acknowledges the multi-dimensional nature of the subject matter, the layering of the social, emotional, political, and experiential (Briganti, Mezei, 2012; Mallett, 2004); and that a comprehensive perspective on the meanings and purposes of home need to account for this complexity through an inter-disciplinary approach. Saunders and Williams (1988) address this issue when they state the following: 
Precisely because the home touches so centrally on our personal lives, any attempt to develop a dispassionate social scientific analysis inevitably stimulates emotional and deeply fierce argument and disagreement. The home is a major political background-for feminists, who see it in the crucible of gender domination; for liberals, who identify it with personal autonomy and a challenge to state power; for socialists, who approach it as a challenge to collective life and the ideal of a planned and egalitarian social order. (p. 91)

Mallett (2004), in her review, takes a conceptual step back and, instead of considering ways of discussing the idea of a home specific to a number of disciplines, asks: Is home "(a) place(s), a space(s), feeling(s), practices, and/or an active state of being in the world? (p. 65). Her review, then, explores the different ideas that a domestic space serves as a repository for in the AngloEuropean imaginary. Thus, she covers such issues as an ideal home, the conflation of the ideas of a family and a domestic space, gender, and journeying, among others. Briganti and Mezei (2012), whose work is an anthology of writings on home titled The Domestic Space Reader, consider the idea of a home from the point of view of the relationship between an individual and the spatial, cultural, and historical context he or she is in. They subdivide their anthology into the study of liminal spaces, gendered spaces, house and a psyche, and interiors, among others. What is theoretically significant in these explorations of literature on the domestic space is an understanding of a home that conflates the notions of a dwelling, a household, and a social unit that it holds, an approach possible only through an interdisciplinary prism, an approach that Mallett (2004) describes as "a complex view of home that takes into consideration the interaction between place and social relationships" (p. 69). This perspective is very new in the field that, until very recently, has been preoccupied with the study of a home as a physical structure (the most telling example of this approach would be Rybczynski, 1986. Also see Rapport \& Dawson, 1998; Porteous, 1976). Carsten and Hugh-Jones (2005), for instance, suggest that "much of the more comparative and theoretical work on the anthropology of architecture has been done not by 
anthropologists but by architects and art historians (...). One reason for this neglect is that houses get taken for granted" (p. 3).

This understanding of the meanings of a home in relation to the social structures they maintain and are maintained by, both inwardly and outwardly (see, for instance, Giddens, 1984; Saunders and Williams, 1988; Pahl, 1984), is one of the theoretical challenges I face, when considering HHMs in relation to the literature on the domestic space. The interdisciplinary view of homes generally considers them as constructed by and maintained through lived relationships of kinship. For instance, Saunders and Williams (1988) define home as a "simultaneously and indivisibly a spatial and a social unit of interaction" (p. 82) that emerges through the coming together of the physical shell of the abode and the social unit that is a household (also see Giddens, 1984). They further suggest that the physical features of home "both enable and constrain" behaviors and relationships (p. 82). They take their argument further still by arguing that a home is, thus, the physical "setting through which basic forms of social relations and social institutions are constituted and reproduced" (p. 82; also quoted in Mallett, 2004). This definition centres around the assumption that the very existence of a home is a result of the practices of kinship. The social structures of kinship that the homes maintain and are maintained and structured through are forever in flux, which determines the living and the passing of a home. For instance, Massey (1994) suggests that "no single simple "authenticity"-a unique eternal truth of an (actual or imagined/remembered) place or home-to be used as a reference either now or in the past" (p. 199), since a home is constituted through social relations that take place within a location, and is thus continually evolving, its boundaries unstable (for more on this, see Rapport and Dawson, 1998). 
There are few things more stable and less affected by the flux of social changes outside its walls than the arrangement of artifacts within an $\mathrm{HHM}^{43}$. Further, historic house museums are curated to structure and maintain the familial hierarchy and the meanings of the relationships that are no longer. If anything, from the point of view of being a "home" to somebody, they are staged to be imprints of dead bodies onto their external world. Thus, they are immune to change. The relationships of kinship are embodied in objects and through the organization of the domestic space at the HHMs (the process made possible through the trump effect ${ }^{44}$ ), and not through lived experiences of kinship. I suggest that one of the aspects of the heterotopic work done by HHMs is the maintenance of the symbolic markers of a traditional familial household in the world, where the family as the "kinship system has arguably declined in significance as a structuring principle of social life" (Saunders and Williams, 1988, p. 82). Thus, the value of the home rests specifically in its ability to withstand change. It can be argued that one quality of a house is to give meaning to (or to interpret) the passing of time, while providing a physical and an emotional shelter. In a way, by advancing the notion of a time gap, I make a similar point, except the home providing shelter does so not by helping one make sense of change by situating it within the continuity of time, but by pretending the change is not happening.

A good example to illustrate this discussion on the meaning of familial kinship in relation to the blurriness in HHMs' transition from a familial home to a form of domestic emplacement performed through the work of the time gaps, would be the fact that, in some HHMs, interpreters

\footnotetext{
${ }^{43}$ While HHMs present as homes, the recognition that they are staged projects created to represent an idea of a historic home is central to the analysis of these sites. While changes do take place within the interior of the museums, they are not reflective of the changes in the relationship of kinship of the people who occupy them, but of their function as museums.

${ }^{44}$ In Chapter 2 of this dissertation, I describe the process through which a temporal alternative truth becomes real within the lived experience of a phenomenological touch (Merleau-Ponty, 1962/2004) as a function of a time gap. I describe this property as the "trump effect."
} 
do not dress in costume and do not partake in story-telling about the paranormal, specifically because the descendants of the family that used to live in the house are still alive. One instance of such a house in Toronto is Spadina House. These HHMs are within the blurry phase between being a childhood home to someone still alive, and a creative project of constructing one through interpretation and curation. This difficulty suggests the relationship between a creator and a project that is a home, the making sense of it within the framework of meanings attributed to the relationship between the familial unit and the domestic space it occupied.

\section{Historic House Museums as Makers of a Home}

The question, then, becomes: How do historic house museums problematize the notion of a home? Based on my discussion on HHMs and nostalgia in Chapter 1, it seems as though considering time gaps as the homes one longs for, rather than inhabits (see, for instance, Chapman and Hockey, 1999; Wright, 1991), would answer my question. Tucker (1994) notes that "most people spend their lives in search of home, at the gap between the natural home [conceived as the home environment conducive to human existence, i.e. dry land] and the particular ideal home where they would be fully fulfilled" (p. 184, emphasis in the original) ${ }^{45}$. I think that, with very few exceptions, most HHM staff members and most invested visitors would not consider a house museum as their idea of an ideal home they would want to inhabit. The world of phantasy-the staging of it, the pretend inhabiting of it-does not have to align with a

\footnotetext{
${ }^{45}$ One of the ways in which literature on the subject of the ideal home considers what I, following Tucker (1994), describe as a gap, is as tension between what is and what could be. Sommerville (1992) goes as far as suggesting that this tension between an ideal home and a real home is imbedded within its very notion. Jackson (1995) identifies one's home as the very site of tension, when he writes: "[Home] is always lived as a relationship, a tension... [L]ike any word we use to cover a particular field of experience, [home] always begets its own negation... [It] may evoke security in one context and seem confining in another" (pp. 122-123).
} 
desired version of reality, just a version of reality that has a purpose to serve at that particular point in time.

I suggest that the very gap between the two-the home that is inhabited and one's ideal home-is the space of the yearning, where the imaginary takes over. This gap could be bridged through the experience of pretend time travel, by engaging with the place that carries the markers of familial togetherness and of a time associated with permanence of moral and relational values. My argument is that HHMs can thus be studied as poetic metaphors for a version of a domestic space one yearns to experience, a metaphor located within the gap between the home one longs for and the one occupied.

Garber (2001), in Sex and Real Estate, addresses this gap as a kind of a longing, the romancing of a dream, when describing home as an actuality of the diverse desires in people's lives: Home as a mother, as a lover, as a place of escape, as a place where one's personal history takes place or is tied to, among others. She points out that domestic spaces can also be manifestations of unfulfilled desires, when she writes: "Perhaps increasingly, for busy people, space has come to substitute for time, and the house becomes the unlived life. (...) The place where we stage the life we wish we had time to live" (Garber, 2001, p. 207). Home, thus, emerges as an actuality of the life that does not get lived, a place that represents desire that postmodernity creates, but does not allow one to fulfill in the reality of day-to-day life. The dreaming of a life that is structurally different is the work of imagination. In considering HHMs as poetic metaphors for an idea of the domestic, I suggest that HHMs function as physical manifestations of a phantasy, which satisfies desires that go unfulfilled in postmodernity. As any kind of an imagining, they are results of creative labor. My discussion on time gaps and emplacement in this chapter, then, becomes about exploring the kinds of imaginaries these 
staged domestic spaces are there to fulfill and the aspects of emplacement and home-making they draw on to construct what I describe as a poetic metaphor.

\section{Home and $a$ body/psyche}

Another theme in the academic discourse on home that I need to engage with in my analysis is the discussion on the home, the body, and the psyche. This literature explores the relationship between a person's embodied and socially/historically contextualized self and the domestic (see, for instance, Adams (1996); Burbank (1917/2012), Gilman (1899/1980), and between a person's psyche and the experience and meanings of a home (Freud; 1953; Jung, 2012; Vidler, 1992) I organize this section of my literature review along these theoretical lines. From this point of view, the home emerges as a metaphor for a body, a place that is an extension of it, its growth into the world, or a metaphor for a mind. The exploration of the domestic, thus, becomes an exploration of an individual's inner self.

Freud (1953) is the first thinker to have introduced the idea of a lived-in space as a subject of oneiric experiences in his essay "Representations by Symbols in Dreams - Some Further Typical Dreams" and thus opened the door to the exploration of the relationship between the psyche and a home. In his 1919 essay “The Uncanny," he, for the first time, explains the notion of a core sense of the imminent dread that rests within the very heart of spaces that we hold as intimate and trustworthy, the sense of what Vidler (1992) describes as a "disquieting slippage between what seems homely and what is definitely unhomely" (p. x). Examination of historic house museums as sites of the urban uncanny offers an intriguing perspective on the workings of the uncanny in the age of fractured urban postmodernity. These sites emerge as intuitively recreated instances of emplacement endued with a range of qualities of a familial domestic space, ghosts and all. Analytically, the idea of the uncanny has a potential to unpack 
some of the relationships a modern person develops with the urban environment, the kinds of spaces he or she seeks out and the way they are used. Once identified, however, instances of the uncanny can be analyzed as symptomatic of specific relationships we form with spaces within a fractured city scape.

A visitor who walks through a house museum can normally see personal everyday things abandoned as if their owner had to step out due to some emergency and is about to return. A shaving razor may be resting next to a pot filled with water; ingredients for bread making may be laid out on the kitchen table in front of the hot stove; lacy nightgowns are at times left on the bed in the room where girls lived in the 1860 s; an embroidery is resting on the table, waiting to be finished. Looking at the objects that represent human experience can be as uncanny as looking at a human body objectified in the form of a museum attraction. The intimate experience of one's daily rituals is carved open for everyone to see. It does not have the protection of glass; it is not made into an object of art by somebody's expert-opinion. Instead, it is an extension of someone's body, a projection of an experience of someone's body into the material space of his or her domestic environment. What makes this experience of the uncanny even more powerful is the fact that this somebody has been dead for quite some time.

These objects, and one's presence through them, appear to have overcome the natural course of events from life to death. They are very much not dead, but also not wholly alive. It deprives visitors of the loss, makes it look as if life can still continue on some unknown terms. A visit to a house museum is thus a phantasmagoric process that asserts the existence of life beyond that in the present. It offers to bring the past back, suggesting that the past can be reanimated, relived, re-tasted, re-smelled. The theme of the uncanny is one of the Anglo-Saxon imaginaries I explore further in this chapter. 
Jung (2012) critiques the Freudian take on the relationship between the psyche and a home in his work "Memories, Dreams, Reflections." He describes a dream in which he descends from an upper story of a house furnished in a rococo style down to the cellar, evocative of Roman times. Jung (2012) uses the lower levels of the house as an allegory for a primitive self, and the upper floors-for his conscious self, thus describing a domestic space as an archetypal symbol of the self ${ }^{46}$. Several authors further unpack the notion of a home as a symbol, an expression, or a way of building of the self (see, for instance, Cooper, 1976; Despres, 1991; Tucker, 1994; Havel, 1992).

Garber (2001) discusses the origins of the idea of a human body as a measure for architectural design in history. She quotes Vitruvius (born c. 80-70 BC, died after c. 15 BC), a Roman architect, who prescribed that the proportions of a human body be used as a guiding principle for building temples. She further refers to the work by Plato, the Bible, and a medieval treatise on the interiority of the body and a home. In this discourse, the body is conceptualized as an instrument of measure of the built environment, and the architecture emerges as following the natural design - at times as inspired by the design. Further, the relationship between a house and a female body is one of the prominent themes in the literature on the domestic. In 1917, Emily Burbank, in Woman as Decoration, described a female body as an element of the domestic interior, "an important factor in the decorative scheme of any setting - the vital spark to animate all interior decoration, private or public" (p. 130). This perspective betrays the idealized view of the house as a female domain, prevalent in the $19^{\text {th }}$ century. Adams (1996), who studies Victorian views on the relationship between childbirth and the architecture of the house,

\footnotetext{
${ }^{46}$ Cooper (1976) works to unpack Jung's (2012) articulation of a house as a universal archetypal symbol for the self in her article "House as Symbol of the Self."
} 
describes the lying-in room (a room dedicated to childbirth and the month following it) as a "symbolic and a visible extension of the mother's body, an observable space through which doctors could expand the conceptual limitations of the body" (pp. 103-104). This equation of a female body and its health with the structure and the workings of a house is especially prominent in the advice from an issue of an 1889 Women's Penny Paper. Pregnant women were encouraged to check the sanitary state of their house, especially the drainage pipes and ventilation. "You who breath such air, breathe in what is poisonous, and this poison is racing through your blood into every limb in your body with every breath you draw!" (Florence Stacpoole, "Maternity Rules for Mothers' Meetings," Women's Penny Paper 6, July 1889; p. 4; quoted in Adams, 1996) ${ }^{47}$.

The Yellow Wallpaper by Charlotte Perkins Gilman (1899/1980) is an important text to review in this context, both from the point of view of the literature on the relationship between a female body and a home, and from the point of view of the discourse on the uncanny. In this short story, Gilman (1899/1980) describes a young woman's descent into psychosis in a firstperson narrative. Deprived of the ability to work by her physician husband as a form of recuperation following childbirth and restricted to a room (a former nursery), the narrator becomes preoccupied with the color and the pattern of the wallpaper, in which she sees other women, trapped. The woman's descent into madness is not a result of the unknown terrors dwelling within her psyche and within the familial home, which would be a traditional plot in a Gothic horror story. Instead, it is a consequence of repression and isolation, a theme that allows one to consider the piece as a feminist commentary on the theory of the uncanny and establishes the feminist view on the site of the domestic as manifested oppression, rather than the obscure

\footnotetext{
${ }^{47}$ Teyssot (1984) is another author who writes about the $19^{\text {th }}$-century identification of a house with a body. His discourse in particular centers around the house as an extension of the epidermis and the $19^{\text {th }}$-century fear of dust mites and miasmas.
} 
horrors of one's familial home. Since, in this chapter, I explore HHMs as a poetic metaphor for a home, rather than a domestic space organized through experiences of kinship, what I interpret as Gilman's (1899/1980) commentary on the uncanny, while important to mention here, does not directly impact my articulation of the meanings and purposes of domesticity as employed in the work of $\mathrm{HHMs}^{48}$.

Diana Fuss (2012), in her essay The Sense of the Interior: Four Writers and the Rooms that Shaped Them, suggests that "to attribute substance and materiality to architecture, and imagination and metaphor to literature, misreads both artistic forms." And that when we disrupt "the too easy bifurcation between literal and figurative space," "the seemingly intractable distinction between literary metaphor and architecture reality [...] quickly falls away" (p. 346). She quotes Heidegger (1997), who, in Poetically Man Dwells, suggests that a poem is a kind of building (an "original admission of dwelling" (p. 112)), and Bauchelard (1997), who, in The Poetics of Space, identifies a house as "one of the greatest powers of integration for the thoughts, memories and dreams of mankind" (p. 84).

As I have mentioned earlier, historic house museums are frequently used as sites for artistic installations and performances, in which the creative art itself becomes integrated within the site, feeds off of its interpretation of a temporality and cultural meanings. The dwelling is used as a creative tool in composing the story of lives and bodies emplaced-through dance, theatre, and story-telling, among others. These staged public performances have everything in common with the creative work done by interpreters and engaged visitors. When describing HHMs as a poetic metaphor for a domestic space, I refer to the creation of a site and of the

\footnotetext{
${ }^{48}$ For the same reason, in situating my discussion on HHMs in its relationship to the literature on home, I do not engage with the body of discourse on home as a gendered space (see, for instance, Cohen, 2006; Crenshaw, 1994; Hooks, 1991; Hunt, 1989; Van Herk, 2012; Young, 1997).
} 
experience of it through creative labor. Borrowing a word from Bauchelard (1997), I suggest that, from the point of view of the academic discourse on home, HHMs could be understood as a form of integration of a dwelling, objects within it, a story, and a performing body ${ }^{49}$. In this chapter, I suggest that, as far as the construction of the sense of a home is concerned, a historic home is a creative and embodied labor, rather than a purely intellectual pursuit, because one draws on the resources of the shared and intimately personal imaginary and lived experiences to fill it with meaning.

In the introduction to this dissertation, I quote one interpreter's explanation of why she refers to HHMs as "homes" rather than "houses. ${ }^{50 "}$ In it, she suggests that the visitors understand the lived space better, connect to it differently, if they imagine themselves living in a historic home. This also suggests that a visitor is offered the creative position of someone who could infuse the space with personal meaning as a way of making sense of it. I suggest that the creative labor of the imaginative leap activates the time gap, making the heterotopic work possible ${ }^{51}$.

\section{Emplacement: Literature review}

In this section, I unpack the position of my discussion in relation to the academic discourse on emplacement. My overall argument in this chapter is that HHMs are artificially created forms of emplacement and that the staging of a domestic space (or an idea of a domestic space, if we consider HHMs as poetic metaphors) is one of the ways of creating one. In fact, if one were to attempt to create a place that reflects the hierarchy of communal meanings in their relationship with the past, which is how I define emplacement in this work, a home would be the most obvious form to draw on. In that sense, the creation of a domestic space that represents

\footnotetext{
${ }^{49}$ I unpack the notion of a performing body in Chapter 4 of this dissertation.

${ }^{50}$ I would also like to add that, from my experience, the two terms, "historic homes" and "historic house museums," in administrative sources and in professional conversations are frequently used interchangeably.

${ }^{51}$ In my earlier discussion, I use the words "active willing engagement" to describe this process.
} 
some aspect of the community's past is the logical way to mark where "we" are as a group within the geography of an occupied space. It is poignant, then, that most HHMs in Toronto, which is an important gateway for newcomers to Canada, once served as homes to first generation immigrants. In other words, HHMs mark off sites of communal meaning within the alienating and fractured urban space, by creating homes that mark the beginning of one's life ("Home is where one starts from," T. S. Eliot suggests in Four Quartets), but also of the beginning of the nation.

As I have mentioned earlier in this chapter, the academic discourse on emplacement frequently defines it as something that is disappearing and in opposition to places devoid of communal or cultural meaning (see, for example, Augé, 1995; Entrikin, 1991). To begin my discussion on the meanings and the makings of emplacement, I would like to outline the properties of both places and non-places, as they have been discussed in literature up until now.

Theories of emplacement are a result of a relatively recent shift in spatial theory and are marked by the growing recognition of the concept of built lived environment as a political, economic, cultural, social, and experiential construct and an important factor in social interactions. The beginnings of the shift ought to be traced to Henri Lefebvre, who introduced the idea of social relations as being produced and transformed through space. Lefebvre's work (1992) positions the daily life as linked with the production and consumption of different spaces; and the process of being as implicitly connected to space.

Lefebvre (1992) posits that space is a complex social construction, which affects everyday practices and perceptions. Philosophically, he approaches space as something that is both material and social, "a set of relations and forms," and describes social space as emerging as a result of social interactions and as the means to reproduction of social relations of production 
(Lefebvre, 1992, p. 116). Thus, to Lefebvre, a social space is simultaneously a mental and a physical construct and is occupied on both of these levels. He conceptualizes space as not a physical container that holds society, informing its structure through the means of its materiality, but as an inscription of social practices, a manifestation of the social order that both informs practices of social life and is informed by them.

Lefebvre (1992) recognizes a three-part dialectic that informs the production of the social significance of space: everyday practices and perceptions (l'espace perçu); representations, theories, or ideas about space (l'espace conçu; maps, city plans); and the spatial imaginary (l'espace vecu). Since a social significance of space is constituted through the process of interaction, any analysis of space, according to Lefebvre, should consider the question of power and authority: "(Social) space is a (social) product [...] the space thus produced also serves as a tool of thought and of action [...] in addition to being a means of production it is also a means of control, and hence of domination, of power" (Lefebvre, 1992, p. 25).

Lefebvre's (1992) work was a philosophical critique of capitalism through the discussion of everyday practices and production of social space. This introduction of spatial critique as a vector in theory of modernity was ground-breaking, since, arguably, up to that point most historians tended to disregard space as a determinant in the unfolding of history and interpret meanings and actions from the point of view of their temporal constitution. The sociological perspective on a human being, then, was reduced to the examination of "the intersections of history, biography, and society" (Soja, 1989, 139) ${ }^{52}$. Thus, modernity was largely discussed as a temporal problematic, a totalizing narrative, unconcerned with particularities of place.

\footnotetext{
52 Jameson, for instance, notes that "all isolated or discrete cultural analysis always involves a buried or repressed theory of historical periodization" (Jameson, 2006, p. 409).
} 
The lack of "spatial imagination" in academia and its benefits as a method of historical and sociological analysis are addressed by Soja (1989), who unpacks it as a form of simultaneously historical and geographical materialism. Soja opens by arguing that the privileging of time and history over space and geography has led to an understanding of modernity as age, in which traditions are destroyed and replaced. Spatial imagination, on another hand, allows for consideration of modernity as the time of complex reorganization of temporal and spatial relations, a point also advanced by Lyotard (1984). This shift in perspectives, according to Soja, can be a generative source of new critical theory.

Soja defines spatiality of social life as "a practical theoretical consciousness that sees the lifeworld of being creatively located not only in the making of history, but also in the construction of human geographies (...)" (Soja, 1989, p. 136). He further suggests that the empirical dimensions of human existence are bound by socially constructed abstracts of time, space, and social being, a perspective very much in line with Harvey's (1985) discourse on the relationship between capital and lived environment. The spatial order, Soja continues, "arises from the (social) production of space, the construction of human geographies that both reflect and configure being in the world" (Soja, 1989, p. 25). This spatial turn in critical theory, according to Soja, does not negate the importance of historical analysis, but instead suggests that analysis of the spatial order of societal life could work as a complementary axis. In addition to spatiality and temporality, Soja describes the third variable, the social conditions of being-in-theworld, as the personal and collective experience of life resulting from "the constitution of society, the production and reproduction of social relations, institutions, and practices" (Soja, 1989, p. 25). 
Foucauldian discourse on space provides an important dimension to the discussion at hand. Foucault (1986), who famously pronounces history as "the great obsession of the nineteenth century" (p. 22), also suggests that "the present epoch will perhaps be above all the epoch of space" $(1986,22)$. He unpacks this point by saying that "we are at a moment $(\ldots)$, when our experience of the world is less that of a long life developing through time than that of a network that connects points and intersects with its own skein” (1986, p. 22). Drawing on this perspective, Foucault develops a spatio-temporal configuration of history, in which an analysis of temporality becomes entwined with the study of the social production of space. In a way, Foucault $(1984 ; 1986)$ cuts open the study of history to the study of interpretive geography. His idea of heterotopias are a good example of this perspective. The major difference of this perspective from the analytical framework offered by Soja $(1989)$ is that Foucault $(1984 ; 1986)$ is more interested in the interconnection between the changes in the material space and discursive practices, not the primacy of one over another, which, he says, never has any meaning.

Foucault notes the shift from the understanding of space from the point of view of "emplacement," a space understood in terms of it being sacred or profane, protected or open, urban or rural, which existed in the Middle Ages (Foucault, 1986, p. 22). Today, he argues, "the site is defined by relations of proximity between points or elements," and "our epoch is one in which space takes for us the form of relations among sites" (Foucault, 1986, p. 23). Modernity in the city is often associated with the destruction of neighborhood culture. It replaced symbolic representations (i.e. urban architecture and organization of city space) of communal hierarchy, identity, communal history, with the form of city planning governed by the logic of capitalist production and consumption. In that sense, as per Harvey (1985), money dissolves the community and, therefore, becomes the real community - an "urban community." The emerging 
city is the site which cannot foster an "organic society," a space only capable of fostering “solitary individuality” (Augé, 1995, p. 78).

These two notions, the "neighborhood culture" and "emplacement," are connected from the point of view of the discourse on place versus space in modernity in the work by Entrikin (1991) and Augé (1995). Entrikin defines place as the coming together of space and experience. A place, then, is a space filled with personal or cultural meaning, which can function as a source of identity. He describes a place as something that is simultaneously internal and external to human experience and notes that "we live our lives in place and have a sense of being part of a place, but we also view place as something separate, something external" (Entrikin, 1991, p. 7). Entrikin's (1991) most intriguing suggestion, from my point of view, is that these places of meaning represent the wholeness of temporality and space, since they are narrative constructions that embody collectivity of personal experiences. Stripped of its experience, as happens in the context of a modern city, Entrikin (1991) argues, the place becomes a mere location.

Augé (1995) focuses on what he describes as “non-places," a notion similar to Entrikin’s (1991) “locations.” To non-places, Augé opposes “anthropological places,” which are “formed by individual identities, through complicities of language, local references, the unformulated rules of living know-how" (Augé, 1995, p. 101). While an anthropological place can be defined as relational, historical, and concerned with identity, a non-place, he argues, "creates the shared identity of passengers, customers or Sunday drivers" (Augé, 1995, 101). The user of a non-place is in a contractual relationship with it: "the space of non-place creates neither singular identity nor relations; only solitude, and similitude" (Augé, 1995, p. 103). The conceptualizations of "location" by Entrikin and a "non-place" by Augé share some of the characteristics with "hyper 
spaces" as described by Jameson (1994) in regards to the disjuncture between the body and the built environments that these spaces produce.

My discussion supports the ontological perspective on space as a vector in critical theory, along with the notions of time and being. It also asserts the interconstitutive relationship between space, human condition, and social relations. From the point of view of its contribution to critical spatial theory, the project aims to uncover specific social and cultural meanings that are invested socially created instances of emplacement by studying the types of socio-spatial relations these environments evoke and maintain. Thus, I consider historic house museums as dynamic and dialectical structures. Through my analysis, they emerge not as relics of the past, but as present spaces that come forth through and create the possibility for contemporary social relations.

Experiences of a Body as a Marker of Emplacement: House museums, fire, and back pain

Although the room is the same size and shape as the cellar next to it, the sensation it gives is the perfect opposite: light and warmth. Cold and dark haven't got a chance. Yes - low in the basement and under a very low ceiling, but with the candlelight reflecting off the glazes on old teacups and crockery, off polished brass and copper pots and pans, and with the red flames licking round the hissing black kettle - warmth and light have won. David Severs, 18 Folgate Street: The Tale of the House in Spitalfields

In this section, I explore the experiences of a body (my body, specifically, as well as lived embodied experiences described by other interpreters) as the entry into my interpretation of the processes through which the sense of emplacement is created. In Chapter 2, I discussed the experience of the physical environment of an HHM from the point of view of a connective encounter with the materiality of the place. In this chapter, I use this same lens to consider how corporeal engagement is used as a way of attaching and maintaining meanings of emplacement at HHMs. 
The kitchen is where I begin my analysis. Studying domesticity at the hearth might appear formulaic, but it is a substantiated approach in the case of a historic house museum. Imagine walking into an empty house and having to make it livable. To do that, one would first have to address the pressing issues of food, washrooms or outhouses, and the kinds of living conditions that would be appropriate for the season (lit fireplaces and extra blankets in the winter, open windows in the summer). As I was conducting my research, the Mackenzie House Museum staff were considering ways in which more life could be breathed into the house (the same vocabulary has been used to describe the transition in several other historic house museums). The first place they started was with a more active interpretation of the kitchen: More cooking workshops and ongoing cooking that visitors would observe during tours.

The kitchen brings forth the question of the body in its relation to the museum as a domestic space like no other room in a house can. It is a space that produces things that can be tasted - hot, crunchy, smelling of fire, making one feel full, lifting one's spirits. It is also a place that is warm: There is almost always a fire burning there during colder months. Finally, it is a place that necessitates a fair amount of work that is physical, as much as it is interpretive. It is telling of general ideas about what museological work entails that, at the start, I did not think that kitchen work would be physically hard. After all, I was doing interpretive museum work, and my assumption was that this kind of work was supposed to be mainly intellectual. It turned out that part of my work as a researcher entailed using my body within the historic house space in a way that enabled the imaginative leap between conceiving of the site as a museum to opening up to its other ways of being, other avenues, through which people who work here relate to the space.

I have observed that kitchen is the place where people feel most at ease. The staged interior of parlors and sleeping quarters, with intimate belongings of people who used to live 
here laid out, can make a visitor feel like a voyeur. In fact, some visitors make comments to that effect. Also, the reasons for these living quarters and how we use these rooms have changed over the past 150 years. A kitchen, on another hand, is a room the purpose of which everyone can understand and can relate to, and this kind of understanding transcends generational and cultural borders, too. Visitors also seem to be quite comfortable touching things in the kitchen. This could be because this is the space where things don't work (and, at times, do not make sense) unless one uses his or her body to make them work. Perhaps this is the way we naturally attempt to explain that space to ourselves. On another hand, this desire and perceived permission to touch can be the result of the general sense of things being slightly less formal, of it being a place where one can let go a little. The touching of the things is frequently discussed by museum professionals in meetings and informal conversations, since it is a contested issue that deals with both questions of engagement with a museum space, but also with preservation. This is how Ella unpacked the visitors' behavior in the kitchen:

Have you ever had the experience of walking in and having someone just suddenly start touching stuff (referring to my work as an interpreter)? I mean, you get that all the time, where people just want to touch stuff. Because it is familiar, it is the kitchen. They have been totally respectful of the artifacts everywhere else, but they get into the kitchen, and their hands are all over the place.

I also had the experience here [Mackenzie House] and at Gibson House, where we cook over the open hearth, I'm taking someone through, and they are looking. And often it would be someone who speaks no English, and I don't speak their language. So, we are just looking, and looking, and looking. And then we walk into the kitchen, and all of a sudden, there is this old woman who I have not been able to connect to, who just goes over and lays her hands on the fire, lays her hands on the stove, and she just goes: "I know this." That's so... cool! Seeing people just recognizing something suddenly and having such strong associations with it. Like they see a butter churn, and they know exactly what that is. And you can tell that at one point they have used it, or their grand mother or somebody... and it is just such a strong memory. Because also so much of what we see in the kitchen has been used more recently in other parts of the world, so it is living memory for so many people. The bedrooms are so specifically North American, European, but when it comes to kitchens and cooking technology, so many people from so many parts of the world have living memory of those things. And that's really really cool too. 
Just like visitors feel more comfortable touching things in the kitchen, they also often appear to be a lot more open with each other: They frequently smile more, make more comments, ask more questions. In the beginning of cooking workshops, they come together as strangers, surrounding a cooking table, facing the fire. There always appears to be great emotional engagement with the process. Workshop participants often exhibit a great sense of accomplishment over whipping egg whites to stiff peaks or grinding almonds into almond meal. Teamwork, no doubt, brings people together, but so does the ritual of cooking a meal and sharing it afterwards. This transition from strangers to a group that is comfortable eating together, laughing, happens within the few hours of the workshop.

For a historic cook, active interpretation of an 1860s kitchen involves producing different kinds of food for long stretches of time (an interpreter's shift is normally around five hours). That includes whisking, mixing, kneading the dough, lifting pots filled with water, feeding the fire - all while wearing a restrictive period dress and interacting with visitors. Some historic kitchens in the GTA have open hearths, some have fire-burning stoves. Both emit a lot of heat, which adds to the physical strain, since work dresses are usually made of heavy cotton and require at least one petticoat. From my experience at Mackenzie House, the physical strain of an interpreter's five-hour shift came from walking up and down three flights of stairs in a dress, a hoopskirt, and a petticoat. Over the course of the day, the hoopskirt sometimes slid down onto my hip bones under its own weight (something that was my fault and was due to the lack of skill in securing it properly), and left markings on my skin. The work in the kitchen, however, is far more strenuous physically than interpretation of the house. A day of assisting at a cooking workshop feels like a thorough work-out. 
This kind of work compels interpreters who do it regularly to connect to the space and the experiences of people who lived here from the point of view of an active embodied self located in the present. One starts to conceive of oneself and his or her day-to-day life in relation to what it must have felt like back then. Consider, what Ella had to say on the subject:

I do find myself on a hot day thinking, I am so glad, I have air conditioning at least in my bedroom, and that I am not cooking over an open fire. I am definitely aware during the extremes of weather. There were a couple of years, where I had horrible horrible foot problems, where I had to wear running shoes all the time. And I do think all the time... all those people and their bodies. That's one connection that I definitely make. Because I have gone through a period of having a bunch of chronic pain issues and just thinking about... when my work as a historical interpreter has been accommodated, because I can't lift that pot... I'm just thinking... like what would the women of this house do? I cannot move that pot. I have an accommodation at work. They are saying that someone else will come in and move the pot for me, when the pot needs to be moved. And so, I just think about people's backs a lot. I have foot problems, and I also have back problems, and I work with the printing press... I think about their backs... and just how the necessity. It makes me wonder were people stronger? Were their backs in better shape? Is the way in which we live making us more prone to these back injuries? Were people just constantly pushing through? Is it that I can't deal with their work, because I did not develop the body necessary over the course of my life to do this work? Or is it that they could not either, because they did not have a choice. That's one of the things I think about for sure.

There is a powerful element of perceived authenticity of an embodied experience, the recognition that one cannot fake a feeling of something - pain, warmth, fear, satiation. I have noticed a certain excitement associated with feeling things in my body that come from doing the manual work of running an 1860s household while dressed in historically accurate clothing. That excitement has nothing to do with the joy of pretense, but comes from feeling as though a curtain onto a historical mystery, what it actually truly felt like to be living then, is being lifted just a little bit. As if I could use my body within this space as a portal to a different historical period and become privy to the intimate details of one's everydayness in the $19^{\text {th }}$ century. It is highly unlikely that, if this particular experience is, in fact, shared by others, it would be openly 
discussed, since it comes too close to the guarded impasse. In my personal experience, the excitement is followed by a certain sadness, as the futility of it dawns on me. Nothing I do now can make me feel things that a 34-year-old woman's body felt back in the 1860s on her average day in her average kitchen. Her unvaccinated body would have developed on different food, shaped by a different lifestyle, changed through multiple births. She also conceived of her body differently and attributed different meanings to what it felt like to inhabit it.

This shift in conceiving of the space, which starts at the level of the body, brings on a shift in interpretation of the house, with the social history, the minute details of everyday lives of people, gaining prominence. Havel (1994) conceives of home as a center of a series of concentric circles. The circles represent forms of life experiences associated with the family, community, village, town, nation, and so on. He writes: "All the circles of our home (...) are an inalienable part of us, and an inseparable element of our human identity. Deprived of all the aspects of his home, man would be deprived of himself, of his humanity" (p. 31). The position at the hearth of an HHM's poetic metaphor for the domestic allows one a point of narrative entry into concentric circles at home in a different temporality. This experiential being within the center of the circle infuses (for a short period of time) the realm of the city and the country with a very different meaning. The kind of social history that comes into focus has depth and is often associated with the use of material artifacts and specific embodied experiences associated with that use. If one were to imagine the different levels at which a historic period could be interpreted, on one extreme are the names, battles, and dates; the politics of tea rituals would be somewhere in the middle; and the knowledge that one had to keep the candles in a special box attached to the wall, so that the rats would not get them, would be on the other end. Among other kinds of history, the narrative of domesticity that is lived and detailed is the kind of social history that a historic house 
museum space has the capacity to generate. Ashleigh, when discussing the kind of public history historic house environments communicate, offered:

(It is) the kind of stuff that really you can't learn from the book. You can learn who won a battle from a book, but actually being able to... well... a hero... what was the hero's life like? What were they eating? What were they carrying? What did their feet feel like? That, I feel, would be a more interesting side of war history...

History gets communicated over a conversation during communal cooking, where the complexities of social, economic, and cultural aspects of the period are expressed in micro details. For instance, visitors learn about hygiene standards by realizing that there was a practice of building up grease on cookie sheets to keep the baked goods from sticking, instead of washing them after use. Questions like "Where did the rose water come from?" "Why were the Victorians intrigued by it?" bring up discussions about the idea of the Orient and the international trade in luxury goods. The conversation about chemical leavenings, or their absence in certain recipes, leads to the talk of War of 1812.

Each point in the conversation over a cooking table is associated with a sensory experience - that of either smell, touch, or sound. One of the central elements is fire, something that, incidentally, is experienced through all three senses. To begin with, the hearth appears to have a natural pull: When people first walk into the kitchen, where the fire is lit, they seem to want to move closer to it, some extending the palms of their hands to feel the heat. Later in the cooking workshops at Mackenzie House, a lot of the mixing and the kneading gets moved to the adjacent day room to get a break from the heat of the stove, which absorbs it gradually over the course of hours. The fire is the primary thing that organizes a day of cooking. The fire in an 1860s stove needs to be lit hours before the cooking starts; it needs to be watched and fed at twenty minute intervals. A cook in a historic kitchen often develops an internal timer attuned to 
his or her fire. One cannot set a signal for when the necessary temperature will be reached (although cooks often do stick small thermometers inside cooking chambers to satisfy food safety regulations, but even those stay quiet). There is also no guarantee that the estimated cooking time will be enough for each batch. Instead of the reliability of a modern-day stoverange, a cook deals with the organic matter of the fire, something he or she needs to understand and conform to. The making of the food here is associated with the crackling and the smell of the burning wood, and the kind of a temperamental strong heat that is absent from the experience of a modern domestic environment.

The experience of regular work with fire appears to lead to an intriguing range of associations and emotive references for the staff at historic house museums. Some grow to associate the smell of fire with being hungry, fire becoming a reference for food, a connection that is absent from the experiences of a modern-day city-dweller. I have noticed it myself to a more specific degree on a recent tour to a historic house museum, where the fire was lit in the kitchen but no cookies were served. Like Pavlov's dog I have been trained that cold weather, the warmth of an old house, and the crackling of a fire are precursors to a freshly baked ginger bread cookie. Some have noted, however, that the smell of fire becomes a referent for the experience of temporal space created by the museum. Ella shared: "If I am working with the fire, if I am cooking, the smell will be in my hair. So... the smoke will keep pulling me back. If I don't shower, then the smoke will keep pulling my mind back into the history a little bit.”

The physical engagement with the process is expected from the participants in any cooking workshop. In the words of a workshop instructor at Mackenzie House, the point of the workshop, is that "everyone has to get their hands into the bowl." The arms and hands tire from washing the butter with rose water, whipping egg whites, grinding almonds. The smell of rose 
water wafts through the air. I often felt the heat in the palms of my hands for several hours while kneading the dough and baking cookies during my shifts as an interpreter in the kitchen ${ }^{53}$.

Once, mid-workshop, I noticed a small piece of dough lying on the kitchen table. It had not made it on to the cookie sheet and was awaiting clean-up. It looked as if it would feel warm, soft, yet elastic. I could not resist picking it up and squeezing it between my fingers to see if it would, in fact, feel like that to the touch. It was exactly the way I had imagined it: the flour, butter, eggs, sugar, some spices had been worked into the consistency of play-doh. I kept working it between my fingers. It had an unexpected calming effect. I then remembered how much butter went into this recipe. I knew that the butter was about to start melting in my hands, leaving a layer of grease. With a pinch of regret, I dropped the piece into the garbage bin.

In my consideration of an HHM as a poetic metaphor, I suggest that the experiences of and in the kitchen help create and maintain the idea of a home that is a secure, warm, and welcoming place, where both meals and work are shared, and rules and rituals are grounded in unquestionable ideas. Cooking in an HHM kitchen also gives one a sense of security, of being anchored in meaning and purpose: Recipes, cooking methods, even cooking utensils do not change, nor will they ever. The menu here is not subject to nutritional concerns, latest discoveries in science, or allergy considerations. The cooking in the time gap present gives one a sense of doing things right. A cook never needs to question herself. She or he never needs to go faster either, since the timeline is not so much about feeding people as it is about exemplifying a process, and the time it supposedly took is part of that process, which is perceived as authentic.

\footnotetext{
${ }^{53}$ In fact, my hands got injured regularly during my shifts as an assistant in the kitchen: I cut them on the edges of old cookie cutters, burnt them on the stove and, subsequently, stuck the burned part into a basin filled with a mix of bleach, etc. It is my fault entirely, but it points to the very physical, embodied experience of heritage happening here.
} 
The bedrooms and the rest of the house, however, harbor a different kind of a domestic imaginary, which I associate with the idea of the uncanny. I discuss it in the following section.

At Home with the Unhomely: The ghost stories and the fear of displacement in historic house museums

As I have mentioned earlier, historic house museums are infamous for ghost sightings and are a reliable feature in the urban ghost folklore. Inglis and Holmes (2003), in their analysis of ghost narratives of Scotland, suggest that "ghostly qualities have been used (...) to create particular sociospatial contexts" since the beginning of modernity. (p. 50). "[Scotland's] landscapes, cityscapes, and habitations have been interpretatively re-created over the last two centuries producing conceptions of Scottish history which privilege the mysteriousness of a Highland and Celtic past," they write (p. 50). I suggest that the Mackenzie House's reputation as the most haunted house in North America has similar roots. This museum reportedly had such a severe problem with hauntings in the 1950s that an exorcism had to be performed in the early 1960s. When the museum was transferred from a private owner to the City of Toronto, the inventory listed "one ghost (exorcised)," making the house museum the second public institution in the country listing a ghost in an official government document. The first was the Gibraltar Point Lighthouse. From my observations as a historic interpreter, about one third of our visitors come because of these stories, and, on average, at least 8 out of 10 people I talked to during a regular shift would ask questions about my experiences with the ghosts. In this subchapter, I suggest that the HHMs' function as sites of the urban uncanny is symptomatic of a deep-seated relationship with a domestic space.

Central to establishing the idea of the uncanny is the thought that the environment is endowed with a kind of bodily characteristic, a projection or an extension of the body into its lived space. Another element of the experience of the uncanny that points to it as an embodied 
experience, rather than an exercise in interpretation, is the fact that ghost stories always involve descriptions of sensory experiences I referred to earlier. This section of my dissertation explores spatial conditions of historic house museums as a setting where the workings of the uncanny assume tangibility. It suggests that house museums invoke the uncanny by offering access to what lies, first, beyond the boundaries of materiality, since material objects in such museums work to embody the intimate lives of people. Second, they offer access to what lies beyond life and death, since the everyday lives of people we come to know have ended, at times hundreds of years ago, and yet it looks as though they continue on. The objects in house museums appear to have overcome the natural course of events from life to death, thus creating the illusion of the loss of the loss. Finally, it will explore historic house museums as sites on the border between reality and fantasy by destabilizing one's take on his or her temporal and spatial reality.

The idea of the uncanny is tied to the notion of a lived environment both through the etymology of the term and through some of the suggested applications in social theory. The English term "uncanny" is the translation of the German term "unheimlich," which means "unhomely," i.e., something that evolves from a familiar and a trusted environment, but is by its nature alien to it (for more see Freud's (1919/1953) analysis of the linguistic origins of the term). Thus, as I have mentioned in the literature review in this chapter, uncanny stands for a core sense of the imminent dread that rests within the very heart of spaces that we hold as familiar and safe. In his 1919 essay titled “The Uncanny," Freud (1919/1953) establishes the uncanny as "that class of terrifying which leads back to something long known to us, once very familiar" (p. 2) and proceeds to explore the linguistic history of the term through its etymology and the use of the idea as a literary tool in the literature of the Romantic period. He then uses his analysis as a ground for establishing the origins of the uncanny in the repression of fears of death and the 
infantile castration complex and in the suppression of primitive animistic beliefs in the psyche of a modern man. "An uncanny experience occurs $(\ldots)$ when the primitive beliefs we have surmounted seem once more to be confirmed," he writes (p. 17). Freud (1919/1953) suggests that the experience of the uncanny can be the result of the "doubt as to whether an apparently animate object really is alive and, conversely, whether a lifeless object might not perhaps be animate" ( $\mathrm{p}$. 135). Vidler (1992) explores this point by suggesting that uncertainty regarding the framework of our reality is at the core of the uncanny.

The idea of the uncanny poses great difficulties in any kind of academic discussion, since it stands to identify something that is by definition beyond the grasp of one's intellectual ability and, hence, beyond conceptual analysis. The uncanny is something that we only suspect we know, so, perhaps, examples might be a better way to approach it. Having connected the feeling of the uncanny to the infantile factor, Freud (1919) seeks out specific instances of the uncanny things, such as the repressed belief in the omnipotence of thoughts (for example, the dread of an evil eye), the fear of the dead coming alive or the fear of hauntings, the animistic nature of the world (e.g., the fear of dolls coming to life or the uncanny feeling produced by lifelike robots), and the fear of doubling (e.g., doppelgangers or involuntary returns to the same situations or spaces, as inside a labyrinth). He also points out that the feeling of the uncanny can sometimes come with a sense of fate, as in the uncanny events were somehow destined to happen, and that whatever reminds of the principle of repetition-compulsion also appears to us as uncanny. Freud (1919) elaborates on the relationship between the uncanny and the sphere of the familiar, or, for the sake of the proposed discussion, the domestic, by pointing out that in German the term "heimlich" has evolved to be sometimes used interchangeably with "unheimlich." "Heimlich," in these instances, is used to signify a closed and private space used to conceal secrets. Freud 
(1919) articulates this ambiguity in the definition of the lived environment as the possible dual nature of the domestic sphere, with the unheimlich as "in some way or other a sub-species of heimlich" (p. 2).

Freud (1919) brings up the city in his writings on the uncanny once when talking about the uncanny quality of a maze, of the terror of going in circles while trying to find the way out. The city, thus, emerges as an alien and infinitely unknowable space, which is both modern, and therefore not intimately familiar, but also imbued with somewhat animistic qualities. It has the ability to lead a person where it wants the person to go. The slippage here occurs between the unfamiliar into familiar, which is almost scarier. The familiar is the very sense of the uncanny terror, the knowledge that this has happened before, and that the potentially terrifying thing that is about to happen, perhaps, has happened before; that the drive towards it is both within you and external to you. The uncanny, then, is defined as a way to interpret the relations between the psyche and the lived environment, the body and the domestic space it occupies, the individual and the urban space.

Ultimately, the uncanny can be described as the blurring between fantasy and reality, an experience of space that merges the two. This reverberates through the work of a house museum, which appears to perpetuate the belief that spaces and objects can hold memories, and that a form of a time travel is possible through the communion with these objects and the spaces they create. In the contemporary city, which both alienates and numbs its inhabitants into becoming flaneurs, the staged house museums allow us to reformulate the functions and meanings of a lived environment, the speed of time, and the way we engage in conversations with each other. I believe these homes were the result of cultural necessity. However, as these familial homes, haunted with age-old memories, emerge as part and parcel of the fractured modern city space, 
the uncanny becomes the metaphor for the fundamentally unliveable modern condition. These homes are not quite dead, but not quite alive either.

The urban stories surrounding HHMs are such a significant part of their narrative that how to tell them, when to tell them, and if to tell them has been a part of the curatorial decisionmaking process for decades. One of the questions I was asked during the interview for the volunteer position at Mackenzie House was: "What would you do if a visitor asked you about ghosts?" (paraphrased). I was told that this was a standard question asked of all interviewees in all historic house museums in Toronto. The regulations in regards to ghost stories in various house museums have changed over time, with some curators being quite comfortable with the ghostly aura surrounding the houses and some being vigorously against making it a part of the available narrative for the purpose of establishing historical accuracy as the focus of the historic house experience. While most interpreters feel quite comfortable answering questions about ghosts, they will generally attempt to treat them as a side curiosity and move on with the account of the lives of the inhabitants before their passing. The ghost tours of the houses, always held around the Halloween night, then, have a feeling of being a free-for-all in regards to both the ghost folklore and the ambiance of the house, with tour guides focusing on the goriest details, while the candles cast dancing shadows on the walls.

Uncanny qualities of these spaces add to their ability to function as urban heterotopias. Specific instances of the uncanny afford experiences of temporal and spatial breakages and create conceptual platforms for exploring unconventional ways of conceiving of temporality and space and, for some, opportunities to reconsider their ideas for alternative futures ${ }^{54}$. These

\footnotetext{
${ }^{54}$ Some of the specific examples of historic house museums offering opportunities for consideration of alternative pasts and futures would be Steam Punk fair at the Campbell House Museum, Toronto, in June, 2013; the art project "He named her Amber" in the Grange by Iris Haussler (2008-2010); the art installation "LandSlide: Possible
} 
environments create two conditions that make such imaginative breakthroughs possible. First, they present spaces in which current rules for what space and time mean and how they should be used are broken. The physical space of a house museum and the objects of material culture within it appear to hold time at a standstill. The lives of people, objects, the very progression of history are suspended. Second, house museums function as performative spaces: Not only do they sanction people to behave in rather unusual ways, but they won't function unless people do. In other words, unless visitors take part in this game of pretense, a house museum, in the vast majority of cases, will be just an old house filled with an assortment of furniture.

One of the examples of a spatial and temporal breakage created by time gaps would be the grounding of a historic house museum site in the urban geographical context without a real referent in real time. All the historic house museums included in this study, within their narratives refer to what the space around them used to be as opposed to what is there now. While, in part, it is an attempt to unpack the history of the built environment, it is also an attempt to extend the temporality of a historic space experienced in the present into the modern spatiality, to conceive of it as a historic city that is no longer. For instance, as an interpreter at Mackenzie House, I frequently got questions such as: "What would Isabel see out of this bedroom window at the time?" and: "Where was the church the Mackenzies went to?" It is understandable that answers such as "a ten-minute walk from here" would be found less satisfying than "close to University and Queen," for instance. However, a contemporary city dweller, firmly located within his or her temporality and spatiality, would not be as invested in the specificity of the answers, since it is clear that the city core has changed so much in the past century and a half, the Heritage Meetup for girls and their dolls at the Black Creek Pioneer Village. 
exact identification of a downtown corner is quite useless. A general direction and the approximate amount of time it would take to get there would then constitute a more exact answer than an identification of a street intersection. What I observe most frequently, however, are attempts at reading existing streets as forms of palimpsest, as though the multiple layers still exist there underneath the glass exteriors of the modern shops and condo buildings. The questions asked by the visitors and the answers given by the staff, thus, betray a suggested reframing of the ways both parties attempt to conceive of the spatial and temporal dimensions of the city. Another example of this way of thinking would be the then-and-now pictures of Toronto that have became quite popular on social networks in the past few years. These pictures juxtapose an image of the same building or a street corner from the historic past and now. Some of these images are, at times, animated. It is poignant, then, that, as I have mentioned in the Introduction to this dissertation, the historic house museums in Toronto, when taken together, form a coherent community, much like a $19^{\text {th }}$-century town, now preserved within the boundaries of a modern metropolis. In a way, the sites form an alternative urban geography that would make sense as a coherent municipal space in a different historic temporality.

Discussions on the urban uncanny generally refer to an experience of things not being quite right, beyond one's understanding, a source of fear that is beyond one's ability to identify it. One night at Spadina House in the fall of 2015, I felt I came quite close to touching that ethereal substance: After a night of making fascinators, the participants of the workshop were offered a piece of coffee spice cake along with a warm cup of cider. The meal was lit by candlelight. I have commented on how unusual the cider tasted - it was both sweeter and, somehow, lighter than the usual fare served at historic house museums at that time of year. As it turned out, the apples for the cider (which the staff referred to as "heritage apples") came from 
the Spadina House orchard. The varieties called "snow apples" and "Baldwin apples" 55 " do not keep as well as other kinds, so they are not sold in stores. The Spadina House orchard, ruled by interests other than commercial, got to keep their trees, and they now produce this very special kind of flavorful cider, which is unlike any other found in Toronto. It is a drink that is inaccessible beyond the spatial limits of the house; its taste comes from the trees that have been growing on the property for close to two centuries, out of the very dirt of the Spadina hill. I believe that here the Spadina House Museum has accomplished the near impossible. While inhabiting the space of the house brings forth a certain sense of the uncanny, and so do the instances in which temporalities clash, for example, when people take selfies at The Great Gatsby party each summer, the actual consumption of the fruit that grew on the historic property as part of the original recipe introduces the kind of tangibility that can be made sense of on the terms of the body.

The Reach Beyond the Walls: Historic house museums as sites "outside of all places"

The only problem with living inside a painting is the messy business of getting in and out of that wretched frame.

Dennis Severs, 18 Folgate Street. A Tale of a House in Spitalfields.

The interrelationship between time gaps and the rest of the city is one of the most intriguing discoveries in my research. It is also a discussion that, I believe, is to remain openended. I found that the identification of this relationship required a lot of conceptual subtlety and that both I, in my position as a historical interpreter, and my interviewees struggled to find an

\footnotetext{
55 The Baldwins were the family who built the first house on the hill where the Spadina House museum stands now, in 1836. That house later burned down and was rebuilt, and then demolished. Some of the apple trees in the orchard, however, remain from that time.
} 
exact vocabulary to connect our mundane experiences inside and outside of the heterotopia of a historic house museum.

In this subsection, I suggest that the two timespace realities, the one inside and the one outside of the museum, since performing a counter role to each other, are not imposable. There may be several ways to explain the difficulty of describing the everyday experiences of inhabiting them both. First, it is likely that the peculiarities of the experiences that the job of an interpreter entails are normalized within the context of one's life. Most of my interviewees have been doing their jobs for extended periods of time, some for over a decade, and admitted to not being able to imagine what their lives and spaces that they occupy would feel like or what would they mean were they to do anything else. Second, it is quite possible that articulating this relationship is directly related to describing the quality of "otherness" of these sites, which comes close to admitting the presence of the guarded impasse I referred to earlier. The third reason for it has to do with how heteropias present themselves within the context of social and cultural practices that they contest and mirror, and this is the issue that this sub-section addresses.

As a historic interpreter living in Toronto, I observed that while the location of the Mackenzie House Museum is a part of the structure of my city, the space and the experiences of it emerged as autonomous. I will unpack this point by aligning it with Foucault's (1986) discussion on heterotopias. On one hand, I can make sense of this site by approaching the Mackenzie House Museum through clusters of relations that defined my use of it. From this point of view, it is a place where I was productive; a place where I socialized; a place with which I identified, in part, my current professional growth. In that sense, its connection with other spacial and social junctures in my life was evident. However, it was also a space that defied logic 
and the linearity of my time and experiences outside of it. It required a leap of imagination to be productive in the sense that it defined productivity-it was the kind of labor that, at times, rested in the state of being merely present within the house, of holding that space. In that sense, the heterotopia of Mackenzie House is a place that is "outside of all places, even though it may be possible to indicate [its] location in reality," it "exerts a sort of counteraction on the position that I occupy" (Foucault, 1986, p. 24). One might say that, on the level of the experience, my time at Mackenzie House fell out of the context of my life the way it existed outside of it.

Foucault (1986) uses a metaphor of a mirror to explain this aspect of the workings of heterotopias. He suggests that "the mirror functions as a heterotopia in this respect: it makes this place that I occupy at the moment when I look at myself in the glass at once absolutely real, connected with all the space that surrounds it, and absolutely unreal, since in order to be perceived it has to pass through this virtual point which is over there" (p. 24). So, what does it mean to occupy the space inside the mirror, to enable the reality that is a form of active contestation? And, while one is fully inhabiting the reality inside the mirror-holding that space, her palms warm from working the dough by the fire, the smell of smoke in her hair-does the reality outside the walls emerge as the mirror reality?

While I do not believe that one can submerge him or herself into the reality of a historic house museum so fully as for the outside world to appear as its reflection ${ }^{56}$, I would like to suggest that it is precisely this quality of a heterotopic space that makes it fall out of the structure of everyday lives and spaces. The two places, inside and outside of the mirror, emerge as dependent on each other, and yet autonomous, claiming a reality of their own. An engaged visit

\footnotetext{
${ }^{56}$ While this may not be the case for interpreters working in historic house museums, there have been experiments conducted that argue for the possibility of deep confusion as a result of temporal displacement. David Severs, whose museum I refer to frequently, is, no doubt, one of such cases.
} 
to a historic house museum may be perceived as an exciting event that deepens one's experience of the city and one's life. A visitor makes a mere attempt at encountering the space beyond the frame, while keeping one foot firmly rooted outside of it. A day-to-day entering and leaving of such place by an interpreter, an active performer who enables the performance of a heterotopia, however, becomes complicated by the need to inhabit the two realities fully. The being on one side of the mirror, for the period of time spent there, negates the existence of the other. This is precisely what makes a profound difference between taking off an 1850s dress and exiting a recreated Victorian domestic space to reenter the streets of Toronto and changing from office shoes to walking shoes to step outside of an office door.

In 1922, in his book The Girl in the Golden Atom, Ray Cummings wrote: "Time is what keeps everything from happening at once." This has become his most popular line, repeated by physicists, such as John Archibald Wheeler, throughout the century that followed. The quote essentially describes how we now conceive of what happened following the Big Bang: Time and space, which, prior to it, were one, separated, with time becoming the organizer, keeping things from happening at the same time. In that sense, the time gap of a historic house museum is very much a pre-Big Bang kind of a cultural construction. Time here is not used to organize space, but rather to describe it, infuse it with meaning, it becomes its property. When used this way, time becomes a referent, loses its ability to flow, it settles, instead, and, in the words of David Severs (2001), becomes "thick as treacle" (p. 11). Time and space are one thing that co-create the meaning of this heterotopia: The temporal and spacial/material merge to form the experience of a withdrawal from the context of everyday life in urban postmodernity.

The straddling of the movement between the space within the heterotopia-behind the glass, "outside of all places" (Foucault, 1986, p. 24)-and the space outside of the heterotopia 
presents a definitional challenge and came through in my research as the interviewees' inability to articulate the relationship between the historic museums, where they worked, and the world outside their walls. They also had trouble explaining what it meant to them to exit the space, transition from work to leisure. These were the specific questions my interviewees had difficulty with: "Do you think your work at the museum affects the way you think about the kind of Toronto that you encounter every day?" and "Does what you do at the museum in any way affect your everyday life outside of the museum? If so, in what ways?"

A recognition of this movement came through in interviews in the form of the interviewees recognizing the affective relationship with spaces and meanings they hold. For instance, Louise, an interpreter who held multiple part-time contracts in three of Toronto's HHMs for close to a decade, suggested that, since she has transitioned to a full-time job at a historic house museum, she finds she has a need to get out and do things in the city at night. Louise now spends long hours within a restored domestic space, often by the fire; there is always a pot of warm tea in the kitchen. So, at night, she admits, she needs to get out, being at home feels like "too much domesticity." She feels there is a need to "break away from it," to be in places that are loud, surrounded by people, see cars driving by. Here, an active submersion in the space of a heterotopia invokes a deeper need to expose oneself to the opposite that it reflects.

Martha, an interpreter who worked in the network of Toronto's HHMs for close to twenty years, doing interpretive work as well as research, offered:

I think it makes it easier to feel you are on a continuum, whereas before I started working at historic sites, you see an old building: "Oh... nice." But now you can sort of see it as part of the fabric that used to be here. So, you are walking through different layers and different times. It is easier to envision, to fill in the gaps and put yourself back there. And it's quite appealing to do on a sunny day... walking down... I have different routes I take down walking towards the train station. Depending on what mood I'm in, but yeah, you can have these little moments of transport. Where you can feel connected to an 1850s 
pedestrian walking the same route, and the route I take is not far off from Mackenzie's walk to work as well, when he is walking down to his print shop at King and Victoria. And a lot of our walking tours not coincidentally are kinda built around that as well. And it has made me more aware too... like when we lead our walks... with our "Unlady-like" walk, I'm always looking for alleys, because people really enjoy an alley, and even if the alley is a modern alley, it still has that feel suddenly of being more in the $19^{\text {th }}$ century mode, if you are taking a narrow little street. I've noticed that with the ghost tour, when we walked behind the Campbell House, people really like that little stretch off King Street. Even though you are surrounded by modern buildings, it still feels like a historic experience cutting through there with silence, whereas Queen street is just to the south and loud. And I am finding that when I am visiting other cities as well, you have a moment when you are looking around and you imagine how it would have been two hundred years ago. So, I think historical imagination is something you get from working in and loving these kinds of sites.

Here, an interviewee suggests that she taps into an alternative dimension of the city, different temporal "layers," that are made available to her through what she describes as "historical imagination," therefore transferring the experience of the house onto the space of the city. While she is, indeed, reaching beyond the walls, she is not bringing together the outside and the inside, but, rather, transferring the inside onto outside. This point is made stronger by the interviewee's description of the walk through Toronto. At first, the city emerges as a mere set for a story, but that first impression is misleading. The back alleys of contemporary Toronto - dark, holding things and stories that are unlooked for, unscripted - feel like a "historic experience" to my interviewee, as the city begins to function as a historic house museum, where, too, intimate unexpected stories reside in corners, hidden behind an old chair, which, at times, is known to rock on its own, a painting, a grandfather clock.

I observe similar attempts of transferring the inside of a museum onto outside in the way the visitors interact with the space of the museum. One of the more popular questions I got asked on tour when in the Mackenzies' bedroom, was "What would they see out of this window?" This curiosity bears a first-hand familiarity to me: I too make it a point to look out of the windows, 
when visiting historic bedrooms. To me, it is an attempt to connect intimately with a person from the past, a view out of the window being mostly a solitary experience, something often contemplated in the moments of self-reflection, but rarely shared. The visitors' curiosity goes beyond this, however. They want to know what was out there, when the Mackenzies lived in the house; what was the Toronto they inhabited. The intimacy of the experience of an undisturbed gaze through a bedroom window emerges as a gateway into the experience of a different time.

I have found there is a certain sense of precarity and, at times, tension in the relationship between the world inside the site and its immediate location within the city. A hundred to two hundred years ago, the emplacement of the sites, the location of the inside of the house in relation to the rest of the world was a harmonious one. The houses were where they were for clear political, social, economic, environmental, and lifestyle reasons. This is no longer true. Instead, the location of the houses now disrupts the logical layout of the urban space. Mackenzie House, as I have mentioned in the introduction, sits in one of the most commercial areas of the contemporary downtown, whereas in the $1860 \mathrm{~s}$, it was built as a suburban townhome. Gibson House, a marker of North York's farming past, was built in 1851 amidst farm lands and forests, and is now surrounded by freshly built condo buildings and shopping centers. When another condo tower was erected by the Gibson Square Condominium development, museum attendance dropped significantly: The house became hard to find, obscured behind its namesake giant. Some museum goers I have talked to assumed it had been demolished.

Often times, the setting of the house informs its history and determines its story and its significance as a museum. The discussion of what was out there when the family lived in the house is normally part of any tour at all sites. Some narratives are expressive in their sense of loss. For instance, the plaques on hiking trails surrounding Todmodern Mills and the narrative of 
the tour guides I followed when doing this research, lament the loss of vegetation and the animal life that were present in the area in the 1800s. The narrative of the Campbell House Museum includes the story of it being moved, which is illustrated by high quality photo prints hanging on its walls. The house needed to be rescued, when its location was no longer viable for commercial reasons.

Out of ten house museums in Toronto, Colborne Lodge is the only one that enjoys a history as a kind of a time emplacement capsule. Its surroundings have changed surprisingly little since the times the Howards lived there, if one were to consider the growth of the city. George Howard's will made his house becoming a museum contingent upon the land being transferred to the city and preserved as a park. This is one of the reasons I am exploring this site as a paradigmatic exemplar that encapsulates the qualities of domesticity and emplacement in the conclusion to this chapter. The inside of the house, in this case, does not clash with but extends into the natural environment around it. One still has to go on a nature hike to get to it, the windows of the drawing room still look onto the wall of trees, and even the view from Jemima's second floor bedroom is quite similar to what she would have observed. As I mentioned in the beginning of the chapter, her window looks upon her grave, which she watched getting built, while suffering from breast cancer. All that both strengthens the feeling of coming home and amplifies its uncanny qualities. It is poignant, then, that out of all of my interviews, it was the staff members from Colborne Lodge that appeared to struggle the least with the question of leaving and entering the heterotopic space in their answers. In all cases, it was the experience of hiking through High Park that allowed them to both "settle" into the state of mind of the museum and to leave the museum behind when they were done with the shift. 
David Severs (2001) addresses the issue of the location of his house museum as well. In 18 Folgate Street. A Tale of a House in Spitalfields, Severs (2001) begins his description of the museum space from outside the walls, the area where the house is located, except his description is not of the current temporal or historical condition, nor does he describe what the area was like in the 1770s. He talks about the kind of outside that is the inside of the house extended. This temporal space emerges as non-linear, and his discourse follows the same logic as the answer I quote earlier in this section, in which the staff member describes the dark alleys of contemporary Toronto as invoking "historical imagination.” Consider Severs' (2001) narrative below. He opens with a general description of Spitalfields:

Folgate Street stands in the ancient Liberty of Norton Folgate, Bishopsgate Without, Spitalfields. The word liberty and without, when applied to ancient English place names implied that certain freedoms were associated with a region which sat outside the boundaries of a city or church's jurisdiction. Unorthodox beliefs and lifestyles were attracted to Spitalfields and settled here in the same quest for liberty. (p. 15)

The next paragraph, however, addresses an immediate experience of the house:

If you have worn a suit for tonight's adventure, then what was until recently shabby Folgate Street might make you feel overdressed. Whereas - when still over the boundary of the City in Bishopsgate - you might have felt inappropriately attired in anything less. Without the Bishop's Gate in London Wall a loosened sense of liberty prevails, which contrasts sharply with so rigid and regimented a place as the City of London - within. ( $\mathrm{p}$. 15)

The following paragraph, once again, jumps around the time periods:

Being outside and extreme is what Spitalfields is all about. In medieval times the area was occupied by two classic categories of outcasts: the lepers and the insane, and Spitalfields derives its name from the leper hospice, St. Mary's Spital and the fields on which it stood. (p. 15)

Severs (2001) appears to be spilling the character of the house onto the area around it by claiming the opposite is true, that the life of an outcast, a lifestyle outside the norm is somehow innate to the locale, that his house-this enclave of "otherness"-was somehow destined to be 
there, feeding into the rhetoric of fate that is present in the narratives of many historic house museums.

As quoted in the epigraph to this subsection, Severs (2001) laments the difficulty of getting in and out of the "wretched frame" (p. 1), and he did not, for the most part, as he used his house museum as his primary residence. His submersion into the time gap was such that, towards the end of his life, he expressed the fear that, perhaps, the family really was not there. For people that do not live their lives inside the time gap, the tension and disjointedness of the experience of the outside world in relation to the inside world is integral to the entering and the leaving of that space. An attempt at extending the temporal space of the museum onto the rest of the city is an attempt to ease the experience, for some, or to stay inside the house, for others, to continue inhabiting it as a kind of dreamland, but I don't believe it suggests that the two realities are counter imposable onto each other. The time gaps of historic house museums are isolated within themselves also because it is a need of a healthy cognitive function to believe that an inhabited consensual reality is true and absolute, even for a period of time. The timespace at each side of the mirror establishes patterns for how the reality needs to be perceived.

\section{Conclusion}

Colborne Lodge is a historic house museum in Toronto's High Park that beckoned the pizza delivery driver in the snowstorm in the beginning of chapter 1 and served as a site for my adventures with the paranormal in the beginning of this chapter. To outline my conclusions on the question of emplacement in relation to the work of historic house museums, I would like to unpack this site as a paradigmatic exemplar of what I have described as an attempt at creation of an anthropological place in urban postmodernity. I will demonstrate just how this particular historic house presents and performs the experiential markers of domesticity and emplacement I 
have discussed in this chapter, and how this performance substantiates my perspective on it as an instance of what I call a time gap.

One of the ways in which the uncanny comes forth in the performance of this particular historic house is its insistence on remaining a domestic space for the same family unit for 180 years. There has not been a generational shift, the passing on of the house from parents to children and then grandchildren, such as has been the case with Spadina House. This kind of transition infuses the space with a sense of natural flow of time and familial continuity. Instead, the house that John Howard, an architect and Toronto's first city planner, built, initially, as a cottage in 1836, has remained largely unchanged since the last remaining servants passed away over a century ago. Most of the artifacts inside the house once belonged to John and Jemima, and now belong to the story of them that the house preserves and narrates. This apparent resistance to the natural flow of time creates a layered experience of a domestic space, which is warm, familiar, lived in, and loved, but, on another hand, stagnant in its insistence on appearing exactly that, a home to the two people who inhabited it over a hundred years ago. The location of the house in the middle of High Park reinforces this experiential double exposure, the homely and the unhomely, since the setting of the house has changed very little in the span of time it has stood there, which has not been the case for any other historic house museum in Toronto.

It may, in part, be an ironic coincidence that while I now interpret Colborne Lodge as a site that affords emotional, experiential, and physical withdrawal from the anxieties of a postmodern urban lifestyle, back in 1836 , John Howard built it as a place to escape from the bustle of Toronto. While now I consider its natural setting as one of the anthropological markers contributing to the qualities of emplacement, back then it was specifically its remote location and 
the experience of nature that constituted the environment in which the Howards felt they could rest and be creative.

The built environment of the Howards' familial home has grown to reflect the organic qualities of the natural environment it was designed to blend into. The house started out as a summer cottage, but, with time, grew into the primary residence for the couple: John and Jemima Howard eventually moved there to retire from John's busy career, the intensity of which made him a sick man in his 50s. The rooms and floors were added around the stem of the fireplaces. The staff advises visitors to the house, who are wary of getting lost, to think of it as a snail - its multiple hallways and rooms all go in a circle. The house grew, as the needs of the couple changed. A summer kitchen with a then modern stove was added to the one with the open hearth. A gallery was built out back to showcase Jemima's and John's paintings. Additional rooms were added on the second floor to accommodate Jemima, who, in the final four years of her life, required around the clock care. Small changes in the house, too, can be traced to the daily lives of the couple: An additional doorway in the hallway was introduced, so that Jemima would not wonder off outside in her morphine-induced state (the drugs were used to alleviate the pains caused by cancer). At the time of John Howard's death, the house had 32 bedrooms, two kitchens, and an in-door bathroom, one of Toronto's first.

The continuous growth of the house and changes in its organization that slowly came into being, as lives and bodies changed and developed new needs; its shape as a snail, the architectural solution of making the hearth the stem, around which the rooms were developedall that adds an anthropomorphic quality to this space. What contributes to this is that John Howard, an artist, a highly innovative architect, was the very mind behind the organization of his own domestic space, which now tells his story. The house comes forth as an expression of how 
he conceived of the needs of his and Jemima's bodies, in relation to the built space and the natural world outside.

Historic house museums at times may appear to be unexpectedly bare, especially if they allow self-guided tours. As I have mentioned in Chapter 2, at a lot of these sites, such as, for instance, Gibson House in Toronto, anything smaller than a coffee mug is frequently stripped from the rooms to avoid easy pocketing. And then there are those rare sites which boast a large collection of exquisitely made authentic artifacts, such as the period rooms in art museums or museums of natural history. Both ends of this spectrum result in spaces that lack a lived-in feeling, since both are missing the kinds of "personables" that are part of one's everydayness without any reasonable prospect of becoming an heirloom. Largely due to its historic circumstances, Colborne Lodge managed to preserve a distinctly lived-in feel, more so than other historic house museums in Toronto. Howard's attention to architectural details and his investment in the running of the household is evident. The space feels very well loved, there is a presence of someone's work at making the house comfortable, making the house into a home, that is apparent both through its design that matched the needs of the inhabitants, and everyday things that were once chosen, held, used by John and Jemima. The house feels like the clothes that were just taken off of one's body and that still preserve its warmth, shape, and smell.

One of the things that contributes to the experience of the house is the fact that it is very much a destination. Whereas a large portion of the foot traffic at Mackenzie House are walkersbyes, in order to get to Colborne Lodge one has to hike through High Park from a TTC station or else take a Queen St. streetcar and walk up a hill from there. The journey there has to be intentional and consider what the park would be like in current weather conditions. Driving there in winter involves a reasonable concern for the state of the roads. It does, in a way, become a 
quest. Its otherness in terms of pace (and space) feels therefore justified, as in, in a house in a remote wooded location things really can run differently and feel differently. The story of the house as a place of recluse comes full circle, in a way: In his deed, John Howard gave the house and the lands surrounding it to the city under the condition that the area should be preserved as a park, and the house should become a museum, thus precluding any possibility of substantial change. 
CHAPTER IV: Performance of History as a License to Play: Historic house museums and the joy of pretense

In the process of writing this dissertation, I discovered that, since one of my tools was autoethnography, I ended up having to admit to the kinds of things that I would normally prefer to keep to myself. One of these things was that sometimes I got the sense of an invisible presence of the Mackenzie family. It came at random times and could never be foretold. Sometimes it came when I was by myself in the historic bedroom and my side vision captured a movement of the shadows on the wall. Sometimes it happened when the outside city noises, contemporary to my own body, suddenly and unexpectedly grew quiet. And then the stairs creaked. The sense that maybe the family in some way was still there created a feeling of intrusion, of not having the right to be there, in someone else's lived-in space; much less having the right to tell their story, to talk about their personal lives in as much as detail as I did. The familiarity with the intimate details of someone's everyday life in the past co-existed with the uncanny quality of the domestic space, like a light casting a shadow. Those moments and the feeling that I was intruding were something I kept to myself, but I always wondered if others working at the museum had them and what they meant to them. This isn't something I would be comfortable asking directly. It comes too close to approaching the guarded impasse.

During one of the quieter hours of the shift on a Sunday, it happened to be the last hour, I sat in the modern gallery with a colleague of mine discussing the embalming methods in the 1860s. The subject came up in relation to the story of George Mackenzie, who was run over by a train in Illinois in 1861 and had to be transported back to Toronto for burial. "Would they have attempted to preserve his body?" we wondered, "Would it be possible if his ligaments were as badly battered as we know them to have been? Would they have used a cast iron casket?" It was a discussion filled with gruesome detail. When the day was over, I walked back into the house to 
change into my "civvies" (the in-house term some interpreters use to describe their regular clothing). The panic attack struck as I was climbing the creaking stairs. I felt as though the house was attempting to push me out, to expel me with one forceful motion. I pulled the strings of my petticoat and ripped the dress off, jumping out of the pile of clothes on the floor. A minute later, I was running down the precious century and a half old staircase, two steps at a time. This story is my only contribution to the Mackenzie House ghost narrative, the one that I shared with visitors during haunted tours on Halloween. It is not much, but it is steeped in an intimate experience of terror. This experience was likely the result of an unrecognized guilt before the house and the family that lived in it over opening their doors, exposing them to all who would care to ask, and unpacking their moments of grief in technical detail. In the absence of the warm breathing bodies, the cold empty house became the shadow cast by the light.

In this chapter, I will draw on my earlier discussion on the meanings and functions of materiality and emplacement in historic house museums in exploring the performative embodied engagements with the space that I observed during my research. The chapter on performance in this dissertation comes last because, I suggest, it is an embodied, emotional, and intellectual engagement with space, materiality, and the sense of place that activates the time gap; the throwing in of the sentient body that is both craving and allowing itself to fill sensory and psychological gaps present in its experiences of self and the everyday ${ }^{57}$. In this chapter, I extend this argument by suggesting that, within the context of an HHM, the performative practice becomes a site of catharsis and self-reflexivity. It allows one to perform his or her other self, and engage with his or her life on other emotional, physical, and intellectual terms by exploring and filling in the loosely drawn outlines of lives which ended a long time ago.

\footnotetext{
${ }^{57}$ In earlier chapters, I refer to this as an act of willing active engagement with the time gap.
} 
My use of the term performance in this discussion defines a consistent behavior that goes beyond reproducing a specific event in history, which has been deemed significant. For the purposes of this dissertation, I conceptualize performance as any work done within a house museum space that makes use of the space and things within it with the purpose of enhancing or maintaining the experience of an alternative spatiality and temporality. This involves any discursive or embodied relationship between the staff, volunteers, and the object of their performance - material artifacts, lived environment, and stories they tell. In that sense, my findings and the analysis of them supports Casey's (2003) observation of a shift in the role of cultural history museums from interpreting meaning to performing meaning, and Terry's (2008) suggestion that "in living history museums, meaning is no longer tied to the object as it is in art and anthropology museums; rather it is created in the interaction between interpreter and visitor, interpretation and location, and artifactual arrangement and architectural context” (p. 106).

I would like to outline specific ideas that delineate my conceptualization of performative work as it is carried out within time gaps. To begin with, my analysis suggests the view on the practice of heritage in historic house museums as a form of performative behavior. This proposition further establishes the importance of the study of heritage through analyzing subjective and affective engagements with space, things, and time (Waterton and Watson, 2013). It also establishes the experience of heritage as immediate and stresses the importance of engaged participation (Gumbrecht, 2004; Tomlinson, 2007). Further, it supports the idea that meanings that emerge within time gaps are not merely interpretive, but experiential (Daugbjerg et al., 2014; Lash and Lury, 2007), which asserts my earlier analysis of heritage as an embodied practice. Finally, following Daugbjerg et al. (2014), I suggest that the practice of heritage as a form of performative work transcends the mind-body binary. In that, it further extends my 
consideration of heritage as experienced and made possible through a sentient body. This view on performative work establishes it as a context and proposes the idea of performance as an attempt at creating and maintaining space. In that, I build on the argument by David Crouch (2013) who suggests that:

(...) the idea of performativity positions our practices, actions, relations, memories, performative moments as emerging context too. These many facets of being, alive, and affected, commingle in a fluid, part open, part limited manner. (p. 21)

I begin my work in this chapter by first outlining the position of my study of performance in relation to the academic discourse on the subject. I then engage with analysis of performance in a house museum setting by first exploring the role of an interpreter. This sets the stage for a discussion on performative work as a form of an engagement with the materiality and temporality within the time gap, the kind of performance that, I suggest, appears to vivify things and in-betweenness of things, activating the time gap. I then address the question of the relationship between a performing self and the accounts of the people whose lives the museums are dedicated to preserving, and discuss performance as a site of emotional catharsis. Further, I expand my analysis by exploring the relationship between performative work of the museum staff and the audience. Finally, I consider the relationship between a performer and the site of a historic house museum, the turning of a museum institution into a domestic site through a form of active engagement with the domestic space.

\section{Performance and Heritage: Literature review}

The study of reenactments of the past are currently drawing a lot of interest in the field of critical heritage studies (see, for instance, Agnew, Lamb, 2009; Jackson, Kidd, 2011; Schneider, 2011; Kalshoven, 2012). The International Journal of Heritage Studies published an issue dedicated entirely to it in 2014. The study of re-enactment of heritage emerged out of the 
interdisciplinary approach to the study of the processes of heritagization encouraged within critical heritage studies. Daugbjerg et al. (2014) note that the study of this subject matter emphasizes the definition of heritage as an immediate process and raises new issues in heritage research, such as the (in)significance of authenticity, “(...) the nature of multisensory textures of experience, embodiment and material culture, and the impulses driving our era's increasing thirst for re-living heritage" (p. 684). While these studies discuss performative aspects of heritage work, they generally focus on heritage re-enactments as a form of theatrical play acting. I have found little work that focused on performance within a historic site as a way of creating and maintaining a different sense of temporality and spatiality. Mads Daugbjerg (2014) talks about the re-enactors' relationship with physical objects that are part of the performance as a way of "patch-working" a sense of the past through piecing together, among other things, immediate embodied experiences and shared first-hand experiential knowledge of these objects (p. 724). Further, when talking about his autoethnographic experience of the American Civil War reenactment, Daugbjerg (2014) suggests that the participants' immediate experience of their costumes, shoes, specifically:

(...) remain(s) at the core of the experience. They (the shoes) do not, however, in themselves hold the magic moments or powerful experiences - they do not possess 'agency' per se - but must be animated, worn, given life. Like the Chestertown jacket allowing me to join in on and momentarily touch the materialized memories (...), and add my own minimal amount of wear and tear to its accumulated value, the power of my company comrades' equipment and accoutrements was strongly dependent on their continuous use, on on-going human engagement, and on the specific entanglements with other tangibles. (p. 732)

Rivka Syd Eisner (2014) considers a different quality of re-enactment of heritage, once again discussing a staged performance. In her analysis of The Drought and Rain dance trilogy by Vietnamese-French choreographer Ea Sola, she explores the ability of dance to blur the boundary 
between the present and the past. She writes that: "The performances enact a different form of historical (re)productivity, not predicated on a linear materialism, but based on processes of temporal turn and re-turn" (p. 798).

While these studies tackle larger issues dealing with the practice of heritage, such as the role and meanings of embodied and shared experiences and the issue of temporality in the practice of heritage, they do not provide a coherent theorization of what constitutes performance per se, which is something I work towards in this chapter. Here, my focus is on performance, rather than re-enactment, because of the broader sociological and a cultural studies perspective I take on the phenomenon of HHMs. In chapter 1, I argued for a wider theoretical perspective on the phenomenon of historic house museums and drew on the work by McLuhan (1997), Innis (1951), and Carey (1989) to unpack my own perspective. Similarly, in this chapter, I argue for a need for a cultural studies perspective on performance in HHMs. While the scholarship in critical heritage studies approaches historic sites specifically as spaces that establish the terms for a relationship with the past, the cultural studies approach allows me to assume a wider angle on what constitutes heritage work within these sites and to consider historic homes as spaces that perform a cultural function by carrying out specific heterotopic work. Continuing that line of thought, I aim to understand performance as a kind of a behavior that is both conditioned by and aims to maintain the structure of meanings within HHMs. Below I provide a wider academic context for my theorization of performance within HHMs.

The theoretical notion of performance was first introduced in the 1960s by John Austin in his work How to Do Things with Words. Austin (1962) does not, in fact, use the term performance, but he does define the notion of a performative utterance, which denotes a capacity to create meaning through the use of language. A good example of that would be the 
pronouncement of a couple as married during a marriage ceremony. John Searle (1979) built on Austin's (1962) work in developing his own philosophy of the rules of language. Searle (1979), while largely agreeing with Austin (1962), distinguishes between constitutive and regulative rules of language and unpacks the semantic rules that contribute to the processes of meaningmaking. Essential to this earlier position on performative utterance is the view on speech acts as a form of rule-governed behavior and an understanding of a speaker as a conscious agent who acts and speaks out of his or her intent.

The postmodern turn in academic discourse on performance was concerned with the relationship between structures of power and the notion of performance, thus shifting the focus from the view of a performative utterance as capable of consummating an action, to its capacity to create and perform an identity.

Derrida (1972) argued that the boundary between performative utterance and the context within which it is made is blurry, and that every word gains its meaning from all its past uses. Thus, the use of language is directly determined by its past and holds the possibility of its future. Further, Derrida (1972) argues that, since one can never understand the meaning of a word in every instance it has been used, every act of speaking is always on the verge of not being quite understood. Butler (1993) describes performativity as "that reiterative power of discourse to produce the phenomena that it regulates and constrains" (p. 3). Her discussion places emphases on the way identity is constructed as a result of performative actions. Butler (1993) explains gender as a rehearsed act, made real through repetition of a normalized script. While I draw on some of Butler's (1999) ideas when unpacking the mechanics of the performance made possible by the time gap, I need to note the major premise in her theory, the idea that the normalized script of gender gets internalized, thus making gender a result of the making of one's self, the 
process that makes bodies socially intelligible. The script informs everyday communication and behavior, and the identity is constructed as a result of performative actions; it is an unreflective process. In the case of performance within historic house museums, a performer is always conscious that he or she creates an illusion of a different temporality governed by an alternative set of rules.

In Gender Trouble, Butler (1999) writes: "If the inner truth of gender is a fabrication and if a true gender is a fantasy instituted and inscribed on the surface of bodies, then it seems that genders can be neither true nor false, but are only produced as the truth effects of a discourse of primary and stable identity" (p. 136). This idea can explain the workings of drag, where gender gets acted out in ways that make its constructedness obvious. I suggest that, within the construct of a time gap, one's belonging to an idea of a temporality and spatiality can be performed, taken on in ways that point to its constructedness without taking away the value of the experience. The "truth effect" (Butler, 1999, 139) stands here, as well. Much like in the case of physical objects that get to take on meanings specific to their location within the museum and in the context of one another, thus bringing into effect what I, in chapter 2, describe as a "trump effect" (an alternative truth that stands within the context of a time gap), a performing body can enjoy a form of temporary validation.

The performative behavior I refer to in this work stands for the behavior and speech that are brought on by and maintain the meanings invested in the environment of a time gap. I would like to draw on Eve Kosofsky Sedgwick's (2003) work in explaining this point. In Touching Feeling: Affect, Pedagogy, Performativity, Sedgwick (2003) unpacks her idea of the periperformative as all that surrounds the performative act, but is not directly a part of it. Thus, the periperformative is the witness and, in many ways, the condition of a performance. To 
explain the concept, Sedgwick (2003) uses an example from Austin's work (1962), specifically the utterance "I dare you." She asserts that this utterance presumably involves a singular first (" $I$ dare you") and a singular second person ("I dare you"). However, the utterance also depends on "the tacit demarcation of the space of a third-person plural, a "they" of witness, whether or not anybody is present at the moment of the utterance (p. 69). The "they," in Sedgwick's (2003) discourse, represents the context that can be objectified, spatialized, and depersonalized: It can be, at once, architectural and visual, moral, political, and institutional. Using Sedgwick's (2003) language, I suggest that the space of the performance within a house museum is never "I-you," but "I-you-time gap." The performative scene incorporates the performer, the audience, and the various periperformative elements that normalize and bring forth the performance by constituting the context within which it obtains its meaning, and by bearing witness to it. The periperformatives, in the case of a time gap, are events, the experiential environment, physical objects invested with meanings, the a-historically contextualized home that is invested with ideas of what a home is - in other words, the periperformatives are meanings invested in the physical and experiential environment of HHM spaces. Periperformatives are not circumstances but the cause and, in some ways, a purpose of a performative behavior in a time gap. They provide an entry into the time gap to a performing body by establishing the script of the performance, and the performing body activates a time gap, makes it work, by engaging in a performance of an alternative temporality.

Further, I would like to address the aspect of playfulness in my articulation of the performative work done within time gaps. I believe there are two qualities of playfulness that time gaps draw on: Playfulness as a form of seduction, a process in which performance emerges as a form of a promise (Austin, 1962; Felman, 2002), and playfulness as a form of disruption. I 
will discuss each one of them separately. Shoshana Felman (2002), in her work The Scandal of the Speaking Body: Don Juan with J. L. Austin or Seduction in Two Languages, analyzes a promise as a form of a performative utterance by reading Austin's work (1962) through the lens of Moliere's interpretation of Don Juan. Her analytical position is within the overlap between that of a linguist and a philosopher. One of the points that Felman (2002) makes is that Austin (1962), much like Moliere's Don Juan, is after enjoyment of a performative utterance, rather than its success. Rather, a promise's ability to misfire (as Don Juan's promises always do) is affirming of its ability to conduct meaning. Felman (2002) writes: "If the capacity for misfire is an inherent capacity of the performative, it is because the act as such is defined, for Austin, as its capacity to miss its goal and to fail to be achieved, to remain unconsummated" (p. 55-56, italics in the original). Don Juan, while always breaking his promises, uses words to get what he wants, thus reaffirming the language's ability to bring on real life changes (At one point, Felman (2002) quotes Claudel to unpack that: "That promise that my body made you I am powerless to fulfill" (p. 42). Thus, Felman (2002) suggests that body exists in excess of its performative speaking, wherein lays the scandal of the body.

I suggest that time gaps draw on the performance's ability to seduce, since it holds an ability to bring on real change. A seduction is also the kind of promise that opposes (or suggests a possibility of an opposition) the stable meanings of the external world. HHMs may seduce in many ways. It may be the seduction of the uncanny, the pull of the horror that one is attracted to and cannot escape; the seduction of the poetic of a stable domestic place uncomplicated by demands of postmodernity; finally, it may be seduction of time travel, of a perceived ability to tap into the workings of a place that appears to be outside the spatial and temporal logic of the world external to it. In many ways, the pleasurable experience of being seduced can be construed 
as what constitutes the purpose of the experience. Much like the promises made by Don Juan, these ones may and do, at times, misfire.

Another function of playfulness within a time gap is its ability to function as a tool of and for disruption. When one plays within the space of a time gap, one acquires an ability to disrupt the status quo without bringing on real changes in the life outside the museum. The tools for playfulness abound within the space of the museum. There are costumes, objects set within an idea of their original historic environment, stories-all woven into a coherent narrative and validated through historic evidence. An example of that kind of playfulness could be an interpreter cross-dressing while doing historic interpretation of the house, during Pride month. Another example of that could be an attempt to try on roles within a historic household or attempt to envision the kinds of relationships one could have with people who lived in the house over a century ago (I unpack this point with examples further in this chapter). Finally, playfulness can be about trying on ideas (political, religious, etc.) about life that one does not subscribe to in reality. Consider this explanation by Liam on how he draws on this property of play in his work as an interpreter:

I'd like to think that the visitor will eventually (...) take on the role of Mackenzie in some way. (...) And it is not gender-specific. It's not like the men are gonna see themselves as Mackenzie, and the women are gonna see themselves as his wife. It is beyond that completely. And I would like to think that eventually, if I am to contextualize why someone gathered together 200 farmers at the corner of Yonge and Eglington and marched into the city, that I can eventually put them in that role. So, I would like to think that if I have done my job well, they could stand in his shoes a little bit. Walk a mile in someone else's shoes, right? They can sort of understand what happened here, then. And then understand how it plays out in the rest of the drama of this place as well. It's not just that. It is "what happened next." How did that influence this. How did we end up where we are now together.

Thus, in this case, playfulness emerges as a way to understand a story better by taking on a role, playing with ideas and life stories without making changes in real life. Further in his interview, 
Liam argued that "performance in a house museum is a disruption that leads to a good understanding of what happens in the contemporary life," thus defining performance as a way of enacting scenarios of social and intimate lives in the past with a goal of understanding both history and the present better.

Following Daubjerg et al. (2014), I want to point out that the approach Liam describes above defines the space of the performance as a space outside of both the past and the present, which is the temporality of a time gap. The performance has to set aside the present, in order to perform the past. It is also not of the past. Daubjerg et al. (2014), when unpacking this issue, refer to Schneider (2011), who suggests that the past in the instance of performance is not not the past; and cite Nichols (2008), who suggests that re-enactments "effect a fold in time," a "temporal vivification in which past and present coexist in the impossible space of a fantasmatic" (p. 88). The work of Goffman (1956) on performance provides an interesting perspective on this phenomenon. In his book The Presentation of Self in Everyday Life, Goffman (1956) offers a dramaturgical analysis of everyday interactions. He suggests that people perform within a setting that consists of a stage and a backstage, where the performance is prepared. The set-up of the stage guides the performance. Both the audience and the performer have an agreed-upon understanding of the situation, which grants performance coherency. Goffman's (1956) idea of the performance is, undeniably, spatial. However, even though my argument focuses on performance as creating a form of an alternative temporality, one may argue that interpreters have a backstage to their performance as well, which allows them to enter into the physical stage of their performances. It emerges as a form of a transitory space between the external world and the heterotopic space of the time gap, where people change into historic costumes, store away their civvies and electronics and then emerge looking differently. In that sense, the temporal 
space created through the performative act within a house museum, the "fold in time" (Nichols, 2008), emerges as a front stage. Even still, the transitory space of the back stage does not exist within the same performed temporality as the front stage; it does not belong to the temporal space of the performance.

Finally, Baudrillard (1990; 2012) offers another perspective on performativity that, I believe, is helpful to my analysis of time gaps. According to Baudrillard (1990; 2012), a performance in postmodernity does not have any relation to reality and is always a referent of itself: The sign relates only to the sign. Thus, there is never a fixed relationship between discourse and the reality outside of it. Performativity itself emerges as a logic of the era, where the model of reality precedes reality. While the properties of a performance within an HHM adhere to Baudrillard's $(1990 ; 2012)$ ideas in regards to the illusory nature of meanings in postmodernity and the blurring of the real and the unreal, performance within an HHM does not have the quality of a magic show. It is playful, without being a hyper version of entertainment. It is a postmodern simulation of the relationship between a subject and an object, without the ecstasy of capitalism, the pleasure of a commodity. While the phenomenon of an HHM is entirely a cultural product of modernity, it is about decommodifying an object, undermining the capitalistic drive of modern subjectivity. Further, I would like to emphasize that, within the space of a time gap, it is the fact that the playfulness is a conscious act that makes it entertaining. Visitors and staff alike are aware that they are engaged in a form of simulation, and thus they can allow themselves to be seduced by it. The playfulness of the simulation is that it is consciously a simulation. 
The Role of the Interpreter: Active agent or a body in costume

In Chapter two, I suggested that the kinds of relationships between material objects, space, and a sensory body that the time gap enables can be described through Merleau-Ponty's (1974) articulation of a human body as "a thing among things" (p. 284). To substantiate this suggestion, I have explored tactile and sensory qualities of a visit to a historic house museum. This very idea, articulated through the vocabulary of a curator, came up regularly in interviews with other interpreters and in my personal experiences. For instance, Ashleigh offered:

I guess you are sort of like a living artifact... A reproduction (laughing), but an artifact nonetheless... So, if you are representing a nineteenth-century woman, then you should be treating the costume, the dress, as a nineteenth-century woman.

In that sense, an interpreter acts as an artifact in space by virtue of being within an environment that turns everything into an artifact-taste, smell, lighting, sounds, or an absence of sounds. The discussion on the performative work, however, done by the interpreters and the audience, takes this discussion further and opens questions of agency, since the becoming of an artifact is, in fact, a form of performance carried out by a willing participant. A quote by Severs (2002) addresses the multiplicity of factors at play here. "From you everything in your sight begins, just as everything in your sight returns to you," he writes, bringing together the notions of the body, agency, and establishing the centrality of the position of a participant in forming the experience of space (p. 135).

My central proposition in regards to the role of an interpreter within a house museum space is that, rather than a house absorbing an interpreter's voice within the folds of its narrative, thus turning him or her into a mouthpiece for an established story, it suggests specific conditions for exercising an interpreter's agency. I believe this not to be merely a form of restriction or delimitation but, rather, an instance of someone agreeing to the rules of a game, in which the 
entry comes forth as an act of an independent agent. Thus, the house simultaneously commands a certain kind of a performance and allows space to move freely within the constraints of an outlined role, as long as the rules of the temporality are sustained throughout that performance. The performance, then, is moulded by an interpreter through the sensory embodied experiences of a costume, the house, responses of the audience, historical and personal narratives, and the sticky impasse that is the notion of time within the space of a house museum. A performer is at once a body being thrown in but also a sight from which all commences. This, in part, addresses the central line of questions the discussion on a performative space is supposed to address: "What is the role of an active contemporary self in construction of these experiences? Do these performances assume deliberation or do they, at least in part, emerge as a result of the context? Can they be consequences of the material setting?"

This perspective explains both instances: When an interpreter may feel very much like an artifact, with tourists taking pictures of him or her without asking permission, and when he or she claims an interpretive right to understanding the workings of the space through being in it for extended periods of time. I am referring, for instance, to claiming a better understanding of where a dry sink would have been located not because one has done a lot of research into configurations of Victorian kitchens, but because of having a lived experience of cooking in one. Thus, as an interpreter, one is both - a part of the narrative, an element in the experience that is a historic house museum, and an agent who makes sense of it from the position of his or her experience, the "sight," from which all begins and to which all returns.

I have observed that there are different levels on which an interpreter can engage with the time gap. This is best exemplified by one's relationship to one's body in costume. There was a stark difference in how my costumed body felt that was noticeable immediately: My back 
straightened because of the cut of the dress, my movements were slowed down by the weight of the hoop skirt and the added consideration with which I now needed to watch my movements, as I walked up or down the stairs and moved past historic artifacts. I found that I treasured this shift. It activated an internal sensory switch that put me into my house museum mode.

This change perhaps added a different dimension to a sense of my emplaced self, but it was not profound enough to keep me from conceiving of my costumed body as a kind of an artifact that enhanced the telling of the narrative of the house, an artifact that could be put together and then disassembled when needed. When asked, I lifted my skirts to demonstrate how many petticoats I was wearing and what a hoop skirt looks like. I also attempted to gauge how far my dresses would allow me to progress in pregnancy before I would have to change them, how fast would I be able to get out of my clothes if my skirt caught on fire. If I were, in fact, wearing historically accurate underwear, and were it not revealing as much flesh as a period piece would have to, I would have been quite comfortable demonstrating that as well. I treated my own self, my body clad in costume, both as a part of this staged temporality to be unpacked and made sense of and as a key to better understanding the conditions of women's lives in Victorian Toronto.

My experiences of a body in costume fall about midway in the range of reactions that I have observed throughout my research. Another interpreter I met in the course of my research has been known to fold her petticoat flat across her chest to let a person past her in a narrow passageway. That was easy for her, because she still somehow managed to wear jeans underneath her period dress. My third example from the other end of the spectrum is Ashleigh, who refused to show her hoop skirt to visitors, inquiring, instead, if they would agree to 
demonstrate their underwear to her. She was also very particular about the historical accuracy of the cut of her dress. This is how Ashleigh explained her perspective on her costumed self:

...I believe if you are going to wear a costume, you need to wear it correctly or not at all. So, if you are not wearing it correctly, you are sending the wrong message and it's misinterpretation. ... so, if you are not wearing them correctly, just put the person in civilian clothes. Because if you make the clothes more comfortable for a modern person, then what you have is a modern person wearing modern clothing. Because the cut of the clothing and the way it is worn reflects a silhouette, and silhouette is part of fashion ${ }^{58}$.

I have found that different depths of internal engagement with a house museum space correlate with degrees of certainty in the validity of one's interpretation of objects within it. For instance, Ashleigh, who treated herself not as a body in costume that is an artifact (like me), or as a contemporary person who happens to have to wear a period dress at work (like the interpreter in jeans), was certain of the validity of her critique of what the museum staff traditionally described as a "petticoat mirror," a mirror imbedded inside a furniture piece traditionally placed in a parlour or at the entrance into the house designed, most think, to check if a skirt was in order. "I cannot see my skirt properly," Ashleigh argued: "It makes no sense to me." Whereas my conception of myself as a modern self, perhaps, would have made me wonder if I merely don't know how to look properly, and the interpreter in jeans under her skirt, perhaps, would not engage with this question to begin with.

I believe that this form of ownership of one's experiences in costume and of the recreated temporality comes with a greater degree of investment in the time gap. There is an observable line there between the kind of interpretation that accepts the narrative given to one and stays in

\footnotetext{
${ }^{58}$ Note that this explanation echoes Severs' (2002) discourse on the shape of a milk jug as being a kind of "signpost" for thinking about a different era. Consider what he writes: "Anything I bought became the centrepiece to my perception of a time in the history (...) As time went on I began to see the shape of a bottle or a milk jug of a particular period as having the same general outline as that age's fashion and design" (p. 6).
} 
the doorway of this temporality, and the kind that relies on lived experiences of performing the kind of being within that space that adheres to its rules, the kind that comes in and rolls up the sleeves. Consider, for instance, Ashleigh's take on the interpretation of what is often described as a "secret" toilet at Colborne Lodge:

Yeah... do you mind if I just go take a look at it? I just want to... (goes to look at the toilet) Ok... I just wanted to make sure that my thoughts were accurate for myself. Unless someone shows me a quote that it's his actual thinking (referring to the house architect wanting to hide the toilet door), I don't buy into it. Just because it's wall papered does not necessarily mean to me that it's secret and it's hiding it. Because there's no mechanism on the door to actually latch close it. And it's in the private side of the house. And there is a door in the dining room that would be closed, presumably no one visiting the house would see it. Or... if they need it, they would still be going to it... and... so, until I see a quote saying that's what he actually had in his mind, I think it's open for interpretation. We all like our toilets discretely placed. I know people who won't buy a house or rent an apartment if the toilet is off the kitchen. We all want them discretely placed, so... I don't know about that.

The costume, in my experience as an interpreter, acts as an entry into the time gap. While that exact thought was not articulated by my interviewees, several of them described the taking off of the costume as something that allows them to "leave the work behind." The feeling of the lightness and the comfort of the "civvies" helps them transition into the world outside of the museum. Questions about the costume were some of the hardest to ask during the interviews. I believe they are the ones that come quite close to the guarded impasse, the production of the "fourth dimension" (Severs, 2002, p.11). There is a distinct experience of otherness in the wearing of the costume that is not often openly discussed. While the costumed body is a performing body, the body in civvies, in my experience, reads as either invisible or else out of place within a historic house museum environment. In chapter 3 on emplacement, I mentioned wearing old jeans and a sweat shirt when assisting during cooking workshops. I found that, while my body in costume had a certain weight, carried a presence, my body in civvies darting in and 
out while my costumed colleague was performing her kitchen duties, was functional, yet lacking in relevant substance.

I also discovered that the kind of substance granted to the interpreter by a costume adds validity to the performance in the eyes of the public, an observation that was confirmed by several of my interviewees. This seemed like an obvious proposition, but I suspected there was a greater depth to it given the complexity of what a contemporary body in costume may represent in a museum space. Thus, at some point in my autoethnographic research, I experimented with this aspect, attempting to give tours alternatively in civvies and in either one of my costumes-the work dress and the parlor dress. Consider one of the earlier entries on the subject in my autoethnographic journal:

Today was one of those days, when I did not wear my costume and regretted it. I always end up regretting it, somehow. It is interesting, however, to think about the differences between conducting the interviews in civvies as opposed to the Victorian parlor dress I usually wear. When I know that I might be allowed to stay in my regular clothes, because my shift is shorter, the day is very hot, and there is renovation upstairs, where we normally change, I try to dress up. So, I wear a professional looking dress and proper shoes. Dressed like that, standing in the middle of the Mackenzies' parlor, I feel more like a trained museum professional. I tend to be more analytical, perhaps, even patronizing of the ways of the Victorians. There emerges a highly defined space of an outsider, which is validated through my museum training and the fact that I know a substantial amount of facts about the time period. The Victorian attire, while not automatically turning me into an insider, makes me sympathize with this world so much more. I cannot possibly be patronizing of the world that I perform inhabiting.

A costume is an artifact that extends the temporality of the time gap into the domain of intimate experiences of a contemporary body. The power of the costume to enhance this experience becomes especially obvious when its function shifts to that of a dress. The shift became apparent when, before I was assigned a proper work dress by the museum, I had to do active interpretation of the kitchen clad in a parlor dress complete with a hoop skirt. Interpreting rooms of the house in a work dress was strange as well: Inviting guests into a formal parlor in something that I wear 
to knead dough seemed inappropriate. Finally, active interpretation in the historic kitchen in civvies felt like a pointless endeavor, like singing without a voice, akin to what Severs (2002) describes as "the millennium without Christ" (p. 24).

The stickiness of the guarded impasse, the fourth dimension that constitutes the time gap, is apparent in the experiences of a performing costumed body. I believe that, to a varying degree, the being in a body in costume contributes to the shared experiential reference for an invested group that are the interpreters. One encounter brought this point home for me: A new administrative employee at one of the museums had struck up a friendly small talk with me. I was getting ready for my shift and casually mentioned that I was slightly worried about fitting into my dress properly, as I had gained a few pounds. This is a reasonable concern for museum workers, since ordering and adjusting dresses is a lengthy process, and we are all invested in costumes fitting comfortably, since we spend hours in them communicating with the public. It was not a complaint, nor was it a request for a compliment. In the shared experiential language of our group, I realized, it meant something entirely different. My new acquaintance assured me that I looked splendid and she had no doubts that all would be fine, a polite and a friendly response, which made me realize it had at the very least been years since she had given interpretive tours in costume. She was not part of the tribe.

This brings my discussion to the next point, the entry into the heterotopic space. Foucault (1986) addresses it the following way:

Heterotopias always presuppose a system of opening and closing that both isolates them and makes them penetrable. In general, the heterotopic site is not freely accessible like a public place. Either the entry is compulsory, as in the case of entering a barracks or a prison, or else the individual has to submit to rites and purifications. To get in one must have a certain permission and make certain gestures. (...) There are others, on the contrary, that seem to be pure and simple openings, but that generally hide curious exclusions. 
Everyone can enter into the heterotopic sites, but in fact that is only an illusion - we think we enter where we are, by the very fact that we enter, excluded. (...).” (p. 26)

The enabling of the time gap, an active entry into it, requires being a willing participant in it, an internal permission to engage with the terms of this heterotopia. "You either see it or you don't" has become an official motto of David Severs' museum. While most visitors are capable of observing spaces and objects within them, there is a profound difference between running one's glance over the surfaces of things and entering the in-betweenness of them - with one's sentient body and mind. The in-betweenness of things does not buzz otherwise. The entering of the heterotopia of a time gap as a performer requires "activating" the space by being present within it with all of one's senses - and then holding it, following its terms of engagement. A rather straightforward example of that would be my struggle to submit to pacing my work during the active interpretation of the kitchen according to the heat of the Victorian stove and the need to feed the fire, rather than an assignment to produce $\mathrm{X}$ number of cookies by a specific hour. The logic of the time gap subdues a contemporary body to sitting by the fire, idly waiting for the cookies to bake, or for the visitors to stop by. One could read, one could knit, until the fire needs to be fed again. A better example, perhaps, of the various degrees of engagement with a heterotopia would be the three ways of perceiving one's body in costume from earlier in this chapter - an interpreter who is a modern person wearing a costume, me with my approach to my costumed body as a kind of a museum artifact, and the interpreter who allows the dress to enable an internal shift to a different temporality ${ }^{59}$.

\footnotetext{
${ }^{59}$ My observations of bodies in costume agree with the work by Adam and Galinsky (2012), who introduce the term "enclothed cognition." The authors establish a connection between physical and cognitive processes and argue that clothing can directly affect people's embodied and cognitive experiences. Adam and Galinsky (2012) suggest that this effect depends on two factors, symbolic meaning of the clothes and the physical experience of wearing them. Their study of how the wearing of the lab coats affected people's ability to maintain sustained and selective attention established the connection between what we wear and how we think.
} 
Performance as Vivification: Relationship between a performing body and material objects

The question of vivification holds a seeming imperative for a discussion on what constitutes death and life in a historic house museum interior, since it implies the possibility of movement between the two states. My answer to this question is that the time gap suggests a third option. In terms of its performance of temporality, it is a heterotopia that appeases anxiety over the loss of time, and as such, it offers an environment in which time acquires an ability to stay static. Nothing is fully dead or alive, it exists in the realm that is to appear unaffected by the passing of time. Severs (2002) explains this phenomenon by referring to the Folgate House as "an inhabited picture" (p. 1). This suggests that life within a time gap may be still, but not absent. Vivification, then, emerges as an act of faith that infuses the in-betweenness with meaning. A movement that adheres to the narrative and physical conditions of space of a historic house museum and the impulses of the body and the psyche that it invokes is also a movement towards the creation and maintenance of a heterotopia.

The task of an embodied performance within the stillness of time is to maintain a life suspended. The capacious embrace of still life is uncanny: It suggests the capacity for warmth, smells, and sounds of human bodies, but does not deliver, much like the promises of Don Juan in Felman's (2002) interpretation. Instead, it offers a possibility of another way of existing through time. The emptiness of rooms, the absence of life is somehow amplified by the presence of traces of it - geraniums blooming on a kitchen windowsill, a nightgown strewn across a bed, awaiting a girl's body to fill it. This still life is welcoming, yet lacking in qualities of a warm body capable of mortality.

The space and objects within an "inhabited picture" (Severs, 2002, p. 1) have to acquire an agency of their own. They function as a story that a performing body can enter and leave. The 
act of entering and leaving endows spaces with an agency to transport a body into what is interpreted as a different age, which is how the collection of items always adds up to an experiential narrative that is greater than the sum of its material parts (Mills, 2003). Ghost narratives surrounding historic house museums gift things with an ability to remember, to carry a residue of character or personality, holding within them the spirits of the deceased. The narratives of a good number of historic house museums come with a story of how the house came to be a museum. In some cases, such as with Colborne Lodge, the story is that of a decades-long abandonment, in some cases, such as that of Mackenzie House or Campbell House, it is the story of salvation from demolition. The houses, like people, appear to have a kind of destiny, to shift and be many things; they also might appear to have a mind of their own, as Mackenzie House does in my story of feeling "expelled" from it. Severs (2002) talks about the house in Spitalfields as calling to him and states that he has been collecting its contents since he was 18. His exploration of his new house started out with sleeping in each one of its rooms to acquire a sense of its spirit, the kinds of stories it holds. Since it appears as though a spirit of the house is already there, the vivifying aspect of the performance becomes about coming into contact with it, engaging the in-betweenness, becoming a body that is thrown into the flux of things (Merleau-Ponty, 1974).

In my experience as an autoethnographer, this kind of engagement with space and the objects within it grew to be a lot more intense than I suspected. That became obvious at the performance of "Firebrand," a play by Alex Dault about the story of the Mackenzies' return to Toronto, that I mentioned earlier. The audience had to move to different rooms of the Mackenzie House Museum to witness different parts of the story, as it unfolded. At the beginning of the first act, as I settled in with about fifteen other people in the Mackenzies' drawing room, Isabel 
Mackenzie's voice came booming from the hallway. She was calling for her daughter Bel. "She is here! Oh my God, it's like she is really here," was my reaction. A disembodied voice pointed to a possibility that something that I had been performing was, just a little bit, real. And that was confusing, scary, and, for lack of a better word, life-affirming.

\section{"This is the House that Jack Built:" People that lived here and the story that never ends}

The intensity of my reaction to Isabel's voice coming from the hallway-the absence of her body before me neither proving nor disproving her existence-was unexpectedly strong. This lack of awareness of the kind of emotional engagement I myself had grown to develop with the story I was telling was the reason I did not anticipate one of the strongest themes that emerged early on in my study-the fact that most of my interviewees had not just strong opinions about the people whose lives and homes they were interpreting. In fact, most of them had strong feelings about them.

The interviews showed that emotions and personal experiences were one of the primary points of entry into the understanding of human behaviors within a historical context. I discovered that there was a range in the kinds of emotional engagements interpreters developed with the stories. Some emotional responses were similar to the way one would react to a contemporary. Consider the following response by Martha. Here, she is admitting to being upset with William Mackenzie for expressing a particular opinion. This is not the kind of anger, however, that makes the respondent decide that this person is not worth his/her attention. This reaction is akin to an angry disappointment with someone who, he/she thinks, should know better, like a relative or a very old friend who, due to years of closeness, cannot be dismissed on the basis of their convictions. This answer came in one of my early interviews, before I discovered the evident need to ask questions about my interviewees' emotional engagement with 
the people who lived in the houses, as a reaction to this unlikely question: "Do you think the time you have spent at Mackenzie house affected the way you think about the past?"

(...) I think with Mackenzie, the person, there was more of a breakthrough from... being able to envision these flesh and blood people, because Mackenzie's flaws are so relatable. (...) ...like when it's complaining about how tired he is. And why are people bothering him to get the newspaper out on time, he is busy, that kind of thing. It feels... there's no barrier between how a modern person would complain. I find him the most relatable individual. And through him... and through other people, the past seems like another country, but it wasn't really. The same bothers and the same delights were present then, so yeah, I do find that via Mackenzie I was able to sort of stop thinking of people in the past as almost fictional figures and see them as... real flesh and blood walking the streets of Toronto just because his words are so relatable a lot of the time... even when you are mad at him. Even when you feel: "Oh God, why did you say that..." But you know, that's not unusual with a modern figure either, so...

\section{Me: You mentioned that you sometimes can feel mad at Mackenzie?}

Well, sure. I mean... there are periods when he is not likable. Every year... or every two years, rather, we get a group from Penn State and Ryerson who want to talk about Mackenzie: The American years. And we don't talk a lot about Mackenzie and the American years here, because you know, there's too much to talk about otherwise. But he is kind of a pill for a part of that time, you know... He blames Black citizens of Toronto. He feels: "Why didn't they help me? They should have helped me. And if they have known better, they would have helped me." And you just sort of want to give him a smack. (...) So if somebody asks... you know... I would never pretend that Mackenzie is a hero or a role model... he is an interesting guy at an interesting time.

As the interviews progressed, it became obvious that the relationships my respondents developed with the inhabitants in the house were multi-layered, formed over long periods of time, in some cases decades, and that they, in part, were a result of, on one hand, continuous research, and on another, a baggage of lived experiences that could be used to connect to the choices and grievances of the former inhabitants of the house. Either way, the continuous quest for deeper understanding was evident. Consider the following passage from an interview with Martha, in which she comments both on her emotional and her intellectual engagement with the story:

(...) any little fact I can dig up on Isabel is always so gratifying, 'cause you have to work hard to find it, but until this year, even after all these years here, I did not really have a window onto Isabel, but with these little facts and realizing that after the Rebellion she has 
a choice of either sequestering with the kids or going after him. And the fact that she goes after him to help, that she takes that risk. I started to imagine all the tasks she would have to do to actually go after him. Destroying the papers... maybe, at least that's part of the whole folklore, hiding the printing press - maybe [a few words here undecipherable], but certainly taking the kids to Kingston, begging permission from Sir Francis. And I was finding it very... I was telling the story as part of the "Unlady-like" tour this week-end, I was thinking how frightening... I was able to feel the fear for her a little bit, because... the fact that she does not know how this journey is going to end for her when she sets out after him. Will she be attacked? Because she was travelling on her own, which was considered a major breach for a woman to do, but also she is the wife of the most wanted criminal in Upper Canada. She must have known that her life was in danger throughout this. And then in danger again at Navy Island. But the fact that she decides to do it. Because I guess, when I first started here, I saw her more as a sort of patient help-maid, but she is starting to emerge more as her own determined person who did not always agree with her husband. I saw a quote recently saying that full family was reformed, but she did not support the Rebellion.

The shift between conceiving of the people that used to live in the interpreted homes not as historical characters but as fellow humans becomes both more complex and obvious when interpreters begin to unpack relationships using their own lived experiences. Consider this perspective offered by Ella:

I come from a family of politically oriented people. I was raised in a very political family. My father is a public political leader. Not party politics, but politics. But there were a lot of people who thought he was great. They would call him up in a crisis. He was a leader of his union. So, a lot of people saw him as a great progressive leader, and he was all of those things. He was also a really nice guy. But at home! Oh my gosh... here he was, fighting for women's rights in the workplace, and all that stuff... equity, equity, equity! But he could not iron his own shirts! Right? And I ironed his shirts every morning. So, the gender stuff that was happening in our house... not reflective of what was happening personally... so when I read about Mackenzie... I think what was really going on in his house? And I do find I have to be careful about how much about my own experience and my own family... recognize when I sort of... am putting stuff on Mackenzie. Because I feel again...

progressive, very public figure... but I know that the external image and the internal reality can be really really different... and there is so much evidence that it is! For this man... in that he was so charismatic, but his living situation was such a disaster. And I do find I have to be careful to recognize the difference between what I know about Mackenzie and what I think about Mackenzie...

Me: Because we spend a lot of time with him... in one way or another...

Yes, and definitely developing feelings... I do say to people: "I don't think I would like him." And I think that has to do with some of the characters, the people I have met in my 
life. I do say sometimes: “And the baggage I have about certain personalities... I don't think he is someone I would enjoy spending time with."

This trying on of the historical figures' lives, as one does with his or her costume, allows for effortless shifts from historical interpretation to an openly creative performance, as the ones, for instance, that a Mackenzie House staff member reenacts during the Mackenzie House cemetery tours. In order to explain the relationship between Janet Mackenzie, a strong woman who appears to have inherited her father's fiery temper, and her husband, Liam, the interpreter who in that context was acting as an actor, in a first-person monologue suggested that it is ironic that things that may draw one to a person can make it absolutely impossible to live with them. One can be initially attracted to the passion and the drive, but these are exactly the things that might make her unbearable as a life partner; one can be drawn to a flame, but keep on getting burned throughout his life. My suggestion here is that without the invested relationship between the interpreter and the interpreted lives, the stories of the families would be dry timelines decoded from letters, census data, newspaper articles, entries in a family Bible. Active emotional engagement with the lives of these people brings out the complexity of a historically contextualized human life. It also points to a need for a form of transference as a point of entry into this interpretation. This approach to understanding the lives of people long dead is similar to how interpreters grow to make sense of historical spaces and material objects within them - by inhabiting them and by using them. It is also illustrative of the approach to social history assumed by historic house museums - it suggests we unpack the whys before we attempt to understand the whats. This is how Ashleigh explained it:

(...) an object is more interesting to me if you tell me why it is here, or how it fits in. It sort of goes back to historiography. Ceasar crossed the Rubikon is a historical fact, but it's not history. The why he crossed and the implications of his crossing, those are the history. That's what I want to know... I don't want to know the historical fact about the object, I 
want to know why it is here, how it fits in, which is why I think personal hygiene is so much fun to interpret... and the kitchen. Because everyone can relate to those two things.

Another feature that, I believe, captures the relationship between the performing body and the personal stories of people that inhabited the house is the cathartic effect both the performance and the exploration of other people's lives appear to have. The house, in this case, emerges as a mediator between ourselves and the imaginary, and the lives of people long dead function as a way to make sense of our own, to validate our misgivings, to release oneself into the human nature that is the reason behind the progression of history. In looking back, one eventually ends up witnessing images of one's own self, and the exploration of the house becomes the experience of one's own psyche. The movement away from the current emotional condition becomes a movement further into it. While the mirroring function of a heterotopia transcends far beyond the cathartic qualities of an embodied performance, this particular quote from Foucault's (1986) discourse does help to further unpack this point:

Starting from this gaze that is, as it were, directed toward me, from the ground of this virtual space that is on the other side of the glass, I come back toward myself; I begin again to direct my eyes toward myself and to reconstitute myself there where I am. The mirror functions as a heterotopia in this respect: it makes this place that I occupy at the moment when I look at myself in the glass at once absolutely real, connected with all the space that surrounds it, and absolutely unreal, since in order to be perceived it has to pass through this virtual point which is over there. (p. 4)

I considered why something so charged as an emotional relationship between interpreters and the people they interpret had escaped my attention at the exploratory stage of my research, a project that, in part, attempted to determine and understand the kinds of connections the people formed with historic house museums. I even remember being surprised at some point by another trainee figuring out that she was the same age as Isabel was when she moved into the house in the 1850s. I wondered why that would be important and felt uncomfortable with the kind of 
relationship with the people in the story and their house that this statement suggested. The researcher in me, I believe, was fighting to claim a sort of detachment from the personal context of the house, the personal being equated with "not professional," objective, threatening to the very purpose of my time at the museum. The researcher in me was encountering a museum interpreter attempting a certain level of historical expertise. Gradually, however, I grew to realize that I, unbeknownst to myself, developed a strong emotional response to a person about whom we know the least, Isabel Baxter Mackenzie. What we do know about her is overshadowed by the grandiose figure of her husband, the leader of the Upper Canada Rebellion and the first mayor of Toronto. At the same time, the details of her life point to a woman of impossible emotional strength, determination, and intellect. I find this lack of information on her daunting, as if all I have is a general outline, a hint of a mystery. It was the opaque outline of the object of my emotional engagement that made it easy to conceal it from myself. I have walked the path from a researcher, a museum interpreter attempting to gain a sense of a professional detachment, to someone who was eventually overcome by the conditions of the house and the kind of storytelling it compels. This is how Martha commented on one's journey through this process:

...I think working here you realize that people are multi-faceted. More than it may first appear. And that you are not going to get the full grip on the person maybe within that first couple of years. The more research, the more research, and a tiny fact can shine such a light. You can't judge by the words, you have to judge by the actions. And the actions sometimes can be incredibly illuminating. I don't know if I would have had patience as a student to realize that you just have to wait it out. That you won't be able to find all that you want to find right away. You won't know everything within the confines of this one project. But if you keep going, gradually more and more stuff will come to you. I think this is part of the enjoying of the Mackenzie House as well. Knowing that there's a lot of stuff as yet to be discovered. There are still undiscovered things about this family.

There is always hope that a collection of journals by one of the more opaque characters will show up in someone's attic, a hope voiced by several of my interviewees, for instance, in regards 
to Jemima Howard of Colborne Lodge. Since people who once lived in houses emerge but through hazy outlines, their actions filled with feelings and histories of our own, the house, while perfectly still, presents a fluctuating story. This changing nature of the narrative, the fact that it is unpacked and, at times, understood differently by interpreters, adds a lived-in quality to the domestic space, contributes to the effervescent quality of the experience of the time gap, which offers a form of being that is beyond life and death, that is neither stagnant, defined once and for all, nor is it animate.

\section{Performance as a Site of Connection with an Audience}

One of the things that substantiates the working of the time gap is the coming together, the entering of it by people, the continuous performative retelling of the story through any activity that enhances the experience of the "fourth dimension" (Severs, 2002, p. 11). Here, performance emerges as a communal activity, which can be more or less successful depending on the kind of contact that is formed between the parties. The interpreters, then, act as gatekeepers who welcome the visitors into the fourth dimension, exhibit ways of making sense of the time gap. Most of my interviewees cited good contact with the audience as one of the greatest sources of satisfaction in their work. This also became obvious in my day-to-day conversations with my colleagues and my personal experiences. This is how Ella described experience that gives her most enjoyment at work:

I love cooking programs. I like groups. I like anything with a group. I think that... six to twelve people. Having a small audience and being able to make them laugh is really enjoyable for me. And being able to connect. Seeing people make connection between their lives and the lives of the family in really meaningful ways... like when we are doing cooking programs... I feel like people are able to see... feel like they can have a conversation with the women who lived in the house, because when it comes to food, there is so much you can talk about. Just like today... provided translation services, you can have a conversation with anyone in the world about what they eat, and how it's prepared, and all this kind of stuff, so... it's so easy to reach past the boundaries of space and time, when you are dealing with something as familiar as food... or how people sleep, and what 
people wear, it's just so easy. Everybody is an expert in what they eat, what they wear, what their bedding looks like. And so for me, seeing that when I talk about a mundane person's... Mackenzie's life... and they are able to respond with authority to what I'm saying by making the connections to their own lives... that I find immensely satisfying. Because I would find it very dissatisfying if the people left and what they've learned is that there's someone in that museum who knows a lot of stuff. That there's an expert in there.

The conversations at the cash register after the tour is over inevitably focus on what happened during it, what questions were asked, did the visitors get into it, often with a room-by-room description of people's reactions. There is a very deep kind of dissatisfaction that arises from not being able to form a connection with the audience after trying to engage them using every possible angle. In my experience of giving tours for two and a half years, that only happened once. Consider my autoethnographic description of that experience:

Somehow, I had only one tour today: A gentleman from New Orleans, a fashion designer. It was the most confusing tour I have ever taken a person on. It was very difficult to gauge what he was interested in. I got a feeling he was mostly interested in telling me things himself, but that he would need to respect me more to do that. Had a lively discussion with him on the history of men's collars in the XIX century and that was my greatest accomplishment after spending my 45 minutes trying out different ways of telling the story and failing every time. The collars were the only angle I have found. I felt exhausted after, the whole ordeal felt Sisyphean.

Most tour guides with very rare exceptions have a contingency of stories that bring people in.

Some of these can be quite sensationalist and involve illegitimate children, extramarital affairs, mental illness, and ghost stories. I have observed that this tool set becomes quite refined over time, with some interpreters developing subtle turns of phrases they use to "shake up" the group, to bring them back in, if the visitors' attention feels scattered. Ashleigh mentioned the following:

one of my favorite questions from children... or anybody... was how many children did they have. And I answer the question the same way here... I may get the numbers wrong. I say "Mackenzie had 13 children. Isabel had $12 \ldots$ and here, Jemima had no children, and Howard had 3." 'cause then immediately "uh?" 
Here, Ashleigh used the cue to discuss a larger issue in social history, to engage the visitors in a way that forced them to question the foundations of what they thought they knew about the age.

She continued:

Because people have this context of relationships... and monogamy... and premarital sex being very...

Me: Like it just never happened?

It never happened. That's right. It never happened. They never engaged in fornication, they never engaged in extramarital sex. And I would use this quote: "There may not have been much divorce, but there was plenty of marital break down." And people don't see it... it's nothing new, it's just easier to get out of it today. With the lower classes, it was also very easy, you could just: "see you later." And go have a date with somebody else. So, I guess I really do like the personal side of history. But I like telling everybody's history at the same time... although it is sensationalist, but it is stories that people love to hear.

I have observed it to be an established practice to invite the visitors to make an imaginative leap and attempt to envision themselves as inhabitants of that space in that time period. As an interpreter, I felt more comfortable contextualizing the experiences of womanhood in the tales of everyday life: I specifically asked my visitors to consider where they think water for the house would come from. How would they get it into the kitchen? How much water they think they would need a day considering there were five people living in the house? How would it feel to carry out that task in the winter, etc. Ashleigh, when further elaborating on the issue, described the approach she takes in her interpretive work the following way:

... at the Fort (Ashleigh is referring to the Fort York National Historic Site in Toronto) we would have much larger groups. So, it was not uncommon to have a class of thirty-odd students with you in the soldiers' quarters. And the soldiers' barracks are meant to accommodate 32. And that could include up to four families in peace to two families in times of war. And so I would use the room as an example of living conditions for that class... for them to imagine all of them living in that room in that space. That many of them, in that space. And generally speaking, the students then start with: "Oh my God! There is not enough beds... where's the toilet? Where is this? Where is that?" So that leads to them trying to put themselves into the life ... and how they would cope with living in those conditions. And they come up with the questions and try to figure out the answers themselves. I prefer trying to form discussions, so the kids would figure out the 
answers on their own, rather than telling the facts. So to speak... saying "how would you all sleep in this room? Where would the married people sleep?" I prefer having the kids tell me the story. Have them figure it out, than me just regurgitating all the information. So the soldiers' barracks was a very easy place to do that.

This interpretive tactic draws the audience into the figuring out of the space, joins visitors and tour guides in their effort to make sense of the fourth dimension. This coming together over the making of the story is not unlike coming together over a table to share a meal. When a true contact is established, all the participants share in using the house, its stories, and the performative body of a tour guide as a mediator enabling their imaginative and, at times, emotive leaps. In performance studies, this kind of a performative act on behalf of the gatekeeper enabling these processes, an interpreter, is described as a "closed loop feedback model" (Tedlock, 2005), a kind of performance in which the performer is feeding off emphatic reactions of the public. Tedlock (2005) describes it the following way: "Such performances operate on a feedback principle of approximating reality by checking the details and the refining the representation in a reiterative or "closed loop" approach" (p. 470).

To conclude this section, I would like to note that one of the key aspects that determine the meaning of the performance for the audience and for the functioning of the time gap is that this way of engaging with the site and the temporality it holds requires that ideas should be embodied, symbolically communicated through human behavior. This adds a very particular kind of aura to the encounter with the site as an experience that cannot be reproduced and that is immediate. Thus, one of the key values of the performance is its irreproducibility. A brochure can be copied, a recorded audio tour can be played over and over again, but a walk through with a tour guide cannot. I believe this quality of the performative behavior within a historic site holds several intriguing research questions that I could not approach within the parameters of my 
research: What is the relationship between the transiency of the performance and the permanency of a temporality and a materiality it is attempting to affirm? Does this transiency hold different meanings for the public who, upon leaving the site, observe interpreters staying within the house as if inhabiting it? Which meanings does it hold for the interpreters? Is the transiency of this experience a manifestation of the time gap giving into what it is contenting? Is it, in fact, the defeat of the mirror? The following quote from Baerenhold et al. (2004) would help unpack this point:

Anticipated by expectant and impatient children, constructed with engagement and eagerness the castle rises as the masterpiece, the high spot of the day. For a couple of hours the castle is centre stage for the performance of play, and the applause of an admiring audience. It is the centre for this happy moment of pleasure and joy. As afternoon arrives the sea rises and slowly erodes the fortifications. The family leaves. Waves roll gently on the shore and at the end of the day no trace of the performance of the day is left. All is washed away and the castle only towers in the memory of the family, on the celluloid pictures brought home, and the anticipation of the next day on the beach. (p. 3)

\section{Positioning of a Performing Body in Relation to the Space of the Museum}

In unpacking the ways in which a performer may engage with a historic space, I had to consider the division between domestic and administrative. I have come to the conclusion that this division within a historic house museum is not given to concrete categorization and quite difficult to control within a rigid administrative structure. In my research, I could distinguish three specific areas in which this clashing between an intuitive and organic being (a kind of inhabiting) within that space and a perspective on a museum space as an institution is expressed. This conflict comes forth on the level of the intimate aspects of one's relationship with the space, in instances when a museum worker develops a perspective on his or her environment that transcends the position of someone who enters the space to interpret it and then is able to leave it behind. The next level is the division between the use-value and the artifact-value of the material objects within the museum space, instances when the uses of the space as a site of the domestic, 
or a space where the past is vivified through the performance, conflict with the imperative of conservation. The third level is the domain of management, instances where the staff's perspective on the running of the museum exposes the position akin to that of running a household.

My understanding of the staff's relationship to the space of the museum benefited greatly from an interview question that dealt with a favorite part of the museum year. The patterns began to emerge quite quickly with the majority of answers referring to the seasons and what those feel like, rather than a thematic or a programming period in the museum cycle. The following answer by Martha, for instance, is representative of the general trend:

...having the garden in bloom. Walking through that garden a couple of times a day, I think, is good. When I was up at Spadina, I would always take a little while and walk through their garden. Have my break at 3:00 and eat an apple and get outside a little bit. But there are benefits to all seasons. I guess the season I probably find hardest, and this is more due to my personal sensitivities, is October to December, because I miss the sun.

While all of the interviewees also referred to the content of programming or the kinds of museum responsibilities different seasons entail, the answers, however, often established connections between these responsibilities, the seasonal changes as reflected in the performance of the museum, and how that informed the staff's experience of the site. The following answer from Ella, for instance, is especially revealing, since she is openly referencing an alignment of an internal sense of the year and the space of the historic house where she works:

I don't like the winter just because we are not open very much. So, we are closed Monday through Friday, so we are only there on the week-ends and for education programs. And I feel very disconnected during that time. So, I don't like it from that perspective, I like to feel... like being a museum is sort of a continuous thing (...). I feel perpetually disoriented in the winter time. So, I'm not crazy about that. 
Shifts in a museum year closely follow seasonal changes in the lives of people outside of the museum, as well as the seasonal rhythm characteristic of a domestic space. Thus, on one hand, there is a rhythm to a year determined by the flow of tourists in the summer and the school calendar. On another hand, there is also an established calendar of special events associated with Christmas, Halloween, Remembrance Day, and other occasions. Decorations within the house change, and so do the smells, the selection of items in the gift shop, the size of tour groups, the kinds of programming that the staff do. The shifts in the work of the museum and changes within the space of the historic house are reliable, they always come full circle and echo the cycle of social life outside of the museum.

The answers that addressed seasonal changes in the domestic environment have inevitably brought up the issue of temporality in the construction of the house museum space. The question these answers dealt with might as well have been: "How does the experience of a temporality shift through seasons in its expression as a space of the domestic?" The following is an example of an interpreter, Ella, contemplating the relationship between the idea of seasons now and in Victorian Toronto in response to my question:

(...) I think fall is a very interesting period for museums of that period because it's so much of preparing for the cold and the dark and all of that. (...) We are talking this year about actually getting some canning happening this fall... that we will actually both in terms of interpretation, but also in the modern part of the museum get ourselves ready for winter by doing some canning and all that kind of stuff. (...) I think that's interesting, because it is juxtaposition to now, when really what we are thinking that "Oh, it's cold, we won't be able to be outside as much." People today are thinking: "Oh, it's going to be a little depressing in the winter." And that I think is the way that a lot of people today think about winter, just sort of in terms of the mood, but not in terms of...

Me: Upkeep?

Well, yeah, for Mackenzies, I think, we are not talking about survival. We've moved out of "Are we or are we not going to survive this winter?" But still that idea to having to really plan and provision for yourself and having to really be ready for these dramatic changes that were going to happen. Same thing with spring. A couple of 
years ago we did an actual spring baking workshop, and that was really interesting, because we were able to talk about rhubarb and how exciting it is to actually have something real, like, fresh to eat. And I find that an interesting juxtaposition to the way we experience food today, where we have whatever we want, wherever we want. So, I find that kind of thing really interesting. I think the two ends of winter are really interesting times. And help us really understand some of the significant differences between the life then and the life now, life before and after refrigeration.

My intention in unpacking the staff's relationship with the museum seasons was to suggest that the duality between the administrative management of the museum as an educational institution and the being within a historic house museum is not a neat binary. The kind of work that these spaces require transcends the museum-house binary and reflect the nature of the space that is both public and domestic; contemporary and an embodiment of its own kind of a temporality; a space that extends beyond itself into its natural environment, while being locked within its own interpretive narrative. Hence, I see my operative use of the binary in this analysis as instrumental to dissolving it.

The kitchen happened to be the first place where I articulated that my relationship with Mackenzie House was now informed, in part, by a sense of ownership and belonging. This telling moment would not have occurred had I not shifted roles from being a tour guide and a cooking assistant to a paying guest, for the purposes of this research. By that time, I had been assisting in cooking workshops at Mackenzie House for about two years. I quickly realized that being just a "visitor" is quite challenging, after you have been regularly involved in "running the house" for quite some time. I was so used to cleaning up, changing the water, and generally making sure that the kitchen ran smoothly during those workshops, that I did not manage to snap into the participant role for the entire length of the workshop. This appears to be a common experience among the museum staff and it is not specific to kitchen workshops. 
I discovered, that in the case of the Mackenzie kitchen, there was so much intimacy in my acquaintance with that space-I cooked in it; I interpreted it, acted as a host when conducting tours, dressed in period clothing, as if inviting people into my own kitchen, my own everydayness. I also acted as a help-girl when assisting in workshops - quiet, quick, efficient, unseen, dressed in old jeans, and, when I remembered, an apron to keep the grease off an old sweatshirt. I dashed around with dirty dishes, clean dishes, ingredients, fed the fire in the stove, made sure people had chairs to sit on, poured them tea. The day I came in as a visitor, I kept the gaze of someone who knows where the pots and pans are. I would have felt embarrassed if something went wrong, I realized. As if it were, in some way, my home and my kitchen.

This entanglement of an active self with the space, which is apparent from my example, is by far not a rare occurrence among museum workers, as it became obvious from my research. Here is a simpler example of another interpreter in a similar predicament: One of the museums ran an event "with a touch of anarchy," where visitors were invited to interact with the space on their own without being led through the house by a tour guide. The one interpreter on duty was to wear civvies and take care of signing people in. And yet, she could not stop herself from interpreting the space, long paragraphs of historical information and stories about the family pouring out in response to the visitors' questions. She apologized every time, suggesting that she just cannot distance herself from the space.

Parts of the houses that are used for active interpretation (hands-on experiences and interpreting through demonstration) are also the sites where the boundaries between use-values and artifact-values of material objects and spaces appear to be negotiable to a degree. Most rooms in the house contain objects that can be touched by visitors. This may vary from being able to examine what a horse hair seat cushion feels like to the touch, how it is similar to silk, but 
sturdier; to having the option of putting on a hoop skirt, a corset, and a petticoat and walking around the room. The boundaries of the visitors' interactions with these objects are established by the museum management. Active interpretation, however, is quite literally a messy process with possible situations of force majeure-bottles of ink may get spilled onto hundred-year old surfaces, pieces of firewood might appear to be the right size, but then get stuck halfway inside the burner, the bottom part already catching on fire, the top part sticking out of the stove.

When I was first learning the ropes around the historic kitchen, I took to asking: "Is this an artifact? Can I use this to cut out cookies? Roll out the dough? Can I pour water into this?” Most times, I would be getting a definite "yes" or "no." At other times, the answer would be: "Is there an article number on that thing?" Thus, by the time I had reached a verdict regarding a museum object, I would normally have already developed an applied and immediate use for it, considered it as a solution to my problem, examined it for evidence of age, and tracked down my program officer, object in hand.

The article number answer does seem obvious, but even here not everything is particularly straightforward. A historic kitchen is a room that is used for one of its original purposes, cooking, but it is also a curated space, where objects are interpreted and preserved. Thus, a space where objects are preserved is also a space where people spill, eat, burn fires. Is there a way to attach an article number to an original stove? I addressed the question of whether or not original cookware could be used in cooking to a historic cook who has either cooked or taught workshops in three of Toronto's historic house museums. The answer was: "I think there is wide range of opinions and practices on this subject. Generally, the questions seem to be will using it cause damage? Are they plentiful and easily replaced? Cast-iron baking bread and tart 
pans are used in many kitchens because they are basically indestructible and there are lots of them around."

This transcending of the museum space as a site of preservation that can be managed to a space that is lived in and actively used is apparent also in how historic spaces are used. Some of the historic house museums have what they call "modern" spaces added to the original building. Such is the case with Mackenzie House, where the addition houses a modern kitchen, washrooms, laundry facilities, and a printing press. Even there, however, the original dayroom is used for interviews and staff meetings. Both at Colborne Lodge and Mackenzie House, I was able to carry out my interviews with staff in restored spaces of the historic house - a dayroom, the front parlor, and the kitchen.

The entanglement, which suggests a relationship with the space of the museum that, on one hand, transcends the boundaries of a job, and, on another hand, questions the functional binary between a government institution and a living domestic space within a historic house museum, in some cases is expressed through how the museums are run. In the fall of 2015, a newly hired program officer at Colborne Lodge was faced with a peculiar difficulty. She had discovered that the previous officer in charge kept next to no record of the specifics of what was done in preparation for special events in the house. For instance, the fall fair on the museum grounds, which is a regular event that locals have grown to expect, features potatoes baked in coals and apple cider cooked over an open fire. "How many potatoes would we need?" my interviewee wondered: "300? 600? I had no idea..." The same applied to the order of apple cider, and to preparation for Christmas. The new officer had to walk through the house with the staff that had worked there for a long time, asking them what they remembered about decorations that went into each one of the rooms. Somehow, for someone to just know what was required to 
have the house museum running smoothly was sufficient for years, a scenario which seems improbable in operations of a government institution, but worked well for a house museum. The new officer ended up having to call the usual suppliers and ask them to deliver "the usual amount," which somehow extends this operational model beyond the boundaries of a museum into how it can be perceived by the community: A museum that can be a "regular" and require a consistent supply of potatoes at regular intervals.

This same non-linearity in the meanings and uses of museum spaces can be exemplified by a misunderstanding between the fire department and the Mackenzie House Museum that happened some time ago. One of the staff members had started the fire in the stove first thing in the morning in preparation for a day of cooking. It would be hard to establish now if it had perhaps produced inordinate amounts of smoke, but she was monitoring it and obviously felt in control. In fact, the staff member was getting the ingredients ready when a team of firemen in full gear came barging into the historic kitchen through the window, determined to save the museum worker trapped inside. The smoke alarms had been triggered at the fire station, and it took a while to explain that all was, in fact, as it was supposed to be.

I would like to emphasize the thesis that I consider from a variety of viewpoints throughout this chapter: Within a historic house museum space, performance is inseparable from the environment that it infuses with meanings. Drawing on Sedgwick (2003), I suggest that the architectural and visual environment, objects within it, special events, rituals of the yearly cycle of interpretation, and interactions with the audience environ the performance, stand witness to it, emerging as a condition within which a performance gains its validity, but also a purpose that justifies the very need for it. 
During his interview, Liam suggested that "real things connect people with something at a distance," although he could not quite explain what that meant. From the vantage point of this study, however, I would like to suggest that the distance he is referring to is the distance of time, and the performance within a time gap is something that allows one to bridge that. Performance, then, is the reach through time that brings an object-a house, a plate, a printing press-into the actuality of a "fold in time," the temporality of a time gap (Nichols, 2008, p. 88), giving it weight and validity. This proposition explains two other points made by Liam in his interview, which resonated with observations made by my other interviewees, as well. Liam stated: "We tell stories with things here, that's all we got!" He also described historic artifacts as "an element of truth." Without an authentic object, then, there would be no distance to bridge, and the performance would just be a mere act of play-acting that does not create or maintain spaces capable of holding an alternative temporality. 


\section{CONCLUSION}

Let me end by briefly exploring the implications of this dissertation for the work of historic house museums from the point of view of them being instances of time gaps, museums, and sites, where meanings of heritage emerge.

I imagine myself walking into the Mackenzie House Museum kitchen. I am wearing a work dress, which is supposed to be easier to do things in, except I can still only carry one thing when walking up the stairs, and I still need to navigate around furniture in ways I do not when wearing jeans. The dress will feel heavy, but putting it on allows me to submerge further into a space outside of the concerns that haunt me outside of the historic home and to focus more on what I am about to undertake. I need to get the fire started in the stove before the museum opens to the public, and I give myself about an hour to get it to the temperature I need. I want it scalding hot, because I imagine myself wanting to bake that day, which is something I do in my life outside of the museum, when I am feeling creatively stumped. I will find the measured pace of the baking process and the absolute quiet of the basement room-safe for the sound of the logs crackling-creatively nourishing. I imagine myself bypassing a stack of newspapers in the crate and using my dissertation to start the fire. I imagine ripping the pages into strips, slowly; the physical energy of the burning paper creating so much heat that, first the kindling, then the logs readily catch on fire. I imagine the fire being really strong, furious almost, and so I would rush to contain its wispy tongues within the belly of the stove; I would need for the heat to rise all the way to the baking shelf. I imagine using one of the recipes that is rarely used. I would want something quite complex to be a result of the next five hours in the kitchen; I would want it to be a rare experience for whoever comes to the tasting. 
This imagining is a way to bridge the experience of the writing of this dissertation in the world outside of a historic house museum and the making sense of it from the point of view of the workings of the time gap and my performance as an interpreter within it. In terms of the work of a time gap, I suggest, the physical burning of the dissertation that works to enhance the experience of the house as a phantasy of a lived-in domestic space, among other things, would make sense. Further, my personal catharsis of resolving a number of emotional issues accomplished through the process of burning and baking would also feed into the heterotopic work done by HHMs within the personal life space of my modern self.

In terms of the practical implications that this dissertation has for the interpretive work of historic homes as museums, I suggest that my research helps discern the qualities of an HHM experience that help enhance the kinds of experiences of history that visitors and staff are drawn to, and the kinds of interactions with objects and between people that facilitate the learning process within the space of a historic home. In that sense, my work supports the discussion by Franklin D. Vagnone and Deborah E. Ryan, who unpack it in their book Anarchist's Guide to Historic House Museums, and on Vagnone's blog, Twisted Preservation. Vagnone's and Ryan's (2015) work is written as a form of criticism of the mainstream approach to running historic house museums: In general, they suggest, a visit to one is not unlike being invited to dinner at your best friend's house, but then being asked to stand in the hallway and listen to someone talk about the food being served. The authors argue that historic homes need to be interacted with in ways that allow visitors to explore them as lived-in environments. The point is to allow a visitor to experience a historic space from the point of view of a socially, politically, and culturally situated modern self. For instance, one of the rubrics on Vagnone's blog is titled One-Night Stand. In it, Vagnone explores the physical, emotional, and intellectual aspects of his experience 
of spending a day and a night in various historic homes across the United States ${ }^{60}$. While Vagnone's and Ryan's (2015) work is focused on the practical aspects of interpreting an HHM space, my work, I believe, helps uncover what makes these experiences work, what constitutes their value and the need for them.

Finally, as far as my contribution to the field of critical heritage studies is concerned, I suggest that my dissertation helps to further the study of heritage that considers it as a dynamic and immediate process that helps establish connections between the past and the present that may assume a variety of physical and performative forms. I would like to illustrate that point with an example. On the second floor of the Post Oak Whole Foods Market in Houston, a sign on the wall reads: "Reclaimed brick from historic Milwaukee buildings." The printing is done right on the surface of the bricks-there is no plaque to signal a designation by some kind of heritage board. It has an "old times" and a slightly "hipster" kind of a feel to it, with slightly outdated typography and the kind of inexactness of lines that comes from doing-or pretending to do it- by hand. The sign does not offer any further information: Is there a connection between Milwaukee and Houston in respect to the purpose of the demolished building? Is there any significance to the wall made of these bricks being directly above the Whole Foods brewery? The sign simply states the provenance of the material the wall is made out of: The bricks were elsewhere a long time ago, they added up to something else that had a purpose and use, and now they are here, being this. This suggests that there is meaning and value attributed to the material quality of the bricks beyond them being a means of construction, the kind of value that justified transporting bricks across the country to build a wall. The very to-the-point nature of the sign suggests that

\footnotetext{
${ }^{60}$ See, for instance, Twisted Preservation. (2017). "One-Night Stand: The quiet voice of bricks" [blog post]. Retrieved from https://twistedpreservation.com on April 17, 2017.
} 
this value rests entirely in the bricks' provenance - their age and their having been something else. It also suggests that their provenance changes what they are, constitutes their significance; grants them an ability to take this presumably innate meaning with them, wherever they go. This value is not significant enough, however, for the bricks to be allowed to keep their original color or even the signs of their aging - the walls are painted a uniform grey to go well with the ambiance of the store. This allows the store to preserve its anonymity, to keep its quality as a non-place.

I cannot think of any other grocery store chain that would move old bricks from out of state to build a wall, but things definitely "jump into forms" (Stewart, 2007) here at the Whole Foods Market, where the idea of spiritual and physical wholesomeness aligns with a somewhat esoteric view on the qualities of the material and upgrades everyday experiences of heritage to the domain of the upper middle class. Heritage, thus, becomes a consumable good, along with amber chewing beads for babies and chocolate non-GMO organic soy milk. This, in turn, raises a range of new questions. When this Whole Foods Market is demolished, will the bricks just be thrown away? What would be the variables in the decision-making process? Would the bricks be used to build something else? Would there be another sign, and, if so, what would it say? Would having been a part of a grocery chain store somehow take away the value of the bricks by tampering with the suggested authenticity of their origins? Their auratic qualities? What is the boundary between presumed authenticity or an aura and the capitalist imperative of transiency of goods? And, finally, how would all these meanings and values align in the assigning of value to these reclaimed bricks? In other words, how would new meanings, cultural and economic imperatives "jump into forms" and what would be different about them then? 
In terms of my contribution to the field of critical heritage studies, my dissertation is a response to the need for the kind of critical theory that would be able to explain these processes and be loose enough to allow us to ask questions and make observations that break through theoretical brackets; a kind of theory that would be open to the fragmented nature of our experiences in postmodernity and the way we use heritage to counter them or make sense of them and ourselves within this current cultural, economic, and social context. 


\section{APPENDICES}

Appendix 1: Site Visit Itinerary ${ }^{61}$

\begin{tabular}{|c|c|c|}
\hline Museum & Date & Visit type \\
\hline \multirow[t]{3}{*}{$\begin{array}{l}\text { Spadina Museum: } \\
\text { Historic House and } \\
\text { Gardens }\end{array}$} & March $29^{\text {th }}, 2015$ & $\begin{array}{l}\text { Diaspora Dialogues book club, meeting with } \\
\text { Joseph Kertes, the author of The Afterlife of } \\
\text { Stars }\end{array}$ \\
\hline & April $16^{\text {th }}, 2015$ & Regular tour \\
\hline & October $16^{\text {th }}, 2015$ & $\begin{array}{l}\text { Hands-on Fascinator Workshop and House } \\
\text { Tour }\end{array}$ \\
\hline \multirow{2}{*}{$\begin{array}{l}\text { Campbell House } \\
\text { Museum }\end{array}$} & March $29^{\text {th }}, 2015$ & Regular tour \\
\hline & April $25^{\text {th }}, 2015$ & $\begin{array}{l}\text { Performance of Mamet's "The Boston } \\
\text { Marriage" }\end{array}$ \\
\hline \multirow[t]{4}{*}{ Colborne Lodge } & March 27, 2015 & Regular tour \\
\hline & October $3^{\text {rd }}, 2015$ & Fall Fair \\
\hline & October $30^{\text {th }}, 2015$ & Haunted High Park tour \\
\hline & January $11^{\text {th }}, 2015$ & $\begin{array}{l}\text { Museum visit for part-time staff working in } \\
\text { other house museums }\end{array}$ \\
\hline \multirow{2}{*}{$\begin{array}{l}\text { Fort York National } \\
\text { Historic Site }\end{array}$} & June $5^{\text {th }}, 2015$ & Regular tour \\
\hline & October $17^{\text {th }}, 2015$ & $\begin{array}{l}\text { Toronto Early Music Fair; } \\
\text { Magna Carta Exhibit }\end{array}$ \\
\hline \multirow{3}{*}{$\begin{array}{l}\text { Gibson House } \\
\text { Museum }\end{array}$} & August $19^{\text {th }}, 2015$ & Regular tour \\
\hline & November $7^{\text {th }}, 2015$ & Etsy fair \\
\hline & November $13^{\text {th }}, 2015$ & Regular tour \\
\hline \multirow[t]{2}{*}{ Montgomery's Inn } & October 10,2015 & Regular tour \\
\hline & October 14,2015 & $\begin{array}{l}\text { Celebration of Winter Market and World } \\
\text { Food day }\end{array}$ \\
\hline \multirow[t]{2}{*}{ Scarborough Museum } & July $17^{\text {th }}, 2015$ & Regular tour \\
\hline & Oct. 21,2015 & Regular tour and recipe tasting \\
\hline \multirow{2}{*}{$\begin{array}{l}\text { Todmodern Mills } \\
\text { Heritage Site }\end{array}$} & March $3^{\text {rd }}, 2016$ & Regular tour \\
\hline & March $11^{\text {th }}, 2016$ & Regular tour \\
\hline
\end{tabular}

\footnotetext{
${ }^{61}$ The Mackenzie House Museum is not included in this list, because it was a site of an autoethnographic study. In my position of a volunteer tour guide and an assistant at cooking workshops, I have attended most of the events held at Mackenzie House between March 24, 2015 through March 24, 2016, the length of my study as identified by Ryerson University REB.
} 
Appendix 2: List of Interview Questions ${ }^{62}$

- How did you first start working at this museum? Why did you decide to apply for work here?

- Do you have any special interests that have led you to this position? Please describe them.

- Is there anything specific that you look forward to when you come to your shift at the museum? What is it? Why?

- How would you describe your role at the museum?

- Which parts of your work at the museum are especially meaningful to you?

- What is your favorite part of your job? What gives you the most enjoyment? What gives you the most satisfaction?

- Do you think your work at the museum in any ways affects your everyday life outside of the museum? If so, in what ways?

- Do you think your work at the museum affects the way you think about the kind of Toronto that you encounter every day?

- What was the most memorable moment in your time at the museum in the past month? In the past year?

- Does what you do at the museum in any way affect your everyday life outside of the museum? If so, in what ways?

- Which part of the museum year is your favorite? Why?

- Is there anything specific you look forward to when you are done with your shift at the museum?

- How do you rest from your work at the museum?

${ }^{62}$ This list was used as a general guide. I aimed to cover all of these questions with all interviewees, but the structure of the interviews was not rigid. 
Appendix 3: Interview Consent Form

RYERSON

UNIVERSITY

\section{Ryerson University Consent Agreement: Interviews}

You are being invited to participate in a research study. Please read this consent form so that you understand what your participation will involve. Before you consent to participate, please ask any questions to be sure you understand what your participation will involve.

Title: Sense of the Past: Embodied Performance and Living History at Historic House Museums

INVESTIGATORS: This study is conducted by Alevtina Naumova, PhD candidate from the Graduate Programme in Communication and Culture at Ryerson University. If you have any questions or concerns about the research, please feel free to contact Alevtina Naumova at anaumova@ryerson.ca. The research supervisor for this project is Paul Moore, PhD. You can contact him at psmoore@soc.ryerson.ca or at (416) 979 - 5000 (ext. 2604).

PURPOSE OF THE STUDY: The research explores how the past is experienced in the living history house museums: What is specific about these experiences? How does it make us think differently about our heritage? Interviews are a part of this study. The investigator will interview about 35 people, all of whom are former and current staff members at the Mackenzie House Museum, Spadina Museum, and the Colborne Lodge. The results of this research project will contribute to my dissertation and other research papers.

WHAT PARTICIPATION MEANS: If you volunteer to participate in this study, you will be asked to meet with me once for an interview. The interview will take about an hour. It will deal with your work at the museum and the interests and experiences that have brought you here. We will have an option to meet at the museum or at a quiet location of your choice. I will be conducting an unstructured interview, which means that we will be able to deviate from the list of drafted questions. After the study is done, I will make my dissertation and any resulting research papers available to you upon request. I will not be collecting any demographic data as part of this investigation.

POTENTIAL BENEFITS: My dissertation and other research papers can potentially add to the academic dialogue on living history house museums as a separate genre of curatorial work and contribute to a better theoretical understanding of the functions of living history house museums in our society. Further, the study on how these museum environments are experienced and made sense of can be used to develop specific strategies for making the curatorial work more effective. It is important to note, however, that on a personal level you might not gain anything from participating in this study. 
WHAT ARE THE POTENTIAL RISKS TO YOU AS A PARTICIPANT: The potential risks of your participation in the study are very low. You may or may not experience feelings of discomfort if you decide to share some personal experiences associated with your work and interests outside of the museum. If you begin to feel uncomfortable, you can choose to skip a question and/or stop the interview altogether. You do not have to explain your reasons for skipping a question.

CONFIDENTIALITY: By default, the investigator will keep your identifying information confidential. All identifying information will be removed from the text of the dissertation and the research papers, and no one will be able to connect what you say to who you are. The investigator will also keep the record of your conversation separate from the signed consent forms. If you are comfortable with the investigator using your real name and job title in her dissertation and other research papers, please check the appropriate check box on the signature page.

Your interview will be audio-recorded. If you would like to edit the transcript of your interview before I use it for analysis in the study, please indicate so at the end of the interview. The audio version of the interview will be stored on my personal computer and on a USB drive for backup. The interview will be transcribed immediately after the interview. The investigator may or may not take notes during the interview.

I intend to keep all data for one year following the defense of my dissertation, since I might draw on it to illustrate some of the points in later research papers. I will then delete the audio recording of our interview and transfer the transcript of the interview to the archives of the living history museums included in this study.

INCENTIVES FOR PARTICIPATION: You would not be paid to participate in the study.

COSTS TO PARTICIPATION: There are no costs associated with participating in the interview.

VOLUNTARY PARTICIPATION AND WITHDRAWAL: Participation in this study is completely voluntary. You can choose whether to be in this study or not. You may skip any question for any reason at any time during the interview. You may stop participating at any time. If you choose to stop participating, you may also choose to not have your data included in the study. Your choice of whether or not to participate will not influence your future relations with Ryerson University or the investigator, Alevtina Naumova. You may request the withdrawal of your data from analysis up to two months after the interview.

QUESTIONS ABOUT THE STUDY: If you have any questions about the research now, please ask. If you have questions later about the research, you may contact Alevtina Naumova, PhD candidate, at anaumova@ryerson.ca. The research supervisor for this project is Paul Moore, PhD. You can contact him at psmoore@soc.ryerson.ca or at (416) 979 - 5000 (ext. 2604). 
This study has been reviewed by the Ryerson University Research Ethics Board. If you have questions regarding your rights as a participant in this study please contact:

Research Ethics Board

c/o Office of the Vice President, Research and Innovation

Ryerson University

350 Victoria Street

Toronto, ON M5B 2K3

416-979-5042

rebchair@ryerson.ca 
Title: Sense of the Past: Embodied Performance and Living History at Historic House Museums

\section{CONFIRMATION OF AGREEMENT:}

Your signature below indicates that you have read the information in this agreement and have had a chance to ask any questions you have about the study. Your signature also indicates that you agree to participate in the study and have been told that you can change your mind and withdraw your consent to participate at any time. You have been given a copy of this agreement. You have been told that by signing this consent agreement you are not giving up any of your legal rights.

Name of Participant (please print)

Signature of Participant

Date

I agree to be audio-recorded for the purposes of this study. I understand how these recordings will be stored and destroyed.

Signature of Participant

Date

I do not mind the researcher using my name and other identifying information in all research materials produced as a result of this study: 


\section{References}

Ackroyd, P. (2001). Introduction in D. Severs, 18 Folgate Street: The Tale of a House in Spitalfields, (pp. vii-xi). London, UK: Chatto \& Windus.

Adam, H., Galinsky, A. D. (2012). "Enclothed Cognition.” Journal of Experimental Social Psychology, 48(4): 918-925.

Adams, A. (1996). "Childbirth at Home." In Architecture in the Family Way: Doctors, Houses, and Women 1870-1900, (pp. 103-28). Montreal: McGill-Queen’s University Press.

Adler, P. A., Adler, P. (1987). Membership Roles in Field Research. London, UK: SAGE.

Agnew, V., Lamb, J. (Eds.) (2009). Settler and Creole Reenactment. New York: Palgrave Macmillan.

Andersen, J. (1982). Living history: Simulating everyday life in living museums. American Quarterly 34 (3): 290-306.

Anderson, L. (2006). Analytic Autoethnography. In P. Atkinson, S. Delamont (Eds.), Sage Qualitative Research Methods. (Vol. 35, pp. 374-278). London, UK: SAGE.

Anderson, B. (2006). Imagined Communities: Reflections on the origin and spread of nationalism. London, UK: Verso.

Appadurai, A. (1986). Introduction: commodities and the politics of value. In A. Appadurai (Ed.). The Social Life of Things: Commodities in Cultural Perspective, (pp. 3-63). Cambridge, MA: Cambridge University Press.

Arnold - de Simine, S. (2013). Mediating memory in the museum. New York: Palgrave Macmillan.

Ashworth, G., Graham, B., Tunbridge, J. (2008). Pluralising pasts: Heritage, identity and place in multicultural society. London, UK: Pluto Press.

Augé, M. (1995). Non-places: Introduction to an anthropology of supermodernity. (J. Howe Trans.). New York: Verso.

Austin, J. (1962). How to Do Things with Words. Oxford, UK: Clarendon Press.

Bal, M. (1996). Double exposures: The subject of cultural analysis. London, UK: Routledge.

Bal, M. (2007), 'Exhibition as film'. In S. Macdonald, P. Basu (Eds.), Exhibition experiments, (pp. 71-93). Oxford, UK: Blackwell.

Bann, S. (2000). "A Way of Life: Thoughts on the Identity of the House Museum.” In R. Pavoni (Ed.), Historic House Museums Speak to the Public: Spectacular Exhibits vs. a Philological Interpretation of History: Acts of the International Conference of DEMHIST ICOM's International Committee for Historic Houses, (pp. 19-27). Milan: Museo Bagatti Valsecchi and DEMHIST.

Barthes, R. (1972). Mythologies. New York: Hill and Wang.

Bauchelard, G. (1997). “The Poetics of Space.” In N. Leach (Ed.), Rethinking Architecture, (pp. 81-93). New York: Routledge. 
Baudrillard, J. (2012). “The Precession of Simulacra” In M. G. Durham, D. M. Kellner (Eds.), Media and Cultural Studies: KewWorks. Second Edition, (pp. 388-407). Chichester, UK: John Wiley \& Sons.

Baudrillard, J. (2005). The System of Objects. New York: Verso.

Baudrillard, J. (2001a). “Consumer society.” In M. Poster (Ed.), Baudrillard: Selected writings, (pp. 32-59). Cambridge, UK: Polity Press.

Baudrillard, J. (2001b). "For a critique of the political economy of the sign." In M. Poster (Ed.), Baudrillard: Selected writings, (pp. 57-97). Cambridge, UK: Polity Press.

Baudrillard, J. (1990). Seduction. Montreal: New World Perspectives.

Baudrillard, J. (1988). Selected Writings. Cambridge: Polity Press.

Benjamin, W. (1940/1986). Illuminations. (Trans. H. Zohn). New York: Schocken.

Beranek, C. M. (2011). Founding narratives: Revolutionary stories at historic houses. International Journal of Heritage Studies, 17(2): 102-115.

Bergson, H. (2005). Matter and Memory. New York: Zone Books.

Blum, A. (2015). Impasse Analysis. Toronto: Culture of Cities Centre.

Boym, S. (2002). The Future of Nostalgia. New York: Basic Books.

Břenholdt, J. O. (2004). Performing Tourist Places. Aldershot: Ashgate.

Brown, B. (2001). Thing Theory. Critical Inquiry, 28(1): 11-22.

Bruner, E. (1994) Abraham Lincoln as authentic reproduction: A critique of postmodernism. American Anthropologist, 96 (2): 397-415.

Bourdieu, P. (1977). Outline of a Theory of Practice. New York: Cambridge University Press.

Burbank, E. (2012). "Woman as Decoration.” In C. Briganti, K. Mezei (Eds.), The Domestic Space Reader, (pp. 130-133). Toronto: University of Toronto Press.

Butler, J., E. Weed (Eds.) (2011). The Question of Gender. Joan W. Scott's Critical Feminism. Bloomington, IN: Indiana University Press.

Butler, J. (1999). Gender Trouble. New York: Routledge.

Butler, J. (1993). Bodies that Matter: On the Discursive Limits of "Sex." New York: Routledge.

Cabral, M. (2001). Exhibiting and Communicating History and Society in Historic House Museums. Museum International,53(2): 41-46.

Chapman, T., Hockey, J. (Eds.) (1999) Ideal Homes?: Social Change and Domestic Life. London, UK: Routledge.

Carey, J. W. (1989). Communication as Culture: Essays on Media and Society. New York: Routledge.

Carsten, J., Hugh-Jones, S. (Eds.) (1995). About the House: Levi-Strauss and Beyond. Cambridge: Cambridge University Press. 
Casey, V. (2003, September). The Museum Effect: Gazing from object to performance in contemporary cultural-history museum. Paper presented at International Cultural Heritage Informatics Meeting (ICHIM), Paris, France. Paper retrieved from http://www.archimuse.com/publishing/ichim03/095C.pdf

Chatterjee, H. (2008). Touch in museums: Policy and practice in object handling. New York: Berg.

Christensen, K. (2011). Ideas versus Things: The balancing act of interpreting historic house museums. International Journal of Heritage Studies, 17(2): 153-168.

Cromby, J. (2007). Towards a psychology of feeling. International Journal of Critical Psychology, 21: 94-118.

Cohen, D. (2006). "In Possession: Men, Women, and Decoration.” In Household Gods: The British and Their Possessions, (pp. 98-121). New Haven, CT: Yale University Press.

Cohen, E. (1988). Authenticity and Commoditization in Toursim. Annals of Tourism Research, 15: $371-386$.

Cohen, E. (2004). Contemporary Tourism: Diversity and Change. Oxford, UK: Elsevier.

Cole, S. (2004). "Shared Benefits: Longitudical Research in Eastern Indonesia," in J. Philimore, L. Goodson (Eds.) Tourism Research Methods: Integrating Theory with Practice, (pp. 6372). Wallingford: CAB International.

Cooper, C. (1976). “The House as Symbol of the Self," in H. Proshansky, W. Ittelson, L. Rivlin (Eds.), Environmental Psychology: People and their physical settings ( $2^{\text {nd }}$ Ed.). New York: Holt, Rinehart, and Winston.

Crenshaw, K. (1994). "Mapping the Margins: Intersectionality, Identity Politics, and Violence Against Women of Color." In M. Fineman, R. Mykitiuk (Eds.), The Public Nature of Private Violence. New York. Routledge.

Crouch, D. (2012). Meaning, encounter and performativity: threads and moments of space times in doing tourism. In L Smith, E. Waterton, S. Watson (Eds.), The cultural momemt in tourism, (pp. 19-37). London, UK: Routledge.

Crouch, D., Lübbren, N. (Eds.) 2003. Visual culture and tourism. Oxford, UK: Berg.

Cubitt, G. (2007). History and Memory. Manchester, UK: Manchester University Press.

Cummings, R. (1922/2007). The Girl in the Golden Atom. Project Gutenberg. Accessed online at: http://www.pgdp.net

Daugbjerg, M., Syd Eisner, R., Timm Knudsen, B. (2014). Re-enacting the past: Vivifying heritage 'again'. International Journal of Heritage Studies, 20(7-8): 681-687.

Daugbjerd, M. (2014). Patchworking the past: Materiality, touch and the assembling of 'experience' in American Civil War re-enactment. International Journal of Heritage Studies, 20(7-8): 724-741.

Derrida, J. (1972). "Signature Event Context.” In P. Kamuf (Ed.), A Derrida Reader: Between the Blinds. New York: Columbia University Press. 
Despres, C. (1991). "The Meaning of Home: Literature review and directions for future research and theoretical development." Journal of Architectural and Planning Research, 8(2): 96115.

Dicks, B. (1997). "The Life and Times of Community: Spectacles of Collective Identity at the Rhondda Heritage Park," Time and Society, 6: 195-212.

Dicks, B. (1999). "The View of our Town from the Hill: Communities on Display as Local Heritage," International Journal of Cultural Studies, 2(3): 349-368.

Dicks, B. (2000). Encoding and decoding the people: Circuits of communication at a local heritage museum. European Journal of Communication, 15(1): 61-78.

Di Giovine, Michael A. (2009). The Heritage-scape: UNESCO, World Heritage, and Tourism. Plymouth: Lexington Books.

Dudley, S. (Ed.) (2010). Museum Materialities: Objects, Engagements, Interpretations. London, UK: Routledge.

Dudley, S. (Ed.) (2012). Museum Objects: Experiencing the Properties of Things. London, UK: Routledge.

Edensor, T. (1998). Tourists at the Taj: Performance and Meaning at a Symbolic Site. London, UK: Routledge.

Eisner, R. S. (2014). Drought and Rain: Re-creations in Vietnamese, cross-border heritage. International Journal of Heritage Studies, 20(7-8): 798-817.

Entrikin, J. N. (1991). The Betweenness of Place. Toward a Geography of Modernity. Baltimore, MD: The Johns Hopkins University Press.

Felman, S. (1980/2003). The Scandal of the Speaking Body: Don Juan with J. L. Austin, or Seduction in Two Languages. (Transl. by C. Porter). Stanford: Stanford University Press.

Foucault, M. (1986). “Of Other Spaces,” Diacritics 16(1): 22-27.

Foucault, M. (1984). Space, power and knowledge. (An interview with Paul Rabinow), In P. Rabinow (Ed.), The Foucault Reader, (pp. 239-256). (C. Hubert Trans.). New York: Pantheon.

Freud, S. (1919/1953). The Uncanny. In The Standard Edition of the Complete Psychological Works of Sigmund Freud (Vol. XVII). London, UK: Hogarth.

Freud, S. (1953). The Interpretation of Dreams. London, UK: Hogarth Press.

Fuss, D. (2012). “The Sense of the Interior: Four Writers and the Rooms that Shaped Them.” In C. Briganti, K. Mezei (Eds.), The Domestic Space Reader, (pp. 346-349). Toronto: University of Toronto Press.

Garber, M. (2001). Sex and Real Estate: Why We Love Houses. New York: Pantheon Books.

Geertz, C. (1973). “Thick Description: Toward an interpretive theory of culture.” In The Interpretation of Cultures: Selected essays. New York: Basic Books.

Gell, A. (1998). Art and agency: An anthropological theory. New York: Clarendon Press.

Giddens, A. (1984). The Constitution of Society: Outline of the Theory of Structuration. 
Cambridge: Polity Press.

Gilman, C. P. (1980). The Charlotte Perkins Gilman Reader: The Yellow Wallpaper, and Other Fiction. New York: Pantheon Books.

Godelier, M. (1988). The mental and the material. London, UK: Verso.

Goffman, E. (1975). Frame Analysis. Harmondsworth, UK: Penguin.

Goffman, E. (1959). The Presentation of Self in Everyday Life. New York: Doubleday.

Gombrich, E. (1979). The Sense of Order. London, UK: Phaidon Press.

Gordon, A. (2016). Time Travel: Tourism and the Rise of the Living History Museum in MidTwentieth-Century Canada. Vancouver: University of British Columbia Press.

Gubrium, J. F., Holstein, J.A. (2003). Analyzing Interpretive Practice. In N. K. Denzin, S. Lincoln (Eds.), Strategies of Qualitative Inquiry, (pp. 214 - 248). London, UK: SAGE.

Gumbrecht, H. U. (2004). Production of Presence: What Meaning Cannot Convey. Stanford: Stanford University Press.

Hall, C. M., McArthus, S. (1998). Integrated Heritage Management. London, UK: Stationary Office.

Hammersley, M., Atkinson. P. (1983). Ethnography: Principles and Practice. London, UK: Routledge.

Handler, R. and Saxton, W. (1988). "Dyssimulation: Reflexivity, Narrative, and the Quest for Authenticity in "Living History." Cultural Anthropology, 3(3): 242-260.

Harrison, R. (2013). Heritage: Critical Approaches. London, UK: Routledge.

Hardy, D. (1988). "Historical geography and Heritage Studies.” In Area, 20(4): 333-338.

Harvey, D. (2001). Heritage pasts and heritage presents: Temporality, meaning and the scope of heritage studies. International Journal of Heritage Studies, 7(4): 319-338.

Harvey, D. (1985). Money, Time, Space, and the City. Consciousness and the urban experience: Studies in the history and theory of capitalist urbanization, (pp. 1-35). Baltimore, MD: The John Hopkins University Press.

Havel, V. (1992). Summer Meditations. (P. Wilson transl.). New York: Knopf.

Heidegger, M. (1997). "Poetically Man Dwells.” In Neil Leach (Ed.), Rethinking Architecture, (pp. 104-119). New York: Routledge.

Hewison, R. (1987). The Heritage Industry: Britain in a climate of decline. London, UK: Meltuen London Ltd.

Hodge, C. J., Beranek, C. M. (2011). "Dwelling: Transforming narratives at historic house museums." International Journal of Heritage Studies, 17(1): 97-101.

Hodge, C. J. (2011). A new model for memory work: Nostalgic discourse at a historic home. International Journal of Heritage Studies, 17(2): 116-135.

Hodge, C. J. (2009). "Materialities of Nostalgia at the Old Homestead." Archaeologies, 5(3): 488-510. 
Hooks, B. (1991). Yearning: Race, Gender and Cultural Politics. London, UK: Turnaround.

Hunt, P. (1989). "Gender and the Construction of Home Life.” In G. Allan, G. Crow (Eds.), Home and Family: Creating the Domestic Sphere. London, UK: Macmillan.

Huyssen, A. (2003) "Introduction," "Chapter 1: Present Pasts, Media, Politics, Amnesia." In Heussen, A., Present pasts: Urban palimpsests and the politics of memory, (pp. 1-29). Stanford, CA: Stanford University Press.

Inglis, D., Holmes, M. (2003). "Highland and Other Haunts: Ghosts in Scottish Tourism." Annals of Tourism Research, 30(1): 50-63.

Ingold, T. (2007). Materials against Materiality. Archaeological Dialogues, 14(1): 1-16.

Innis, H. A. (1951). The Bias of Communication. Toronto: University of Toronto Press.

Ireland, M. J. (1990). "Come to Cornwall, Come to Land's End: A Study of Visitor Experience at a Touristic Sight." Problems of Tourism, 8(3/4): 33-53.

Jackson, M. (Ed.) (1995). At Home in the World. Sydney: Harper Perennial.

Jackson, A., J. Kidd. (Eds.) (2011). Performing Heritage. Research, Practice, and Innovation in Museum Theatre and Live Interpretation. Manchester: Machester University Press.

Jameson, F. (2006). Postmodernism, or the Cultural Logic of Late Capitalism. In M. G. Durham \& D. M. Kellner (Eds.), Media and Cultural Studies: Key Works (Rev. Ed.), (pp. 482521). Malden, MA: Blackwell.

Jung, C. G. (2012). “Memories, Dreams, Reflections.” In C. Briganti, K. Mezei (Eds.), The Domestic Space Reader, (pp. 135-138). Toronto: University of Toronto Press.

Kalshoven, P. T. (2012). Crafting the Indian. Knowledge, Desire and Play in Indianist Reenactment. Oxford, UK: Berghahn.

Kirshenblatt-Gimblett, B. (1998). Destination Culture: Tourism, Museums, and Heritage. Berkley, CA: University of California Press.

Kreps, C. F. (2008). “Appropriate Museology in Theory and Practice.” Museum Management and Curatorship, 23(1): 23-41.

Kreps, C. F. (2005). "Indigenous curation as intangible cultural heritage: Thoughts on the relevance of the 2003 UNESCO Convention. Theorizing Cultural Heritage, 1(2): 3-8.

Kreps, C. F. (2003). Liberating Culture: Cross-cultural perspectives on museums, curation, and heritage preservation. London, UK: Routledge.

Kusenbach, M. (2003). Street phenomenology: The go-along as ethnographic research tool. Ethnography, 4(3): 455-485.

Lash, S. (2010). Intensive Culture: Social Theory, Religion and Contemporary Capitalism. London, UK: SAGE.

Lash, S., and Lury, C. (2007). Global Culture Industry: The Mediation of Things. Cambridge: Polity Press.

Leavitt, J. (1996). Meaning and Feeling in the Anthropology of Emotions. American Ethnologist, 23(3): $514-539$. 
Lefebre, H. (1992). The Production of Space. Oxford, UK: Wiley-Blackwell.

Levent, N., Pascual-Leone, A., Lacey, S. (2014). Multisensory Museum: Cross-disciplinary Perspectives on Touch, Sound, Smell, Memory, and Space. Lanham: Rowman \& Littlefield.

Levin, C. (1984). "Baudrillard, Critical Theory and Psychoanalysis." Canadian Journal of Political and Social Theory, 8(1-2): 35-53.

Lindbergh, A. M. (1991). Gift from the Sea. New York: Random House.

Littler, J., Naidoo, R. (Eds.) (2005). The Politics of Heritage: The Legacies of 'race.' London, UK: Routledge.

Lowenthal, D. (1998). The Heritage Crusade and the Spoils of History. New York: Cambridge University Press.

Lowenthal, D. (1985). The Past is a Foreign Country. Cambridge, MA: Cambridge University Press.

Lyotard, J. (1984). The Postmodern Condition: A report on knowledge. (G. Bennington \& B. Massumi Trans.). Minneapolis, MN: University of Minnesota Press.

MacCannell, D. (1976). The Tourist: A New Theory of the Leisure Class. New York: Schocken.

MacCannell, D. (1973). Staged Authenticity: Arrangements of Social Space in Social Settings. American Journal of Sociology, 79(3): 589-603.

Macleod, E. (2006) Decolonizing interpretation at the Fortress of Louisbourg National Historic Site. In G. Sherbert, A. Gérin and S. Petty (eds) Canadian Cultural Poesis: Essays on Canadian Culture, (pp. 361-380). Waterloo: Wilfred Laurier University Press.

Mallett, S. (2004). Understanding Home: A critical review of the literature. The Sociological Review, 52(1): 62-89.

Malnar, J., Vodvarka, F. (2014). “Architectural Design for Living Artifacts.” In A. PascualLeone, N. Levent. (Eds.), Multi-sensory Museum: A Cross-disciplinary Perspective on Multiple Modalities of a Museum Experience, (pp. 213 - 231). Lanham, MD: AltaMira.

Malnar, J., Vodvarka, F. (2013). New Architecture on Indigenous Lands. Minneapolis: University of Minnesota Press.

Marcus, G. (2007). "What is at Stake - and is Not - in the Idea of Multi-sited Ethnography," In H. L. Moore, T. Sanders (Eds.). Anthropology in Theory: Issues in Epistemology, (pp. 618 - 621) Oxford, UK: Blackwell.

Marcus, G. (1995). Ethnography in/of the World System: The Emergence of Multi-Sited Ethnography. Annual Review of Anthropology, 24: 95-117.

Maso, I. (2001) Phenomenology and Ethnography in P. Atkinson, S. Delamont, J. Lofland, L. Lofland (Eds.), Handbook of Ethnography. London, UK: SAGE.

Merleau-Ponty, M. (2004). The World of Perception. O. Davis Trans. London, UK: Routledge.

Merleau-Ponty, M. (1974). “Eye and Mind.” In J. O’Neill (Ed.). Phenomenology, Language and Sociology: Selected Essays of Maurice Merleau-Ponty, (pp. 280-311). London, UK: Heinemann Educational Books. 
Mezei, K., Briganti, C. (2012). “Introduction.” In K. Mezei, D. Briganti (Eds.), The Domestic Space Reader, (pp. 3-16). Toronto: University of Toronto Press.

Moore, A. (1980). "Walt Disney World: Bounded Ritual Space and the Playful Pilgrimage Center." Anthropological Quarterly, 53: 207-218.

McKercher, B., du Cros, H. (2002). Cultural Tourism: The Partnership between Tourism and Cultural Heritage Management. Binghamton, NY: The Haworth Hospitality Press.

McLuhan, M. (1997). “Acoustic Space.” In M. A. Moos (Ed.), Media Research: Technology, Art, Communication, (pp. 39-44). Amsterdam: G \& B Arts.

Mead, G. H. (1959). The Philosophy of the Present. La Salle, IL: Open Court.

Meijl, T. v. (2005). The Critical Ethnographer as Trickster. In Anthropological Forum, 15(3): 235-245.

Miller, D. (Ed.). (2005). “Introduction.” In D. Miller (Ed.), Materiality, (pp. 1-50). Durham, NC: Duke University Press.

Morisset, L. (2016). What does heritage change? Association of Critical Heritage Studies Third Biennial Conference. Montreal, Canada.

Moore, K. (Ed.). (1994). Museum Management. London, UK: Routledge.

Mills, S. (2003). Open air museums and the tourist gaze. In D. Crouch, N. Lübbren (Eds.), Visual Culture and Tourism, (pp. 75-88). New York: Berg.

Milner, M. (1981). A Life of One's Own. New York: The Putnam Publishing Group.

Munn, N. (1992). The Cultural Anthropology of Time: A Critical Essay. Annual Review of Anthropology 21: 93-123.

Nora, P. (1989). “Between Memory and History: Les Lieux de Mémoire.” Representations, 26: $7-24$.

Nichols, B. (2008). "Documentary Reenactment and the Fantasmatic Subject." Critical Inquiry, 35(1): 72-89.

O’Neill, J. (1985). Five Bodies: The Human Shape of Modern Society. Ithaca: Cornell University Press.

Pahl, R. E. (1984). Divisions of Labour. Oxford, UK: Basil Blackwell.

Palmer, C. (2009). "Reflections on the Practice of Ethnography within Heritage Tourism." In M. L. Stig Sorensen, J. Carman (Eds.) Heritage Studies: Methods and Approaches. New York: Routledge.

Palmer, C. (2005). "An Ethnography of Englishness: Experiencing Identity through Tourism.” In Annals of Tourism Research, 32: 7 - 27.

Papoulias, C., Callard, F. (2010). Biology's Gift: Interrogating the Turn to Affect. Body \& Society, 16: 29-56.

Pavoni, R. (2001). Towards a definition and typology of historic house museums. Museum International, 53(2): 16-21. 
Peacock, P. (2011). Interpreting a Past: Presenting Gender History at Living History Sites in Ontario (Unpublished doctoral dissertation). Queens University: Kingston, Ontario, Canada.

Pels, P. (1998). The spirit of matter: On fetish, rarity, fact and fancy. In P. Spyer (Ed.), Border Fetishisms: Material Objects in Unstable Spaces, (pp. 91-121). New York: Routledge.

Pendlebury, J., Townshend, T., Gilroy, R. (2004). The Conservation of English Cultural Built Heritage: A Force for Social Inclusion? International Journal of Heritage Studies, 10(1): 11-31.

Peponis, J., Conroy Dalton, R., Wineman, J., Dalton, N. (2004). "Measuring the effects of layout upon visitors' spatial behaviors in open plan exhibition settings." Environment and Planning B: Planning and Design, 31(3): 453-73.

Petrov, J. (2011). Playing dress-up: Inhabiting imagined spaces through museum objects. In S. Dudley, A. J. Barnes, J. Binnie, J. Petrov, J. Walklate (Eds.), London, UK: Routledge.

Pinna, G. (2001). Introduction to historic house museums. Museum International, 53(2): 4-9.

Pine, B. J., Gilmore, J. (1999). The Experience Economy. Boston: Harvard Business School Press.

Pink, S. (2009). Doing Sensory Ethnography. London, UK: SAGE.

Porteous, J. D. (1976). “Home: The Territorial Core.” Geographical Review, 66(4): 383-390.

Pye, E. (Ed.). (2007). The Power of Touch: Handling Objects in Museum and Heritage Context. New York: Routledge.

Raible, C., Carter, J. C., Withrow, D., York Pioneer and Historical Society. (2009). From hands now striving to be free: Boxes crafted by 1837 Rebellion prisoners: An analysis and inventory of 94 boxes. Toronto: Published by the York Pioneer \& Historical Society to mark the 175th anniversary of the incorporation of the City of Toronto.

Radu, S. (2014). "Making Ourselves at Home: Representation, Preservation \& Interpretation at Canada's House Museums." Electronic Thesis and Dissertation Repository. Paper 2361.

Rapport, N., Dawson, A. (1998). Migrants of Identity: Perceptions of Home in a World of Movement. Oxford, UK: Berg.

Ravelli, L. J. (2006). Museum texts. Communication frameworks. New York: Routledge.

Renfrew, C. (2001). Symbol before concept: Material engagement and the early development of society. In I. Hodder (Ed.), Archaeological Theory Today, (pp. 98 - 121). Cambridge, MA: Polity Press.

Rybczynski, W. (1986). Home: A Short History of an Idea. New York: Penguin Books.

Saldanha, A. (2010). Skin, affect, aggregation: Guarttarian variations on Fanon. Environment and Planning A, 42: $4210-4227$.

Samuel, R. (1994). Theatres of Memory. London, UK: Verso. 
Sartre, J. (1956/1992). Being and Nothingness: A phenomenological essay on ontology. New York. Washington Square Press.

Saunders, P., Williams, P. (1988). "The Constitution of the Home: Towards a Research Agenda." Housing Studies, 3(2): 81-93.

Schorch, P. (2013). “The experience of a museum space.” Museum Management and Curatorship, 28(2): 193-208.

Schneider, R. (2011). Performing Remains. Art and War in Times of Theatrical Reenactment. New York: Routledge.

Schwartz, H. (1996) The Culture of the Copy: Striking Likenesses, Unreasonable Facsimiles. New York: Zone Books.

Searle, J. (1979). Expression and Meaning: Studies in the Theory of Speech Acts. Cambridge University Press.

Sedgwick, E. K. (2003). Touching Feeling: Affect, Pedagogy, Performativity. Durham: Duke University Press.

Severs, D. (2001). 18 Folgate Street. A Tale of a House in Spitalfields. With an Introduction by Peter Ackroyd. London, UK: Vintage and Chatto \& Windus.

Shackel, P. A. (2011). America's Home Town: Fiction, Mark Twain, and the Re-creation of Hannibal, Missouri. International Journal of Heritage Studies, 17(3): 197-213.

Shannon, C., Weaver, W. (1949). Mathematical Theory of Communication. University of Illinois Press.

Smith, L., Campbell, G. (2015). The Elephant in the Room: Heritage, affect, and emotion. In W. Logan, M. Nic Craith, U. Kockel (Eds.), A Companion to Heritage Studies, (pp. 443-460). Malden, MA: Wiley-Balckwell.

Smith, L. (2006). Uses of Heritage. London, UK: Routledge.

Soja, E. (1989). 'History: Geography: Modernity.' Postmodern Geographies: the Reassertion of Space in Critical Social Theory, (pp. 10-42). London, UK: Verso.

Somerville, P. (1989). "Home Sweet Home: A critical Comment on Saunders and Williams.” In Housing Studies, 4(2): 113-118.

Stewart, K. (2008). Weak Theory in an Unfinished World. Journal of Folklore Research, 45(1): 71-82.

Stewart, K. (2007). Ordinary Affects. Durham, N. C.: Duke University Press.

Stokes, J. C. (2013). How to do Media \& Cultural Studies. London, UK: SAGE.

Tedlock, B. (2005). The Observation of Participation and the Emergence of Public Ethnography. In N. K. Denzin, Y. S. Lincoln (Eds.), The Sage Book of Qualitative Methods $\left(3^{\text {rd }}\right.$ Ed.), (pp. 467-481). London, UK: SAGE. 
Tedlock, B. (2000). Ethnography and ethnographic representation. In N. K. Denzin, Y. S. Lincoln (Eds.), Handbook of Qualitative Methods ( $2^{\text {nd }}$ Ed.), (pp. 455-484). London, UK: SAGE.

Tedlock, B. (1999). From participant observation to the observation of participation: The emergence of narrative ethnography. Journal of Antrhopological Research, 47: 69-94.

Terry, A. (2013). Gender, Canadian Nationhood and 'Keeping house': The Cultural Bureaucratisation of Dundurn Castle in Hamilton, Ontario, 1900-1960s. Gender \& History, 25(1): 47-64.

Terry, A. (2008). Claiming Christmas for the Tourist: 'Living History' in Dundurn Castle. Journal of Heritage Tourism, 3(2): 104-120.

Teyssot, G. (2012). "Water and Gas on All Floors: Notes on the Extraneousness of the Home." In C. Briganti, K. Mezei (Eds.), The Domestic Space Reader, (pp. 147-153). Toronto: University of Toronto Press.

Tomlinson, J. (2007). The Culture of Speed: The Coming of Immediacy. London, UK: SAGE.

Tilden, F. (1957). Interpreting our heritage. Chapel Hill, NC: University of North Carolina Press.

Tucker, H. (2003). Living with Tourism: Negotiating Identities in a Turkish Village. London, UK: Routledge.

Tucker, A. (1994). "In Search of Home,” Journal of Applied Philosophy, 11(2): 181-187.

Tunbridge, J. E., G. J. Ashworth. (1996). Dissonant Heritage: The Management of the Past as a Resource in Conflict. Chichester: John Wiley \& Sons Ltd.

Urry, J. (1996). How societies remember the past. In S. MacDonald, G. Fyfe (Eds.), Theorizing museums: Representing identity and diversity in a changing World, (pp. 34-69). Oxford, UK: Blackwel.

Uzzel, D. (1998). Interpreting our heritage: A theoretical interpretation. In D. Uzzel, R. Ballantyne (Eds.), Contemporary issues in heritage and environmental interpretation, (pp. 11-25). London, UK: The Stationary Office.

Vagnone, F., Ryan, D. (2016). Anarchist's Guide to Historic House Museums. London, UK: Routledge.

Van Herk, A. (2012). "Cleansing Dislocation: To Make Life, Do Laundry.” In C. Briganti, K. Mezei (Eds.), The Domestic Space Reader, (pp. 194-199). Toronto: University of Toronto Press.

Vidler, A. (1992). The Architectural Uncanny: Essays in the modern unhomely. Cambridge, MA: The MIT Press.

Walsh, K. (1992). The Representation of the Past: Museums and Heritage in the Postmodern World. London, UK: Routledge.

Warner, M. (2002). "Publics and Counterpublics," Public Culture, 14.

Waterton, E., Watson, S. (2013). Framing theory: Towards a critical imagination in heritage studies. International Journal of Heritage Studies, 19(6): 546-561. 
Waterton, E., Watson, S. (Eds.) (2011). Heritage and Community Engagement: Collaboration or Contestation? London, UK: Routledge.

Waterton, E. (2010). Branding the Past: The Visual Imagery of England's Heritage. In E. Waterton, S. Watson (Eds.), Culture, Heritage and Representations: Perspectives on Visuality and the Past, (pp. 155-172). Aldershot: Ashgate.

Waterton, E., Smith, L., Campbell, G. (2006). The utility of discourse analysis to heritage studies: The Burra Charter and social inclusion. International Journal of Heritage Studies, 12(4): 339-355.

West, P. (1999). Domesticating History: The political origins of America's house museums. Washington, DC: Smithsonian Institution Press.

Willis, P., Trondman, M. (2000). “Manifesto for Ethnography,” Ethnography, 1: 5-16.

Wineman, J. D., Peponis, J. (2010). “Constructing spatial meaning: Spatial affordances in museum design'. Environment and Behaviour, 42(1): 86-109.

Wood, E., Latham, K. (2014). The Objects of Experience: Transforming visitor-object encounters in museums. Walnut Creek, CA: Left Coast Press, Inc.

Wood, E., Latham, K. (2011). The Thickness of Things: Exploring the Curriculum of Museums through Phenomenological Touch. Journal of Curriculum Theorizing, 27(2): 51-65.

Wright, G. (1991). "Prescribing the Model of Home.” Social Research, 58 (1): 213-225.

Wright, P. (1985). On Living in an Old Country. London, UK: Verso.

Young, L. (2007). Is There a Museum in the House? Historic Houses as a Species of Museum. Museum Management and Curatorship, 22(1): 59-77.

Young, I. (2007). Intersecting Voices: Dilemmas of Gender, Political Philosophy, and Policy. Princeton, NJ: Princeton University Press.

Young, L. (2006). Villages that never were: The museum village as a heritage genre. International Journal of Heritage Studies, 12(4): 321-338.

Zhang, H. (2016). Sticky Ambiguity: Aging, death and the ethical condition of elder care. Toronto: Culture of Cities Centre. 